\title{
ANÁLISE NUMÉRICA E EXPERIMENTAL DAS TENSÕES RESIDUAIS GERADAS DURANTE O PROCESSO DE TÊMPERA DE CILINDROS DE AÇO AISI 1045, 4140 E 4340
}

\author{
Dissertação apresentada à Escola \\ Politécnica da Universidade de São Paulo \\ para obtenção do título de Mestre em \\ Ciências - Programa de Engenharia \\ Metalúrgica e de Materiais
}




\section{ANÁLISE NUMÉRICA E EXPERIMENTAL DAS TENSÕES RESIDUAIS GERADAS DURANTE O PROCESSO DE TÊMPERA DE CILINDROS DE AÇO AISI 1045, 4140 E 4340}

Dissertação apresentada à Escola Politécnica da Universidade de São Paulo para obtenção do título de Mestre em Ciências - Programa de Engenharia Metalúrgica e de Materiais

Área de Concentração:

Engenharia Metalúrgica e de Materiais

Orientador:

Prof. Dr. André Paulo Tschiptschin

SÃO PAULO 
Este exemplar foi revisado e alterado em relação à versão original, sob responsabilidade única do autor e com a anuência de seu orientador.

São Paulo, agosto de 2012

Assinatura do autor

Assinatura do orientador

\section{FICHA CATALOGRÁFICA}

Ariza Echeverri, Edwan Anderson

Análise numérica e experimental das tensões residuais geradas durante o processo de têmpera de cilindros de aço AISI 1045, 4110 e 4340 / E.A. Ariza Echeverri. --São Paulo, 2012. $177 \mathrm{p}$.

Dissertação (Mestrado) - Escola Politécnica da Universidade de São Paulo. Departamento de Engenharia Metalúrgica e de Materiais.

1. Tensão residual 2. Têmpera 3. Aço I. Universidade de São Paulo. Escola Politécnica. Departamento de Engenharia Metalúrgica e de Materiais II. t. 
A Juliana e Isaac dedico esta realização. 


\section{AGRADECIMENTOS}

Desejo expressar os meus sinceros agradecimentos a todos os que possibilitaram a realização deste trabalho:

Em especial, ao Prof. Dr. André Paulo Tschiptschin, por todo o apoio na orientação, idealização e acompanhamento deste trabalho, pela amizade, pelo tempo compartilhado e pela oportunidade e confiança que deposita na comunidade colombiana.

Ao Prof. Dr. Hélio Goldenstein, pelo apoio, amizade e esclarecimento de dúvidas e pela troca de ideias e constante disponibilidade de repassar seus conhecimentos, não só da Ciência dos Materiais.

Ao Prof. Dr. Nelson Batista de Lima, do Instituo de Pesquisas Energéticas Nucleares - IPEN, pelo apoio e disponibilidade que teve durante o processo de medição das tensões residuais por difração de raios $X$.

Ao Prof. Dr. Roberto Martins de Souza, do Laboratório de Fenômenos de Superfície, da EP-USP, pelas contribuições e ensinamentos no início deste processo, e pelas valiosas sugestões.

Ao Prof. Dr. Cesar Roberto de Farias Azevedo pela amizade e pelas sugestões e ideias no exame de qualificação.

Ao Prof. Dr. Marcelo de Aquino Martorano pelo auxílio nas medições do coeficiente de transferência de calor e ampliar o meu conhecimento sobre o assunto.

Ao Eleir Mundim Bortoleto, do Laboratório de Fenômenos de Superfície, da EP-USP, pelas sugestões assertivas para o desenvolvimento do modelo numérico.

Ao meu primo e irmão Juan Carlos Erazo Suárez pelo imensurável apoio e por ter sempre o conselho certo, para ele meu agradecimento e minha admiração. 
Ao meu amigo Marcelo Rojas "Marcelor" pela ajuda na parte experimental, pela nossa amizade, sorrisos e visitas constantes para perguntar "cómo va?" "todo bien?".

Aos meus amigos, do laboratório Luis Armando Espítia Sanjuan, Luis Bernardo Varela, Mario González Ramírez, Ana Maria Villegas, Daniel Rodrigues Junior, Duberney Hincapie, Arthur Seiji Nishikawa e Rafael Maia pela convivência e amizade, e por estarem sempre dispostos a ajudar e incentivar-me a levar a bom porto este trabalho.

Ao meu grande amigo Alan Barros de Almeida pela amizade, constante ajuda nas dúvidas do português, pela "alegria", palavras de força, trocas de ideias e bons momentos compartilhados.

Ao meu irmão José Wilmar Calderón Hernández pelo apoio incondicional.

Aos amigos da Colômbia Jhon Wilson Ospina, Juan Manuel Martínez, Leonardo Hernández, Edwin Orlando Franco, Camilo Augusto Montoya Sanz, Carolina Franco Londoño, Rubiel González Hurtado, Mauricio González Quiceno e Rubén Dario Matallana pelo apoio e por estarem sempre na torcida.

Gostaria de agradecer especialmente a quem ilumina meu caminho com sua luz amorosa, Juliana Gómez Mejía, obrigado por todo amor, apoio, incentivo e por ser meu constante bem-estar.

À Universidade de São Paulo e ao Programa de Pós-Graduação em Engenharia Metalúrgica e de Materiais PMT-EP-USP, por esta oportunidade de especialização e realização pessoal, e ao CNPQ, pela bolsa de estudo fornecida. 


\section{RESUMO}

O objetivo deste trabalho é analisar a distribuição das tensões residuais que resultam da combinação das variações volumétricas resultantes dos gradientes térmicos e das transformações de fase que ocorrem durante a têmpera de cilindros de aço AISI/SAE 1045, 4140 e 4340. O modelo matemático usado para este objetivo utiliza o programa AC3 de modelagem de tratamentos térmicos (curvas de transformação, curvas de resfriamento, microestrutura e a dureza do material), para alimentar um modelo de elementos finitos, considerando acoplamento termomecânico e comportamento não linear elasto-plástico, para previsão de tensões residuais em cilindros de aço AISI/SAE 1045, 4140 e 4340 temperados em água. São apresentados, também, os resultados de observações metalográficas e perfis de dureza que confirmam qualitativamente as previsões do programa AC3. A verificação do modelo numérico por elementos finitos foi efetuada através da medição das tensões residuais nos cilindros de aço com o emprego da técnica de difração de raios $X$. A simulação numérica, através do método dos elementos finitos comprova, nos três casos estudados, a existência de tensões residuais de compressão na região superficial após o processo de têmpera e indica de maneira quantitativa e qualitativa que as tensões mais significativas são as tangenciais. Os resultados obtidos a partir do modelo numérico mostraram uma aderência significativa em comparação com os resultados experimentais.

Palavras-chave: Modelamento por elementos finitos. Têmpera. Tensões residuais. Simulação de tratamento térmico. Difração de raios $X$. 


\begin{abstract}
The aim of this work is to analyze the distribution of residual stresses resulting from combination of volumetric changes due to heat gradients and phase changes occurring during the quenching process of AISI/SAE 1045, 4140 and 4340 steel cylinders. The mathematical model used for this objective uses the AC3 program for modeling thermal treatments (transformation curves, cooling curves, microstructure and material hardness), whose results were fed into a finite element model, considering thermal-mechanical coupling and non-linear elastic-plastic behavior for forecasting of residual stresses in AISI/SAE 1045, 4140 and 4340 steel cylinders quenched in water. The observed microstructures and measured hardness confirmed qualitatively the previsions of the AC3 program. The results of finite element modeling were compared to experimental measurements of residual stresses measured at the surface, using X-Ray diffraction techniques. The finite element numerical simulation shows, for the three studied cases, the presence of compressive residual stresses in the surface region after a quenching process and indicates qualitatively and quantitatively that the most significant stresses are the tangential ones. The results obtained from the numerical model showed a significant adherence in comparison with the experimental results.
\end{abstract}

Keywords: Finite element modeling. Quenching. Residual stresses. Heat treatment simulation. X-Ray Diffraction. 


\section{LISTA DE FIGURAS}

Figura 1 - Influência do teor de carbono: (a) nas temperaturas de início $\left(M_{s}\right)$ e fim da formação da martensita $\mathrm{M}_{\mathrm{f}}$, para aços não ligados. Adaptado de Troiano e Greninger (1946); (b) no teor de austenita retida. Adaptado de Parrish (1999). ...... 30

Figura 2 - Representação esquemática do princípio de aditividade de Scheil.

Figura 3 - Diagrama esquemático para ilustrar a aplicação do princípio de aditividade durante o processo de resfriamento contínuo. A reação não isotérmica segue o caminho marcado pelas setas para duas curvas de transformação nas temperaturas $\mathrm{T}_{1}$ e $\mathrm{T}_{2}$. Adaptado de Pan e Gu (2009) 40

Figura 4 - Diagrama de transformação isotérmica para um aço eutetóide. A, austenita; B, bainita; P, perlita; M, martensita. Adaptado de Callister (2008). 42

Figura 5 - Sobreposição do diagrama de resfriamento contínuo no diagrama de transformação isotérmica para um aço eutetóide. $M$, martensita. Adaptado de Callister (2008). 44

Figura 6 - Relação entre as curvas de resfriamento da superfície e do centro de uma barra de aço temperada. Adaptado de Bhadeshia (2001). 45

Figura 7 - Influência dos elementos de liga no deslocamento das curvas TTT. Adaptado de Soares (1987). 46

Figura 8 - Influência dos elementos de liga na temperatura de início da transformação martensítica, $M_{s}$. Adaptado de Totten (2007).

Figura 9 - Representação da relação entre a temperatura de equilíbrio ( $\left.T_{0}\right)$ e a temperatura $M_{s} . \alpha, \gamma$ e $T \alpha \gamma$, representam ferrita alfa, austenita e a temperatura de transição $\gamma \leftrightarrow \alpha$, respectivamente. Hornbogen (1983). 48

Figura 10 - Diagrama TTT para um aço ligado com as curvas de transformação da perlita e da bainita separadas. As linhas 1 e 2 representam $o$ início e o fim da transformação de perlita, respectivamente; as linhas 3 e 4 representam o início e o fim da transformação bainítica, respectivamente. Adaptado de Totten (2007)

Figura 11 - Curva de resfriamento e da taxa de resfriamento no centro de uma peça temperada. Adaptado de ASM (1991). 50 
Figura 12 - Representação dos três tipos de tensão residual em um material bifásico depois do processo de têmpera. Adaptado de Liscic (2007).

Figura 13 - À esquerda - representação das tensões térmicas na superfície e no núcleo de um cilindro ideal com comportamento linear elástico durante a têmpera; à direita - vista superior das tensões térmicas. As setas indicam as direções das tensões, o ponto e a xis representam a tensão de compressão e de tração, respectivamente e $\sigma \mathrm{l}$, $\sigma \mathrm{r}$ e $\sigma \mathrm{t}$, representam as tensões axiais, radiais e tangenciais, respectivamente. Adaptado de Liscic et al. (1992).

Figura 14 - De cima para baixo: histórico tempo temperatura, gradiente de temperatura entre a superfície e o núcleo, e desenvolvimento da tensão axial, durante resfriamento, sem transformação de fase, para um cilindro ideal linearelástico. Adaptado de Liscic et al. (1992). 60

Figura 15 - Dependência das tensões térmicas no sentido axial nos diâmetros de cilindros de aço de médio carbono com comportamento ideal linearelástico. Adaptado de Liscic et al. (1992).

Figura 16 - À esquerda - tensões de transformação produzidas por têmpera, na superfície e no núcleo de um cilindro com comportamento ideal linear elástico; à direita - vista superior das tensões de transformação na superfície e no núcleo. As setas indicam as direções das tensões, o ponto e a xis representam a tensão de compressão e de tração, respectivamente e $\sigma \mathrm{l}$, $\sigma \mathrm{r}$ e $\sigma \mathrm{t}$, representam as tensões axiais, radiais e tangenciais, respectivamente. Adaptado de Liscic et al. (1992).....62

Figura 17 - Resfriamento de um cilindro ideal elástico que transforma somente para martensita. Superior - curvas de resfriamento em função do tempo e da temperatura; inferior - curvas de desenvolvimento das tensões de transformação axial oltr. Adaptado de Liscic et al. (1992).

Figura 18 - Desenvolvimento de tensões residuais durante têmpera de um cilindro ideal linear elástico considerando a superposição das tensões térmicas e as tensões devidas à transformação de austenita para martensita. Adaptado de Liscic et al. (1992).

Figura 19 - Tensões residuais térmicas durante a têmpera de cilindros. (a) Curvas de resfriamento e do limite de escoamento em função da temperatura e do tempo. (b) Tensões residuais desenvolvidas ao longo do processo de têmpera. Adaptado de Liscic et al. (1992). 66 
Figura 20 - Comportamento da tensão residual sem levar em conta a transformação de fase. Adaptado de Ebert (1978).

Figura 21 - Tensões residuais de transformação durante têmpera de um cilindro. (a) Curvas de resfriamento e do limite de escoamento em função da temperatura e do tempo. (b) Tensões residuais de transformação desenvolvidas ao longo do processo de têmpera Adaptado de Liscic et al. (1992)............................. 70

Figura 22 - Distribuição de tensões residuais devidas à transformação de fases durante a têmpera de um aço. Adaptado de Ebert (1978). 71

Figura 23 - Comparação das tensões térmicas e de transformação para três diferentes condições de têmpera. (a) e (c) inversão das tensões térmicas depois da superfície e o núcleo transformarem; (b) inversão das tensões térmicas antes da superfície e o núcleo transformarem. $\mathrm{T}_{\mathrm{A}}$ representa a temperatura de austenitização, $M_{S} O$ início da transformação martensítica e $t_{u}$ representa o tempo de inversão das tensões térmicas. Adaptado de Mayr (1987). 72

Figura 24 - Diferentes tipos de tensões residuais desenvolvidas no processo de têmpera. c e s representam o centro e a superfície do cilindro, respectivamente. Adaptado de Liscic (2007) e Schulze et al., (2010) ............................................. 74

Figura 25 - Espalhamento descrito pela lei de Bragg. ................................ 76

Figura 26 - Ilustração da medida da deformação com base na lei de Bragg. (HE, 2009). 76

Figura 27 - Representação de $\psi$ em um material policristalino. Adaptado de Eigenmann e Macherauck (1996). 77

Figura 28 - Direções da tensão e deformação principais. Adaptado de Rigaku (2003). 78

Figura 29 - Sistema de coordenadas do laboratório $\left(L_{i}\right)$ em relação ao sistema de referência da amostra $\left(\mathrm{S}_{\mathrm{i}}\right)$. $\mathrm{S}_{\varnothing}$, direção da tensão. $L_{3}$ é a normal à família de planos que difrata. 79

Figura 30 - Processamento da imagem, utilizando-se o software Image J... 89

Figura 31 - Rede para determinação da fração volumétrica. ..........................90

Figura 32 - Definição dos parâmetros iniciais no programa AC3 ….............. 92

Figura 33 - Fluxograma com as inter-relações desenvolvidas no programa AC3 93 
Figura 34 - Imagem de saída do AC3 em um passo (step 14) intermediário da simulação. AA, MM, BB e PP representam austenita, martensita, bainita e perlita, respectivamente. 94

Figura 35 - Programa AC3 Converter ................................................ 95

Figura 36 - Fluxograma do modelo de elementos finitos em Abaqus. ..........96 96

Figura 37 - Distribuição das tensões axiais em um cilindro de aço temperado. Adaptado de Fletcher (1989). 108

Figura 38 - Disposição dos termopares dentro da amostra para obter as curvas de resfriamento durante o processo de têmpera (dimensões em $\mathrm{mm}$ ) 109

Figura 39 - Montagem da amostra no difratômetro de raios X para análise de tensão residual no sentido axial. 113

Figura 40 - Posicionamento dos corpos de prova para medição da tensão residual. (a) Posição para medida de tensão residual axial. (b) Posição para coleta de dados para medição da tensão residual tangencial. 115

Figura 41 - Curvas de resfriamento experimentais e simuladas em duas posições dentro dos cilindros temperados, para as três experiências realizadas (1 e 3 aço 4340; 2, aço 1045) e das obtidas através do Abaqus. Tmr e Tc, representam as temperaturas a $3 \mathrm{~mm}$ da superfície e no centro do cilindro, respectivamente... 116

Figura 42 - Diferençaentre as temperaturas medidas experimentalmente no centro (Tc) e perto da superfície (Tmr) dos cilindros (1 e 3, AISI 4340 e 2, 1045) em função da temperatura perto da superfície. Tmr e Tc, representam as temperaturas a $3 \mathrm{~mm}$ da superfície e no centro do cilindro, respectivamente.

Figura 43 - Derivadasdas curvas de resfriamento para o experimento 1 (AÇO AISI 4340). Tmr e Tc, representam as temperaturas a $3 \mathrm{~mm}$ da superfície e no centro do cilindro, respectivamente. 118

Figura 44 - Fluxo térmico transiente na superfície do cilindro de aço AISI/SAE 4340, durante a têmpera em água com agitação; (a) em função do tempo; (b) em função da temperatura.

Figura 45 - Curvas de resfriamento temperatura - tempo. As curvas tracejadas indicam as curvas sem a inclusão do calor latente de transformação e as curvas contínuas as que incluíram o calor latente de transformação durante a têmpera em água com agitação para uma barra cilíndrica de 25,4 mm de diâmetro. Os números 1, 2 e 3, indicam os históricos de variação de temperatura calculados em $0 \mathrm{R}, 0,23 \mathrm{R}$ e $0,55 \mathrm{R}$, respectivamente (onde $\mathrm{R}$ é o raio do cilindro). 122 
Figura 46 - Microestruturas da superfície do aço AISI 4340 após tratamento térmico de têmpera em água com agitação. (a) Aumento 500x; (b) Aumento 1000x. Ataque LePera modificado.

Figura 47 - Microestruturas da parte intermediária do aço AISI 4340 após tratamento térmico de têmpera em água com agitação. (a) Aumento 500x; (b) Aumento 1000x. Ataque LePera modificado.

Figura 48 - Microestruturas da parte central do aço AISI 4340 após tratamento térmico de têmpera em água com agitação. (a) Aumento 500x; (b) Aumento 1000x. Ataque LePera modificado. 126

Figura 49 - Microestruturas da superfície do aço AISI 4140 após tratamento térmico de têmpera em água com agitação. (a) Aumento 500x; (b) Aumento 1000x. Ataque LePera modificado. B (Bainita), M (Martensita).

Figura 50 - Microestruturas da parte intermediária do aço AISI 4140 após tratamento térmico de têmpera em água com agitação. (a) Aumento 500x; (b) Aumento 1000x. Ataque LePera modificado. B (Bainita), M (Martensita). 128

Figura 51 - Microestruturas da parte central do aço AISI 4140 após tratamento térmico de têmpera em água com agitação. (a) Ampliação 500x; (b) Ampliação 1000x. Ataque LePera modificado. B (Bainita), M (Martensita).

Figura 52 - Microestruturas da superfície do aço AISI 1045 após tratamento térmico de têmpera em água com agitação. (a)Aumento 500x; (b)Aumento 1000x. Ataque Nital 2\% e Vilella. B (Bainita), M (Martensita), P (Perlita). 131

Figura 53 - Microestruturas da parte intermediária do aço AISI 1045 após tratamento térmico de têmpera em água com agitação. (a) Aumento 500x; (b) Aumento 1000x. Ataque Nital 2\% e Vilella. B (Bainita), M (Martensita), P (Perlita). 132

Figura 54 - Microestruturas da parte central do aço AISI 1045 após tratamento térmico de têmpera em água com agitação. (a) Aumento 500x; (b) Aumento 1000x. Ataque Nital 2\% e Vilella. B (Bainita), M (Martensita), P (Perlita).

Figura 55 - Micrografias dos aços AISI 4340 (à esquerda) e 4140 (à direita). Os óvalos indicam regiões com indícios de ocorrência de segregação. 134

Figura 56 - Curva de resfriamento contínuo para o aço AISI 4340. As linhas $M_{s}$ e $M_{f}$ indicam o início e o fim da transformação martensítica, respectivamente. $B$, $\mathrm{F}$ e $\mathrm{P}$ indicam o início dos campos bainítico, ferrítico e perlítico, respectivamente.136 
Figura 57 - Evolução microestrutural do processo de têmpera em água para o aço AISI 4340. (a) $6 \mathrm{~s}$, temperatura da superfície (Ts) $342^{\circ} \mathrm{C}$, temperatura do centro (Tc) $549^{\circ} \mathrm{C}$; (b) $9,3 \mathrm{~s}$, Ts $257^{\circ} \mathrm{C}$, Tc $408^{\circ} \mathrm{C}$; (c) $11,6 \mathrm{~s}$, Ts $212^{\circ} \mathrm{C}$, Tc $333^{\circ} \mathrm{C}$; (d) $14,6 \mathrm{~s}$, Ts $167^{\circ} \mathrm{C}$, Tc $260^{\circ} \mathrm{C}$; (e) $22,7 \mathrm{~s}$, Ts $91^{\circ} \mathrm{C}$, Tc $134^{\circ} \mathrm{C}$; (f) $35,5 \mathrm{~s}$, Ts $44^{\circ} \mathrm{C}$, Tc $57^{\circ} \mathrm{C}$. AA e MM representam austenita e martensita, respectivamente. 138

Figura 58 - llustração do estado microestrutural final após tratamento térmico de têmpera em água com agitação, indicando uma microestrutura 100\% martensítica ao longo da secção transversal do cilindro para o aço AISI 4340. ... 139

Figura 59 - Variação da temperatura no processo de têmpera em água para o cilindro de aço AISI 4340. 140

Figura 60 - Resultado final da porcentagem de cada microestrutura formada e da predição de dureza em função da profundidade, na simulação numérica desenvolvida através do AC3. FE3C, MART, BAIN, PEARL, FERR, AUST, ASQU (RC) representam cementita, martensita, bainita, perlita, ferrita, austenita retida e dureza (em escala Rockwell C), respectivamente. 140

Figura 61 - Curva de resfriamento contínuo para o aço AISI 4140. As linhas $M_{s}$ e $\quad M_{f}$ indicam 0 início e 0 fim da transformação martensítica, respectivamente. $\mathrm{B}, \mathrm{F}$ e $\mathrm{P}$ indicam os campos bainítico, ferrítico e perlítico, respectivamente. 141

Figura 62 - llustração do estado final da microestrutura após tratamento térmico de têmpera, indicando as porcentagens de cada microestrutura ao longo da secção transversal do cilindro para o aço AISI 4140. MM e BB representam martensita e bainita, respectivamente.

Figura 63 - Curva de resfriamento contínuo para o aço AISI 1045. As linhas $M_{s}$ e $M_{f}$ indicam o início e o fim da transformação martensítica, respectivamente. $B$, $\mathrm{F}$ e $\mathrm{P}$ indicam os campos bainítico, ferrítico e perlítico, respectivamente. 143

Figura 64 - llustração do estado microestrutural final após tratamento térmico de têmpera, indicando as porcentagens de cada microestrutura ao longo da secção transversal do cilindro para o aço AISI 1045. MM, BB e PP representam martensita, bainita e perlita, respectivamente.

Figura 65 - Perfil de dureza (HRC) do aço AISI 4340. Resultados calculados pela modelagem no AC3. 145

Figura 66 - Perfil de dureza (HRC) do aço AISI 4140. Resultados calculados pela modelagem no AC3. 145 
Figura 67 - Perfil de dureza (HRC) do aço AISI 1045. Resultados calculados pela modelagem no AC3.

Figura 68 - Resultados da dureza em função da distância do centro da amostra para os aços 4340, 4140 e 1045.

Figura 69 - Dureza da superfície até o centro de barras de aço temperado. (a) 4140, (b) 1040 e (c) 3340. Colpaert (1992)... 148

Figura 70 - Tensão residual para o aço AISI 4140, austenitizado e resfriado dentro do forno. Gráfico gerado pelo difratômetro de raios X Rigaku Rint 2000. As linhas de cor vermelha e azul representam os resultados para os valores de - $\psi$ e de $+\psi$, respectivamente. (a) Resultados das tensões no sentido axial (b) Resultados das tensões no sentido tangencial. 150

Figura 71 - Gráfico gerado pelo difratômetro de raios X Rigaku Rint 2000 da distribuição da tensão residual na superfície do aço AISI 4340 (a) axialmente e (b) tangencialmente. As linhas de cor vermelha e azul representam os resultados para os valores de - $\psi$ e de - $\psi$, respectivamente. As quatro colunas inferiores descrevem, de esquerda à direita, o resultado da tensão, o fator de segurança, o coeficiente angular e o valor obtido de $2 \theta$ em $\psi=0$, respectivamente. 152

Figura 72 - Gráfico gerado pelo difratômetro de raios X Rigaku Rint 2000 da distribuição da tensão residual na superfície do aço AISI 4140 (a) axialmente e (b) tangencialmente. As linhas de cor vermelha e azul representam os resultados para os valores de $-\psi$ e de $-\psi$ respectivamente. As quatro colunas inferiores descrevem, de esquerda à direita, o resultado da tensão, o fator de segurança, o coeficiente angular e o valor obtido de $2 \theta$ em $\psi=0$, respectivamente. 153

Figura 73 - Gráfico gerado pelo difratômetro de raios X Rigaku Rint 2000 da distribuição da tensão residual na superfície do aço AISI 1045 (a) axialmente e (b) tangencialmente. As linhas de cor vermelha e azul representam os resultados para os valores de $-\psi$ e de $-\psi$, respectivamente. As quatro colunas inferiores descrevem, de esquerda à direita, o resultado da tensão, o fator de segurança, o coeficiente angular e o valor obtido de $2 \theta$ em $\psi=0$, respectivamente. 154

Figura 74 - Variação da temperatura durante a têmpera para um nó da superfície e um nó do centro. 156

Figura 75 - Distribuição das tensões residuais calculadas pelo MEF para o cilindro de aço AISI/SAE 4340 após têmpera em água com agitação. (a) Axiais (b) Tangenciais (c) Radiais. 
Figura 76 - Distribuição das tensões residuais calculadas pelo MEF para o cilindro de aço AISI 4140após têmpera em água com agitação. (a) Axiais (b) Tangenciais (c) Radiais. 158

Figura 77 - Distribuição das tensões residuais calculadas pelo MEF para o cilindro de aço AISI 1045 após têmpera em água com agitação. (a) Axiais (b) Tangenciais (c) Radiais. 159

Figura 78 - Caminho de nós para determinação do perfil de tensão residual. 161

Figura 79 - Distribuição das tensões residuais ao fim da têmpera, calculadas pelo MEF ao longo da secção transversal do cilindro de aço AISI 4340 161

Figura 80 - Distribuição das tensões residuais ao fim da têmpera, calculadas pelo MEF ao longo da secção transversal do cilindro de aço AISI 4140. 162

Figura 81 - Distribuição das tensões residuais ao fim da têmpera, calculadas pelo MEF ao longo da secção transversal do cilindro de aço AISI 1045. 162

Figura 82 - Tensões residuais tangenciais térmicas ao longo do tempo desenvolvidas durante o tratamento térmico de têmpera do aço 4140 165

Figura 83 - Tensões residuais tangenciais térmicas e de transformação ao longo do tempo desenvolvidas durante o tratamento térmico de têmpera do aço 4140 . 166

Figura 84 - Trinca de têmpera iniciada na parte central após têmpera em água com intensa agitação. Aço 4340. (a) Fotografia da peça evidenciando as duas trincas formadas. (b) Micrografia da trinca na região de interseção; aumento 100x. 


\section{LISTA DE TABELAS}

Tabela 1 - Classificação dos aços segundo norma AISI/SAE. Fonte: Bringas (2007), Krauss (2005).

Tabela 2 - Diversas equações para o calculo do $M_{S}$. Fonte: Krauss (1978). 31

Tabela 3 - Mudanças no volume produzidas por transformações de fase. Thelning (1975).

Tabela 4 - Composição química do aço AISI 4140 ..................................... 85

Tabela 5 - Composição química do aço AISI 4340 ..................................... 85

Tabela 6 - Composição química do aço AISI 1045 ....................................... 86

Tabela 7 - Calor latente de transformação. Lee e Lee (2008) .................... 102

Tabela 8 - Calor latente de transformação. Oliveira et al. (2010)................ 102

Tabela 9 - Expansão volumétrica para a composição general e para o aço AISI 4140, 4340 e 1045 em cada fase transformada. Adaptado de Thelning (1975).

Tabela 10 - Parâmetros de regulagem utilizados no difratômetro de raios $X$ para a medição da tensão residual.

Tabela 11 - Análise quantitativa das microestruturas formadas no aço AISI 4340. 135

Tabela 12 - Análise quantitativa das microestruturas formadas no aço AISI 4140. 135

Tabela 13 - Análise quantitativa das microestruturas formadas no aço AISI 1045. 135

Tabela 14 - Resultados das medições de tensão residual pelo método de difração de raios $X$. 155

Tabela 15 - Comparação entre as tensões tangenciais e axiais numéricas e por difração de raios X para os aços AISI/SAE 4340, 4140 e 1045. 163 


\section{LISTA DE SÍMBOLOS E ABREVIATURAS}

$A A \quad$ Austenita

$\mathrm{Ac}_{1} \quad$ Temperatura de início de formação de austenita no aquecimento

$\mathrm{Ac}_{3} \quad$ Temperatura em que a transformação de ferrita para austenita se completa durante aquecimento

AC3 Programa de modelagem de tratamentos térmicos

$B B \quad$ Bainita

CAX4T Elemento de quatro nós com deslocamento e temperatura bi-linear

$C_{p A} \quad$ Calor específico da austenita

$C_{p B} \quad$ Calor específico da bainita

$C_{p M} \quad$ Calor específico da martensita

$C_{p P} \quad$ Calor específico da perlita

$d_{h k l} \quad$ Distância interplanar

$d_{0} \quad$ Distância interplanar padrão

DRX Difração de raios $X$

$\varepsilon \quad$ Emissividade / Vetor unitário adimensional

E $\quad$ Módulo de elasticidade

$E_{A} \quad$ Módulo de elasticidade da austenita

$E_{M} \quad$ Módulo de elasticidade da martensita

$E_{B} \quad$ Módulo de elasticidade da bainita

$E_{P} \quad$ Módulo de elasticidade da perlita 


\begin{tabular}{|c|c|}
\hline G & Taxa de crescimento \\
\hline$h$ & Coeficiente de transferência de calor \\
\hline$h k l$ & Índices de Miller \\
\hline HRC & Dureza Rockwell C \\
\hline I & Taxa de nucleação \\
\hline$k$ & Condutividade térmica \\
\hline$k_{A}$ & Condutividade térmica da austenita \\
\hline$k_{B}$ & Condutividade térmica da bainita \\
\hline$k_{M}$ & Condutividade térmica da martensita \\
\hline$k_{P}$ & Condutividade térmica da perlita \\
\hline$K_{i j}$ & Submatriz da matriz Jacobiana \\
\hline$K \alpha 2$ & Radiação característica \\
\hline$L$ & Comprimento \\
\hline$l_{0}$ & Comprimento inicial \\
\hline M & Mega \\
\hline$M M$ & Martensita \\
\hline$M_{i} / M_{s}$ & Temperatura de início da transformação martensítica \\
\hline$M_{f}$ & Temperatura de final da transformação martensítica \\
\hline$n$ & Número de núcleos por unidade de volume \\
\hline $\mathrm{Pa}$ & Pascal \\
\hline$P$ & Perlita \\
\hline
\end{tabular}




\begin{tabular}{|c|c|}
\hline$q$ & Densidade de fluxo de calor \\
\hline$r$ & Radiação / direção radial \\
\hline $\mathrm{RC}$ & Resfriamento Contínuo \\
\hline$R_{u}$ & Vetor mecânico \\
\hline$R_{T}$ & Vetor térmico \\
\hline S & Somatória de Scheil para patamares isotérmicos \\
\hline$t$ & Tempo \\
\hline$T$ & Temperatura \\
\hline$T_{S}$ & Temperatura da superfície do corpo de prova \\
\hline$T_{M}$ & Temperatura do médio de resfriamento \\
\hline TCC & Tetragonal de Corpo Centrado \\
\hline$T R$ & Tensões residuais \\
\hline TT & Tratamento térmico \\
\hline$V_{\text {exp }}$ & Volume expandido \\
\hline$V_{\gamma}$ & Fração volumétrica da austenita \\
\hline$V_{M}$ & Fração volumétrica da martensita \\
\hline$X$ & Fração de volume transformado \\
\hline$\alpha$ & Ferrita / difusividade térmica \\
\hline$\alpha^{\prime}$ & Martensita \\
\hline$\alpha_{T}$ & Coeficiente de expansão térmica \\
\hline$\alpha_{T A}$ & Coeficiente de expansão térmica da austenita \\
\hline
\end{tabular}




\begin{tabular}{|c|c|}
\hline$\alpha_{T M}$ & Coeficiente de expansão térmica da martensita \\
\hline$\alpha_{T B}$ & Coeficiente de expansão térmica da bainita \\
\hline$\alpha_{T P}$ & Coeficiente de expansão térmica da perlita \\
\hline$\alpha_{1}, \alpha_{2}$ e $\alpha_{3}$ & Cossenos diretores \\
\hline$\gamma$ & Austenita \\
\hline$\Delta T$ & Variação da temperatura \\
\hline$\Delta u$ & Variação do deslocamento \\
\hline$\varepsilon$ & Deformação \\
\hline$\theta, \phi e \psi$ & Ângulos \\
\hline$\theta_{h k l}$ & Semi-ângulo de difração \\
\hline$v$ & Coeficiente de Poisson \\
\hline$v_{A}$ & Coeficiente de Poisson da austenita \\
\hline$v_{B}$ & Coeficiente de Poisson da bainita \\
\hline$v_{M}$ & Coeficiente de Poisson da martensita \\
\hline$v_{P}$ & Coeficiente de Poisson da perlita \\
\hline$\pi$ & $\begin{array}{l}\text { Porcentagem de microconstituinte formado a partir de um processo } \\
\text { difusivo }\end{array}$ \\
\hline$\rho$ & Densidade \\
\hline$\sigma$ & Tensão / Constante de Stefan-Boltzmann \\
\hline$+\sigma$ & Tensão residual de compressão \\
\hline$-\sigma$ & Tensão residual de tração \\
\hline
\end{tabular}




$\begin{array}{ll}\sigma_{e} & \text { Limite de escoamento } \\ \sigma_{e A} & \text { Limite de escoamento da austenita } \\ \sigma_{e B} & \text { Limite de escoamento da bainita } \\ \sigma_{e M} & \text { Limite de escoamento da martensita } \\ \sigma_{e P} & \text { Limite de escoamento da perlita } \\ \sigma_{R I I} & \text { Tensão residual do tipo II } \\ \sigma_{R I I I} & \text { Tensão residual do tipo III } \\ \sigma_{l}^{t e r} & \text { Tensão axial térmica } \\ \sigma_{l}^{t r} & \text { Tensão axial de transformação } \\ \tau & \text { Período de incubação } \\ \psi & \text { Ângulo de inclinação do feixe incidente na difração de raios X }\end{array}$




\section{SUMÁRIO}

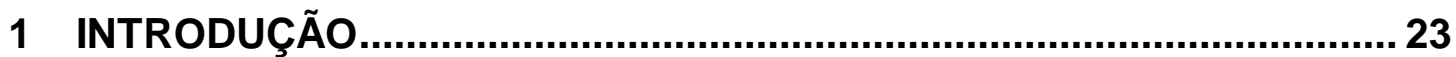

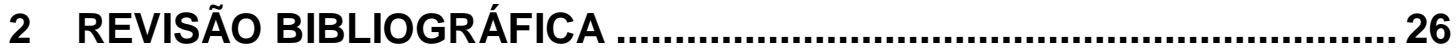

2.1 AÇOS: GENERALIDADES E CLASSIFICAÇÃO ..............................26

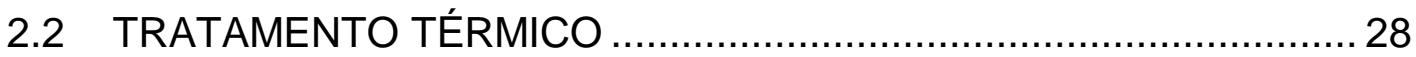

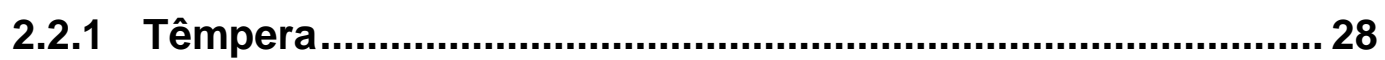

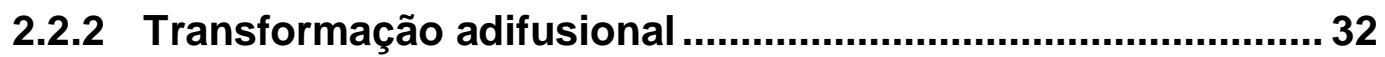

2.2.3 Cinética da transformação difusional .....................................33

2.2.4 Diagramas Tempo Temperatura Transformação (TTT) e de Resfriamento Contínuo (RC) ................................................. 41

2.2.5 Influência dos elementos de liga nas curvas TTT.................... 46

2.2.6 Transferência de calor durante a têmpera............................... 49

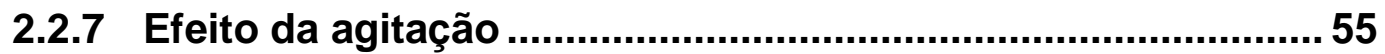

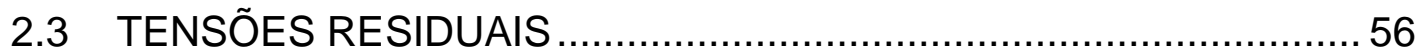

2.3.1 Tensões térmicas no caso de um comportamento ideal linear

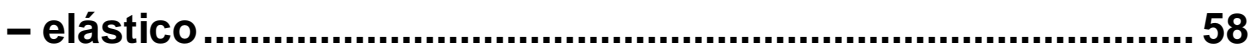

2.3.2 Tensões de transformação no caso de um comportamento

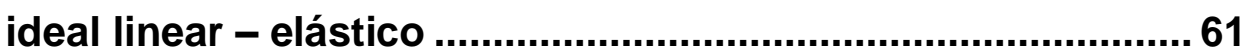

2.3.3 Combinação das tensões térmicas e de transformação no caso de um cilindro ideal linear elástico 63

2.3.4 Tensões residuais no caso do comportamento elasto -

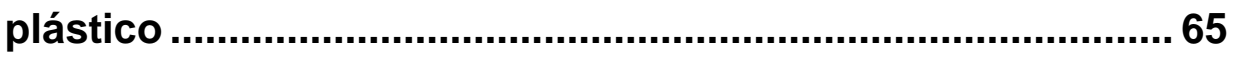

2.3.4.1 Tensões residuais térmicas (sem transformação de fase).... 65

2.3.4.2 Tensões residuais devidas à transformação de fase ............. 68

2.3.4.3 Formação das tensões residuais de compressão na superfície

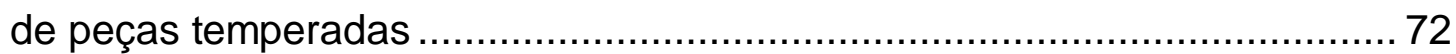

2.3.5 Medida de tensão residual por difração de raios $X$..................75

2.4 MÉTODO DOS ELEMENTOS FINITOS........................................... 82 


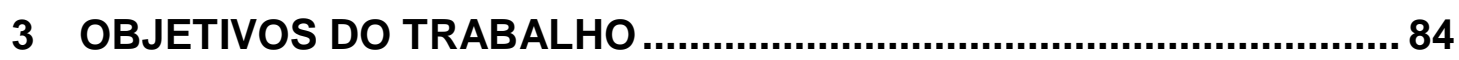

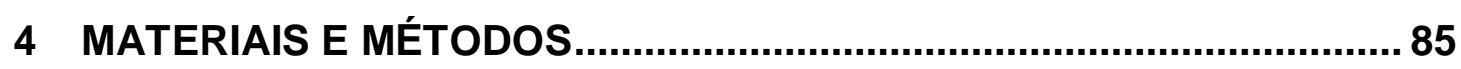

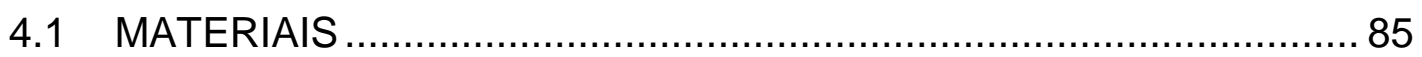

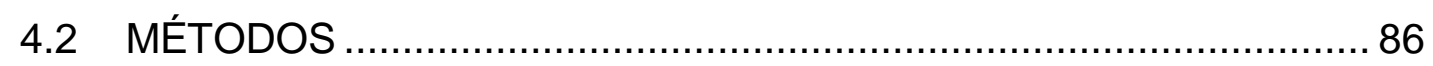

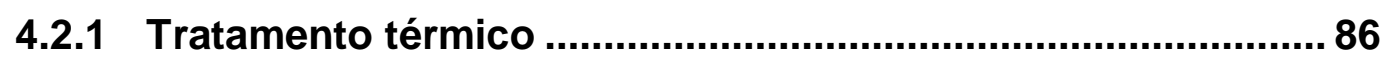

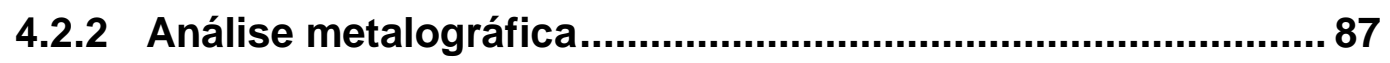

4.2.3 Medidas de fração volumétrica ................................................ 88

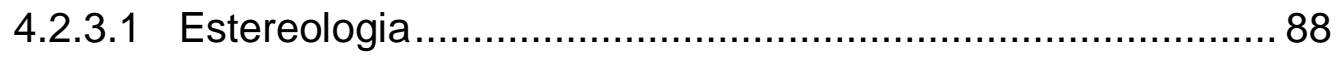

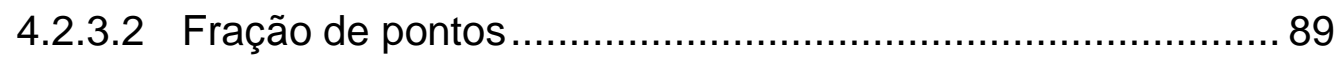

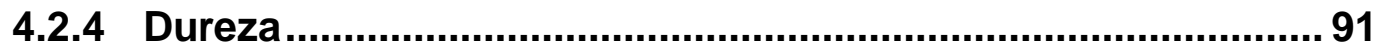

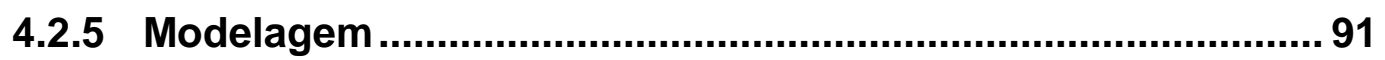

4.2.5.1 Programa AC3 ……..................................................... 91

4.2.5.2 Programa AC3 Converter ................................................... 93

4.2.5.3 Modelagem pelo Método dos Elementos Finitos .................. 95

4.2.5.4 Propriedades Físicas e Mecânicas ...................................... 98

4.2.6 Análise térmica dos experimentos de têmpera.................... 108

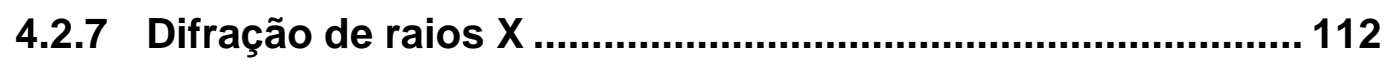

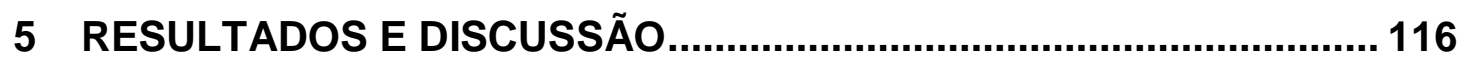

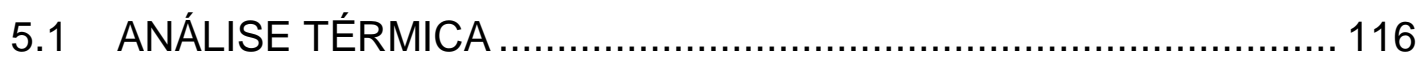

5.1.1 Coeficiente de transferência de calor e fluxo térmico...........116

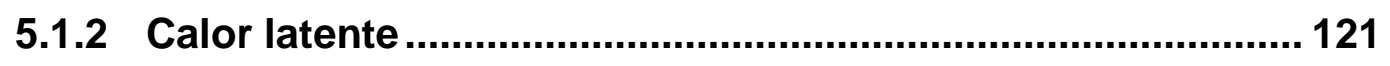

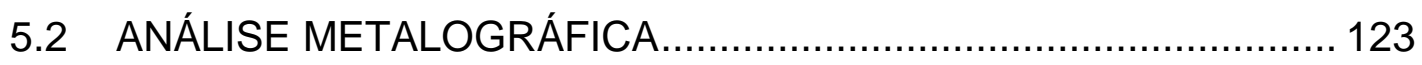

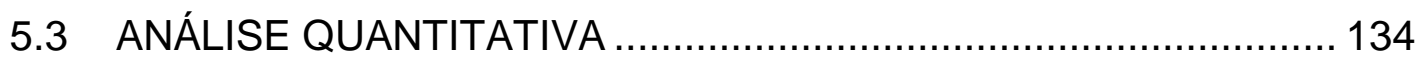

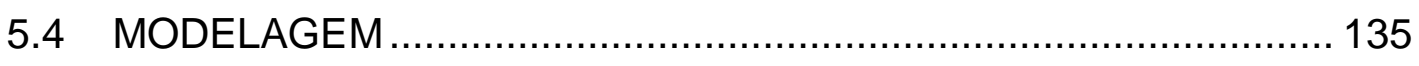

5.4.1 Modelagem microestrutural utilizando o programa AC3 ..... 135

5.4.2 Modelagem da dureza utilizando o programa AC3 …........... 144

5.5 DUREZA CALCULADA EXPERIMENTALMENTE ........................ 146

5.6 TENSÕES RESIDUAIS POR DIFRAÇÃO DE RAIOS X ................. 148 
5.7 TENSÕES CALCULADAS PELO MÉTODO DOS ELEMENTOS

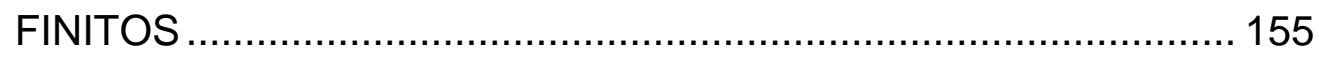

5.7.1 Formação das tensões residuais de compressão na superfície .. 164

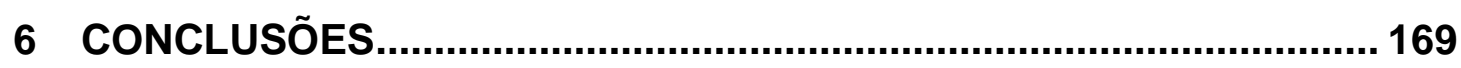

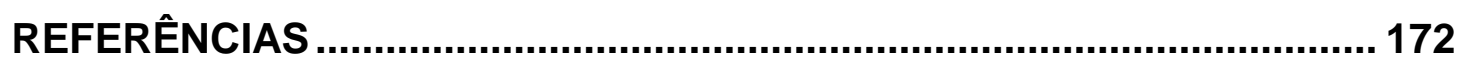




\section{INTRODUÇÃO}

Os tratamentos térmicos dos aços são processos de fabricação que proporcionam aos componentes mecânicos propriedades diferentes das obtidas após os processos de lingotamento, laminação e usinagem. Em muitos casos, permitem a obtenção de propriedades especificadas sem afetar significativamente as dimensões dos componentes. Dentre os diversos tipos de tratamentos térmicos realizados em aços para construção mecânica, a têmpera é uma operação aplicada ao final do processo de fabricação com o intuito de modificar as propriedades mecânicas e físicas do componente, sendo esta destinada a uma determinada melhoria nas características do aço, como aumento da dureza, resistência à fadiga, mecânica e ao desgaste etc. O tratamento de têmpera é caracterizado pelo aquecimento da peça até uma temperatura ligeiramente superior $\left(\sim 50^{\circ} \mathrm{C}\right)$ à temperatura crítica (austenitização), manutenção nesta temperatura por certo tempo e em seguida resfriamento a uma velocidade suficientemente alta para garantir transformação martensítica na superfície do material e também muitas vezes no centro da peça.

No processo de têmpera, é necessário controlar a taxa de resfriamento a fim de melhorar as propriedades mecânicas e, além disto, evitar a formação de trincas e distorções, resultantes tanto das tensões térmicas que se desenvolvem devido aos gradientes de temperatura, quanto das tensões de transformação originadas pelas variações volumétricas decorrentes da decomposição da austenita em agregados de ferrita e carbonetos ou em martensita.

A têmpera nos aços é, portanto, um problema complexo que envolve o acoplamento entre fenômenos térmicos, de transformação de fase e mecânicos, no qual existe uma grande dificuldade de controlar a microestrutura para obter as propriedades mecânicas desejadas, e ao mesmo tempo condicionar o desenvolvimento de tensões residuais e limitar as distorções sofridas pela peça durante e após o processo. Segundo Suraj (2009), tradicionalmente, nas operações de tratamento térmico industrial, os ciclos de tratamento térmico evoluem empiricamente, e uma vez que as propriedades desejadas são atingidas, os ciclos 
raramente são modificados. Esta abordagem empírica resulta, muitas vezes, em condições afastadas da ideal, associadas à baixa produtividade e alto consumo de energia.

Entre outros, para um controle dimensional adequado, são necessários conhecimentos quantitativos e qualitativos das tensões e deformações, associadas ao acoplamento termomecânico resultante de contrações térmicas e transformações de fase durante o resfriamento. Neste contexto, torna-se importante a elaboração de modelos e simulações numéricas capazes de descrever e prever os processos que ocorrem na peça durante a têmpera, as deformações originadas no resfriamento, a evolução da temperatura e da microestrutura, e a forma com que as tensões residuais se distribuem durante e após o tratamento térmico. $O$ conhecimento destas variáveis e de suas interações permite analisar e otimizar as operações de tratamento térmico, a microestrutura do material e as propriedades mecânicas associadas. Como afirmam Prabhu e Fernandes (2007), a simulação baseada nos processos de têmpera permite ao tratador térmico escolher criteriosamente o meio refrigerante e preparar adequadamente a amostra temperada para uma aplicação específica.

No presente trabalho, é feita a modelagem das tensões desenvolvidas durante a têmpera em água de aços médio carbono AISI/SAE 1045, 4140 e 4340, utilizando o método de elementos finitos. Para este objetivo adotou-se uma combinação entre o software de elementos finitos ABAQUS/Standard® e o programa AC3 dedicado à modelagem do processo de têmpera. O programa AC3 prevê as curvas de transformação, a evolução da temperatura, as curvas de resfriamento, a dureza e a microestrutura do material em cada posição entre a superfície e o centro do cilindro. As porcentagens transformadas de cada uma das fases, obtidas utilizando o programa $A C 3$, foram consideradas para determinar as propriedades mecânicas introduzidas no ABAQUS/Standard®. Para a previsão da evolução das tensões residuais e das deformações foram consideradas não somente as tensões puramente térmicas, devido ao transiente, mas também as de transformação. Tratase de um problema termo-elasto-plástico onde os valores das propriedades físicas e mecânicas necessárias para previsão da evolução das tensões residuais e das deformações, foram incluídos levando em conta a dependência da temperatura e as 
fases presentes em função do tempo de tratamento. A verificação e a calibração do modelo numérico computacional foram efetuadas através da medição das tensões residuais com o emprego da técnica de difração de raios $X$. 


\section{REVISÃO BIBLIOGRÁFICA}

\subsection{AÇOS: GENERALIDADES E CLASSIFICAÇÃO}

Aços são ligas ferro-carbono com teor de carbono entre 0,03 e 2,11\% em peso, que podem ou não conter elementos de liga em sua composição química.

Uma das maneiras de classificar os aços é por meio de sua composição química, especificamente, pelo teor de carbono. Os aços de baixo, médio e alto carbono possuem, respectivamente, teores de carbono até $0,25 \%$, entre $0,25 \mathrm{e}$ $0,60 \%$ e entre $0,60-1,0 \%$ (SOUZA, 2001). Existem, no entanto, alguns casos em que os aços ligados podem apresentar um teor de carbono com até 2,5\%; são os chamados aços ledeburíticos.

Aços hipoeutetóides e hipereutetóides são aqueles contendo respectivamente teores de carbono menores e maiores que o correspondente ao ponto eutetóide (aproximadamente $0,76 \%$ de carbono).

Em geral, considera-se que os aços carbono são aqueles em que os teores de elementos além do ferro e do carbono são pequenos ${ }^{1}$, isto é, não contem mais que $1,00 \%$ de $\mathrm{Mn}, 0,30 \%$ de $\mathrm{Si}, 0,05 \%$ de $\mathrm{S}$ e $0,04 \%$ de $\mathrm{P}$. Já os aços com mais alta porcentagem de elementos de liga são conhecidos como aços ligados ou aços-liga, que, de acordo com a quantidade de elementos acrescentados em sua composição, podem ser classificados como aços de baixa, média ou alta liga.

A introdução de elementos de liga nos aços para construção mecânica é feita a fim de aumentar a profundidade de endurecimento por têmpera e a resistência mecânica, conferir uniformidade na resistência em peças de grandes dimensões e aumentar a resistência ao desgaste.

\footnotetext{
${ }^{1}$ Não é possível estabelecer uma separação clara entre os aços de baixa liga e aços carbono, e uma definição precisa destes últimos é difícil (ROTHERY, 1968).
} 
Os aços de baixa liga para construção mecânica são referenciados pelas normas DIN, AFNOR, UNI, JIS, AISI, SAE, etc. A norma mais utilizada, na qual se baseia a norma brasileira ABNT, é a norma AISI/SAE (AISI - American Iron and Steel Institute / SAE - Society of Automotive Engineers), que usa quatro dígitos para designar cada composição química de aço. Os dois primeiros dígitos indicam o principal elemento de liga ou grupo de elementos de liga, como listado na Tabela 1. Os dois últimos dígitos indicam o teor de carbono nominal aproximado, multiplicado por 100 .

Tabela 1 - Classificação dos aços segundo norma AISI/SAE. Fonte: Bringas(2007), Krauss (2005).

\begin{tabular}{|c|c|}
\hline Designação SAE/AISI & Tipo de Aço \\
\hline $10 \mathrm{XX} * / \mathrm{C} 10 \mathrm{XX}$ & Aço carbono; máximo 1,00\% de Mn \\
\hline $11 \mathrm{XX} / 11 \mathrm{CXX}$ & Usinagem (ou corte) fácil, com alto S \\
\hline $13 X X$ & Mn $1,75 \%$ \\
\hline $23 X X$ & Ni com $3,50 \%$ \\
\hline $25 X X$ & Ni com $5,00 \%$ \\
\hline $31 X X$ & Ni $1,25 \% ; \operatorname{Cr} 0,65 \%$ \\
\hline $33 X X / E 33 X X$ & Ni 3,50\%; Cr 1,55\% \\
\hline $40 X X$ & Mo 0,20 ou $0,25 \%$ \\
\hline $41 X X$ & Cr 0,$50 ; 0,80$ ou $0,95 \%$; Mo 0,$12 ; 0,20$ ou $0,30 \%$ \\
\hline $43 x X$ & Ni $1,83 \%$; Cr 0,50 a $0,80 \% ;$ Mo $0,25 \%$ \\
\hline $44 X X$ & Mo $0,53 \%$ \\
\hline $46 X X$ & Ni 0,85 ou $1,80 \%$; Mo 0,20 ou $0,25 \%$ \\
\hline $47 X X$ & Ni 1,$05 ;$ Cr0,45; Mo 0,20 ou $0,35 \%$ \\
\hline $48 X X$ & Ni 3,50\%; Mo 0,25\% \\
\hline $50 X X$ & Cr 0,28 ou $0,65 \%$ \\
\hline $51 X X$ & Cr 0,80 a $1,05 \%$ \\
\hline $61 X X$ & Cr 0,60 ou $0,95 \% ; \mathrm{V} 0,13$ ou $0,15 \%$ \\
\hline $86 X X$ & Ni 0,55\%; Cr 0,50\%; Mo 0,20\% \\
\hline $87 X X$ & Ni 0,55\%; Cr 0,50\%; Mo 0,25\% \\
\hline $88 X X$ & Ni 0,55\%; Cr0,50\%; Mo 0,35\% \\
\hline $92 X X$ & Si 1,80 ou $2,0 \%$; Mn $0,70 \%$ a $1,00 \%$ \\
\hline $93 \times x$ & Ni 3,25 \%; Cr 1,20\%; Mo0,08 a 0,15\% \\
\hline 94BXX & Ni $0,45 \%$; Cr 0,4\%; Mo 0,15 a 0,25\% \\
\hline $98 X X$ & Ni 1,0\%; Cr 0,8\%; Mo 0,25\% \\
\hline
\end{tabular}

${ }^{\star} \mathbf{X X}$ : indicam a porcentagem em peso de carbono do aço multiplicado por 100. 
Assim, um aço AISI/SAE 1020, por exemplo, é um aço carbono com aproximadamente $0,2 \%$ de carbono em sua composição, sendo o restante ferro e impurezas.

\subsection{TRATAMENTO TÉRMICO}

\subsubsection{Têmpera}

O aquecimento dos aços até a faixa de temperaturas do campo austenítico $(\gamma)$ para transformar a estrutura em cúbica de faces centradas (CFC) é chamado de austenitização. Neste aquecimento aumenta a taxa de difusão dos átomos de carbono que vão progressivamente se redistribuindo dentro da estrutura cristalina do aço para formar a austenita. Um aço que foi austenitizado e depois resfriado bruscamente é dito temperado e apresenta uma estrutura acicular ${ }^{2}$, conhecida como martensita.

Na transformação martensítica, a estrutura de átomos de ferro é submetida a um cisalhamento brusco a partir da estrutura CFC para a cúbica de corpo centrado, CCC, transformação rápida demais para os átomos de carbono se difundir formando carbonetos ou grafita. Os átomos de carbono ficam, portanto retidos nos interstícios octaédricos da estrutura CCC. A característica da transformação é que, num dado cristal, apenas um conjunto de interstícios octaédricos é ocupado e o cristal fica submetido a uma distorção tetragonal (ROTHERY, 1968).

A temperatura até a qual o aço deve ser resfriado para se obter martensita é chamada de temperatura de início de formação da martensita $\left(M_{i}\right.$, mais comumente conhecida como $M_{s}$, do inglês Martensite start). Esta temperatura depende da composição química do aço (é função do carbono, bem como de elementos de liga

\footnotetext{
${ }^{2}$ A martensita é normalmente descrita como "acicular" que significa "com forma de agulha", mas na realidade, a maioria dos cristais de martensita são plaquetas lenticulares que, seccionadas, podem-se apresentar como agulhas (ROTHERY, 1968).
} 
substitucionais). Já a temperatura na qual toda a austenita é transformada em martensita é chamada de temperatura de fim de formação da martensita $\left(M_{f}\right)$.

Para os aços de alta liga a temperatura $M_{f}$ pode ser muito baixa, fazendo com que alguns aços contenham na temperatura ambiente austenita não transformada, comumente denominada de austenita retida. Nestes casos, para obter uma transformação completa, o aço deverá ser temperado diretamente em um meio de resfriamento com temperatura abaixo do $M_{f}$ (PARRISH, 1999). A importância de conhecer a quantidade de austenita não transformada está em que, na maior parte das aplicações, este é um microconstituinte indesejável, pois degrada as propriedades mecânicas dos aços temperados, diminui a sua dureza, resistência à tração e ao desgaste, reduz a resistência à fadiga devido à redução da máxima tensão compressiva atingível na superfície. Propriedades essas que poderiam ser alcançadas se fosse total a transformação para martensita (TOTTEN et al., 2002).

A relação das temperaturas $M_{s}$ e $M_{f}$ e da austenita retida, com o aumento do teor de carbono é apresentada na Figura 1. Pode-se verificar através dessa figura, que acima de $0,7 \%$ de carbono a temperatura $M_{f}$ fica abaixo da temperatura ambiente. Com isto, na temperatura ambiente resta ainda austenita não transformada. Segundo Teixeira (2002), a transformação dos últimos resíduos de austenita se torna cada vez mais difícil, quanto menor a quantidade de austenita remanescente. Desse modo, a reação martensítica teoricamente nunca se completa, mesmo na temperatura zero absoluto, fazendo com que a temperatura final da transformação, $M_{f}$, não seja claramente definida. 


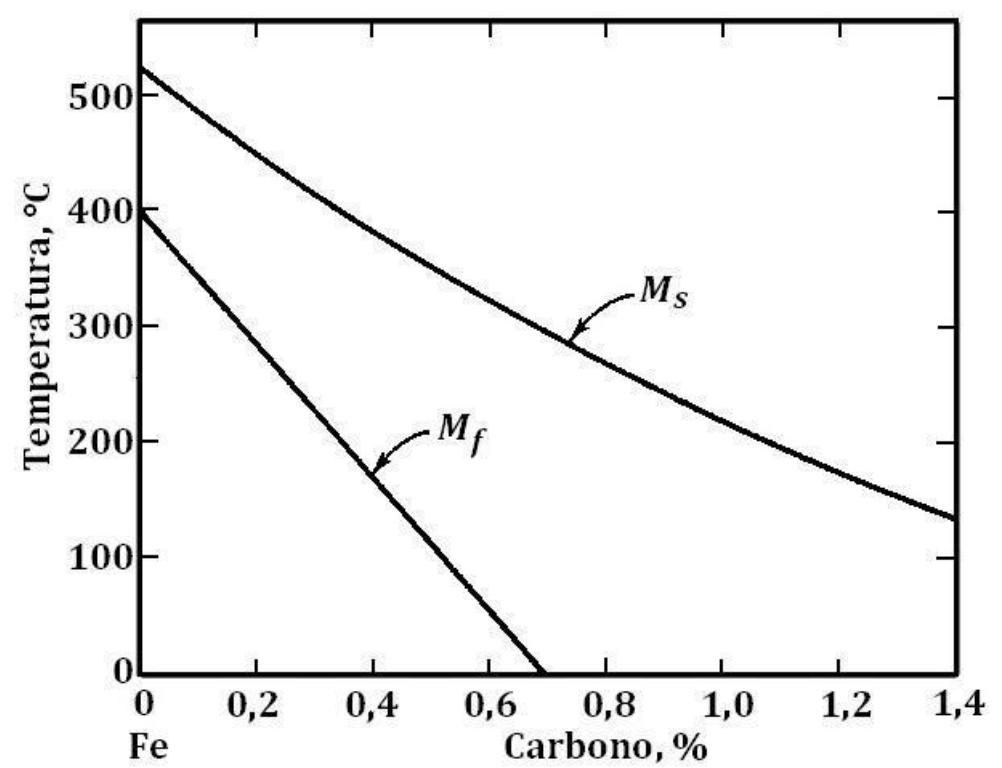

(a)

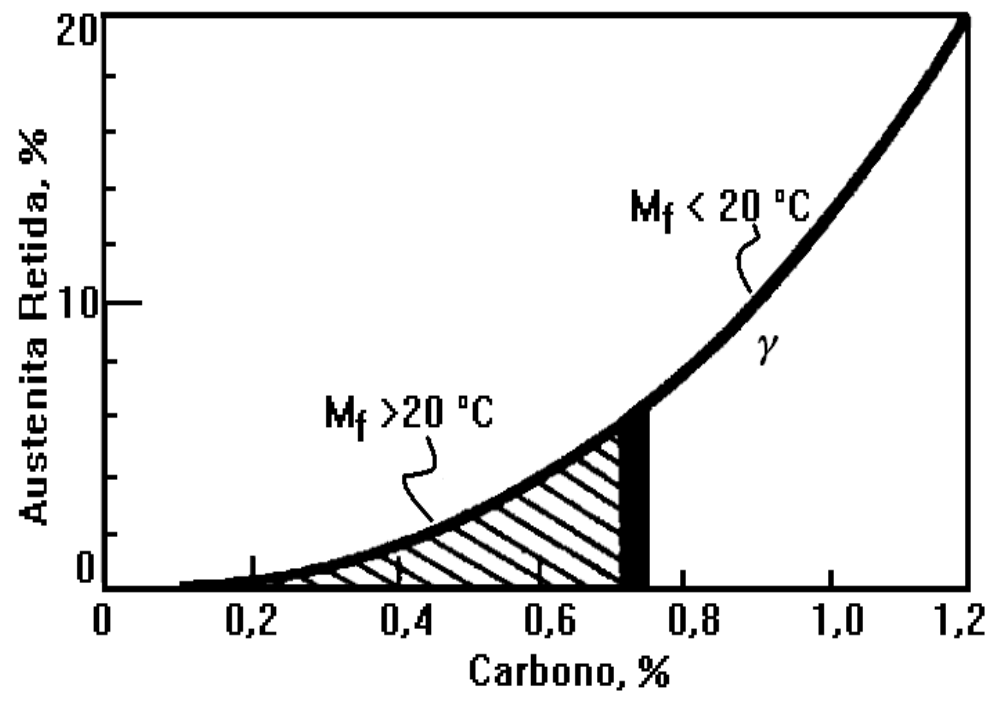

(b)

Figura 1 - Influência do teor de carbono: (a) nas temperaturas de início $\left(M_{s}\right)$ e fim da formação da martensita $\left(M_{f}\right)$, para aços não ligados. Adaptado de Troiano e Greninger (1946); (b) no teor de austenita retida. Adaptado de Parrish (1999).

Bhadeshia e Honeycombe (2006) explicam que nos aços com teor de carbono mais elevado, a relaxação das tensões de têmpera é mais difícil do que no caso da martensita começar a formar-se a temperaturas mais elevadas, para as quais a relaxação de tensões ocorre predominantemente por deformação e não por fratura. Além disso, afirmam que quanto mais baixa for a temperatura $M_{s}$, maior a variação de volume durante a transformação e, por conseguinte, maiores serão as tensões resultantes por deformação. 
Deste modo, devido à grande importância que representa $M_{s}$ na transformação martensítica, esta temperatura tem sido alvo de vários estudos, a fim de desenvolver fórmulas que a relacionam com a composição dos aços, como pode ser observado na Tabela 2.

Tabela 2 - Diversas equações para o calculo do $M_{S}$. Fonte: Krauss (1978).

\begin{tabular}{|c|c|c|}
\hline Autores & Data & Equação \\
\hline $\begin{array}{l}\text { Payson e } \\
\text { Sabage }\end{array}$ & 1944 & $\begin{array}{c}M_{S}\left({ }^{\circ} \mathrm{F}\right)=930-570(\mathrm{C})-60(\mathrm{Mn})-50(\mathrm{Cr})-30(\mathrm{Ni})-20(\mathrm{Mo}) \\
-20(\mathrm{~W})-20(\mathrm{Si})\end{array}$ \\
\hline Carapela & 1944 & $\begin{array}{r}M_{S}\left({ }^{\circ} F\right)=925(1-0,62 C)(1-0,092 M n)(10,033 S i)(-0,045 N i)(1 \\
-0,07 C r)(1-0,029 M o)(1-0,018 W)(1+0,12 C o)\end{array}$ \\
\hline Rowland e Lyle & 1946 & $\begin{array}{c}M_{S}\left({ }^{\circ} F\right)=930-600(C)-60(M n)-50(C r)-30(N i)-20(M o) \\
-20(W)-20(S i)\end{array}$ \\
\hline $\begin{array}{l}\text { Grange e } \\
\text { Stewart }\end{array}$ & 1946 & $M_{S}\left({ }^{\circ} \mathrm{F}\right)=1000-650(\mathrm{C})-70(\mathrm{Mn})-70(\mathrm{Cr})-35(\mathrm{Ni})-50(\mathrm{Mo})$ \\
\hline Nehrenberg & 1946 & $\begin{array}{c}M_{S}\left({ }^{\circ} F\right)=930-540(C)-60(M n)-40(C r)-30(N i)-20(\% M o) \\
-20(S i)\end{array}$ \\
\hline $\begin{array}{l}\text { Steven e } \\
\text { Hayness }\end{array}$ & 1956 & $M_{S}\left({ }^{\circ} F\right)=561-474(C)-33(M n)-17(C r)-17(N i)-21(M o)$ \\
\hline Andrews - 1 & 1965 & $\begin{array}{c}M_{S}\left({ }^{\circ} \mathrm{C}\right)=539-423(\mathrm{C})-30,4(\mathrm{Mn})-12,1(\mathrm{Cr})-17,7(\mathrm{Ni}) \\
-7,5(\% \mathrm{Mo})+10(\mathrm{Co})-7,5(\mathrm{Si})\end{array}$ \\
\hline Andrews - 2 & 1965 & $\begin{aligned} M_{S}\left({ }^{\circ} \mathrm{C}\right)=512- & 453(\mathrm{C})-16,9(\mathrm{Ni})+151(\mathrm{Cr})-9,5(\mathrm{Mo}) \\
& +217(\mathrm{C})^{2}-71,5(\mathrm{C})(\mathrm{Mn})-67,6(\mathrm{C})(\mathrm{Cr})\end{aligned}$ \\
\hline
\end{tabular}

Das fórmulas apresentadas na Tabela 2, a mais comumente utilizada na literatura para calcular a temperatura de início da transformação martensítica, é a equação 1 de Andrews (1965), que fornece uma boa referência para aços de baixa e média liga. O máximo teor dos elementos para aplicação desta fórmula é $0,6 \% \mathrm{C}$, 4,9\% Mn, 5\% Cr, 5\% Ni e 5,4\% Mo. No entanto, a precisão desta equação cai drasticamente para teores de liga maiores. O trabalho de Ghosh e Olson (2001) tentou estender os limites de composição para aços de alta liga, usando uma abordagem que inclui transferência de calor, propriedades magnéticas e a temperatura de equilíbrio (usando as bases de dados do software Thermocalc - 
SSOL, e KMART - kinetics of MARtensitic Transformation) para ligas binárias e ternárias. Esta nova proposta foi bem sucedida para valores de $M_{s}$ maiores que $100^{\circ} \mathrm{C}$, mas apresenta problemas quando a abordagem é estendida para ligas com valores baixos de $M_{S}$ e, além disso, o Co precisa ser tratado de maneira especial (SAUNDERS et al., 2004).

\subsubsection{Transformação adifusional}

Nas transformações adifusionais não ocorre redistribuição dos elementos em solução sólida, por não haver mobilidade suficiente. A transformação ocorre por um deslocamento simultâneo de átomos, por cisalhamento da rede. A decomposição da austenita em martensita é uma transformação tipicamente adifusional, embora, em aços com baixo teor de carbono, alguma difusão de curto alcance desse elemento possa ocorrer (DOS SANTOS, 2007).

Para calcular a quantidade de austenita transformada durante a transformação da austenita em martensita, pode-se usar a equação de Koistinen e Marburger (1959) [eq.(1)].

$$
V_{\gamma}=\exp \left(-\alpha\left(M_{s}-T\right)\right)
$$

onde $V_{\gamma}$ é a fração volumétrica da austenita retida, $M_{s}$, como já foi referido, é a temperatura de início da transformação martensítica, $\alpha$ é um parâmetro que, para a maioria dos aços estudados pelos autores, foi considerado aproximadamente igual a $1,10 \times 10^{-2} K^{-1}$ independente da composição química, e $T$ é a temperatura mais baixa atingida durante a têmpera, sendo que:

$$
M_{S}>T>-80^{\circ} \mathrm{C}
$$

E pelo princípio de complementaridade, pode-se obter a fração volumétrica para martensita:

$$
V_{M}=1-\exp \left(-0,011\left(M_{S}-T\right)\right)
$$


Segundo Koistinen e Marburger (1959), o ajuste de todos os dados plotados para obtenção desta equação determina o grau de transformação, não só para os aços ligados, mas também para os aços carbono. E acrescentam que esta equação geral descreve quantitativamente o progresso da transformação de austenita para martensita e pode ser usada para calcular a temperatura necessária no resfriamento do processo de têmpera para reduzir a quantidade de austenita retida. Além disso, a restrição até $-80^{\circ} \mathrm{C}$ foi imposta, uma vez que os autores fizeram as medições do volume de austenita retida, por difração de raios $\mathrm{X}$, para amostras temperadas até $-79^{\circ} \mathrm{C}$ e consideraram que no início da tempera tem-se $100 \%$ austenita.

\subsubsection{Cinética da transformação difusional}

Quando a decomposição da austenita ocorre em temperaturas muito elevadas, existem condições cinéticas para que os elementos em solução sólida se redistribuam entre as fases presentes, conforme seus potenciais termodinâmicos. $A$ redistribuição ocorre por difusão e sua extensão depende, para cada elemento, da sua tendência em permanecer em cada fase, ou seja, do potencial químico, e da sua mobilidade, dada pela difusividade. Nessas condições, a transformação fica controlada pela difusão dos elementos em solução sólida, sendo então chamada de transformação difusional. Transformações em altas temperaturas são favorecidas por baixas velocidades de resfriamento, pequeno tamanho de grão austenítico e por aços com baixos teores de elementos estabilizadores da austenita, tal como o $\mathrm{Mn}$ (DOS SANTOS, 2007).

A cinética de transformações de fase para o estado sólido depende tanto da nucleação como do crescimento ${ }^{3}$ da nova fase. Para explicar este fenômeno Gür e Pan (2009) supõem, que existe um sistema de transformação de fase em uma certa temperatura, em que a nova fase $\alpha$ é produzida. Se a taxa de nucleação da nova

\footnotetext{
3 Uma expressão matemática para a velocidade de crescimento da frente de uma nova fase, quando a transformação é controlada por difusão, foi proposta originalmente por Zener (1946).
} 
fase é $I$, o número de núcleos por unidade de volume, $n$, da nova fase, formados durante um período $d t$ será:

$$
n=I\left(V-V^{\alpha}\right) d t
$$

onde $V$ representa o volume total do sistema e $V^{\alpha}$ representa o volume da nova fase.

A relação entre o raio, $R_{n}$, dos núcleos e o tempo é representada por:

$$
R_{n}=G(t-\tau)
$$

onde $G$ é a taxa de crescimento linear da nova fase, e $\tau$ é o período de incubação.

Do conceito de volume estendido $\left(V_{\text {exp }}\right)$ sob a suposição de locais aleatoriamente nucleados, obtém-se a equação (6) que sugere que conhecendo a taxa de nucleação e o volume de fase transformada é possível calcular a fração transformada (AVRAMI, 1939). Desta maneira, a variação do volume da fase $\alpha$ pode ser descrita por:

$$
d V^{\alpha}=\left(1-\frac{V^{\alpha}}{V}\right) d V_{e x p}^{\alpha}
$$

Para uma distribuição aleatória de partículas precipitadas, a equação (6) pode ser integrada a fim de obter a fração de volume real [eq. (7)]:

$$
\frac{V^{\alpha}}{V}=1-\exp \left(-\frac{V_{\text {exp }}^{\alpha}}{V}\right)
$$

$\mathrm{Na}$ qual, $V_{\text {exp }}^{\alpha}$ pode ser calculada usando modelos de nucleação e crescimento, desprezando qualquer efeito de interferência entre grãos da fase transformada (BHADESHIA, 2001).

Considerando o caso simples em que $\alpha$ cresce isotropicamente a uma taxa constante $G$, o volume de uma partícula nucleada em um tempo $\tau$ é dado por: 


$$
v_{\tau}=\frac{4}{3} \pi G^{3}(t-\tau)^{3}
$$

Assim, a mudança do volume estendido sobre o intervalo $\tau$ e $\tau+d \tau$ será:

$$
d V_{e x p}^{\alpha}=\frac{4}{3} \pi G^{3}(t-\tau)^{3} I\left(V-V^{\beta}\right) d \tau
$$

Substituindo a equação(6) na equação(9), obtém-se:

$$
d V^{\alpha}=\left(1-\frac{V^{\alpha}}{V}\right) \frac{4}{3} \pi G^{3}(t-\tau)^{3} I\left(V-V^{\alpha}\right) d \tau
$$

Integrando a equação (10), e substituindo $X$ por $V^{\alpha} / V$, teremos que o volume da nova fase gerada em um tempo $t$ é:

$$
-\ln (1-X)=\left(1-\frac{V^{\alpha}}{V}\right) \frac{4}{3} \pi G^{3} I\left(V-V^{\alpha}\right) \int_{0}^{t}(t-\tau)^{3} d \tau
$$

Segundo Cahn (1956) no caso de saturação de sítios com nucleação predominante nos pontos tríplices ${ }^{4}$, a cinética de transformação é dada pela equação (12). Assumindo $X$, como a fração de volume transformado e $t$ o tempo de transformação, é obtida a equação de Johnson-Mehl:

$$
X=1-\exp \left(-\frac{\pi}{3} I G^{3} t^{4}\right)
$$

Nesta equação [eq. (12)] a taxa de nucleação $(I)$ e de crescimento $(G)$ são supostas constantes e a morfologia da nova fase suposta esférica. No entanto, visto que a taxa de nucleação na transformação não é constante, a cinética da transformação difusional pode ser representada pela equação de Avrami ${ }^{5}$ [eq. (13)] que descreve, para os processos dominados pela difusão do carbono, a fração volumétrica de cada fase formada:

\footnotetext{
4 Pontos de nucleação (nas esquinas ou arestas) onde vários grãos se interceptam.

5 Existem algumas outras denominações para esta equação [eq. (13)], como equação JMAK (Jonhson-Mehl-Avrami-Kolmogorov), mas é mais conhecida na literatura como equação tipo Avrami.
} 


$$
X=1-\exp \left(-c t^{n}\right)
$$

onde $c$ representa o coeficiente dependente da temperatura, sendo as vezes, dado também em função da composição química da fase inicial e do tamanho de grão, $t$ é o tempo da reação, e $n$ é o coeficiente dependente do tipo de transformação, relacionado à geometria da fase de crescimento e às condições de nucleação (LI, 2003), e determina a forma da curva. Tanto $c$ como $n$, são constantes do material, dependentes da composição do aço, do tamanho de grão austenítico e da temperatura para uma determinada condição de transformação e podem ser deduzidos a partir de medidas experimentais de dilatação (FANG et al., 1997).

O fator $c$ é uma função da temperatura e representa a influência da taxa de aquecimento sobre as taxas de nucleação, e é dado pela equação de Arrhenius [eq.(14)]:

$$
c=c_{0} \exp \left(-\frac{Q}{R T}\right)
$$

onde $c_{0}$ é o coeficiente pré-exponencial, $R$ é a constante universal dos gases ideais e $Q$ é a energia de ativação para a transformação de fase, incorporando entalpias de ativação de todos os processos que constituem a transformação de fase global (RODRIGUES, 2010).

Com a finalidade de determinar a relação da cinética de Avrami na descrição isotérmica e não-isotérmica, Woldt (1992) demonstrou que esta relação pode ser estabelecida através do método de análise térmico diferencial, proposto por Kissinger (1957), e desta maneira determinar as mudanças na energia de ativação e o expoente de Avrami correspondentes.

Uma vez que a função densidade de probabilidade de Weibull para dois parâmetros $(\alpha$ e $\beta$ ) é descrita de acordo com a equação (15), e a função de distribuição acumulada pode ser obtida a partir de sua integração [eq. (16)]; Kamamoto et al. (1985) propõem que a transformação pode ser considerada macroscopicamente e expressa na forma da função de distribuição acumulada de 
Weibull para um modelo de probabilidade, com base no fato de que a nucleação de uma transformação de fase é um fenômeno probabilístico [eq. (17)].

$$
\begin{gathered}
f(x)=\frac{\beta t^{\beta-1} \exp \left[-(t / \alpha)^{\beta}\right]}{\alpha^{\beta}} d t \\
F(x)=\int_{0}^{t} \frac{\beta t^{\beta-1} \exp \left[-(t / \alpha)^{\beta}\right]}{\alpha^{\beta}} d t=1-\exp \left[-(t / \alpha)^{\beta}\right] \\
X=X_{0}\left[1-\exp \left(a \tau^{b}\right)\right]
\end{gathered}
$$

Nestas equações, $\alpha$ e $\beta$ são conhecidos como parâmetros (ou fatores) de escala e de forma, respectivamente (McCOOL, 1982), $t$ é o tempo, $X_{0}$ é a taxa da mudança volumétrica da nova fase, $a$ e $b$ são variáveis dependentes do material e do tipo de transformação e $\tau$ é definido como:

$$
\tau=\frac{T_{i}-T}{T_{i}-T_{f}}
$$

com $T_{i}$ e $T_{f}$ sendo início e fim, respectivamente, das temperaturas de transformação.

Comparando as equações (13), (16) e (17), propostas por Avrami, Weibull e Kamamoto, é possível observar que estas têm a mesma forma, e estão relacionadas entre si, de acordo com: $n=\beta=b$ e $c=(1 / \alpha)^{\beta}=\tau$. E outra relação interessante, é que $n, \beta$ e $b$, são usualmente números pequenos, enquanto $c, \alpha$ e $\tau$, assumem um amplo intervalo de valores.

Visto que equação de Avrami [eq. (13)] não pode ser aplicada aos processos de transformação não isotérmicos, como a têmpera, atualmente continua sendo amplamente aplicado (BAILEY et al., 2009; CANALE; NARAZAKI, 2010; KANG et al., 2005 e 2007; GÜR; PAN, 2009; PASCON et al., 2004; SEDIGHI; SALEK, 2008) o princípio de aditividade de Scheil (SCHEIL, 1935) para calcular a evolução anisotérmica das transformações de fase a partir das respectivas cinéticas isotérmicas. Na utilização da noção de aditividade, a curva de resfriamento é dividida em "patamares" ou "passos" isotérmicos de duração $\Delta t_{i}$ (à temperatura $T_{i}$ ), como é 
mostrado na Figura 2, utilizando um diagrama TTT, que será explicado na seção seguinte (seção 2.2.4). Quando a soma ( $S$ ), das frações relativas, $\Delta t_{i} / \pi\left(T_{i}\right)$, atinge a unidade, se diz que o período de incubação para uma transformação sob condições não isotérmicas é considerado completo.

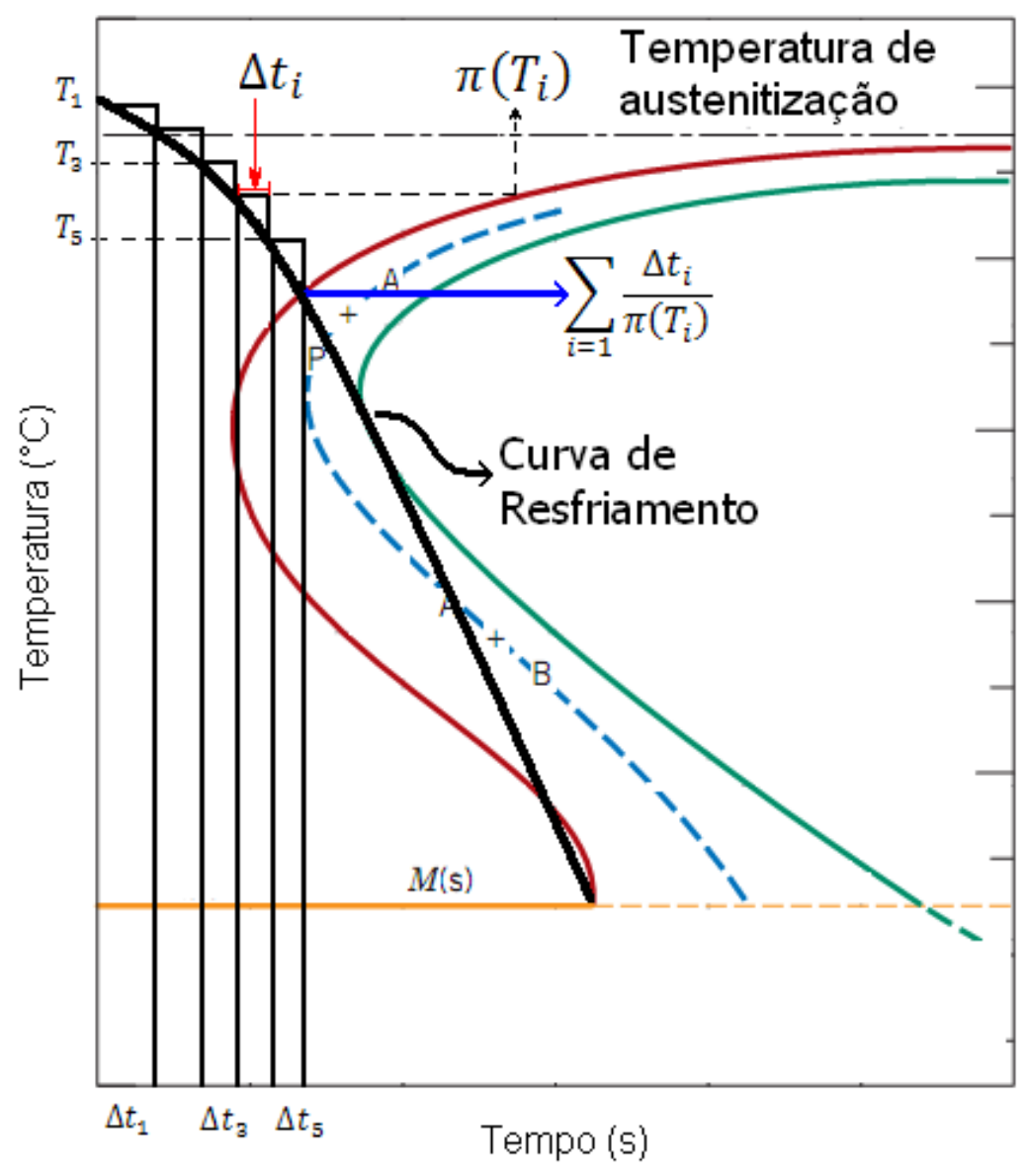

Figura 2 - Representação esquemática do princípio de aditividade de Scheil.

$$
S=\int_{0}^{t} \frac{d t}{\pi(T)}=\sum_{i=1}^{N} \frac{\Delta t_{i}}{\pi\left(T_{i}\right)}=1
$$

onde, $\pi\left(T_{i}\right)$ é a duração do período de incubação da transformação isotérmica, tomada do diagrama TTT, à temperatura $T_{i}$, e $\Delta t_{i}$ é o incremento do tempo no passo $i$.

Uma metodologia para aplicar as descrições da cinética das transformações isotérmicas em casos de transformação sob condições de resfriamento contínuo tem sido aplicada, entre outros, por Fernandes et al. (1985) e Campbell (1989). Neste caso, os cálculos são baseados segundo o pressuposto de que a taxa de 
transformação é uma função única da fração transformada e da temperatura instantânea e não do histórico da evolução microestrutural; em outras palavras, esta hipótese, conhecida como princípio de aditividade, propõe que o material não tem uma "memória" estrutural e, portanto, a transformação durante resfriamento contínuo pode ser aproximada por uma série de transformações aditivas fracionadas (HERNANDEZ, 1996).

Hawbolt et al. (1985) calcularam a partir da equação (19), o tempo de incubação para as transformações de cilindros de aço hipoeutetóides e compararam esses resultados com os dados obtidos experimentalmente através de dilatometria. Esses autores afirmam que a regra de aditividade às vezes superestima o tempo de início da incubação para transformações sob resfriamento contínuo. E sugerem que no primeiro segmento de tempo na temperatura $T_{1}$, a fração $X_{i}$, formada pode ser calculada segundo a equação de Avrami modificada:

$$
X_{i}=1-\exp \left[-c_{i}(T) t_{1}{ }^{n_{i}}\right]
$$

onde $t_{1}$ é o incremento de tempo inicial. Sob estas condições, usando o principio de aditividade (Figura 3), é possível encontrar o tempo $t_{i}$, necessário para obter uma determinada fração de austenita que transforma a uma temperatura $T_{i}$, como mostrado na equação (21):

$$
t_{i}=\left[-\frac{\ln \left(1-X_{i-1}\right)}{c_{i}}\right]^{1 / n_{i}}
$$

com $X_{i-1}$ sendo a fração de austenita já transformada. Para esses cálculos o coeficiente $n$ também é modificado, de acordo com a equação (22):

$$
n_{i}=\frac{\ln \left[\left(1-X_{1}\right)-\ln \left(1-X_{2}\right)\right]}{\ln \left[\left(t_{1}-t_{s}\right)-\ln \left(t_{2}-t_{s}\right)\right]}
$$

onde $t_{s}$ é o período de incubação do processo isotérmico a uma certa temperatura. Desse modo, a quantidade de austenita transformada $\Delta X_{i}$ na temperatura $T_{i}$ em um tempo $t_{i}$ será a diferença entre $X_{i}$ e $X_{i-1}$, como mostrado na equação (23): 


$$
\Delta X_{i}=X_{i}-X_{i-1}=1-\exp \left[-c_{i}(T) t_{1}^{n_{i}}\right]-X_{i-1}
$$

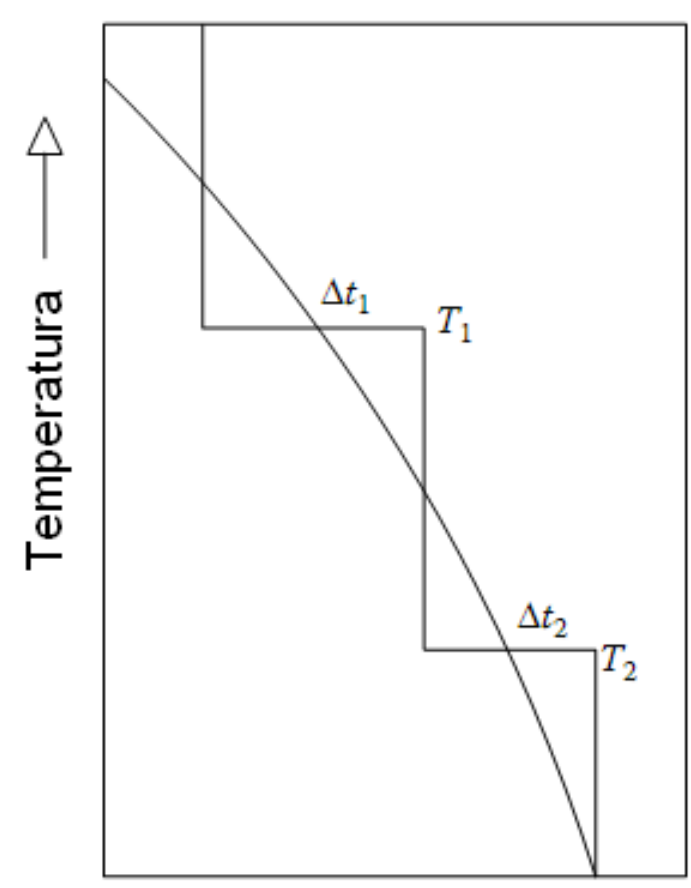

tempo

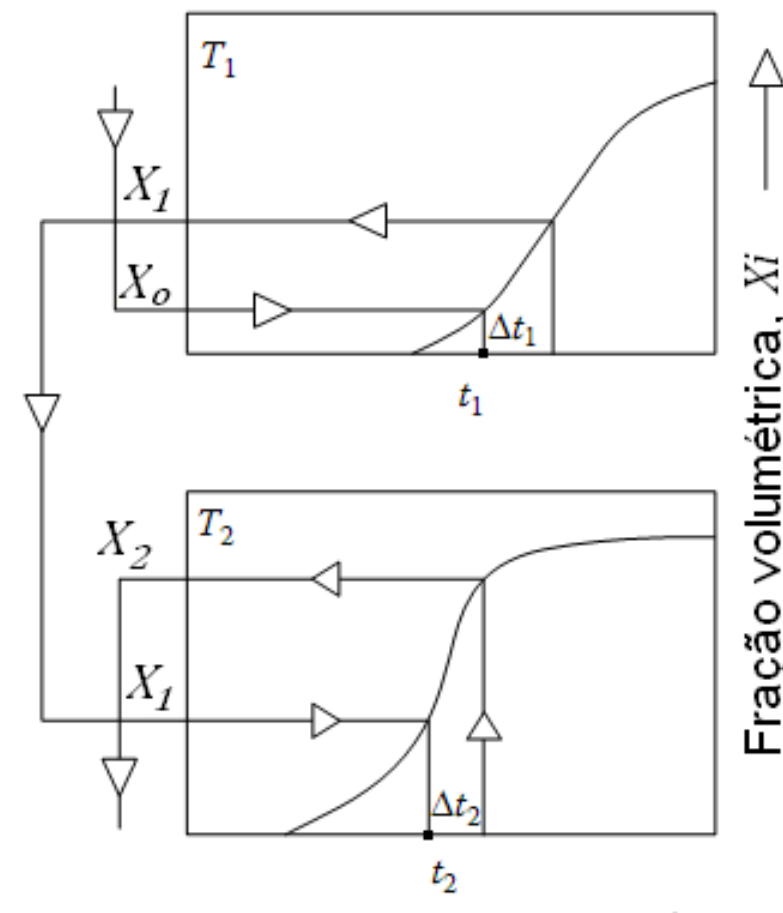

tempo

Figura 3 - Diagrama esquemático para ilustrar a aplicação do princípio de aditividade durante o processo de resfriamento contínuo. A reação não isotérmica segue o caminho marcado pelas setas para duas curvas de transformação nas temperaturas $T_{1}$ e $T_{2}$. Adaptado de Pan e Gu (2009)

Assim, a regra da aditividade, proposta originalmente para apenas o tempo de início de transformação, foi estendida por Avrami (1939) para incluir toda a transformação, propondo que a relação da taxa de nucleação e da taxa de crescimento deve ser usada como um parâmetro para prever, se o princípio de aditividade pode ser aplicado, e depois por Cahn (1956), sob a hipótese de que a cinética da transformação é controlada pela taxa de crescimento e com o objetivo de prever a cinética de transformação em resfriamento contínuo a partir de dados obtidos em condições isotérmicas, na transformação de uma única fase.

Christian (1965), baseado nos conceitos de Cahn, propõe uma abordagem um pouco diferente, considerando que a taxa de transformação deve ser descrita pela relação de duas funções independentes, uma dependente da temperatura e a outra da fracção transformada $\left[h(T)=G\left(X_{i}\right) / \pi_{i}(T)\right]$. 
Como uma alternativa aos métodos de aditividade, Lusk et al. (1999) desenvolveram um modelo cinético não aditivo, incorporado no software DANTE®. No entanto, Simsir e Gür (2010), afirmam que este modelo se baseia principalmente na fenomenologia e não contribui muito para a compreensão da cinética da transformação de fase, embora possa de alguma forma ser interpretado fisicamente.

\subsubsection{Diagramas Tempo Temperatura Transformação (TTT) e de Resfriamento Contínuo (RC)}

Os diagramas de equilíbrio ou diagramas de fase fornecem pares de valores de temperatura e composição química em que as diferentes fases de um determinado sistema são estáveis. Estes diagramas podem ser utilizados para prever as fases formadas em ligas submetidas a resfriamentos lentos, próximo das condições de equilíbrio. Na prática, no entanto, as transformações em geral não ocorrem em condições de equilíbrio e não podem ser analisadas através dos diagramas de fase. Para analisar a cinética das transformações em condições de não equilíbrio foram desenvolvidos os diagramas que levam em conta a variação do tempo. Estes diagramas são denominados diagramas TTT, Tempo, Temperatura e porcentagem de Transformação.

Os diagramas TTT permitem obter a fração volumétrica transformada durante um processo de transformação isotérmico para diferentes temperaturas. A Figura 4 mostra a curva TTT de um aço eutetóide. A área compreendida entre as curvas vermelha e verde representa a região de transformação da austenita $(A)$ para os produtos de transformação perlita $(P)$ e bainita $(B)$, por processo difusional. Nas temperaturas mais baixas encontra-se a região em que ocorre a transformação martensítica delimitado por duas linhas horizontais de temperatura constante $M_{S} \mathrm{e}$ $M_{90 \%}$ cor de laranja, que marcam respectivamente, o início da transformação e a temperatura em que $90 \%$ da austenita se transforma para martensita. A curva tracejada azul corresponde a 50\% de transformação. Além disso, observa-se na região à direita da curva verde e, também na região entre as curvas vermelha e verde a presença das estruturas perlita e bainita. A perlita consiste em uma estrutura lamelar composta por ferrita $\alpha$ (solução sólida de carbono em ferro na estrutura 
CCC, estável na temperatura ambiente) e cementita $\left(\mathrm{Fe}_{3} \mathrm{C}\right)$, que cresce por um mecanismo de cooperação entre estas duas fases. Já a bainita superior é constituída, também, por ferrita $\alpha$ e cementita $\left(\mathrm{Fe}_{3} \mathrm{C}\right)$, podendo ser encontrada na forma de agulhas muito finas de ferrita supersaturada em carbono, com filmes de cementita precipitados nas interfaces das agulhas, presente indistintamente, nas microestruturas resultantes das transformações isotérmicas ou contínuas (CALLISTER, 2008).

A escala de tempo utilizada nesses diagramas é sempre logarítmica para que se possa distinguir em detalhe os tempos de início de transformação, muito curtos principalmente nos aços carbono de muito baixa liga.

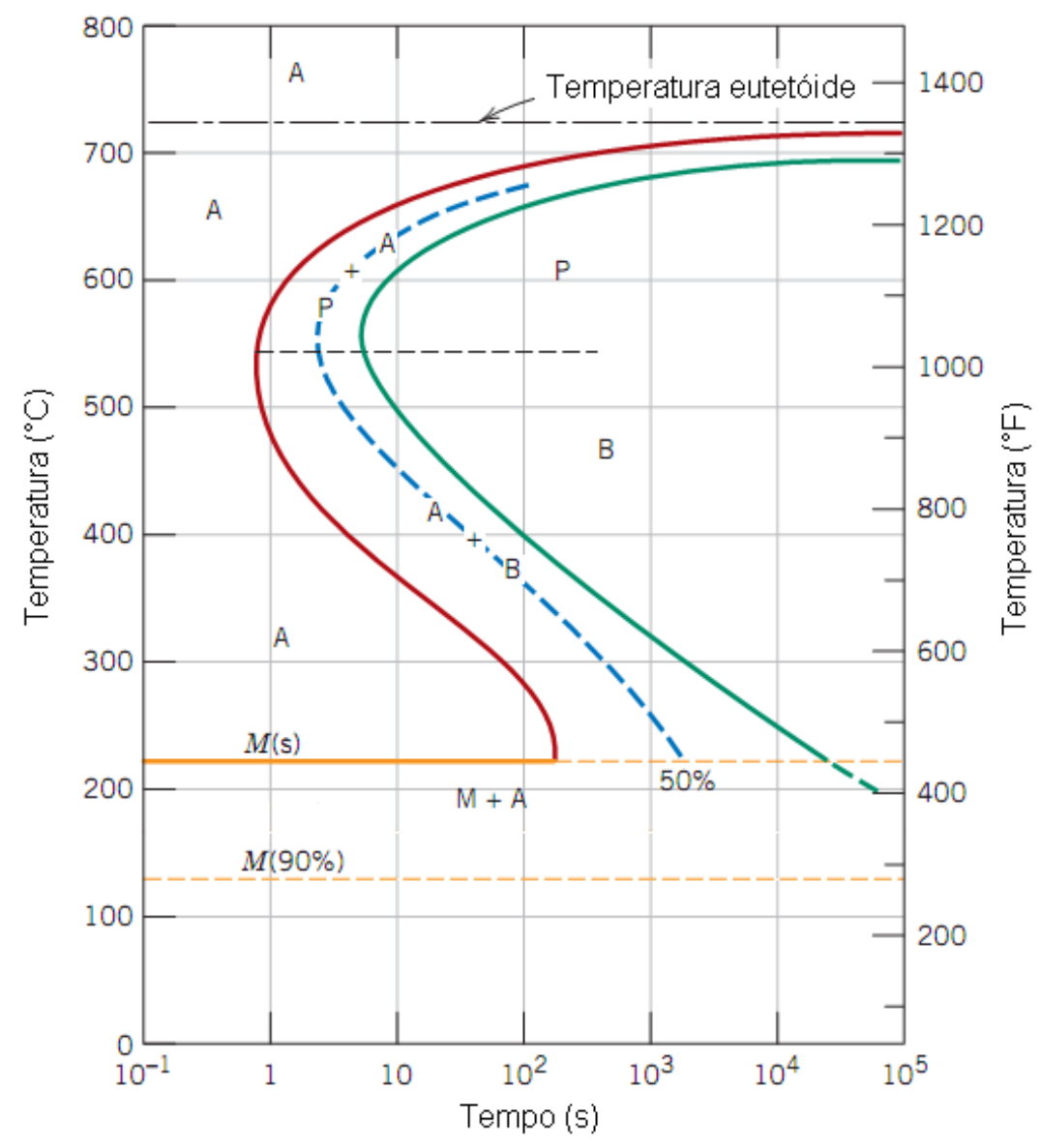

Figura 4 - Diagrama de transformação isotérmica para um aço eutetóide. A, austenita; B, bainita; P, perlita; M, martensita. Adaptado de Callister (2008).

As curvas de transformação nos diagramas TTT tendem a ter uma forma em C, característica das transformações difusionais que ocorrem por nucleação e crescimento. Isto ocorre porque a difusão dos átomos se torna difícil em baixas 
temperaturas enquanto em altas temperaturas a força motriz para que ocorra transformação é reduzida (BHADESHIA, 2002).

A determinação destes diagramas pode ser feita por dilatometria ou medidas de variação de propriedades elétrica ou magnéticas, utilizando corpos de prova cilíndricos submetidos a diferentes taxas de resfriamento; o início da transformação é detectado por dilatometria, medidas de resistência elétrica, permeabilidade magnética ou alguma outra técnica física (BHADESHIA, 2001). Os métodos de medidas de resistência elétrica ou de permeabilidade magnética acompanham as transformações de fase de acordo com as variações dos valores de resistividade e das características magnéticas do aço, respectivamente, em função das fases formadas. Já a dilatometria, que é a técnica mais frequentemente utilizada para o traçado de diagramas TTT, é feita no pressuposto de que grandes variações do comprimento do corpo de prova ocorrem na transformação de fase de austenita (CFC) para misturas de ferrita (CCC) e $\mathrm{Fe}_{3} \mathrm{C}$ ou para martensita (TCC).

Apesar do interesse prático dos diagramas TTT, é muito mais interessante, do ponto de vista da maioria dos tratamentos térmicos industriais, dispor de diagramas de resfriamento contínuos. Este tipo de diagramas são conhecidos como diagramas de transformação em resfriamento contínuo (denominados comumente RC, CRC ou CCT do inglês Continuous Cooling Transformation). Enquanto os diagramas de transformação isotérmica, TTT, definem o tempo necessário para o início e o fim de uma determinada transformação à temperatura constante, os CCT, descrevem a decomposição da austenita em função da taxa de resfriamento (KRAUSS, 2005). De maneira geral, o diagrama CCT é similar ao diagrama TTT, no que se refere às regiões de transformação das fases, mas difere deste por ser construído com curvas de resfriamento contínuo e não por tratamentos isotérmicos.

Comparando o diagrama CCT com o diagrama TTT, observa-se que as regiões de transformação de fases são ligeiramente deslocadas para tempos maiores e temperaturas menores, ficando assim a curva de resfriamento contínuo um pouco abaixo e à direita da curva TTT, como apresentado na Figura 5. 
Os diagramas de resfriamento contínuo são específicos para cada aço, e para diferentes condições (tempo e temperatura) de austenitização, do tamanho de grão da austenita, já que qualquer variação em uma destas condições produzirá diferenças consideráveis na cinética de transformação de fase, na microestrutura e, por conseguinte nas propriedades, após tratamento térmico.

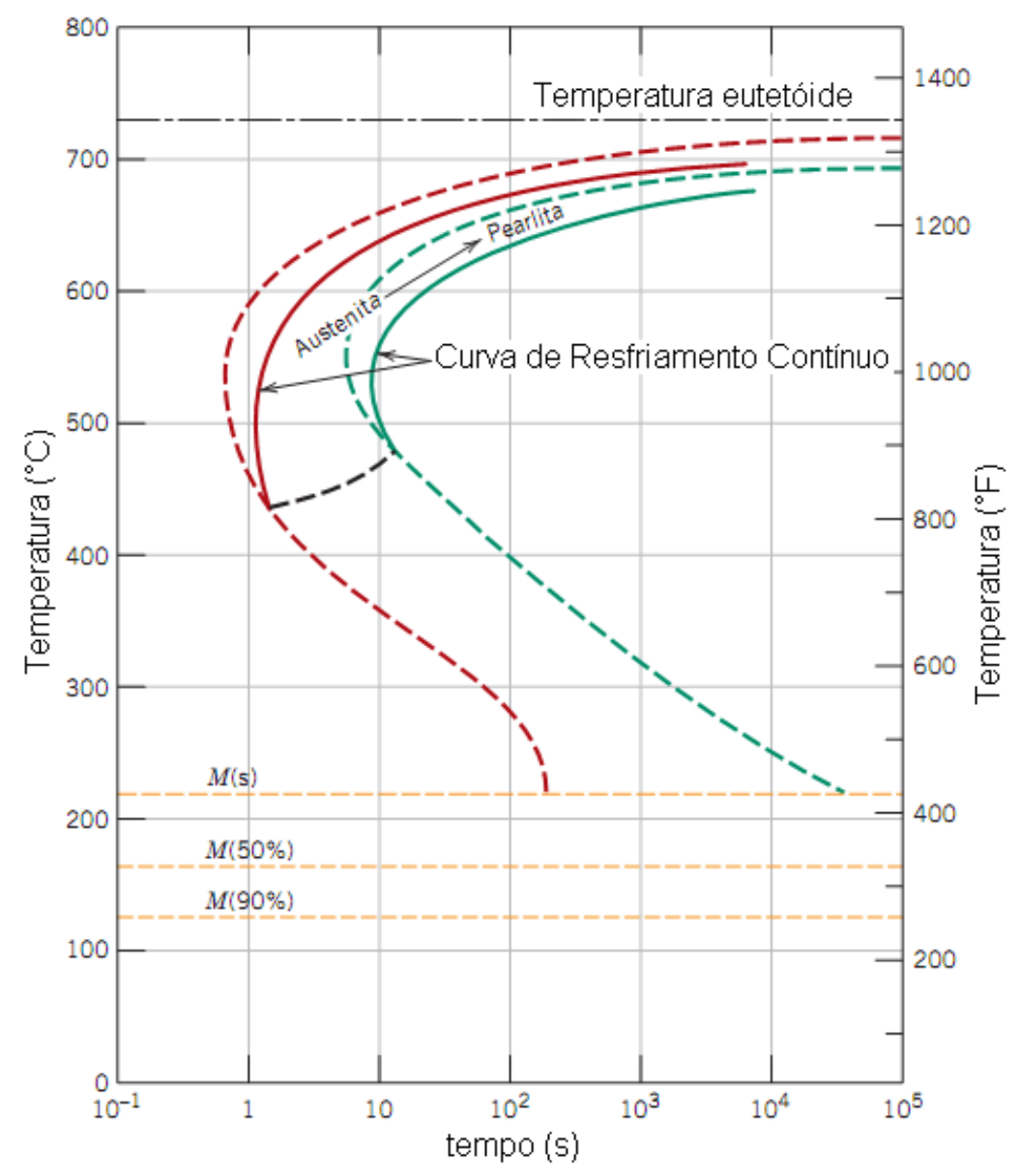

Figura 5 - Sobreposição do diagrama de resfriamento contínuo no diagrama de transformação isotérmica para um aço eutetóide. M, martensita. Adaptado de Callister (2008).

Dependendo da velocidade de resfriamento durante o tratamento térmico, as curvas de resfriamento cruzarão os diagramas de forma diferente. Na Figura 6 estão representadas as curvas de resfriamento, do centro e da superfície de um cilindro, sobrepostas em um diagrama RC. Nesta figura observa-se que uma vez que a temperatura da superfície da peça cai mais rapidamente do que a temperatura do seu interior, a curva do centro intercepta a região bainítica e a região martensítica e a curva da superfície somente a região martensítica, formando-se, portanto, martensita na superfície e uma mistura de bainita e martensita no centro da peça. 


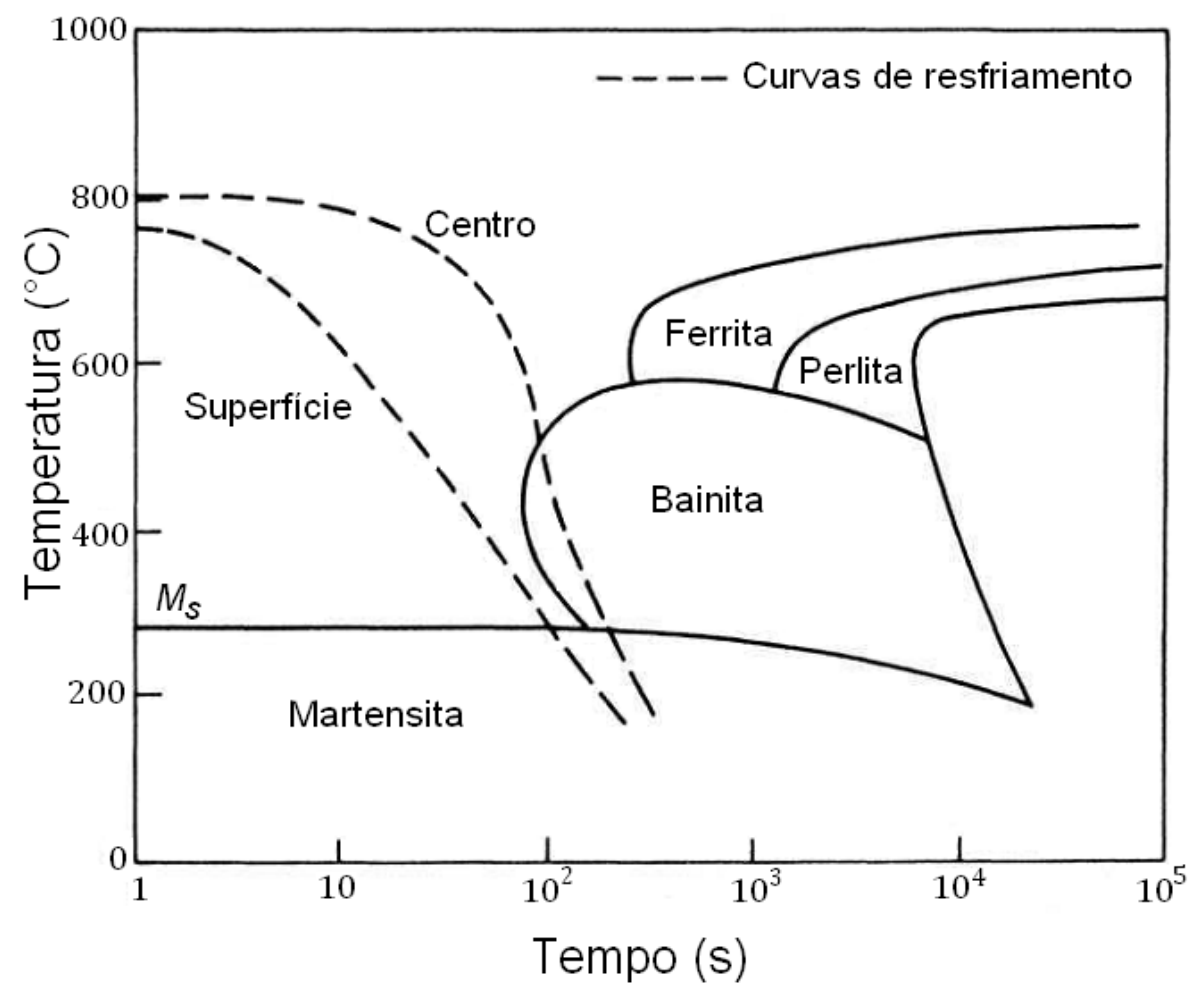

Figura 6 - Relação entre as curvas de resfriamento da superfície e do centro de uma barra de aço temperada. Adaptado de Bhadeshia (2001).

Liscic, et al. (2010) apresentam um método para a descrição da correlação entre as taxas de resfriamento e a dureza durante uma têmpera integrando a área sob as curvas de resfriamento. Um gráfico da área acumulada versus tempo pode então ser utilizado para quantificar a progressão do ciclo de têmpera. Por outro lado, a "ASTM International' tem publicado várias normas que descrevem detalhes da medição e descrição das características dos resfriamentos para diferentes meios de têmpera, incluindo as condições físicas e químicas destas condições; dentre elas: a ASTM D6200-01, para determinação das características do resfriamento para têmpera em óleos por análise das curvas de resfriamento; a ASTM D6482-06, para determinação das características do resfriamento para têmpera em polímero aquoso com agitação por análise das curvas de resfriamento; a ASTM D6549-06, que apresenta o método para determinação das características do líquido refrigerante. 


\subsubsection{Influência dos elementos de liga nas curvas TTT}

Enquanto o teor de carbono determina a dureza alcançada no aço, os elementos de liga permitem desenvolver maiores profundidades de endurecimento por tratamento térmico. Isso é possível adicionando elementos de liga no aço, que desloquem para direita as curvas TTT, permitindo durante a têmpera taxas de resfriamento mais lentas e peças de espessuras maiores sem formação de ferrita proeutetóide ou perlita, em consequência do aumento da temperabilidade. Assim, se o objetivo é, por exemplo, analisar apenas o efeito dos teores de carbono nos aços é necessário que os teores dos elementos de liga, sejam mantidos estritamente constantes, uma vez que pequenas variações na concentração destes provocam diferenças sensíveis na temperabilidade, como é o caso do Mn.

A influência de vários elementos de liga sobre o deslocamento das curvas TTT, está esquematizada na Figura 7.

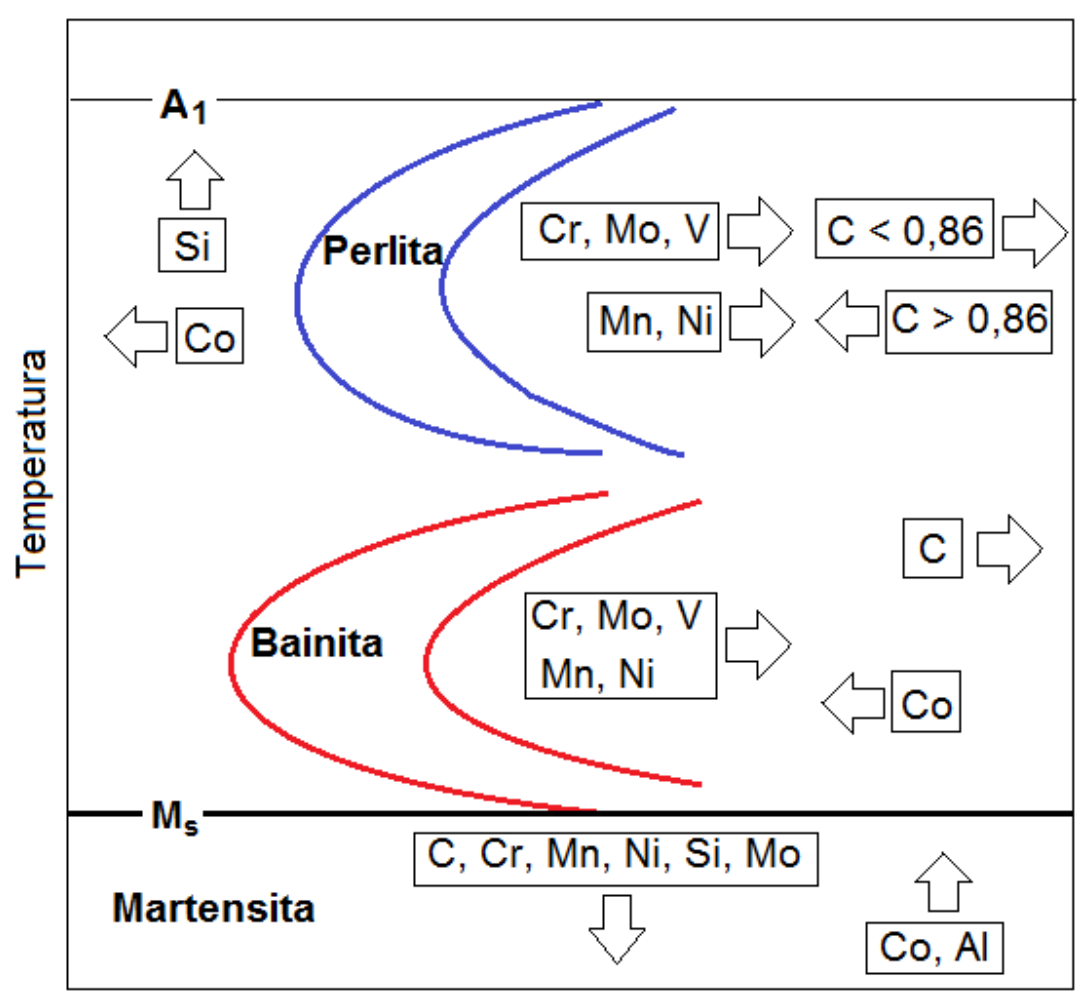

Figura 7 - Influência dos elementos de liga no deslocamento das curvas TTT. Adaptado de Soares (1987). 
Observando a Figura 7, pode-se dizer, de maneira geral, que todos os elementos de liga no aço, com exceção do cobalto, dificultam a nucleação e o crescimento da perlita e da bainita, pois a formação destes constituintes envolve a partição dos elementos de liga entre a ferrita e o carboneto. Esta partição envolve difusão destes elementos na matriz, difusão muito mais lenta do que a do carbono. O tempo para a reação é muito maior e a curva TTT é deslocada para a direita aumentando a temperabilidade.

Como já foi indicado nas fórmulas da Tabela 2, em geral, os elementos de liga adicionados aos aços diminuem a temperatura $M_{s}$. Nas Figura 7 e 8, comprova-se que o Co e o Al são exceções desta característica.

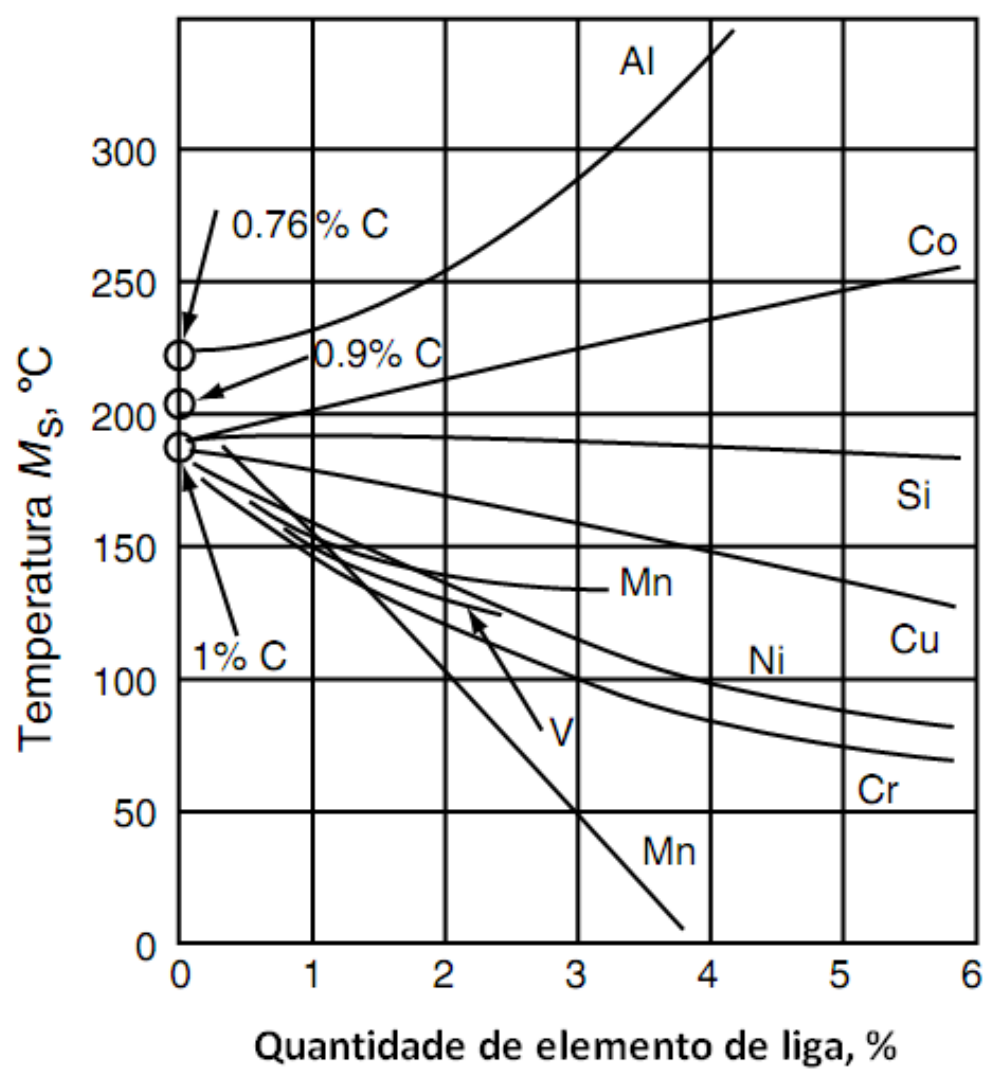

Figura 8 - Influência dos elementos de liga na temperatura de início da transformação martensítica, $M_{s}$. Adaptado de Totten (2007).

Sverdlin e Ness (2007) afirmam que a razão pela qual o carbono e os elementos de liga influenciam na posição do início da transformação martensítica, é principalmente pela mudança na estabilidade termodinâmica relativa das fases $\gamma$ e $\alpha$ do aço, uma vez que a transformação da martensita em si, é uma transformação 
$\gamma \rightarrow \alpha$. Isto pode ser observado a partir da Figura 9, apresentada no trabalho de Hornbogen (1983), a qual esta baseada nos estudos de Zener (1946).

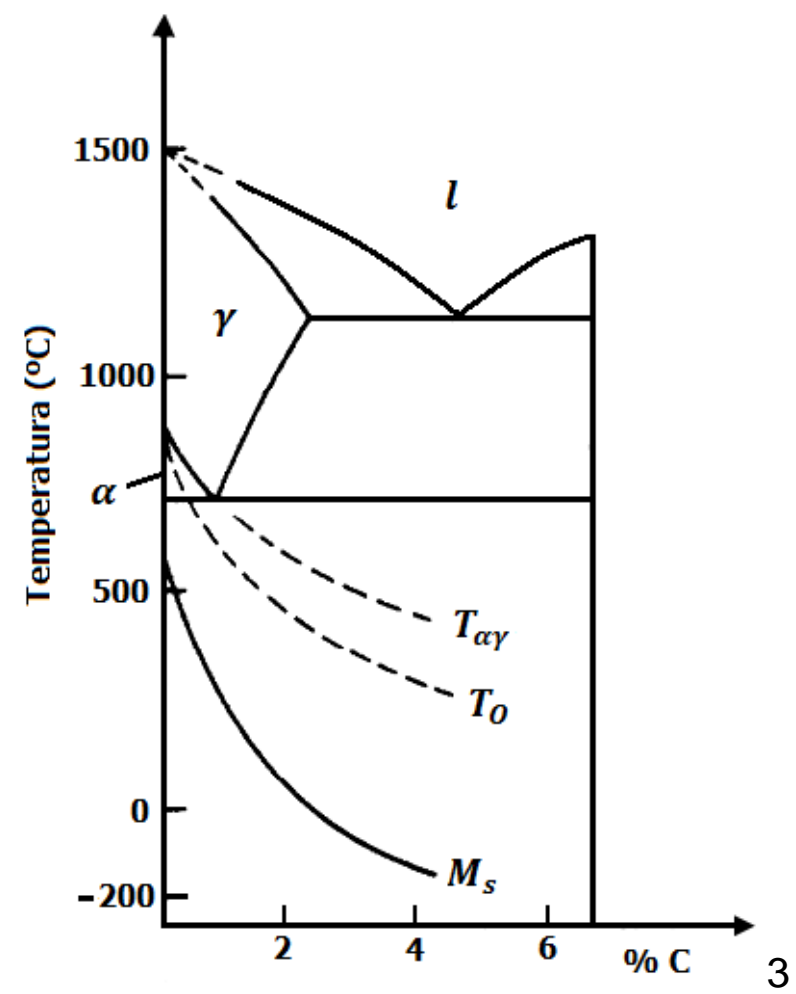

Figura 9 - Representação da relação entre a temperatura de equilíbrio $\left(T_{o}\right)$ e a temperatura $M_{s} . \alpha, \gamma$ e $T_{\alpha \gamma}$, representam ferrita alfa, austenita e a temperatura de transição $\gamma \leftrightarrow \alpha$, respectivamente. Hornbogen (1983).

Um outro aspecto interessante a ser comentado sobre os diagramas TTT diz respeito à separação das curvas para os diferentes constituintes formados, particularmente entre a perlita e a bainita. Alguns elementos químicos adicionados aos aços, tais como Mo e Si, têm a propriedade de separar total ou parcialmente as curvas de transformação da perlita e da bainita como indicado na Figura 10. Com isso, torna-se possível a obtenção de bainita neste aço em condições de resfriamento contínuo. Na maioria das vezes, porém, os campos de formação da perlita e da bainita estão sobrepostos, o que leva ao traçado de uma única curva para o início de transformação para os dois constituintes. Esse aspecto foi considerado no trabalho de Fang et al. (1997), que estudaram a decomposição isotérmica da austenita em um aço C-Mn com adições de $\mathrm{Cr}$, Ni e Mo. 


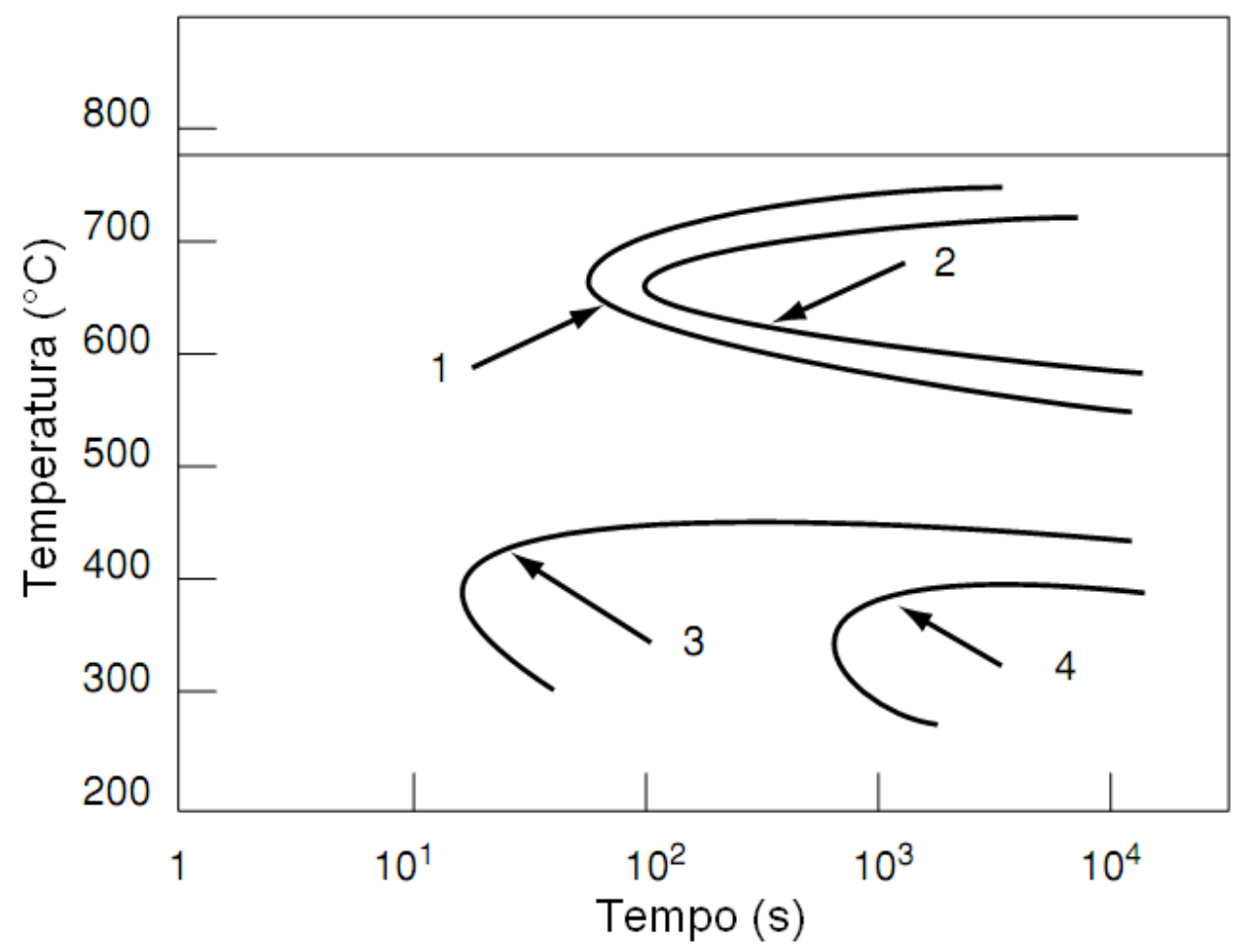

Figura 10 - Diagrama TTT para um aço ligado com as curvas de transformação da perlita e da bainita separadas. As linhas 1 e 2 representam o início e o fim da transformação de perlita, respectivamente; as linhas 3 e 4 representam o início e o fim da transformação bainítica, respectivamente. Adaptado de Totten (2007).

Assim, é importante sempre analisar como os elementos de liga afetam a cinética das transformações indicadas nas curvas TTT, pois o seu deslocamento pode ser ou não uniforme.

\subsubsection{Transferência de calor durante a têmpera}

A transferência de calor para uma peça que foi inicialmente austenitizada e logo resfriada em um meio de têmpera, define a evolução da temperatura no interior do componente e, portanto a evolução microestrutural, as deformações e as tensões que nela acontecem.

O resfriamento durante o processo de têmpera pode ser dividido em três estágios como é apresentado na Figura 11. Estes estágios refletem os diferentes mecanismos de resfriamento que acontecem durante o processo. 


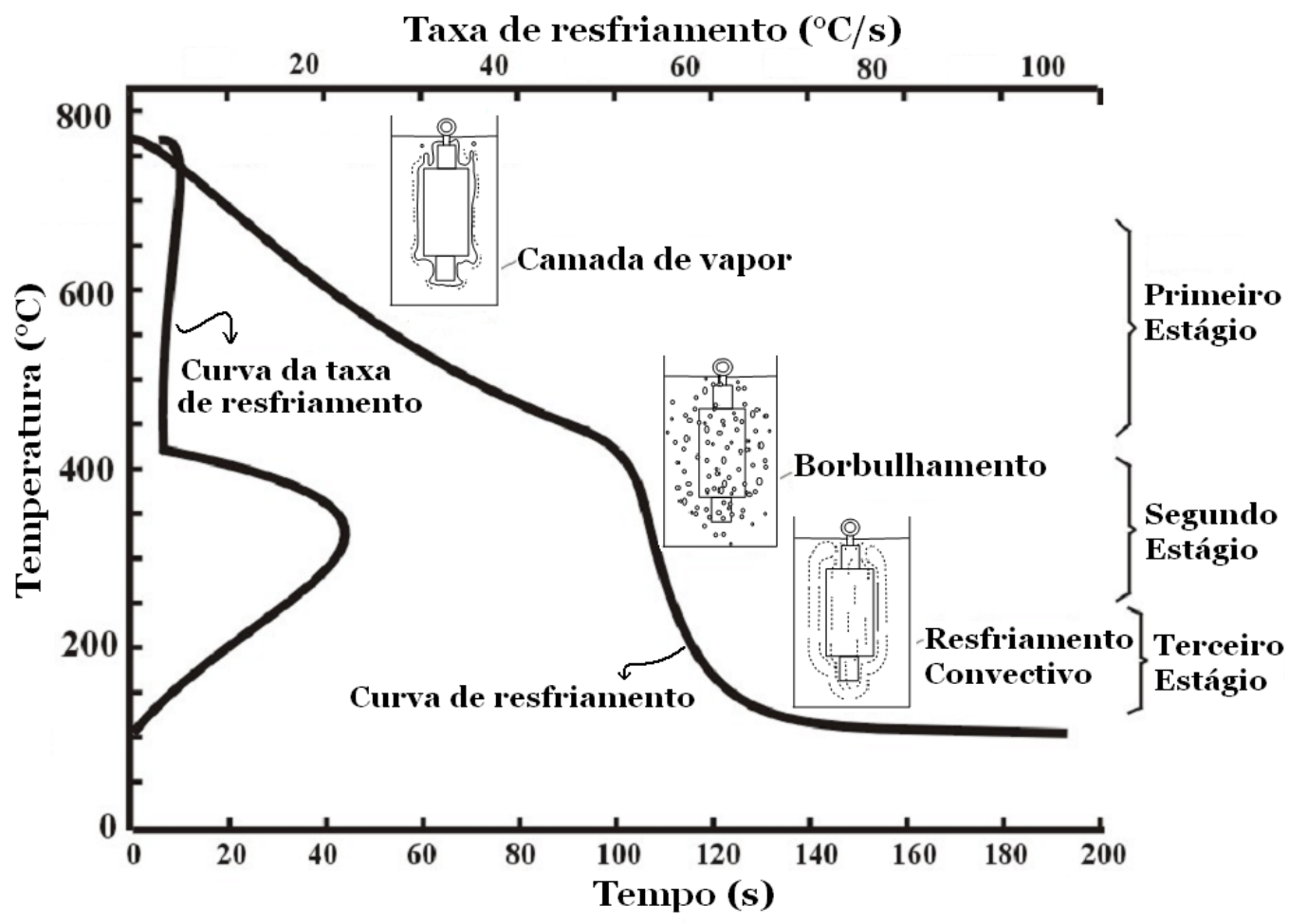

Figura 11 - Curva de resfriamento e da taxa de resfriamento no centro de uma peça temperada. Adaptado de ASM (1991).

No primeiro estágio, quando a peça austenitizada entra em contato com o meio de resfriamento, a sua temperatura é suficientemente alta para vaporizar o líquido, ocorrendo o recobrimento da peça por um filme de vapor. Esta camada de vapor é mantida enquanto o fornecimento de calor do interior da peça à superfície excede a quantidade de calor necessária para vaporizar o meio refrigerante. Durante este período o resfriamento ocorre por condução e radiação através da camada de vapor, que atua como um isolante, fazendo com que seja lento. A temperatura acima da qual a camada de vapor é mantida é chamada de temperatura Leidenfrost ${ }^{6}$ e é independente da temperatura inicial do metal temperado (ASM, 1991; BROOKS, 1996).

Assim que a temperatura na superfície é menor que a temperatura de Leidenfrost, a taxa de nucleação e crescimento de bolhas de vapor diminui quando

\footnotetext{
${ }^{6}$ Nome dado em homenagem ao pesquisador alemão Johann Gottlob Leidenfrost, quem realizou os primeiros estudos (1756) para descrever qualitativamente o conjunto de efeitos observados quando dois meios interagem em temperaturas diferentes criando uma camada de isolação, conhecido como efeito de Leidenfrost (GOTTFRIED, 1966).
} 
uma região do filme de vapor se destaca da superfície devido às forças de flutuação, e o líquido entra em contato com o metal naquela região, dando início ao segundo estágio chamado de nucleação de bolhas ou borbulhamento. Neste estágio acontecem as maiores taxas de resfriamento, devido ao contato do fluído com a superfície do metal, evaporando imediatamente e causando uma grande convecção. O ponto de ebulição do líquido irá determinar o final da etapa de formação de bolhas (ASM, 1991; BROOKS, 1996).

O terceiro estágio começa quando a temperatura da superfície do aço atinge o ponto de ebulição do fluido. Abaixo dessa temperatura, o borbulhamento para, e o resfriamento ocorre por convecção, sendo este controlado pelo calor específico e a condutividade térmica do meio de têmpera. Neste estágio, a velocidade de resfriamento é geralmente a menor entre os três estágios. Se todos os outros fatores se mantêm iguais, as taxas de resfriamento diminuem com o aumento da viscosidade do meio refrigerante (ASM, 1991; BATES, 1993; BROOKS, 1996).

Os processos de têmpera geralmente precisam de taxas de resfriamento máximas nas duas primeiras fases para evitar a transformação perlítica e taxas de resfriamento mínimas na terceira fase, já que a tendência a ocorrerem fraturas, fragilizações ou distorção das peças é mais provável em temperaturas em que a estrutura martensítica pode ser formada. Estas taxas de resfriamento podem ser controladas a partir das condições de transferência de calor entre a superfície do aço e o meio de resfriamento, tornando-se um dos fatores mais importantes no controle da evolução microestrutural e na geração de tensões e distorção (LISCIC et al., 2010).

A remoção de calor nas peças durante a têmpera pode ser descrita matematicamente em termos da eficácia do coeficiente de transferência de calor na interface $(h)$. Para isto, uma relação amplamente utilizada em aços temperados é o número de Grossman $(H)$, conhecido como fator de severidade da têmpera, e definida como $h / 2 k$, onde $k$ é a condutividade térmica do aço. Assim, Grossmann definiu o poder do meio de resfriamento pelo aumento do valor de $H$, que, para a faixa de temperaturas da formação da perlita, varia desde 0,02 no ar sem agitação até 5 para salmoura com intensa agitação. No caso do resfriamento em água, no 
mesmo intervalo de temperaturas $\left(T \sim 600^{\circ} \mathrm{C}\right), H$ assume valores de 0,9-1,0 para água estagnada e de 4,0 para uma agitação intensa (ASM, 1991), o que daria como resultado para aços de médio carbono com $k=30,6 \mathrm{~W} / \mathrm{m}$. K temperados em água com agitação, um valor de $h=244,8 \mathrm{~W} / \mathrm{m}^{2} \mathrm{~K}$. Estes valores forneceram uma orientação valiosa aos tratadores térmicos, desde a sua publicação em 1947, apesar do fato das velocidades de agitação ${ }^{7}$ não estarem definidas (ASM, 1991).

Dependendo da geometria da peça, a equação de condução de calor que regula o fluxo térmico do material temperado pode ser uni, bi ou tridimensional (WELLS; DAUN, 2009). A equação para condução de calor transiente, e fluxo de calor unidimensional na direção $x$, dentro de um componente temperado pode ser definida como:

$$
\rho C_{p} \frac{\partial T}{\partial t}=\frac{\partial}{\partial x}\left(k \frac{\partial T}{\partial x}\right)
$$

onde $\rho$ é a densidade, $C_{p}$ é o calor específico, $T$ é a temperatura, $t$ é o tempo e $k$ é a condutividade térmica da amostra.

De acordo com esta equação [eq. (24)] a distribuição de temperatura dentro de um corpo não depende somente do gradiente de temperatura local, mas também da difusividade térmica, definida como $\alpha=k /\left(\rho C_{p}\right)$, a qual inclui todos os parâmetros termodinâmicos do material e representa a variação de temperatura dependente do tempo de uma peça por causa da condução de calor nãoestacionária (TOTTEN, 2007).

Ao escrever esta equação [eq. (24)] de condução de calor, a variação de energia devido à expansão adiabática $^{8}$ e a variação da energia devido ao escoamento plástico são desprezadas uma vez que, segundo a literatura, sua

\footnotetext{
${ }^{7}$ No Metals Handbook (ASM, 1991) é sugerido um valor de $h$ para todo o processo de têmpera (i.e, os três estágios) na faixa entre 9000 e $12000 \mathrm{~W} / \mathrm{m}^{2} k$ para água a $32^{\circ} \mathrm{C}$ com velocidades entre 0,25 e $0,76 \mathrm{~m} / \mathrm{s}$.

${ }^{8} \frac{E}{1-2 v} \frac{\partial \varepsilon^{t h}}{\partial T} T \dot{\varepsilon}_{m m}$; onde $\dot{\varepsilon}_{m m}$ e $\varepsilon^{\text {th }}$ são a taxa de deformação principal com respeito a cada fase e o tensor de deformação térmica, respectivamente (SJÖSTROM, 1985).
} 
contribuição para a taxa de geração de calor é menor do que 1\% (LISCIC et al., 2010).

No caso em que o fluxo de calor é tridimensional, a equação (24) pode ser escrita como:

$$
\rho C_{p} \frac{\partial T}{\partial t}=\frac{\partial}{\partial x}\left(k \frac{\partial T}{\partial x}\right)+\frac{\partial}{\partial y}\left(k \frac{\partial T}{\partial y}\right)+\frac{\partial}{\partial z}\left(k \frac{\partial T}{\partial z}\right)
$$

Para uma amostra cilíndrica, a equação (25) pode ser definida em termos das coordenadas locais $(r, \emptyset, z)$ por:

$$
\rho C_{p} \frac{\partial T}{\partial t}=\frac{1}{r} \frac{\partial}{\partial r}\left(r k \frac{\partial T}{\partial r}\right)+\frac{1}{r^{2}} \frac{\partial}{\partial \emptyset}\left(k \frac{\partial T}{\partial \varnothing}\right)+\frac{\partial}{\partial z}\left(k \frac{\partial T}{\partial z}\right)
$$

À equação (26) deve ser associada uma outra parcela de calor relacionada com a transformação de fase $(\partial S / \partial t)$, conhecida como calor latente de transformação. Esta fonte de calor, devida à liberação ou absorção de calor produzida pelas reações para que ocorra a mudança de fase, pode ser expressa como:

$$
\frac{\partial S}{\partial t}=\Delta H \rho \frac{\partial V}{\partial t}
$$

onde $\partial S$ é a variação de entropia de fusão, $\rho$ é a densidade, $\partial V / \partial t$ é a taxa de mudança da fração de fase com respeito ao tempo e $\Delta H$ é a diferença entre as entalpias das duas fases a uma temperatura $T$.

Segundo Tensi et al. (1997), o calor ao redor da peça produz gradientes de temperaturas da superfície ao centro da peça, transferindo calor por condução da região com maior temperatura, para a região com menor temperatura. Este fenômeno pode ser expresso pela lei de Fourier da transferência de calor, na qual a taxa de transferência de calor $Q$ fornecido ou extraído, através de uma superfície de área $A$, é definida como:

$$
Q=\frac{\partial Q}{\partial t}=-k A \frac{\partial T}{\partial x}
$$


onde $T$ é a temperatura, $t$ é o tempo, $k$ é a condutividade térmica, $A$ é a área de transferência e $d T / d x$ é o gradiente de temperatura na direção $x$. O sinal negativo na equação (28) é necessário para tornar a equação consistente, isto é, o calor flui de uma região de maior temperatura para uma região de menor temperatura. No caso de cilindros, a área através da qual ocorre o fluxo $A$ de calor é dada por $2 \pi r L$.

A equação (28) também pode ser escrita em termos da densidade de fluxo de calor ( $q$ ), expressa por unidade de tempo e unidade de superfície como:

$$
q=-k \frac{\partial T}{\partial x}=-k g r a d T
$$

onde o gradiente de temperatura ${ }^{9}$ é um vetor normal à superfície isotérmica, dado em ${ }^{\circ} \mathrm{C} / \mathrm{m}$. Esta equação [eq.(29)] apresenta claramente a condutividade térmica como um fator de proporcionalidade na equação de condução de calor e a influência que representam as propriedades do material no transporte de calor.

De acordo coma lei de Newton para transferência de calor convectivo, a quantidade de troca de calor [eq. (28)] entre um corpo e o ambiente ao seu redor dependerá da diferença entre a temperatura da superfície do corpo e a temperatura ambiente [eq. (30)]:

$$
\frac{d Q}{A d t}=h\left(T_{S}-T_{M}\right) \text { para } T_{S}>T_{M}
$$

onde $T_{S}$ é a temperatura da superfície do corpo de prova, $T_{M}$ é a temperatura do meio de resfriamento e $h$ é o coeficiente de transferência de calor, que em condições

\footnotetext{
9 Para um sistema de coordenadas cilíndricas com coordenadas locais $r, \emptyset, z$ e vetores unitários $e_{r}, e_{\theta}$, e $e_{z}$, o gradiente do escalar $T$ é: $\operatorname{grad} T=\nabla T=e_{r} \frac{\partial T}{\partial r}+e_{\theta} \frac{1}{r} \frac{\partial T}{\partial \theta}+e_{z} \frac{\partial T}{\partial z}$

A divergência de um vetor $\boldsymbol{V}$ tendo componentes $\boldsymbol{V}_{r}, \boldsymbol{V}_{\theta}$ e $\boldsymbol{V}_{z}$ é: $\operatorname{div} \boldsymbol{V}=\boldsymbol{\nabla} \cdot \boldsymbol{V}=\frac{1}{r} \frac{\partial\left(r \boldsymbol{V}_{r}\right)}{\partial r}+\frac{1}{r} \frac{\partial \boldsymbol{V}_{\theta}}{\partial \theta}+\frac{\partial V_{z}}{\partial z}$

E o Laplaciano do escalar $T$ é definido como o divergente do gradiente: $\nabla^{2} T=\frac{1}{r} \frac{\partial}{\partial r}\left(\frac{r \partial T}{\partial r}\right)+\frac{1}{r^{2}} \frac{\partial^{2} T}{\partial \theta^{2}}+\frac{\partial^{2} T}{\partial z^{2}}$

No caso de fluxo unidimensional, observa-se fisicamente que o fluxo de calor em uma direção (primeiro, segundo ou terceiro termo do Laplaciano) é proporcional à taxa de variação da temperatura $T$ naquela direção (Lei de Fourier).
} 
reais depende da forma e tamanho da peça, da posição do corpo (em pé ou deitado), da superfície da peça, da taxa de agitação do fluido circundante, das propriedades físicas do material e do fluído ao redor no tratamento, como densidade, calor específico e viscosidade (LISCIC et al., 2010; TOTTEN, 2007).

A vantagem de calcular ou determinar experimentalmente os coeficientes de transferência de calor produzidos na interface por um meio refrigerante sob condições específicas conhecidas é que esses valores podem ser usados com confiança em cálculos de transferência de calor para um modelo de elementos finitos ou de diferenças finitas, e assim, simular o comportamento térmico de peças ou componentes que não tenham sido realmente instrumentados. Estas curvas de resfriamento poderão então ser usadas, em conjunto com curvas TTT ou de resfriamento contínuo, para estimar a dureza e as tensões residuais dos componentes temperados.

\subsubsection{Efeito da agitação}

Nos processos de tratamento térmico, as taxas de resfriamento são influenciadas pela difusividade térmica do material e pela habilidade do meio de resfriamento em remover o calor da superfície do corpo de prova e devem ser suficientemente rápidas ou lentas para permitir a formação da microestrutura desejada. Assim, além do meio de resfriamento empregado, o grau de agitação é também muito importante, pois uma peça temperada em um meio agitado resfria mais rápido do que em meio estagnado. Conforme Dufour (2002), citado por Barros (2006), isto ocorre porque um maior fluxo de fluido sobre a peça melhora a taxa de transferência de calor da peça para o fluido, limitando a duração do primeiro estágio da têmpera, atribuído ao aumento da taxa de condensação da camada de vapor, e acelerando a remoção de calor nos dois estágios seguintes.

Vários autores têm se interessado em avaliar o efeito da agitação na transferência de calor durante a têmpera. Fernandes e Narayan (2007) estudaram este efeito em corpos cilíndricos de aço AISI 1040, temperados em salmoura, água e óleos de palma e mineral, concluindo que a agitação aumenta os picos de fluxo de 
calor em todos os meios de têmpera e retarda a nucleação das bolhas de vapor. Sedighi e McMahon (2000) estudaram a influência da velocidade de agitação e da orientação (axial e perpendicular à amostra) do meio refrigerante na transferência de calor e subsequente desenvolvimento das tensões residuais em cilindros de aço temperados. De acordo com Bates et al. (1993), a otimização da agitação durante o resfriamento permite controlar o gradiente térmico e, com isso, minimizar as distorções. Assim, considerando que a agitação representa um dos parâmetros significativos na severidade da têmpera, muitos pesquisadores (CANALE; TOTTEN, 2005; CANALE; NARAZAKI, 2010; GÜR; PAN, 2009; LISCIC et al., 2010; TOTTEN et al., 2002, 2007) têm se interessado em avaliar e descrever o seu efeito na transferência de calor.

\subsection{TENSÕES RESIDUAIS}

Tensões Residuais (TR) são tensões que atuam num componente ou estrutura na ausência de esforços externos, sejam cargas mecânicas, esforços resultantes de gradientes de temperatura ou de efeitos inerciais. Portanto, pela própria definição, as tensões residuais constituem um sistema em equilíbrio.

A classificação mais comum para tensões residuais é baseada na escala de comprimento $^{10}$. Esta classificação é feita em três categorias: tensões residuais de primeira ordem ou tipo I (macro tensões), tensões residuais de segunda ordem ou tipo II e tensões residuais de terceira ordem ou tipo III (as tipo II e III são também chamadas micro tensões residuais).

As tensões residuais do tipo I são as tensões que são constantes em grandes áreas do material, ou seja, são constantes no volume de vários grãos, e causam deformações uniformes apreciáveis da rede cristalina na região em que atuam. As forças internas resultantes dessas tensões estão em equilíbrio com relação a qualquer seção transversal, e os momentos mecânicos resultantes dessas tensões estão em equilíbrio com relação a qualquer eixo. Qualquer mudança no equilíbrio de

10 Esta classificação foi proposta por primeira vez por MACHERAUCH et al. (1973) baseados na escala sobre a qual a magnitude das tensões residuais se auto-equilibram. 
forças e momentos de um elemento de volume que contém essas tensões residuais muda as dimensões macroscópicas do elemento (LISCIC, 2007). Estas tensões podem estar associadas às heterogeneidades causadas por operações mecânicas (carregamento cíclico, laminação), químicas (nitretação, cementação) ou térmicas (têmpera, soldagem) realizadas sobre o corpo, e em geral, são as tensões que despertam maior interesse nos problemas relacionados com a engenharia.

As tensões residuais do tipo II são as tensões que são constantes ao longo de pequenas áreas microscópicas (um grão ou região do grão) e estão em equilíbrio através de um número suficiente de grãos; são especialmente adequadas para descrever a situação de tensões residuais em aços contendo duas fases com coeficientes de expansão térmica diferentes (LISCIC, 2007).

As tensões residuais do tipo III são as tensões que são constantes em pequenas áreas microscópicas (dentro de várias distâncias atômicas de grãos individuais) e estão relacionadas com discordâncias e outros defeitos do reticulado, portanto, a perturbação do seu equilíbrio não resultará em nenhuma mudança macroscópica das dimensões do material tensionado.

$\mathrm{Na}$ prática, para efeito do estudo de deformações macroscópicas, empenamentos e tensões residuais em peças tratadas termicamente, somente tensões residuais do tipo I são consideradas. As tensões residuais do Tipo I podem também ser originadas em processos de fabricação, tais como: fundição, deformação plástica, aplicação de revestimentos, ou mediante soldagem.

A Figura 12 é uma apresentação esquemática dos três tipos de tensões residuais e de sua superposição em um material bifásico $(\alpha$ e $\beta$ ), após têmpera (LISCIC, 2007). Nesta figura, $\sigma_{R I}, \sigma_{R I I}$ e $\sigma_{R I I I}$ denotam as tensões residuais de primeira (esquerda), segunda (central) e terceira ordem (direita), respectivamente, ao longo do corte $x-x$ de uma seção plana do material. Já a superposição dos três tipos de tensões é apresentada na parte inferior, a qual mostra claramente que tensões residuais de tração em uma determinada direção do componente, estão sempre equilibradas com tensões residuais de compressão em outra região, o que 
indica que o estado de tensão residual de uma peça ou um componente nunca deve ser expresso por um tensor de tensão residual único, ou avaliado em uma única direção, mas sim por uma distribuição tridimensional de tensões residuais.

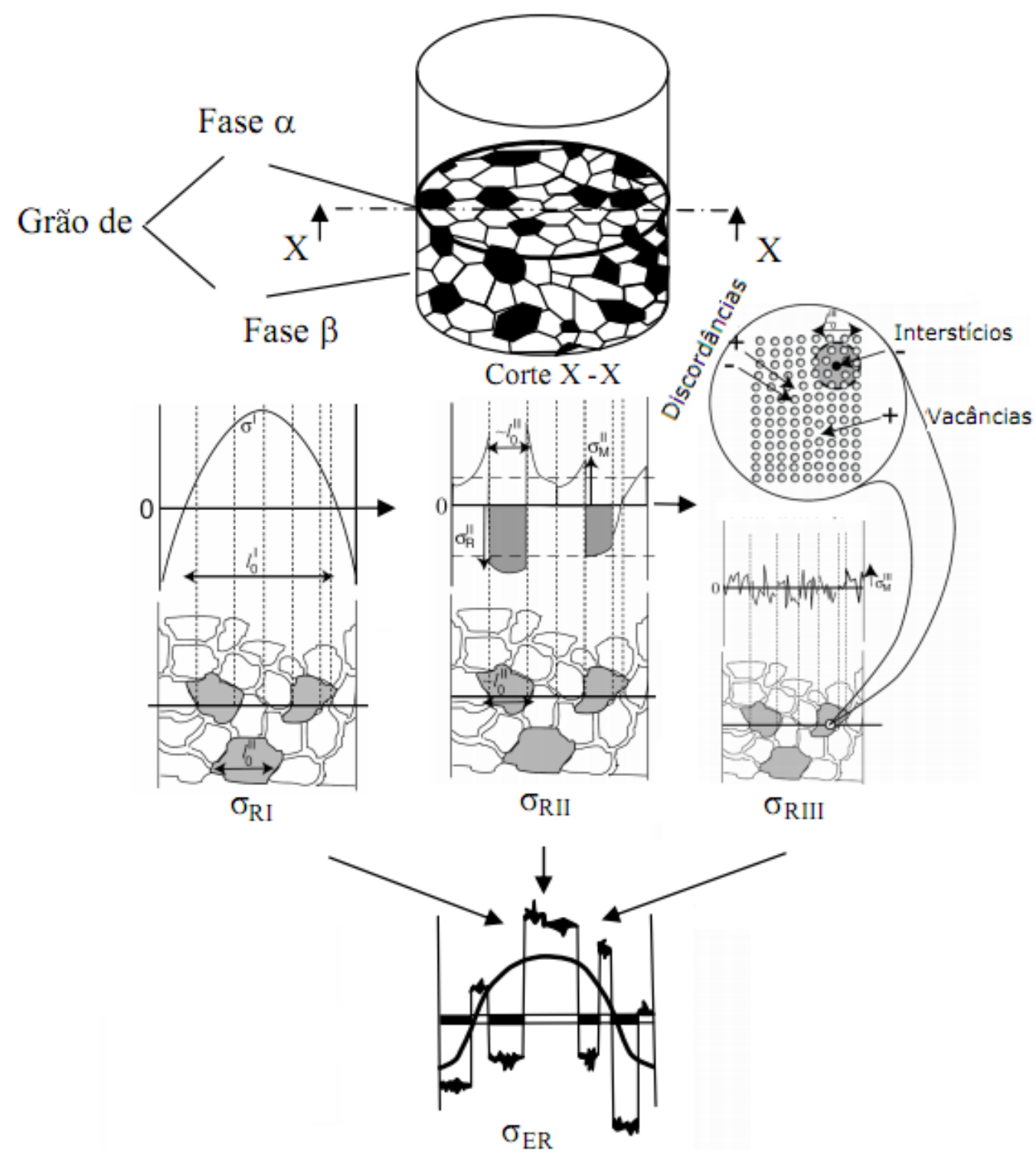

Figura 12 - Representação dos três tipos de tensão residual em um material bifásico depois do processo de têmpera. Adaptado de Liscic (2007).

\subsubsection{Tensões térmicas no caso de um comportamento ideal linear - elástico}

Com base nos trabalhos de Liscic (2007) e Schulze et al. (2010), serão discutidas, as tensões térmicas devidas às diferenças de temperatura locais e 
temporais durante a contração produzida pela têmpera de um cilindro no caso ideal de comportamento linear - elástico.

No início do resfriamento, no processo de têmpera, a temperatura da superfície cai mais rápido que a do núcleo gerando contração nesta região. Como resultado, as zonas da superfície do cilindro são sujeitas a tensão de tração nas direções axial e tangencial, enquanto radialmente são criadas tensões de compressão. A fim de estabelecer o equilíbrio, estas tensões na superfície são contrabalançadas no interior do cilindro, por tensões compressivas axiais, tangenciais e radiais, como é apresentado na Figura 13.
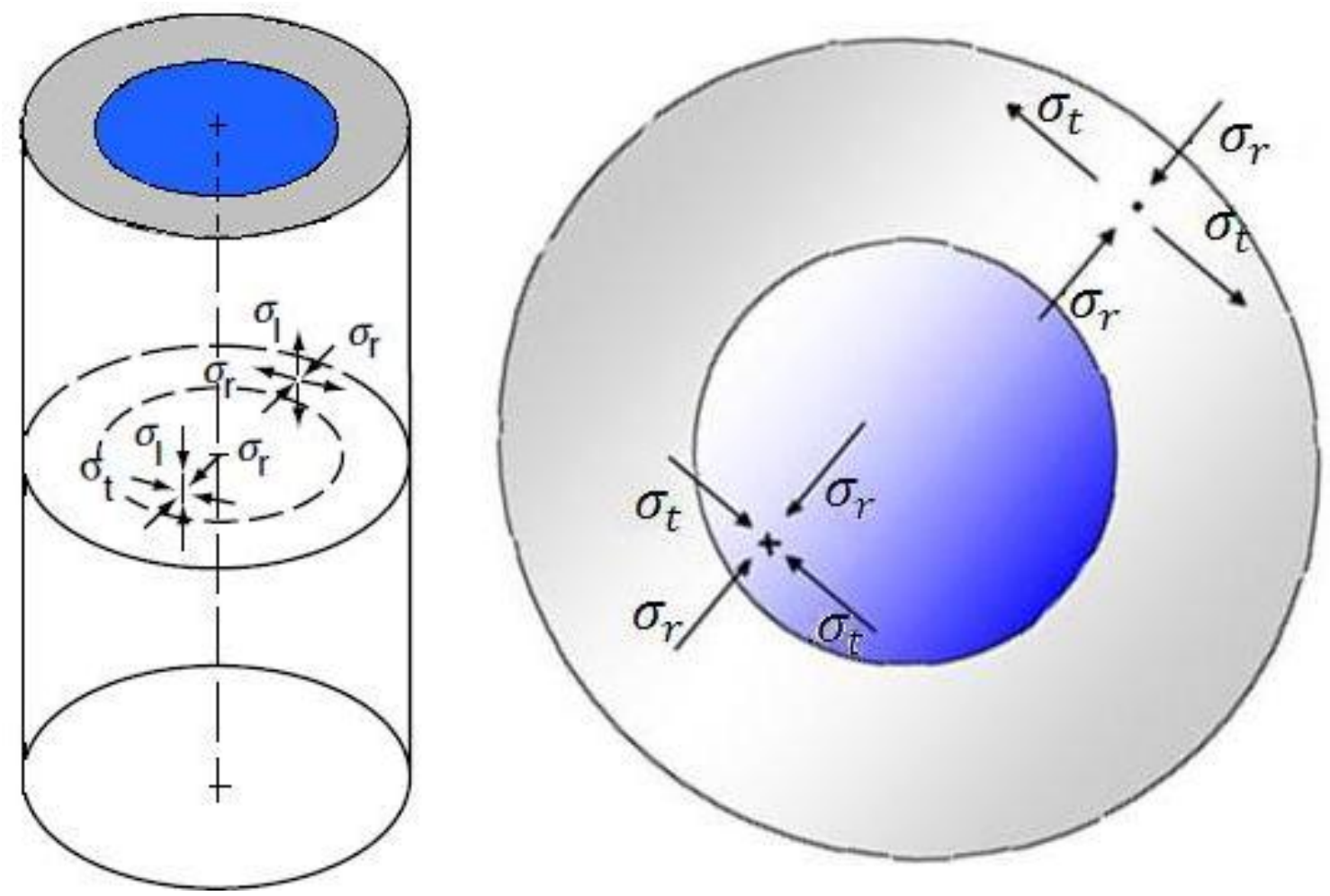

Figura 13 - À esquerda - representação das tensões térmicas na superfície e no núcleo de um cilindro ideal com comportamento linear elástico durante a têmpera; à direita - vista superior das tensões térmicas. As setas indicam as direções das tensões, o ponto e a xis representam a tensão de compressão e de tração, respectivamente e $\sigma_{l}, \sigma_{r}$ e $\sigma_{t}$, representam as tensões axiais, radiais e tangenciais, respectivamente. Adaptado de Liscic et al. (1992).

$\mathrm{Na}$ Figura 14 são apresentadas as diferenças de temperaturas entre a superfície e o núcleo e o desenvolvimento das tensões axiais durante o processo de têmpera. A maior diferença de temperatura, $\Delta T_{\text {máx }}$, é atingida em $t=t_{\text {máx }}$, a partir do 
qual a temperatura do núcleo diminui mais rapidamente que a da superfície, levando a uma redução das magnitudes das tensões de contração em ambas regiões.

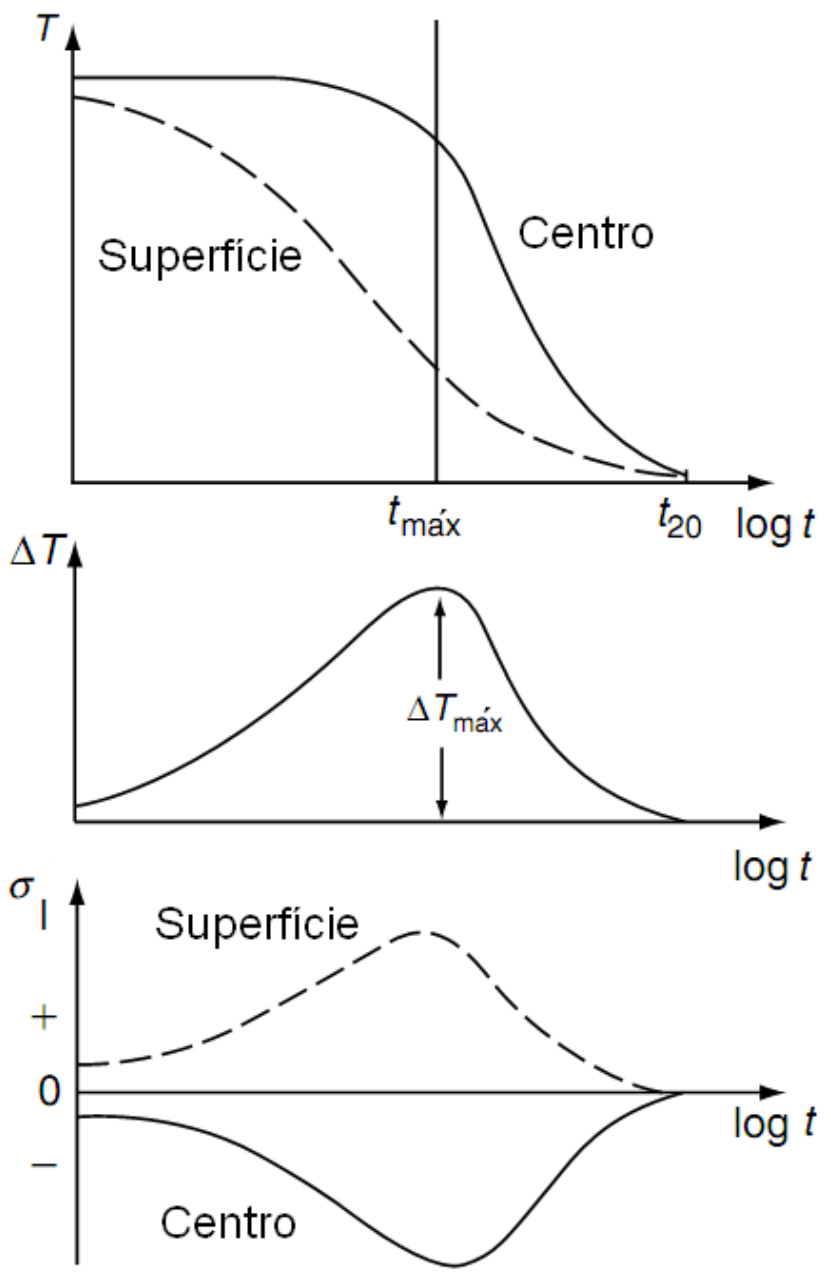

Figura 14 - De cima para baixo: histórico tempo temperatura, gradiente de temperatura entre a superfície e o núcleo, e desenvolvimento da tensão axial, durante resfriamento, sem transformação de fase, para um cilindro ideal linear-elástico. Adaptado de Liscic et al. (1992).

A magnitude da tensão desenvolvida dependerá do diâmetro do cilindro, como é mostrado na Figura 15, para cilindros com diâmetros de 30, 50 e 100 mm, temperados em água. Dado que a máxima diferença de temperatura entre o núcleo e a superfície ocorre nos cilindros de maior diâmetro, estes desenvolvem maiores tensões. Ao atingir o equilíbrio da temperatura aos $20^{\circ} \mathrm{C}\left(68^{\circ} \mathrm{F}\right)\left(t=t_{20}\right)$, estes cilindros, sob a condição ideal imposta aqui, ficam livres de tensões residuais. 


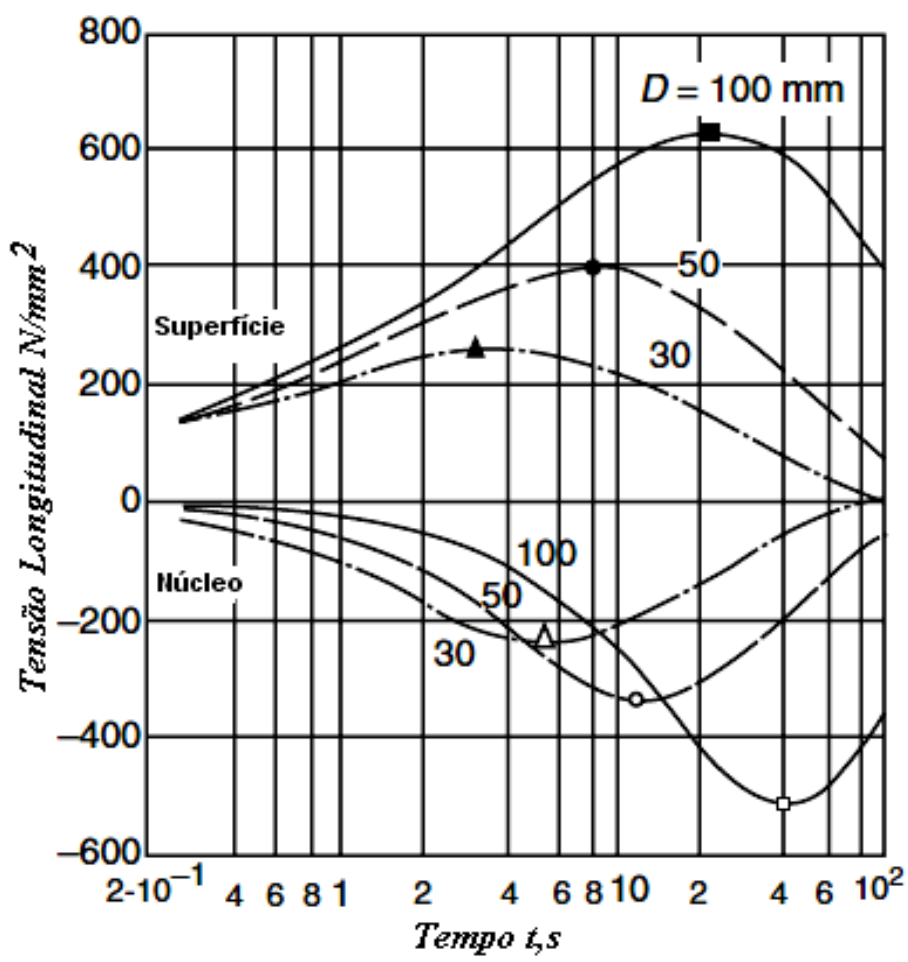

Figura 15 - Dependência das tensões térmicas no sentido axial nos diâmetros de cilindros de aço de médio carbono com comportamento ideal linear-elástico. Adaptado de Liscic et al. (1992).

\subsubsection{Tensões de transformação no caso de um comportamento ideal linear - elástico}

O início do processo de transformação de fase durante o resfriamento no processo de têmpera está representado na Figura 16. Nesta figura pode ser observado um comportamento de tensões oposto ao apresentado pelas tensões puramente térmicas. Neste caso, na superfície, são desenvolvidas tensões de compressão nos sentidos axial e tangencial e tensões de tração na direção radial. Já no núcleo serão desenvolvidas tensões de tração nas três direções. 

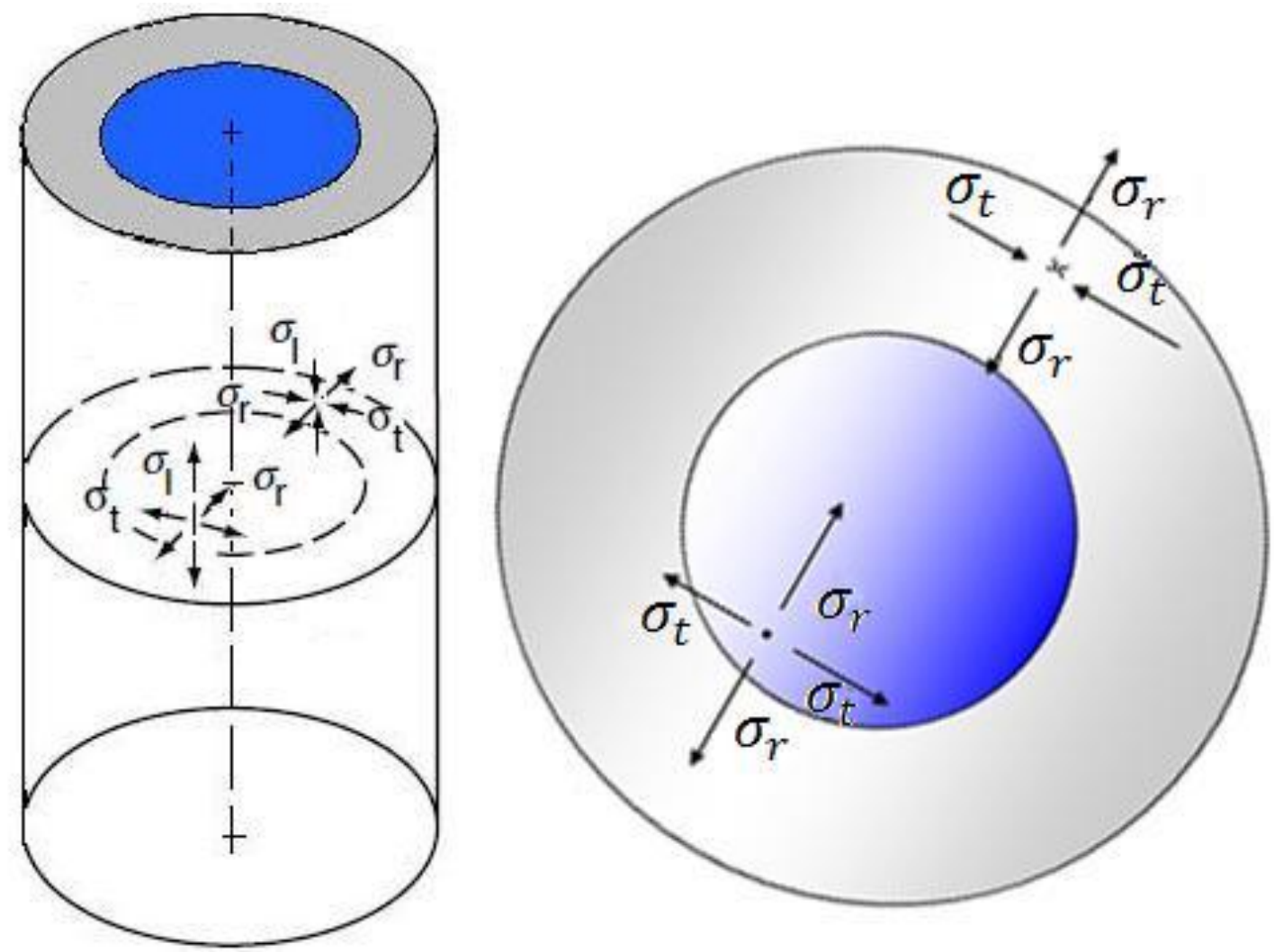

Figura 16 - À esquerda - tensões de transformação produzidas por têmpera, na superfície e no núcleo de um cilindro com comportamento ideal linear elástico; à direita - vista superior das tensões de transformação na superfície e no núcleo. As setas indicam as direções das tensões, o ponto e a xis representam a tensão de compressão e de tração, respectivamente e $\sigma_{l}, \sigma_{r}$ e $\sigma_{t}$, representam as tensões axiais, radiais e tangenciais, respectivamente. Adaptado de Liscic et al. (1992).

As curvas de resfriamento para a superfície e o núcleo, neste caso, estão representadas na Figura 17. Nesta figura, pode-se observar que depois de passar a temperatura de início da transformação martensítica, $M_{s}$, no tempo $t=t_{1}$, se desenvolvem tensões compressivas na superfície, isto devido ao aumento de volume que acontece com a transformação de fase, sendo estas compensadas com o desenvolvimento de tensões de tração no núcleo. 

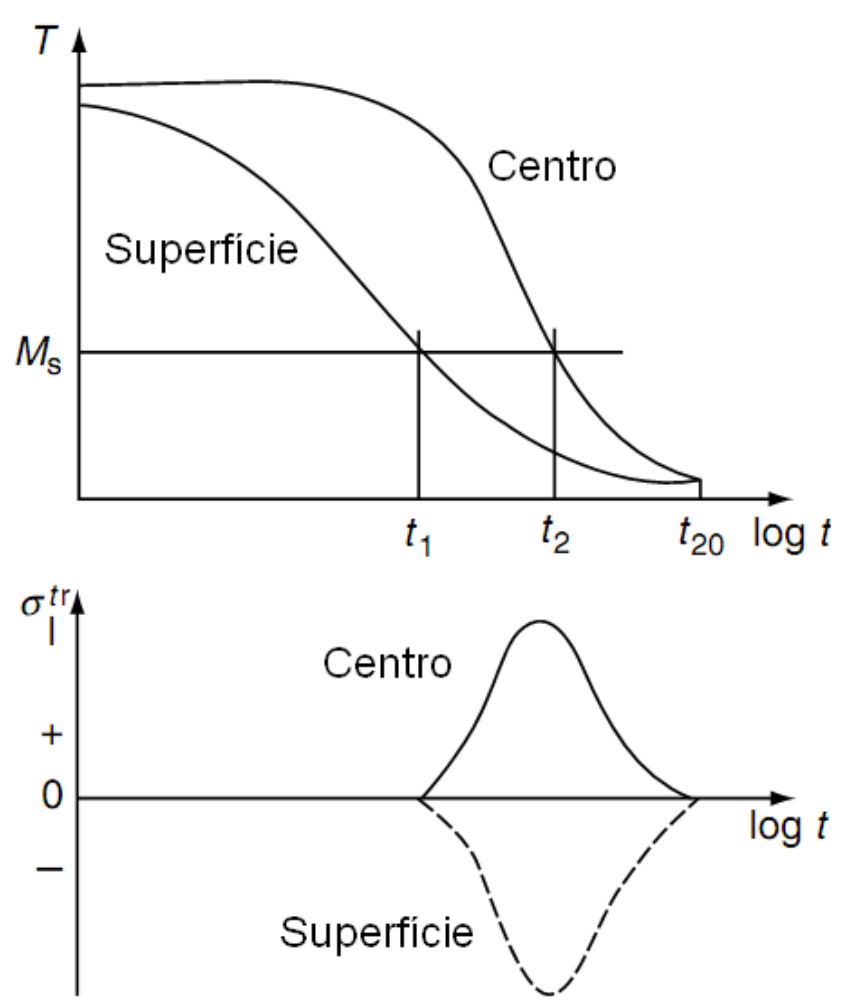

Figura 17 - Resfriamento de um cilindro ideal elástico que transforma somente para martensita. Superior - curvas de resfriamento em função do tempo e da temperatura; inferior - curvas de desenvolvimento das tensões de transformação axial $\sigma_{l}^{t r}$. Adaptado de Liscic et al. (1992).

Quando a temperatura do núcleo atinge a temperatura $M_{s}$ no tempo $t=t_{2}$, o aumento do volume devido à transformação leva a uma redução da tensão de tração no núcleo e, por conseguinte à diminuição da tensão de compressão na superfície. Após atingir o equilíbrio da temperatura em $t=t_{20}$, todo $o$ cilindro terá as mesmas quantidades de martensita e finalmente é estabelecido um estado livre de tensões residuais. No entanto, se fossem formadas diferentes quantidades de martensita em distintas áreas do material, sob as suposições feitas aqui, surgiriam algumas tensões residuais de transformação.

\subsubsection{Combinação das tensões térmicas e de transformação no caso de um cilindro ideal linear elástico}

Quando as tensões térmicas e as tensões de transformação atuam simultaneamente durante a têmpera de um cilindro ideal com comportamento linear elástico, em que austenita é convertida para martensita, ocorre superposição dos 
dois tipos de tensões, como é apresentado na Figura 18. Nesta figura se ilustra de forma qualitativa o desenvolvimento das tensões residuais causadas pela transformação martensítica e pelo gradiente de temperatura em um aço temperado. O gráfico superior apresenta as tensões axiais térmicas, $\sigma_{l}^{t e r}$, e de transformação, $\boldsymbol{\sigma}_{l}^{t r}$, na superfície e no núcleo em função do tempo. Já o gráfico inferior apresenta a superposição das duas tensões em função do tempo. Neste gráfico pode-se observar que, com o início da transformação martensítica, o valor da tensão total no núcleo e na superfície sofre redução imediata.

Uma vez que a transformação ocorre de maneira uniforme em todo o cilindro, no tempo $t=t_{20}$, as tensões de tração no núcleo e de compressão na superfície tendem a zero. Daí quando o equilíbrio da temperatura for atingido, não permanecerão tensões residuais.
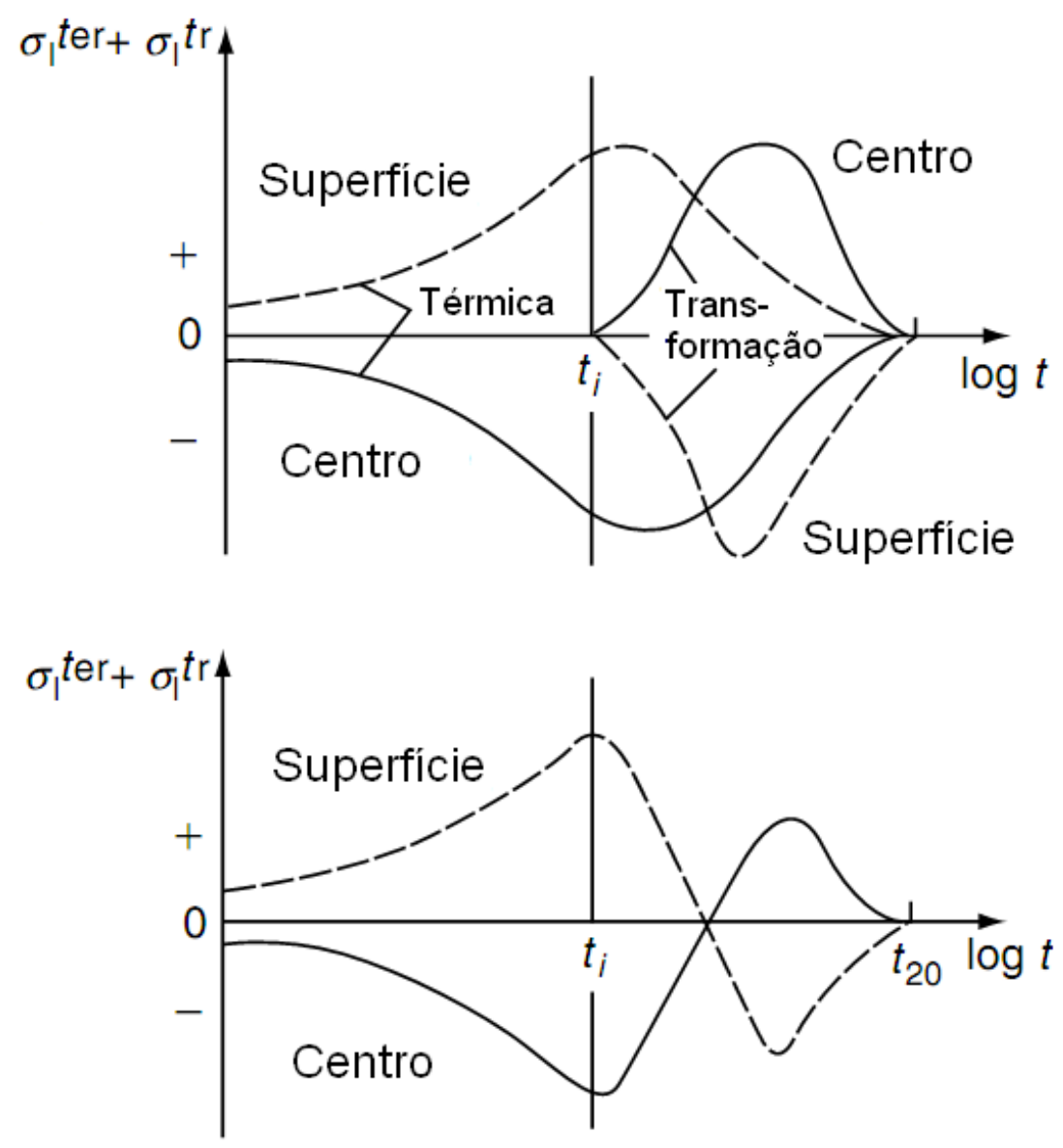

Figura 18 - Desenvolvimento de tensões residuais durante têmpera de um cilindro ideal linear elástico considerando a superposição das tensões térmicas e as tensões devidas à transformação de austenita para martensita. Adaptado de Liscic et al. (1992). 


\subsubsection{Tensões residuais no caso do comportamento elasto-plástico}

\subsubsection{Tensões residuais térmicas (sem transformação de fase)}

O processo de tratamento térmico de têmpera geralmente leva à formação de tensões residuais (do tipo I) durante o resfriamento do componente, por causa dos gradientes de temperatura, que ocorrem entre a superfície e o núcleo, seja para uma única fase ou para uma microestrutura constituída por uma mistura de fases.

Se as tensões formadas excedem o limite de escoamento do cilindro, ocorrem deformações plásticas não homogêneas, e o cilindro fica com tensões residuais após o resfriamento. A distribuição e a magnitude destas tensões residuais dependem fortemente do processo de resfriamento, quanto mais rápida for a têmpera, maior será a diferença de temperatura entre o núcleo e a superfície e, portanto, maiores serão as tensões resultantes na temperatura ambiente. Além do processo de resfriamento (velocidade e meio resfriamento), estas tensões também dependerão da geometria do cilindro (diâmetro e relação comprimento-diâmetro) e das propriedades do material dependentes da temperatura (módulo de elasticidade, condutividade térmica, coeficiente de poisson, coeficiente de expansão térmica etc.).

Liscic (2007) e Schulze et al. (2010) detalham no seus trabalhos o comportamento das curvas de resfriamento da superfície e do núcleo e a dependência dos limites de escoamento, $\sigma_{e}$, da temperatura (e do tempo) durante a têmpera de um cilindro com comportamento elasto-plástico, sem que ocorra transformação martensítica, como apresentado na Figura 19. Nesta figura se observa que no início da têmpera, a temperatura da superfície diminui mais rapidamente do que a temperatura do núcleo [Figura 19(a)] e, como resultado, se desenvolvem tensões axiais de tração na superfície e tensões de compressão no núcleo [Figura 19(b)]. Devido à dependência do limite de escoamento da temperatura, nem a superfície, nem o núcleo, podem resistir a essas tensões sem que ocorra deformação plástica e, portanto, a zona superficial é plasticamente tracionada, enquanto que o núcleo é plasticamente comprimido. Após o tempo 
$t=t_{\text {max }}$, tempo em que ocorre a maior diferença de temperaturas entre o núcleo e a superfície, a temperatura do núcleo diminui mais rapidamente que a da superfície, levando a uma redução das magnitudes das tensões de contração em ambas as regiões. Após o resfriamento adicional, ocorre inversão das tensões uma vez que continua existindo incompatibilidade dos volumes da superfície e do núcleo, e surgem as tensões residuais térmicas de compressão na superfície e de tração no núcleo (como é indicado pelas setas na parte direita da Figura 19(b)) devido às deformações plásticas que acontecem durante o processo.

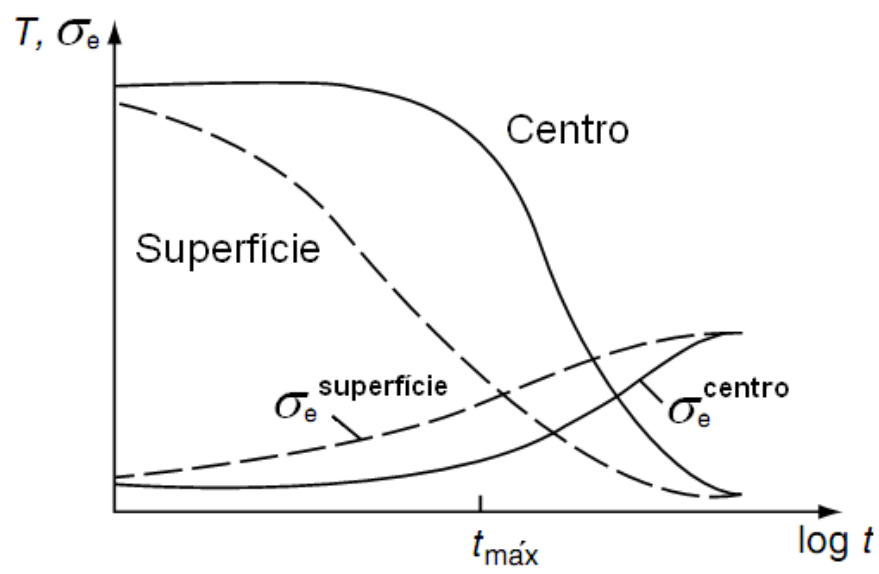

(a)

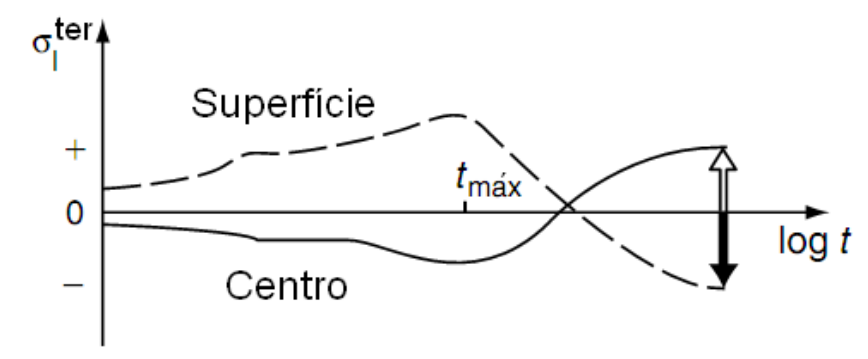

(b)

Figura 19 - Tensões residuais térmicas durante a têmpera de cilindros. (a) Curvas de resfriamento e do limite de escoamento em função da temperatura e do tempo. (b) Tensões residuais desenvolvidas ao longo do processo de têmpera. Adaptado de Liscic et al. (1992).

Ebert (1978) apresenta uma série de diagramas que esquematizam todas as mudanças que ocorrem em função do tempo e da temperatura em uma amostra cilíndrica resfriada em uma faixa de temperatura onde não há transformação de fase, como apresentado na Figura 20. Nesta figura são mostradas as formas de tensão axial desenvolvidas através de uma fatia transversal do cilindro para quatro fases 
diferentes do processo de resfriamento. A linha horizontal indica o estado de tensão residual nulo, as tensões de tração são plotadas acima desta linha e as tensões de compressão abaixo da mesma. No início do esquema (ponto $A$ - temperatura de austenitização), o cilindro está livre de tensões, mas com o início do resfriamento, as diferenças de temperatura entre a superfície e o centro do cilindro desenvolvem contrações na superfície produzidas pela queda mais acentuada de temperatura nesta região em comparação com o centro. Estas contrações fazem com que a superfície seja tracionada, como é mostrado no ponto B da Figura 20, ponto em que ocorre a máxima diferença de temperatura, como indicado na parte esquerda desta figura. A partir do ponto $\mathrm{B}$, o núcleo esfria mais rapidamente que a superfície, levando a uma redução elástica dimensional da superfície até ser obtida a inversão da tensão no ponto $\mathrm{C}$. Como a temperatura continua ainda decrescendo até a temperatura ambiente, pela ocorrência da inversão das tensões no ponto $C$, 0 núcleo fica em tensão de tração enquanto a superfície fica em tensão de compressão, como é ilustrado no ponto $D$ desta figura. Estas tensões térmicas serão proporcionais à diferença de temperatura entre o núcleo e a superfície. A curva "a" mostra a variação da tensão na superfície sob condição elástica e a curva "b" e a curva pontilhada são as variações das tensões térmicas vigentes na superfície e no centro, respectivamente, sob condição elasto-plástica. Se todas estas tensões pudessem ser absorvidas elasticamente, elas aumentariam até o ponto "a" e depois seriam reduzidas até zero, quando todas as partes da seção transversal alcançassem a mesma temperatura (ERICSSON, 1987). 

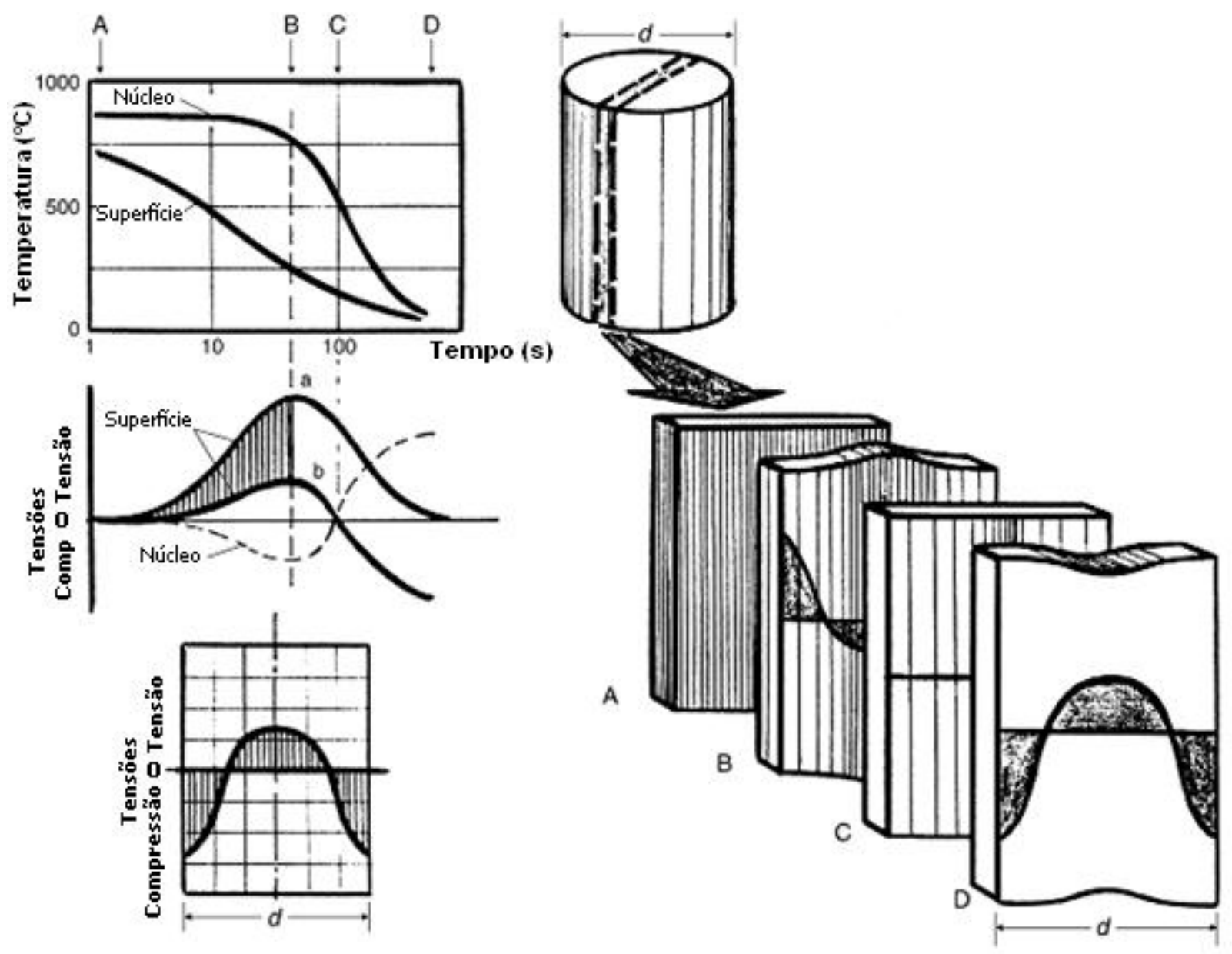

Figura 20 - Comportamento da tensão residual sem levar em conta a transformação de fase. Adaptado de Ebert (1978).

\subsubsection{Tensões residuais devidas à transformação de fase}

Quando se trata dos tratamentos térmicos dos aços, além das tensões residuais térmicas, devem ser consideradas aquelas devidas à transformação de fase, pois durante o resfriamento surgem mudanças não homogêneas no volume, associadas com a formação da nova fase. No aquecimento, por exemplo, a transformação de perlita em austenita ocorre com contração volumétrica da peça, enquanto no resfriamento, a transformação da austenita para martensita, bainita ou perlita provoca expansão. Estas alterações de volume dependerão das fases formadas e do teor de carbono do aço como é mostrado na Tabela 3. 
Tabela 3 - Mudanças no volume produzidas por transformações de fase. Thelning (1975).

\begin{tabular}{ccc}
\hline Transformação & Variação do Volume, \% & $\begin{array}{c}\text { Mudança dimensional, } \\
\mathbf{m m} / \mathbf{m m} \text { ou pol/pol }\end{array}$ \\
\hline Perlita esferoidizada $\rightarrow$ Austenita & $-4,64+2,21(\% \mathrm{C})$ & $-0,0155+0,0074(\% \mathrm{C})$ \\
Austenita $\rightarrow$ Martensita & $4,64-0,53(\% \mathrm{C})$ & $0,0155-0,018(\% \mathrm{C})$ \\
$\begin{array}{c}\text { Perlita esferoidizada } \rightarrow \text { Martensita } \\
\text { Austenita } \rightarrow \text { Bainita inferior }\end{array}$ & $1,68(\% \mathrm{C})$ & $0,0056(\% \mathrm{C})$ \\
$\begin{array}{c}\text { Perlita esferoidizada } \rightarrow \text { Bainita } \\
\text { inferior }\end{array}$ & $0,64-1,43(\% \mathrm{C})$ & $0,0155-0,0048(\% \mathrm{C})$ \\
Austenita $\rightarrow$ Bainita superior & $4,64-2,21(\% \mathrm{C})$ & $0,0155-0,0074(\% \mathrm{C})$ \\
\hline
\end{tabular}

Moyer e Ansell (1975), a fim de determinar a expansão do volume que acompanha a transformação martensítica em aços, com vários teores de carbono (até aproximadamente 1,0\% C), propuseram a seguinte relação:

$$
(\Delta V / V)_{20^{0} C}=3,216+0,859(\% C)-0,343(\% C)^{2}
$$

Berns (1989) sugere que se o valor $(\Delta V / V)$ é conhecido ou pode ser computado, então as tensões internas que são desenvolvidas em uma peça devido às diferenças de temperatura $(\Delta T)$ decorrentes de qualquer aquecimento ou resfriamento unidimensional, podem ser estimadas a partir de:

$$
\sigma=E . \varepsilon=E \cdot\left(\frac{\Delta l}{l_{0}}\right)=E \cdot\left(\frac{l-l_{0}}{l_{0}}\right)=E \frac{1}{3}\left(\frac{V-V_{0}}{V_{0}}\right)=E \frac{1}{3}\left(\frac{\Delta V}{V_{0}}\right)=E . \alpha_{T} . \Delta T
$$

onde $E, l$ e $V$ são o modulo de elasticidade, o comprimento e o volume atômico em uma certa temperatura, e $\alpha_{T}$ e $\varepsilon$ são o coeficiente de expansão térmica e deformação nominal, respectivamente. Esta relação é possível assumindo que as deformações e as transformações térmicas são isotrópicas

Os trabalhos de Liscic (2007) e Schulze et al. (2010) apresentam o comportamento das curvas de resfriamento (Figura 21) da superfície e do núcleo durante a têmpera de um cilindro que se transforma completamente para martensita. Para simplificar, eles supõem que não ocorrem tensões térmicas. 
Na Figura 21(a), além de serem apresentadas as trajetórias das curvas de resfriamento para o núcleo e a superfície, são mostradas as curvas de variação do limite de escoamento, $\sigma_{e}$, nestas regiões, que indicam um crescimento acentuado com o início da transformação martensítica, $M_{s}$, no tempo $t=t_{1}$. A partir do tempo $t_{1}$, a expansão do volume da zona de superfície é impedida pelo núcleo que ainda não transformou e, como resultado, são geradas tensões compressivas na superfície, compensadas por tensões de tração no núcleo. Com o resfriamento adicional, a temperatura do núcleo atinge o início da transformação martensítica, $M_{S}$, no tempo $t=t_{2}$, e o aumento de volume produto da transformação reduz as tensões de tração no núcleo e as tensões de compressão na superfície. Com a continuidade do resfriamento, continua existindo incompatibilidade dos volumes da superfície e do núcleo, criando tensões de transformação de sinais opostos devido às deformações plásticas que acontecem durante 0 processo. Após atingir 0 equilíbrio de temperatura, o cilindro fica com tensões residuais de compressão no núcleo e com tensões residuais de tração na superfície, produto da deformação plástica que ocorre nas duas regiões [Figura 21(b)].

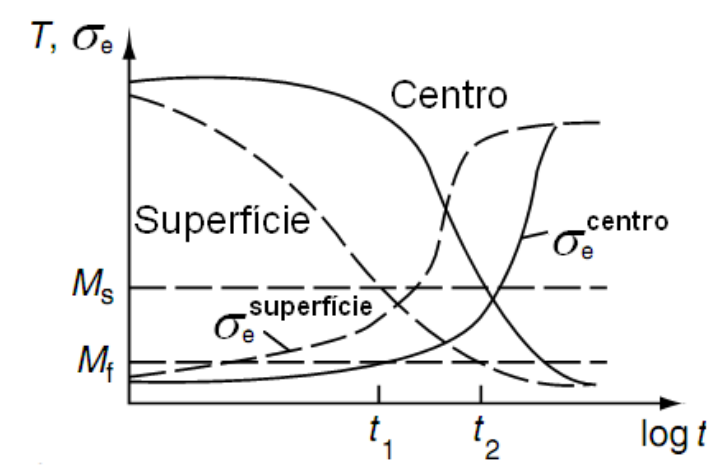

(a)

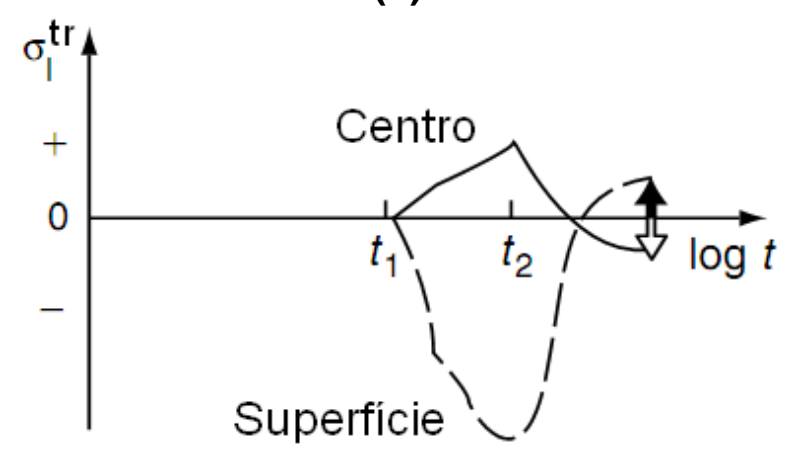

(b)

Figura 21 - Tensões residuais de transformação durante têmpera de um cilindro. (a) Curvas de resfriamento e do limite de escoamento em função da temperatura e do tempo. (b) Tensões residuais de transformação desenvolvidas ao longo do processo de têmpera Adaptado de Liscic et al. (1992). 
A Figura 22 mostra esquematicamente a evolução da tensão residual de peças que resfriam desde a fase austenítica, com diferentes taxas de temperaturas na superfície e no interior do cilindro (EBERT, 1978). O estudo de Ebert (1978) fez esta representação esquemática para um aço cementado ${ }^{11}$, mas estes diagramas são válidos para ilustrar os princípios da evolução da tensão residual para peças temperadas em que a superfície transforma em martensita antes que o centro.

Devido à restrição da expansão do volume no núcleo do cilindro sem transformar, são desenvolvidas tensões de compressão na superfície. No entanto, quando o centro transformar, seja para martensita, bainita ou microestrutura perlita, a expansão do interior coloca a superfície em tensão de tração.
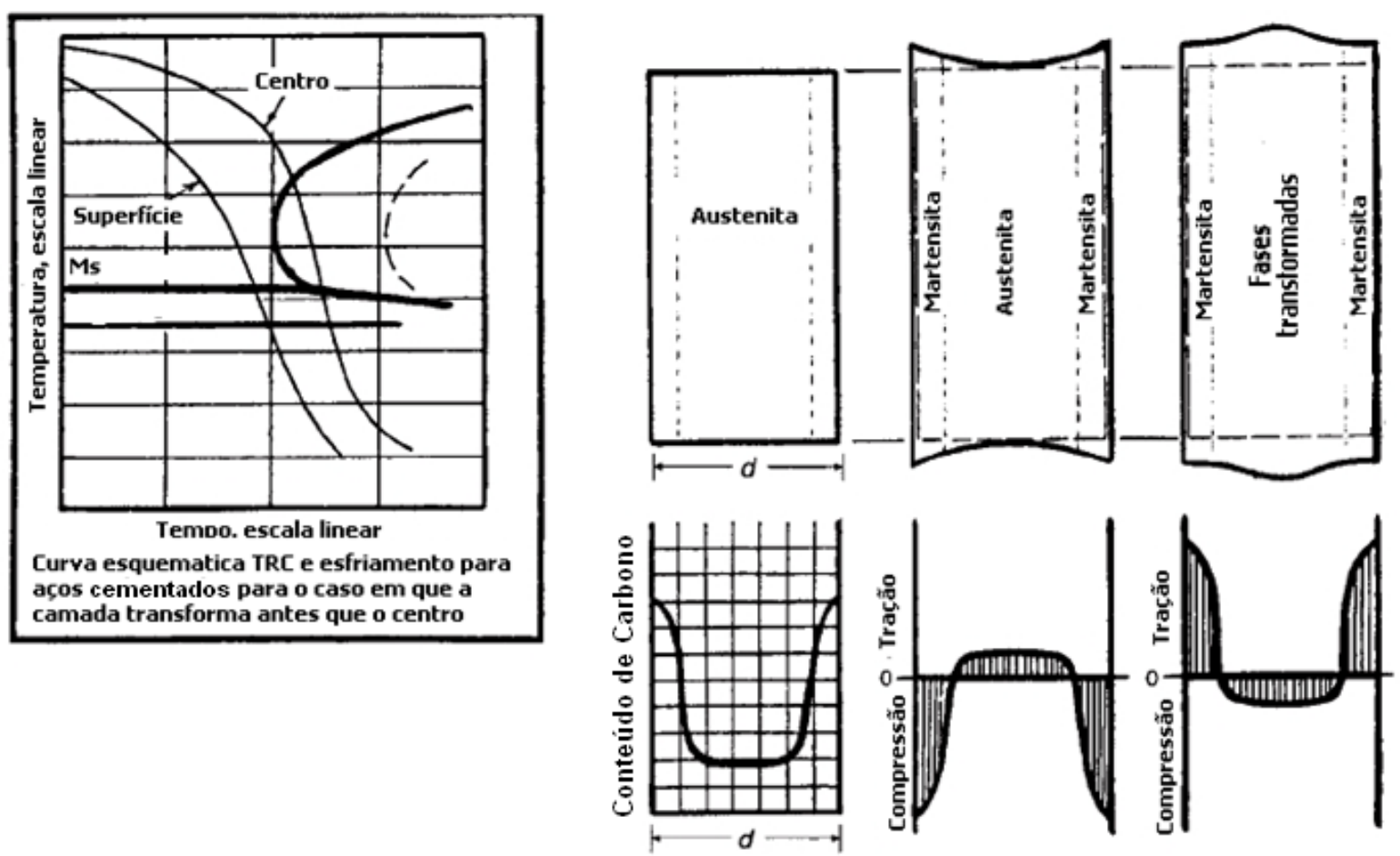

Figura 22 - Distribuição de tensões residuais devidas à transformação de fases durante a têmpera de um aço. Adaptado de Ebert (1978).

${ }^{11}$ Em peças cementadas, os gradientes de carbono normalmente fazem com que o núcleo, por ter baixo carbono, se transforme antes que a camada cementada, resultando em tensões de compressão na superfície (KRAUSS, 2005). 


\subsubsection{Formação das tensões residuais de compressão na superfície de peças temperadas}

Segundo Liscic (2007) e Schulze et al. (2010) é fundamental o fato que qualquer aumento de volume associado à transformação sempre desloca as tensões existentes (independentemente do seu sinal) para valores mais negativos, e como reação, por razões de equilíbrio, as zonas do material não afetado diretamente pela transformação reagem com valores de tensão positivas. Isto quer dizer que as transformações que ocorrem em regiões do material que estão em tensão de tração inevitavelmente reduzem as tensões como é observado na Figura 23(a) e (c), enquanto as transformações que ocorrem em zonas que estão em compressão aumentarão os valores das tensões existentes [Figura 23(b)].

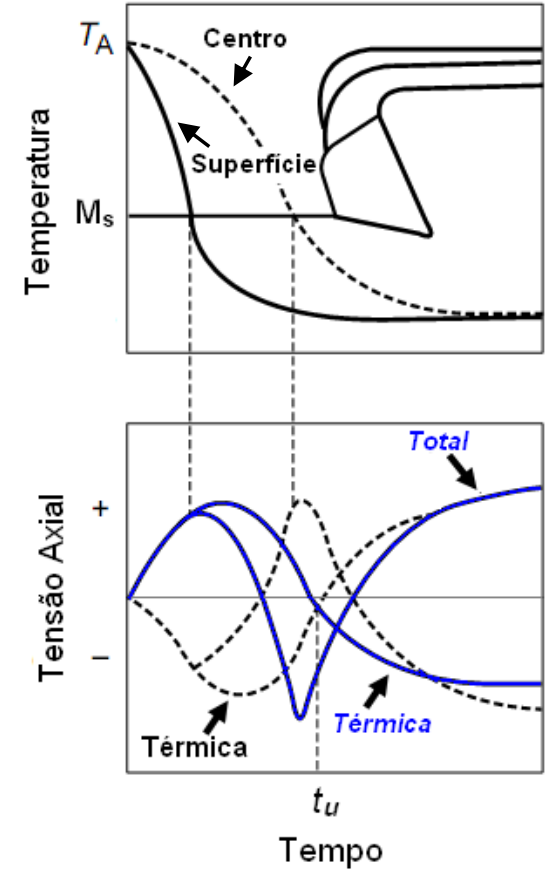

(a)

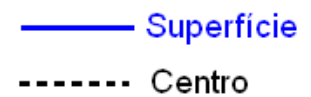

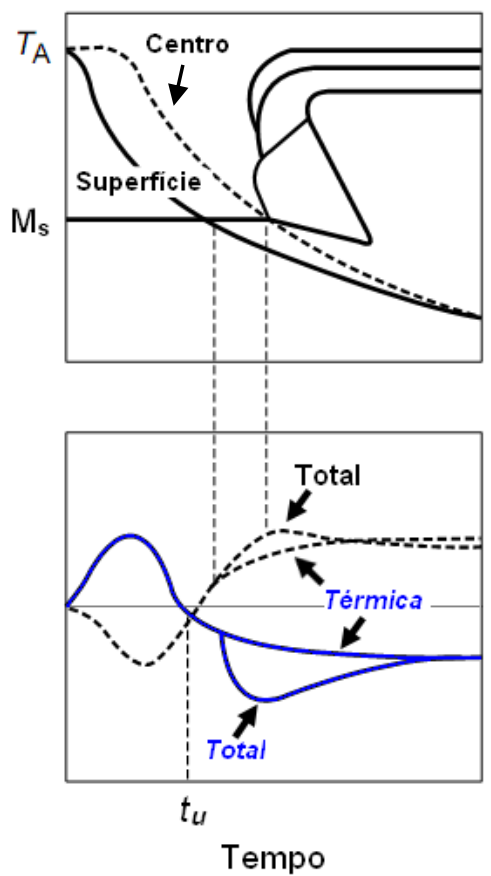

(b)

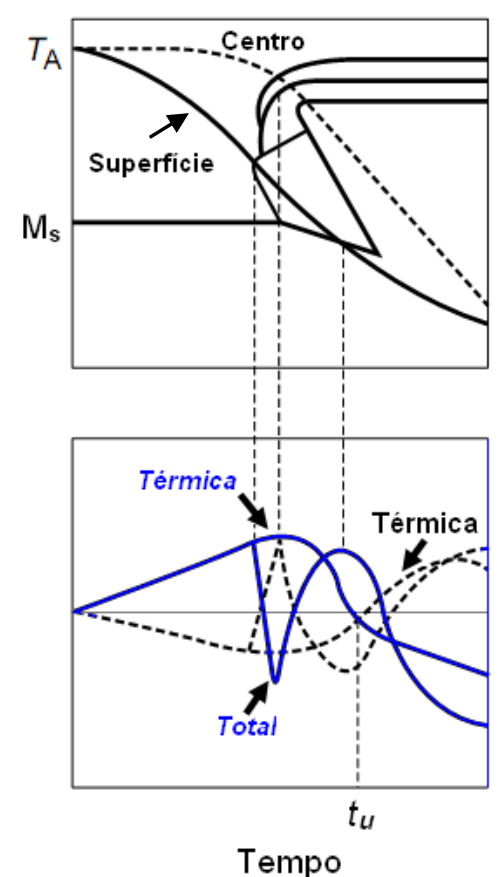

(c)

Figura 23 - Comparação das tensões térmicas e de transformação para três diferentes condições de têmpera. (a) e (c) inversão das tensões térmicas depois da superfície e o núcleo transformarem; (b) inversão das tensões térmicas antes da superfície e o núcleo transformarem. $T_{A}$ representa a temperatura de austenitização, $M_{S} O$ início da transformação martensítica e $t_{u}$ representa o tempo de inversão das tensões térmicas. Adaptado de Mayr (1987). 
De acordo com Bates et al. (1993) e Narazaki et al. (2007) a Figura 23(a) ilustra quando a transformação de fase tanto da superfície como do núcleo ocorrem antes da mudança do sinal das tensões térmicas $\left(t_{u}\right)$. Acima da temperatura da transformação $M_{s}$, as tensões que se formam são térmicas. Com a continuidade do resfriamento a transformação martensítica no centro produz uma componente substancial de tensão de compressão devido ao aumento volumétrico da transformação de fase, e isto faz com que no centro as tensões excedam a tensão de escoamento e ocorra deformação plástica. Quando o centro completa a transformação martensítica a peça fica em tração na superfície e em compressão no centro, simultaneamente. Ainda na Figura 23, no caso (b), é apresentado o caso em que a transformação acontece depois da mudança de sinal das tensões térmicas $\left(t_{u}\right)$. O aumento de volume devido à transformação da superfície adiciona tensões compressivas à superfície. Uma vez que as tensões são equilibradas, há um correspondente aumento das tensões de tração no núcleo. Já na Figura 23(c) durante o resfriamento, o sinal das tensões muda três vezes visto que ocorrem três transformações em instantes diferentes, uma do centro para ferrita e duas para a superfície, inicialmente de austenita para bainita e logo da austenita não transformada, ao cruzar a temperatura de início de transformação martensítica. Como resultado final, neste caso, é obtida uma tensão de compressão na superfície e de tração no núcleo.

Uma análise similar na tentativa de explicar a formação das tensões residuais dependendo do ponto de início da transformação com relação ao estado de tensões térmicas naquele instante, foi feita por Liscic (2007) e Schulze et al. (2010), para um aço AISI 1045 austenitizado a $850^{\circ} \mathrm{C}$ e temperado em água $\left(20^{\circ} \mathrm{C}\right)$. Esses autores mostraram que toda a variedade das distribuições de tensões residuais que surgem durante a têmpera de cilindros de aço pode ser dividida em três grupos principais, como é ilustrado esquematicamente na Figura 24. 

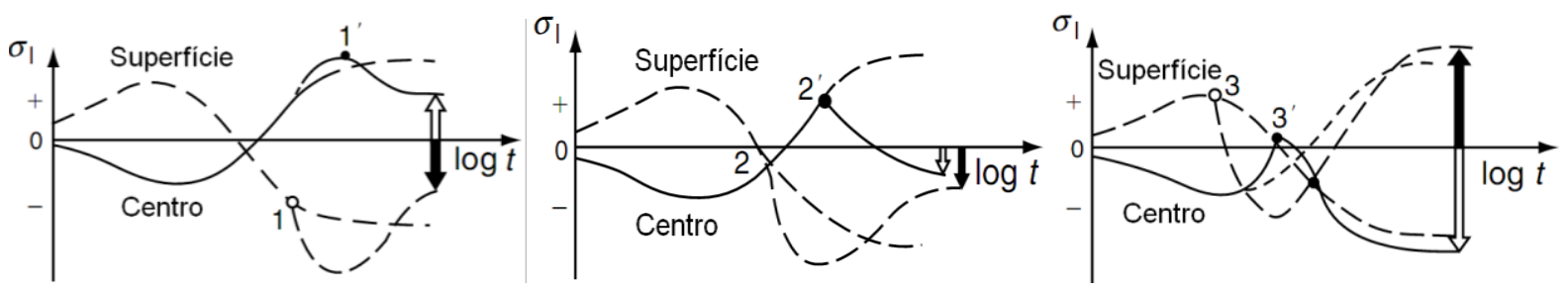

Transformaçầo
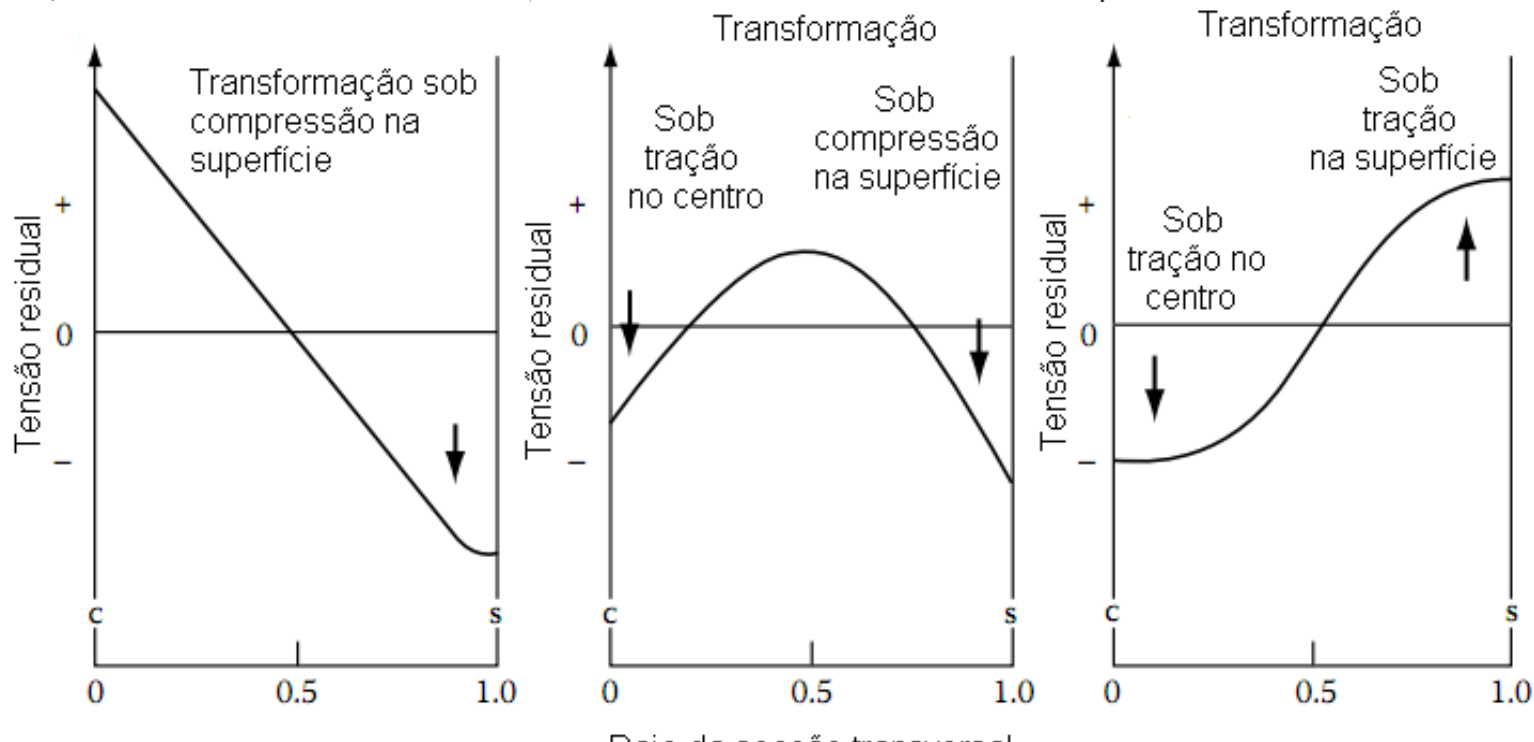

Raio da secçẫo transversa

Figura 24 - Diferentes tipos de tensões residuais desenvolvidas no processo de têmpera. c e s representam o centro e a superfície do cilindro, respectivamente. Adaptado de Liscic (2007) e Schulze et al., (2010).

Nesta figura as setas indicam como as transformações de fase sob estados de tensões térmicas existentes afetam a distribuição de tensões residuais finais. À esquerda desta figura está representado o caso em que a transformação de fase acontece quando o centro se encontra sob tensões térmicas de compressão e a superfície sob tensões térmicas de tração, a parte intermediária desta figura representa quando a transformação de fase ocorre estando a superfície sob tensões térmicas de compressão e o centro sob tensões térmicas de tração, e a figura da direita mostra o caso em que a transformação de fase acontece quando tanto a superfície como o centro se encontram sob tensões térmicas de tração, levando a mais uma inversão de tensões.

Dessa forma, as tensões térmicas presentes na peça são deslocadas para valores negativos de tensão, quando se inicia a transformação devido ao aumento de volume que a transformação produz. E o efeito das mudanças de volume no estado final de tensão residual depende de quando começam as transformações no núcleo e na superfície em relação ao tempo $t_{u}$. 
Sendo assim, é importante considerar as consequências que têm a posição da inversão do sinal das tensões térmicas no entendimento das tensões residuais remanescentes após têmpera.

\subsubsection{Medida de tensão residual por difração de raios $X$}

A difração de raios $X$ é um fenômeno de interação entre a radiação eletromagnética (raios X) e a matéria ordenada. Para a ocorrência da difração é necessário que o comprimento de onda da radiação incidente seja da mesma ordem de grandeza do espaçamento interatômico do material analisado. Quando os raios X incidem sobre um corpo, uma parte dele é absorvida pelos átomos, enquanto que outra é refletida em todas as direções da área irradiada, isto é conhecido como espalhamento de raios $X$. A interferência construtiva dos raios $X$ espalhados, proveniente de vários átomos, caracteriza a difração. No caso de um cristal, a sequência ordenada e periódica de átomos, pode ser visualizada como um conjunto de planos, os quais são denominados planos cristalográficos e indexados através dos índices de Miller, hkl (CULLITY, 1956; KLUG; ALEXANDER, 1974). espalhamento coerente dos raios $X$ (mesma energia da radiação incidente) por um conjunto de planos cristalinos ( $h k l$ ) ocorre em um ângulo bem definido, denominado ângulo de Bragg (Figura 25). A condição de difração é estabelecida pela lei de Bragg (CULLITY, 1956; KLUG; ALEXANDER, 1974).

$$
n \lambda=2 d_{h k l} \operatorname{sen} \theta_{h k l}
$$

onde $n$ é a ordem de difração (normalmente considera-se $n=1$ ), $\lambda$ é o comprimento de onda da radiação incidente, $d_{h k l}$ é a distância interplanar e $\theta_{h k l}$ é o semi-ângulo de difração medido em relação aos raios $X$ incidentes.

A partir da lei de Bragg, é possível relacionar o ângulo $2 \theta$, medido experimentalmente, com a distância interplanar $d$ e o comprimento de onda $\lambda$. Observa-se que embora existam duas maneiras de determinar o parâmetro de rede, seja pela varredura $2 \theta$, em que o comprimento de onda $\lambda$ é fixo e o ângulo de difração $\theta$ é medido, ou a partir da varredura $\lambda$, onde o ângulo de difração é mantido 
constante e o comprimento de onda é variado, nota-se que a técnica de difração de raios X é normalmente restrita ao método de varredura $2 \theta$, uma vez que a utilização de comprimento de onda constante está relacionada ao tipo de ânodo em operação.

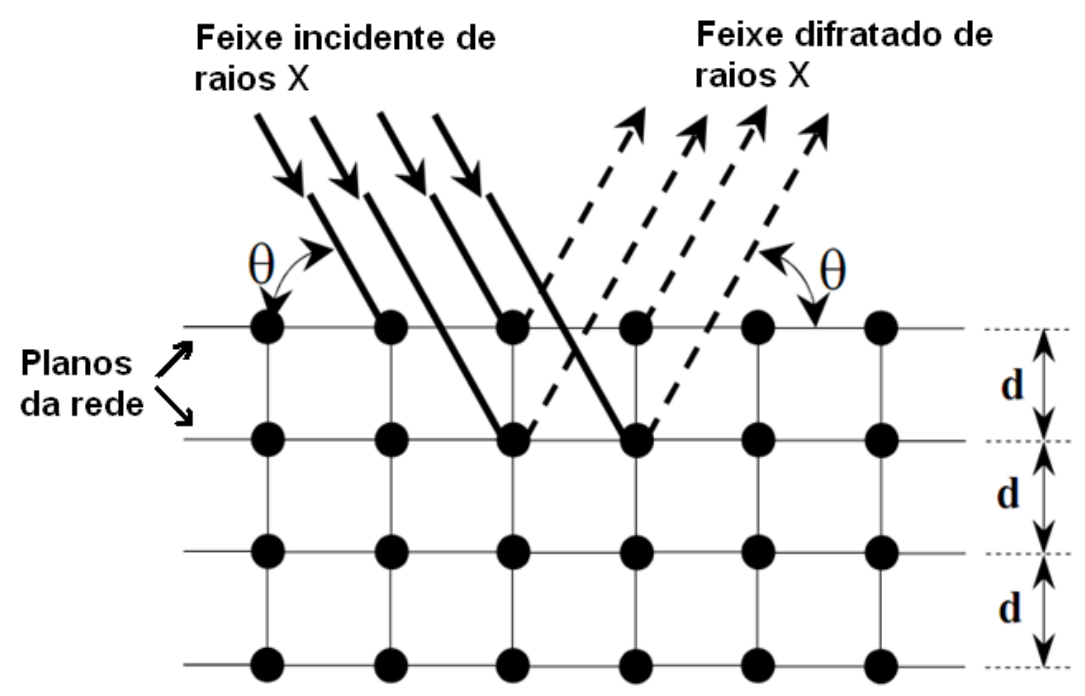

Figura 25 - Espalhamento descrito pela lei de Bragg.

Do ponto de vista de medidas de tensões, a rede cristalina pode ser considerada como um pequeno extensômetro que pode ser lido através de experimentos de difração, uma vez que é possível determinar as deformações induzidas em várias direções, a partir de alterações do parâmetro de rede de um determinado conjunto de planos cristalinos no material tensionado (Figura 26).

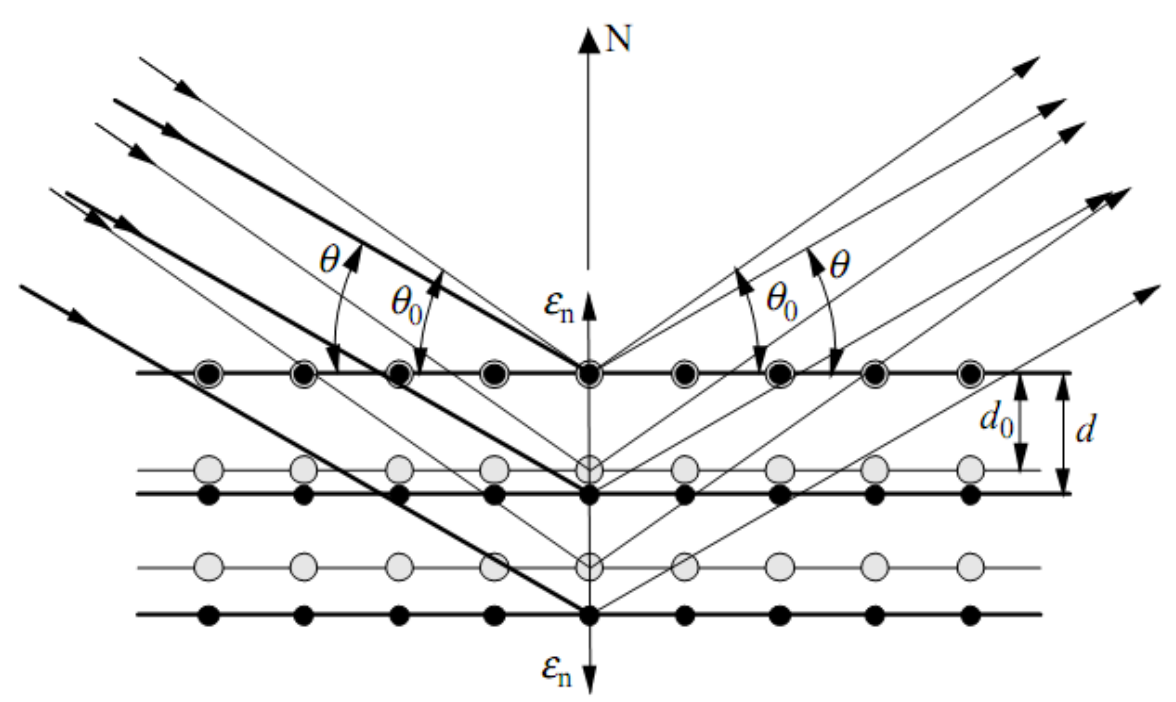

Figura 26 - llustração da medida da deformação com base na lei de Bragg. (HE, 2009). 
Nesta figura (Fig. 26) $d$ e $d_{0}$ são as distâncias interplanares e $\theta, \theta_{0}$ os ângulos de difração para materiais com e sem tensão, respectivamente. $N$, indica a direção normal ao plano e $\varepsilon_{n}$ a deformação na direção ao plano normal, que pode ser obtida pela equação (34):

$$
\varepsilon_{n}=\frac{d}{d_{0}}-1=\frac{\Delta d}{d_{0}}=-\left(\theta-\theta_{0}\right) \cot \theta_{0}=-\Delta \theta \cot \theta_{0}
$$

As tensões residuais podem ser calculadas comparando-se os espaçamentos medidos no material com tensões residuais com aqueles referentes a uma amostra livre de tensões. Para materiais livres de tensões, a distância interplanar é padrão $\left(d_{0}\right)$, mas para um material sob tensões (aplicadas ou residuais), a distância interplanar sofre variações de acordo com a lei de Hooke, com a orientação (ângulo $\psi$ ) da família de planos $h k l$ e da tensão aplicada, conforme mostrado na Figura 27.

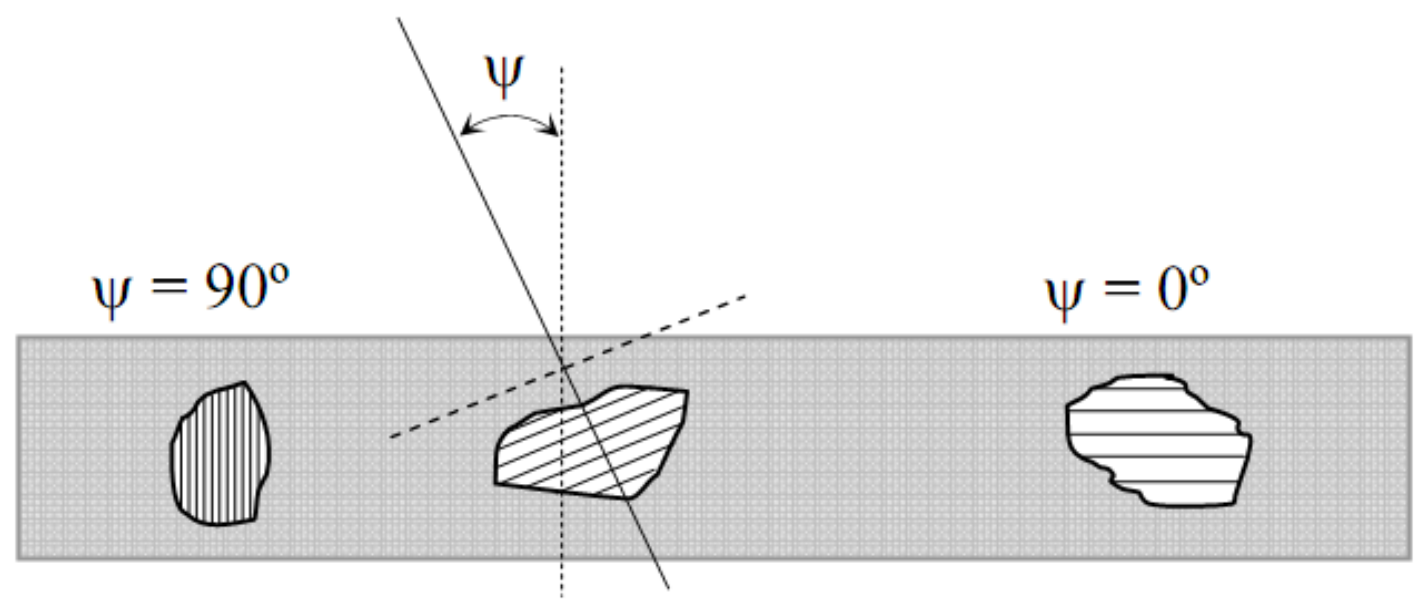

Figura 27 - Representação de $\psi$ em um material policristalino. Adaptado de Eigenmann e Macherauck (1996).

O cálculo da tensão residual utilizando difratometria de raios $X$ baseia-se na determinação de duas componentes de deformação $\varepsilon_{\phi \psi 1}$ e $\varepsilon_{\phi \psi 2}$ nas direções determinadas pelos ângulos $\phi$ (ângulo entre uma direção fixa no plano da amostra e a projeção no plano normal do plano de difração) e $\psi$ (ângulo entre a normal da superfície da amostra e a normal do plano de difração) (Figura 28) de um sistema de coordenadas esféricas (ASSIS et al., 2008). Definindo a relação entre o plano da tensão e a distorção da superfície da amostra, podemos calcular a relação da tensão para um dado grau de inclinação da superfície da amostra. A inclinação do plano de 
difração e o plano da amostra são definidos como $\psi$. Tomando um ponto qualquer na superfície da amostra como foco da medição, podemos definir $\sigma_{1}, \sigma_{2}$ e $\sigma_{3}$ como as tensões principais e $\varepsilon_{1}, \varepsilon_{2}$ e $\varepsilon_{3}$ como as deformações principais (Figura 28). Devido ao plano de tensão, o valor de $\sigma_{3}$ para o eixo $Z$ é zero. No entanto, existe uma deformação $\varepsilon_{3}$, na direção perpendicular ao plano da amostra, causado pelas outras duas tensões principais (PREVÉY, 1986).

A lei da transformação do tensor das deformações permite determinar a deformação, $\varepsilon$, em função das deformações e tensões principais, como:

$$
\varepsilon=\alpha_{1}^{2} \cdot \varepsilon_{1}+\alpha_{2}^{2} \cdot \varepsilon_{2}+\alpha_{3}^{2} \cdot \varepsilon_{3}
$$

onde $\alpha_{1}, \alpha_{2}$ e $\alpha_{3}$ são os cossenos diretores do vetor de deformação $\varepsilon_{\emptyset \psi}$, com relação às direções das deformações principais $\varepsilon_{1}, \varepsilon_{2}$ e $\varepsilon_{3}$.

Para desenvolver a equação básica que relaciona deformação e tensão é necessário escrever as tensões em função de um sistema de coordenadas. O sistema escolhido, geralmente, é o de coordenadas ortonormais coincidentes com os eixos principais da amostra, ou seja, direção transversal (eixo $\mathrm{S}_{2}$ ), direção normal (eixo $S_{3}$ ) e direção do eixo $S_{1}$ (Figura 29), de modo que, $S i \times S j=\delta i j$ (com $\delta i j=0$ se $i \neq j$, e $\delta i j=1$ se $i=j)$.

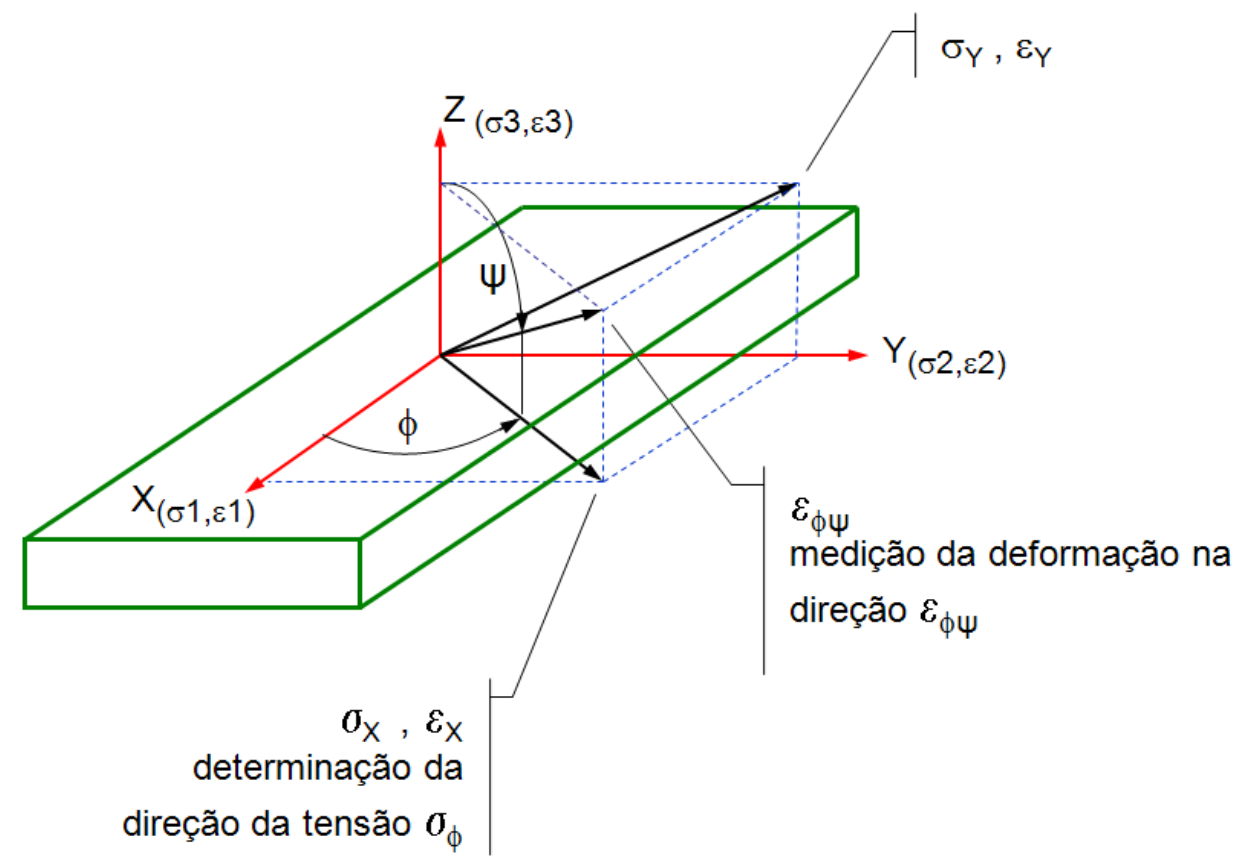

Figura 28 - Direções da tensão e deformação principais. Adaptado de Rigaku (2003). 
Quando a medida é efetivada utiliza-se um sistema de eixos que é o do laboratório (sistema de referência dentro do cristal que está sendo medido) (Figura 29), isto é, os eixos $L_{1}, L_{2}$ e $L_{3}$ (direção normal à família de planos que difrata), de modo que:

$$
\sigma_{i j}^{\prime}=w_{i k} w_{j l} \sigma_{k l}
$$

onde $\sigma_{k l}$ é o tensor de tensão no sistema $\mathrm{S}_{i}$; e $\sigma^{\prime}{ }_{i j}$ é o tensor de tensão no sistema $L_{i}, e:$

$$
\varepsilon^{\prime}{ }_{i j}=w_{i k} w_{j l} \varepsilon_{k l}
$$

onde $\varepsilon_{k l}$ é o tensor de deformação no sistema $S_{i}$; e $\varepsilon^{\prime}{ }_{i j}$ é o tensor de deformação no sistema $L_{i}$, e $w_{i k}$ é a matriz $\left(w_{33}\right)$ de transformação de coordenadas dada por:

$$
w_{33}=\left[\begin{array}{ccc}
\cos \phi \cos \psi & \operatorname{sen} \phi \cos \psi & -\operatorname{sen} \psi \\
-\operatorname{sen} \phi & \cos \phi & 0 \\
\cos \phi \operatorname{sen} \psi & \operatorname{sen} \phi \operatorname{sen} \psi & \cos \psi
\end{array}\right]
$$

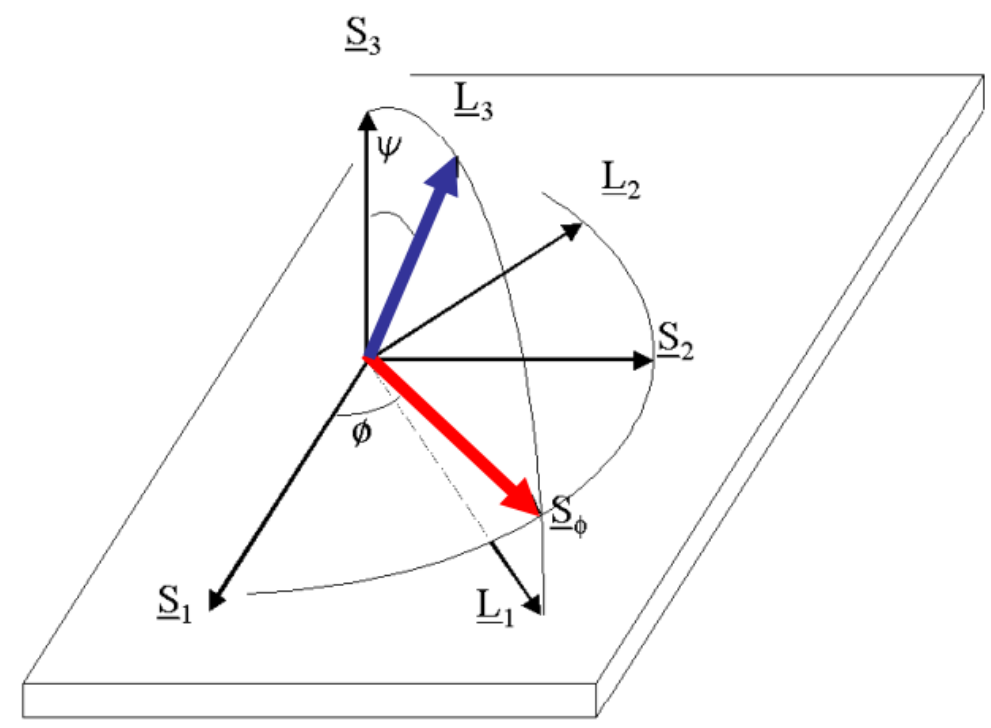

Figura 29 - Sistema de coordenadas do laboratório $\left(L_{i}\right)$ em relação ao sistema de referência da amostra $\left(S_{i}\right)$. $S_{ø}$, direção da tensão. $L_{3}$ é a normal à família de planos que difrata.

Sabendo-se que a relação da tensão associada é:

$$
\varepsilon_{i}=\frac{1}{E}\left(\sigma_{i}-v\left(\sigma_{j}+\sigma_{k}\right)\right) \operatorname{com} i, j \text { e } k=1,2,3
$$


Obtém-se:

$$
\varepsilon_{\phi \psi}=\left[\frac{1+v}{E}\left(\sigma_{1} \alpha_{1}^{2}+\sigma_{2} \alpha_{2}^{2}\right)\right]-\left[\frac{v}{E}\left(\sigma_{1}+\sigma_{2}\right)\right]
$$

onde $E$ é o módulo de elasticidade e $v$ é o coeficiente de Poisson (constantes elásticas do material). Da Figura 28, as tensões principais $\sigma_{1}, \sigma_{2}$ e $\sigma_{3}$ são dadas pelas relações:

$$
\begin{gathered}
\alpha_{1}=\cos \phi \cdot \operatorname{sen} \psi \\
\alpha_{2}=\operatorname{sen} \phi \cdot \operatorname{sen} \psi \\
\alpha_{3}=\cos \psi=\sqrt{1-\operatorname{sen}^{2} \psi}
\end{gathered}
$$

Substituindo as equações (41) e (42) na equação (40):

$$
\varepsilon_{\phi \psi}=\left[\frac{1+v}{E}\left(\sigma_{1} \cos ^{2} \phi+\sigma_{2} \operatorname{sen}^{2} \phi\right) \operatorname{sen}^{2} \psi\right]-\left[\frac{v}{E}\left(\sigma_{1}+\sigma_{2}\right)\right]
$$

onde, $\psi$ e $\phi$ são os ângulos polares e azimutais, $\sigma_{\phi}$ é a componente média da tensão e $\sigma_{1}$ e $\sigma_{2}$ são as tensões principais. A componente de tensão $\sigma_{\varnothing}$ pode ser expressa como:

$$
\sigma_{\phi}=\sigma_{1} \cos ^{2} \phi+\sigma_{2} \operatorname{sen}^{2} \phi
$$

Substituindo a equação (45) na equação (44), obtém-se a deformação na superfície da amostra em um ângulo $\phi$, em função da tensão superficial:

$$
\varepsilon_{\phi \psi}=\left[\frac{1+v}{E}\left(\sigma_{\phi}\right) \operatorname{sen}^{2} \psi\right]-\left[\frac{v}{E}\left(\sigma_{1}+\sigma_{2}\right)\right]
$$

A equação acima relaciona a tensão $\sigma_{\phi}$, em uma dada direção definida pelo ângulo $\psi$ da deformação. Derivando-se, $\varepsilon_{\phi \psi}$, da equação (46) em relação a $\operatorname{sen}^{2} \psi$, e da lei de Bragg [eq. (33)] em função de $2 \theta$, que equivale a: $\Delta d / d=-\cot \theta(\Delta 2 \theta / 2)$, obtém-se:

$$
\sigma_{\phi}=\frac{E}{2(1+v)} \cot \theta \frac{\Delta 2 \theta}{\operatorname{sen}^{2} \psi}
$$


Esta equação [eq. (47)] estabelece a relação entre as mudanças na posição angular e as tensões medidas pela difração de raios X. Assim, para determinar qualquer componente de tensão ao longo da profundidade é necessário medir os ângulos de difração correspondentes às reflexões dos planos cristalinos com normais caracterizadas por ângulos $\psi$ (Figura 28). As variações do ângulo $\psi$ se realizam por inclinações da superfície da amostra em relação ao feixe de raios $X$ incidente. Nesta técnica, conhecida como a técnica de Múltiplas Exposições (MACHERAUCH; KLOSS, 1986), o comprimento de onda é constante para as medidas de difração e o ângulo $\theta$ de incidência de raios $X$ é fixo, resultando em medidas de deformação em uma única família de planos, que é previamente escolhida por apresentar melhor resolução do ângulo $\theta$ de difração (BARBOSA, 1998). Para obter resultados com maior precisão, é necessário que a medição do ângulo $\theta$ seja realizada em mais que duas posições de $\psi\left(\psi_{1}, \psi_{2}, \psi_{3}, \psi_{n}\right)$. Desta maneira, os valores angulares de $\theta_{n}\left(\theta_{1}, \theta_{2}, \theta_{3}, \theta_{n}\right)$, correspondentes a cada ângulo $\psi_{n}$, são plotados em função de $\operatorname{sen}^{2} \psi$.

No entanto, é importante ressaltar que a equação (45) só é válida se os cristais têm um comportamento mecânico linear elástico, o agregado policristalino é homogêneo e quase-isotrópico (material sem textura ${ }^{12}$ ) e se a composição do material, suas deformações e suas tensões são constantes em todo o volume irradiado pelos raios X (SPRAUEL; CASTEX, 1991). Além disso, quando se utiliza o método de $\operatorname{sen}^{2} \psi$, para medir tensão residual, por exemplo, em filmes finos, é necessário utilizar uma variação conhecida como ângulo de incidência rasante, em que o feixe de raios $X$ atinge a superfície da amostra em ângulos rasos (pequenos ângulos de incidência do feixe de raios $X$ em relação à superfície da amostra), fazendo com que a penetração dos raios $X$ seja menos profunda (apenas nas camadas atômicas mais externas) e a maior parte do feixe incidente seja refletido especularmente na superfície.

12 Para avaliar a influência da textura em medidas de tensão residual é necessário o conhecimento da função distribuição de orientações. Esta função nos fornece a fração volumétrica de grãos orientados no material, a partir da qual se quantifica a anisotropia das propriedades físicas dos materiais (LIMA, 1992). 


\subsection{MÉTODO DOS ELEMENTOS FINITOS}

O método dos elementos finitos (MEF) é uma das técnicas de solução numérica aproximada, a qual permite analisar e resolver diversos tipos de problemas físicos, decompondo o domínio do problema em vários subdomínios de geometria simples que recebem o nome de elemento finito. Assim, as condições de equilíbrio são estabelecidas para cada elemento finito que logo por combinação deles formam um sistema de equações matriciais (BATHE, 1996; HUGHES, 1987).

Por meio do MEF é possível obter soluções numéricas para sistemas irregulares ou complexos da engenharia. Com essa finalidade, o método considera um componente contínuo como um conjunto de elementos finitos interligados. Exigese, nestes elementos interligados, que os deslocamentos sejam compatíveis e que as forças internas estejam em equilíbrio em determinados pontos compartilhados por vários elementos (cada um com uma função de aproximação de deslocamentos associada), pontos estes conhecidos como nós. A essa divisão do domínio dá-se o nome de malha ou rede de elementos finitos. Em essência o MEF é um procedimento de discretização do sistema em estudo, já que ele expressa o comportamento em qualquer ponto do elemento, em termos de um número finito de deslocamentos nos pontos nodais multiplicados por funções de interpolação (ou funções de forma), que são geralmente polinômios de pequeno grau, as quais definem o comportamento no interior de cada elemento a partir do comportamento dos nós. Assumir várias relações constitutivas permite que os resultados sejam expressos em deformação ou tensão ao invés de deslocamento (GALLAGHER, 1975; ZIENKEWICZ, 1971).

A primeira etapa no processo de modelagem computacional de um fenômeno físico consiste na identificação dos fatores que influenciam de maneira relevante no problema. Isto implica na escolha adequada dos princípios físicos e das variáveis dependentes e independentes que descrevem o problema, resultando em um modelo matemático constituído por um conjunto de equações diferenciais parciais, entre as quais se incluem a equação de Poisson, Laplace, Helmhotz, Navier-Stocks etc. E a segunda etapa do processo, consiste em obter a solução do modelo matemático, tarefa esta atribuída aos métodos numéricos (RIBEIRO, 2004). 
Em uma análise de um problema que envolve comportamentos não lineares, a solução não pode ser calculada pela resolução de equações lineares. Ao contrário, obtém-se a solução especificando-se o carregamento (térmico, mecânico etc.) como função do tempo e aumentando o tempo para obter a resposta não-linear. Assim, o programa de elementos finitos divide a simulação em determinado número de incrementos e encontra a configuração aproximada de equilíbrio no final de cada incremento de tempo (BORTOLETO, 2010). 


\section{OBJETIVOS DO TRABALHO}

Implementar um novo modelo numérico, acoplando as informações fornecidas pelo programa AC3, que prevê as curvas de transformação, a evolução da temperatura, as curvas de resfriamento e a microestrutura do material a um modelo de elementos finitos, considerando acoplamento termo-mecânico e comportamento não linear elasto-plástico, a fim de analisar a evolução, distribuição e a magnitude das tensões residuais que resultam da conjugação das variações volumétricas provenientes dos gradientes térmicos e das transformações de fase, durante tratamento térmico de têmpera de cilindros de aço de médio carbono AISI/SAE 1045, 4140 e 4340.

Verificar e calibrar o modelo numérico através da medição das tensões residuais utilizando a técnica de difração de raios $X$. 


\section{MATERIAIS E MÉTODOS}

\subsection{MATERIAIS}

Foram utilizados cilindros de $100 \mathrm{~mm}$ de comprimento e 25,4 mm de diâmetro (cilindro semi-infinito), de aços de médio carbono (0,4 e 0,45\% C) AISI/SAE 4140, 4340 e 1045. As análises de composição química (Tabelas 4, 5 e 6) desses aços foram feitas utilizando as técnicas de espectroscopia de plasma e método de combustão (C, S). As composições obtidas foram comparadas com as normas SAE J404/09 e SAE J 403/09.

Tabela 4 - Composição química do aço AISI 4140

\begin{tabular}{ccc}
\hline Elemento & Valores Encontrados (\%) & Valores Especificados (\%) \\
\hline Carbono & 0,39 & $0,38-0,43$ \\
Cromo & 1,01 & $0,80-1,10$ \\
Enxofre & 0,025 & 0,040 máx. \\
Fósforo & 0,018 & 0,030 máx. \\
Manganês & 0,87 & $0,75-1,00$ \\
Molibdênio & 0,17 & $0,15-0,25$ \\
Níquel & 0,12 & ------- \\
Silício & 0,17 & $0,15-0,35$ \\
\hline
\end{tabular}

Tabela 5 - Composição química do aço AISI 4340

\begin{tabular}{ccc}
\hline Elemento & Valores Encontrados (\%) & Valores Especificados (\%) \\
\hline Carbono & 0,41 & $0,38-0,43$ \\
Cromo & 0,82 & $0,70-0,90$ \\
Enxofre & 0,004 & 0,040 máx. \\
Fósforo & 0,010 & 0,030 máx. \\
Manganês & 0,77 & $0,60-0,80$ \\
Molibdênio & 0,23 & $0,20-0,30$ \\
Níquel & 1,74 & $1,65-2,00$ \\
Silício & 0,19 & $0,15-0,35$ \\
\hline
\end{tabular}


Tabela 6 - Composição química do aço AISI 1045

\begin{tabular}{ccc}
\hline Elemento & Valores Encontrados (\%) & Valores Especificados (\%) \\
\hline Carbono & 0,44 & $0,43-0,50$ \\
Cromo & 0,017 & ------- \\
Enxofre & 0,008 & 0,050 máx. \\
Fósforo & 0,016 & 0,030 máx. \\
Manganês & 0,86 & $0,60-0,90$ \\
Molibdênio & 0,0007 & ------- \\
Níquel & 0,0062 & ----- \\
Silício & 0,15 & ------- \\
\hline
\end{tabular}

A análise do teor de carbono e enxofre desses materiais foi realizada pelo método da combustão em equipamento LECO, enquanto a análise dos outros elementos foi feita por espectrometria por plasma no Laboratório do Centro Tecnológico de Controle de Qualidade Falcão Bauer.

Depois de usinados (até $\varnothing 25 \mathrm{~mm}$ ) as superfícies dos corpos de prova, foram lixadas até a grana 1200 antes dos tratamentos térmicos a fim de evitar qualquer efeito adicional da rugosidade ou oxidação da superfície, uma vez que a camada de óxido pode reduzir a taxa de resfriamento e afetar os resultados de temperabilidade (SEGERBERG, 1984) e a rugosidade pode apresentar variações na aquisição dos dados das curvas de resfriamento durante a fase de borbulhamento (PRABHU; FERNANDES, 2007). Além disso, o lixamento teve como objetivo evitar deslocamentos ou erros de leitura nos ensaios de difração de raios $X$.

\subsection{MÉTODOS}

\subsubsection{Tratamento térmico}

A modelagem efetuada visou determinar as tensões residuais originadas pelo ciclo térmico associado à têmpera em água, que por sua baixa viscosidade e alto calor específico tornam-na um meio de têmpera rápido. Para isto as peças foram colocadas em caixas cobertas com carvão para evitar o fenômeno de 
descarbonetação, uma vez que este pode alterar drasticamente o estado final de tensões residuais na superfície (TODINOV, 1999), e em seguida foram austenitizadas até total homogeneização da temperatura. A temperatura de austenitização para o cilindro de aço AISI 4140 foi de $850^{\circ} \mathrm{C}$ e para os de aço AISI 4340 e 1045 foi de $830^{\circ} \mathrm{C}$, com 50 minutos de permanência no forno, nos três casos. Posteriormente, cada peça foi submetida ao tratamento térmico de têmpera em um banho de água em temperatura ambiente, com intensa agitação.

As estimativas das temperaturas de austenitização foram calculadas a partir das temperaturas de transformação de fases $\mathrm{Ac}_{3}$ da equação de Andrews (1965) apresentada a seguir:

$$
\begin{aligned}
A c_{3}\left({ }^{\circ} \mathrm{C}\right)= & 910-203 \sqrt{C}-15,2 \mathrm{Ni}+44,7 \mathrm{Si}+104 \mathrm{~V}+31,5 \mathrm{Mo}+13,1 \mathrm{~W} \\
& -(30 \mathrm{Mn}+11 \mathrm{Cr}+20 \mathrm{Cu}-700 \mathrm{P}-400 \mathrm{Al}-120 \mathrm{As}-400 \mathrm{Ti})
\end{aligned}
$$

Aos resultados da equação (48) foram somados $50^{\circ} \mathrm{C}$, a fim de estimar a temperatura de austenitização, estando esses resultados dentro das faixas sugeridas pelo ASM Metals Handbook (1991).

\subsubsection{Análise metalográfica}

A análise metalográfica dos aços AISI/SAE 4140, 4340 e 1045 foram feitas seguindo os procedimentos de corte e lixamento até a grana 1000 para o desbaste mais grosseiro e polimento final com suspensões com alumina de granulometria $1 \mathrm{e}$ 0,3 $\mu \mathrm{m}$, de acordo com o procedimento metalográfico padrão (ASTM, 2007). Para revelação da microestrutura do aço 1045 foi empregado o reagente químico, usualmente aplicado na revelação de aços carbono, Nital 2\%, álcool etílico e ácido nítrico (2ml de HNO3 em 98ml de álcool etílico, 95\%), por imersão durante $10 \mathrm{~s}$ seguido por $\sim 5 \mathrm{~s}$ em reagente Vilella $(0,5 \mathrm{ml}$ ácido pícrico; $2,5 \mathrm{ml} \mathrm{HCl}, 50 \mathrm{ml}$ $\mathrm{C}_{2} \mathrm{H}_{5} \mathrm{OH}$ ), já para os aços 4140 e 4340 foi utilizado o Le Pera modificado (ALVES, 2008) constituído por uma parte de $1 \%$ metabissulfito de sódio $\left(\mathrm{Na}_{2} \mathrm{~S}_{2} \mathrm{O}_{5}\right)$ diluído em água e duas partes de $4 \%$ de ácido pícrico $\left(\mathrm{C}_{6} \mathrm{H}_{3} \mathrm{~N}_{3} \mathrm{O}_{7}\right)$ diluído em álcool etílico. Após ataque as amostras foram lavadas com água fria e depois com álcool etílico, 
sendo posteriormente secas com ar quente forçado e submetidas ao exame em microscópio óptico Philips modelo XL30, tendo sido obtidas as micrografias apresentadas nos resultados.

\subsubsection{Medidas de fração volumétrica}

De cada amostra, após polimento e ataque, foram capturadas imagens ao longo da superfície transversal preparada, evitando-se regiões que, eventualmente, apresentaram alguma imperfeição de polimento e as regiões muito próximas às bordas, onde a microestrutura apresentou uma fina camada descarbonetada e oxidada. Mantendo-se a imagem sempre bem-focada, foram capturadas imagens com ampliações de 200, 500 e 1000x em cada amostra. Para análise quantitativa das frações volumétricas, as imagens foram analisadas através do software Image $\mathrm{J}$ e de contagem sistemática de pontos explicados a seguir.

\subsubsection{Estereologia}

Após a captura das imagens, de cada amostra, elas foram analisadas por meio do software Image J (Image Processing and Analysis in Java), que é um processador e analisador de imagens em Java desenvolvido com arquitetura aberta, permitindo que os usuários construam macros e plug-ins.

As análises foram executadas compilando-se as imagens de cada amostra, em pacotes diferenciados por regiões. Essas imagens foram duplicadas e convertidas para 8 bits para facilitar a segmentação: aplicou-se para análise das imagens, um limite de detecção (threshold), recurso pelo qual o software estabelece o limiar entre as fases claras e escuras de uma imagem, escolhendo-se o valor de forma a se separar, o melhor possível, as áreas claras das áreas escuras. O valor do "threshold" obtido foi então aplicado nas imagens do pacote e, com o recurso de análise de imagem, foi feita a contabilização dos percentuais das áreas de cada micrografia (Figura 30). Com auxílio do software Excel foram obtidas as médias aritméticas e os desvios padrões desses valores para cada conjunto de imagens. 

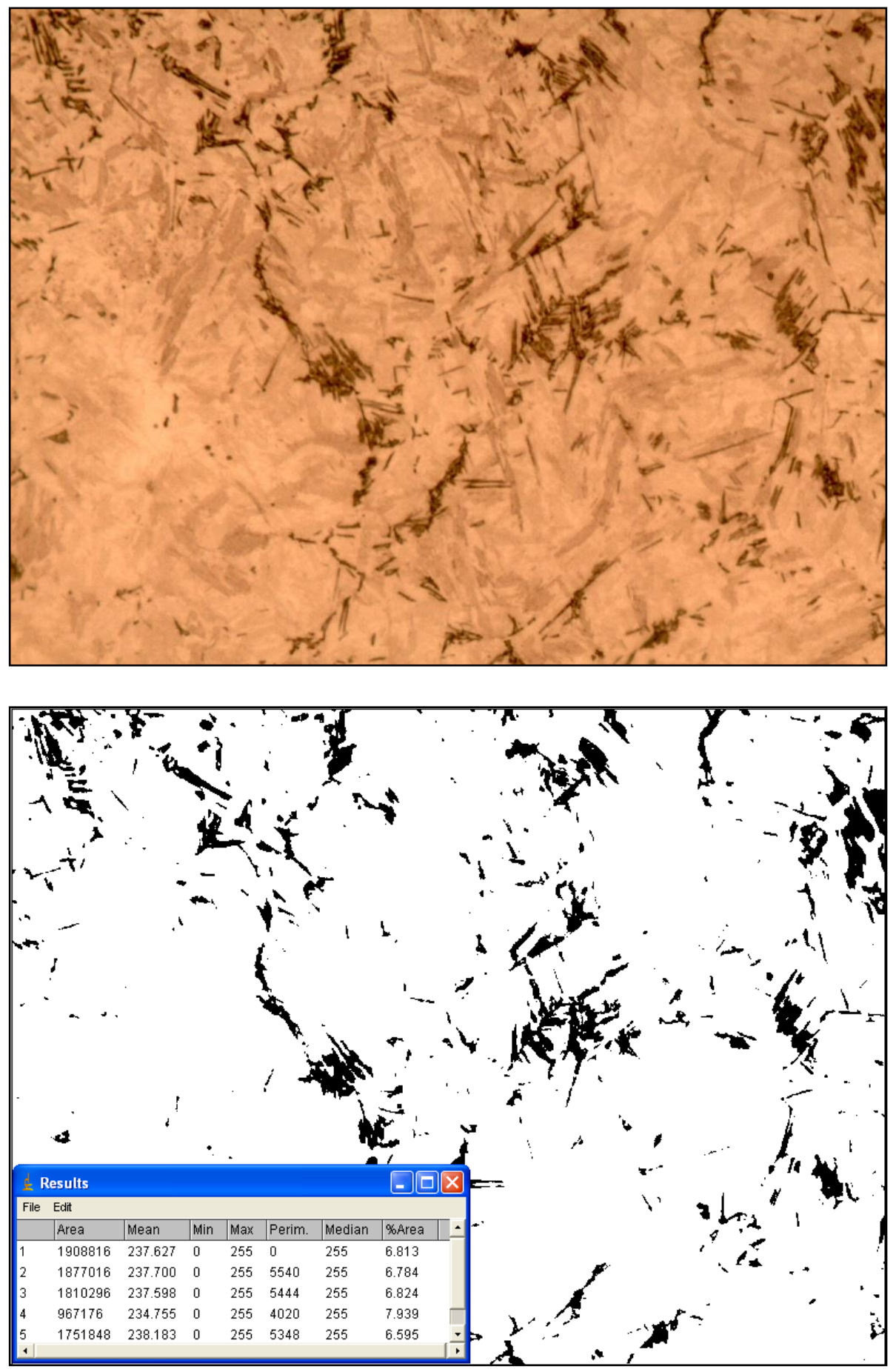

Figura 30 - Processamento da imagem, utilizando-se o software Image J.

\subsubsection{Fração de pontos}

Utilizou-se as especificações da norma ASTM E 562-02 (ASTM, 2002), de determinação da fração volumétrica pela contagem sistemática manual de pontos. Este método consiste em sobrepor uma rede de pontos sobre a fotomicrografia. $O$ 
número de pontos que caem dentro da fase de interesse, dividido pelo número total de pontos da rede, dá a relação numericamente igual à fração volumétrica do aspecto selecionado. Para quantificar a proporção das fases, foram utilizadas malhas de até 391 pontos (Figura 31) sobrepostas na fotomicrografia de interesse.
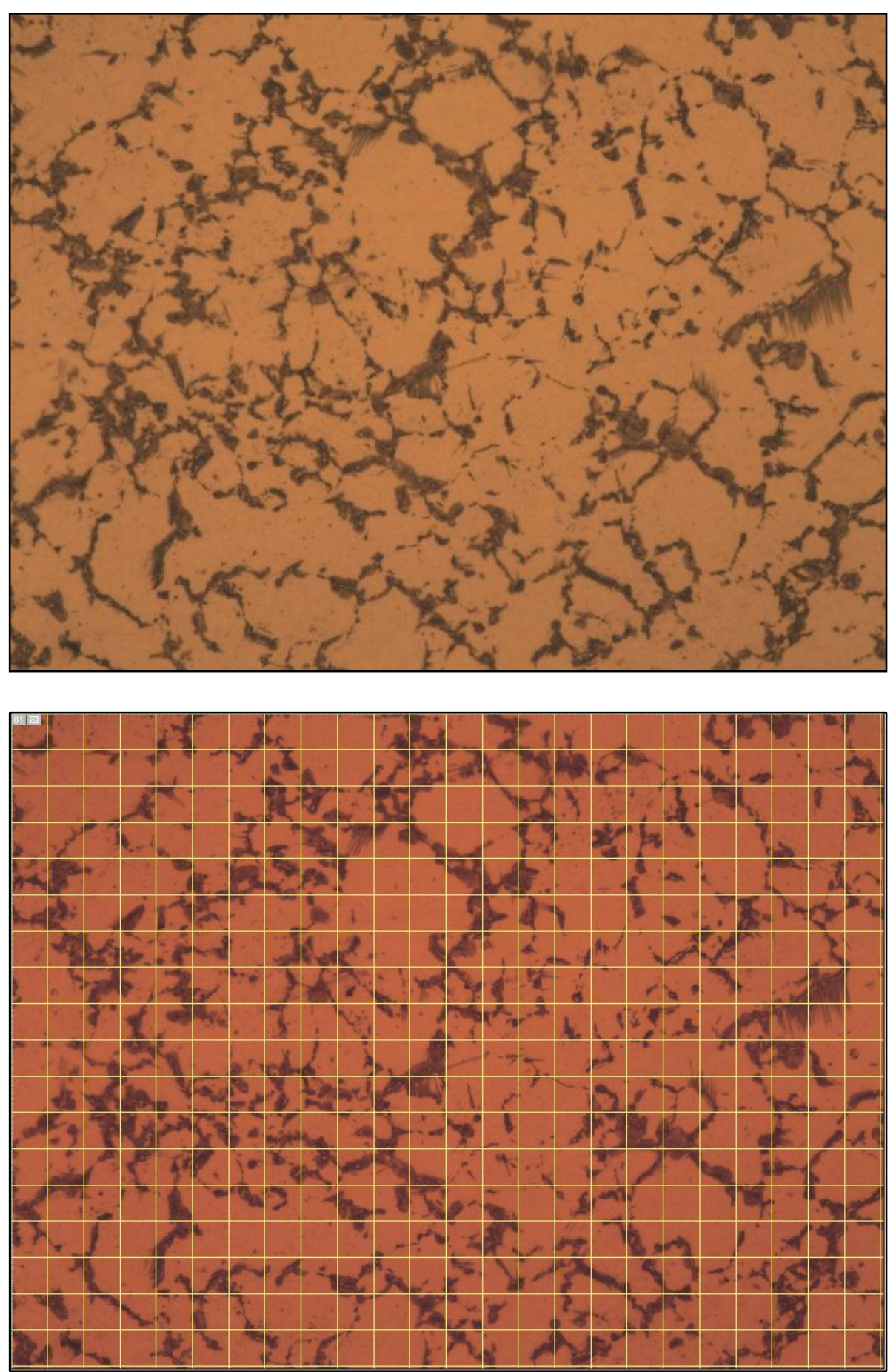

Figura 31 - Rede para determinação da fração volumétrica. 


\subsubsection{Dureza}

As amostras foram cortadas transversalmente em duas metades para se realizar as medidas que possibilitaram o levantamento do perfil de dureza (Rockwell C) das seções médias do corpo de prova. Estes dados foram colocados em gráficos gerando curvas em "U", visando evidenciar a região de transição da mudança de fase, a avaliação da eficiência do processo de têmpera e a validação do modelo desenvolvido no programa AC3 (seção 4.2.7.1) que, usando uma soma linear da dureza característica de cada microconstituinte calcula a dureza total do material (SEDIGHI; SALEK, 2008).

\subsubsection{Modelagem}

\subsubsection{Programa AC3}

O programa AC3 foi desenvolvido em linguagem de programação $C$ de alto nível com uma sintaxe bastante estruturada e flexível, criado pela empresa britânica Marathon Monitors, Ltda (AC3, 1994). Trata-se de um programa extremamente amigável, de fácil utilização que contém uma biblioteca de aços para construção mecânica e que prevê com razoável precisão as curvas $\mathrm{RC}$, as microestruturas e as durezas dos aços modelados. O acoplamento do AC3 com o Abaqus permite modelar tensões residuais de um grande número de aços da biblioteca contida no programa, com diferentes geometrias, condições de austenitização e de resfriamento. O programa AC3 Converter desenvolvido nesse trabalho, permite alimentar o Abaqus com todas as informações e tabelas numéricas geradas pelo AC3.

Assim, o modelo matemático feito utiliza as informações do software AC3 de modelagem de tratamentos térmicos: curvas de transformação, curvas de resfriamento, microestrutura e dureza do material em 20 posições entre a superfície e o centro do cilindro, para alimentar um modelo não linear elasto-plástico de 
acoplamento termo-mecânico desenvolvido através do método dos elementos finitos, para previsão de tensões residuais do cilindro temperado.

Depois de serem definidos a composição do material, a geometria da peça, a temperatura e o tempo de austenitização, devem ser determinadas as condições de contorno para o resfriamento (Figura 32). Inicialmente todos os nós se encontram na temperatura de austenitização. A transferência de calor dentro do componente durante a têmpera é descrita matematicamente através da equação de condução térmica de Fourier, equação (29). A superfície em contato com o meio de resfriamento tem a condição de resfriamento definida pela equação (30). A análise finaliza os cálculos quando a temperatura da amostra atinge a temperatura do meio de resfriamento.

Para cada elemento, em um primeiro momento, calcula-se a soma da nucleação de Scheil, através da equação (19), para os diferentes valores de Scheil usados para a transformação da perlita e bainita, conforme seja o caso. Se a soma de Scheil atinge a unidade, são calculados os parâmetros $n$ e $c$ da equação (13) a partir do diagrama TTT, e depois esta equação [eq. (13)] e a equação (3) são usadas para calcular as porcentagens de fase transformadas, tendo em conta a austenita disponível e a dependência da temperatura para as quantidades de cada fase.

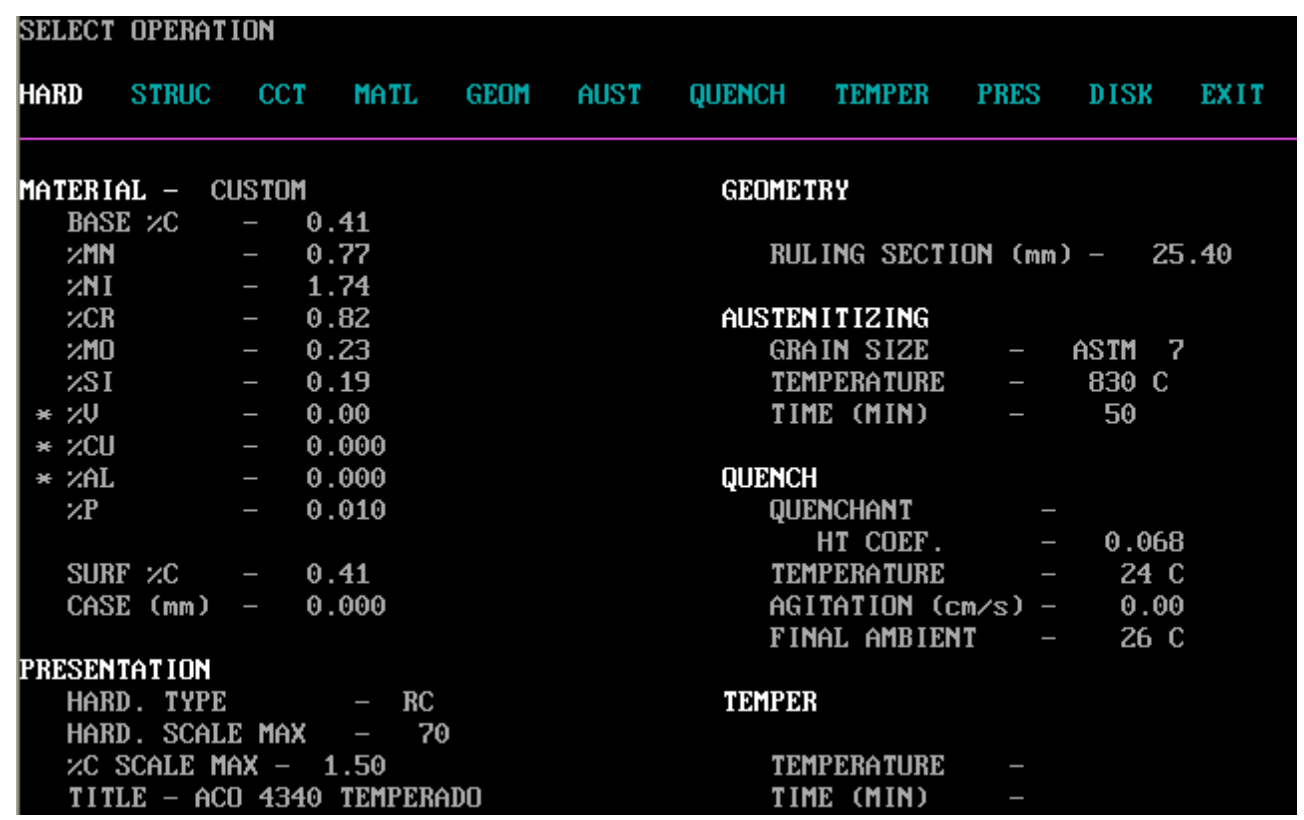

Figura 32 - Definição dos parâmetros iniciais no programa AC3 
Desta maneira, o programa AC3 calcula matematicamente a evolução da microestrutura em qualquer ponto da peça, ao longo do tempo (ver Figura 57), pela sobreposição da curva de resfriamento no diagrama de resfriamento contínuo. As curvas de resfriamento são calculadas, usando a condutividade térmica, capacidade calorífica, temperatura do meio de têmpera e o coeficiente de transferência de calor para a superfície (SEDIGHI; SALEK, 2008). A Figura 33 apresenta uma representação esquemática do programa AC3. O programa divide a curva de resfriamento em 54 intervalos iguais e avalia o estado de transformação para cada ponto, determinando se o ponto está em uma região de transformação e em caso positivo, avaliando quantitativamente quanto de cada fase há no interior do material.

$$
\begin{array}{r|r}
\text { Aço } & \begin{array}{l}
\text { Composição Química } \\
\text { Geometria, } \\
\text { Condições de austenitização }
\end{array} \\
\text { Condições de Têmpera } & \left\{\begin{array}{l}
\text { Tamanho de grão } \\
\text { Temperatura } \\
\text { Tempo }
\end{array}\right. \\
\begin{array}{l}
\text { Coeficiente de transferência de calor } \\
\text { Temperatura } \\
\text { Agitação }
\end{array}
\end{array}
$$

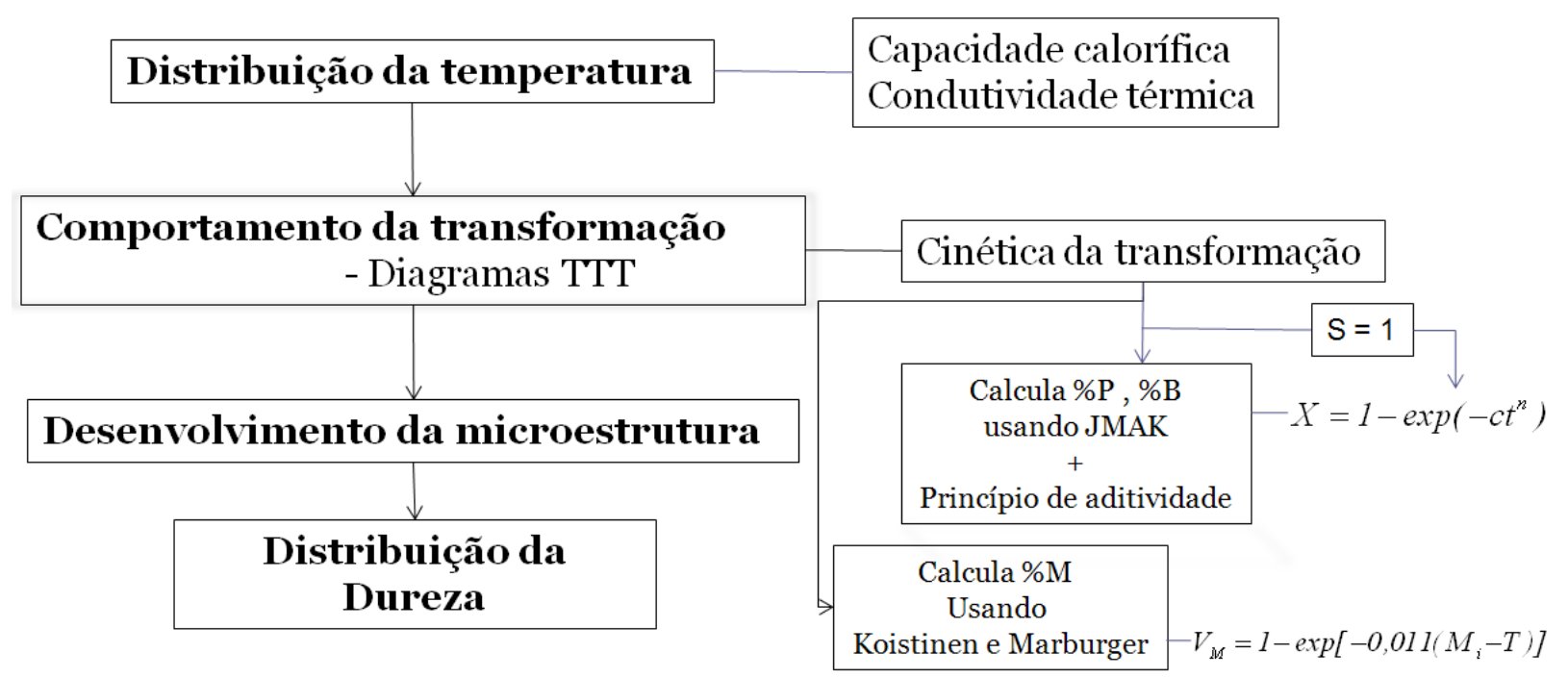

Figura 33 - Fluxograma com as inter-relações desenvolvidas no programa AC3

\subsubsection{Programa AC3 Converter}

Para facilitar a análise dos dados de simulações do AC3 e o acoplamento entre o AC3 e o modelo de elementos finitos, desenvolvemos o programa AC3 Converter escrito em linguagem Java (ECKEL, 2006). O programa AC3 Converter, 
que utiliza a biblioteca de interfaces gráficas SWT (NORTHOVER; WILSON, 2004) exibe uma caixa de texto na qual se lê a saída da simulação realizada pelo AC3 (Figura 34). O programa então gera uma tabela conforme ilustra a Figura 35, na qual é mostrada a fração de cada constituinte em cada anel, para um passo intermediário (step 14) de transformação. Nessa figura se observa, que o resultado fornecido pelo programa AC3, divide o cilindro em 20 posições, desde a superfície (esquerda) até o centro (direita), e no eixo $\mathrm{Y}$ é possível acompanhar as porcentagens de volume transformadas durante o tratamento térmico. Uma das grandes vantagens do programa AC3 que permite acompanhar as porcentagens formadas em cada anel em função da temperatura e do tempo (como mostrado na Figura 57). As letras AA e MM, BB e PP nas Figuras 34 e 35, representam austenita, martensita, bainita e perlita, respectivamente, onde cada par de letras corresponde a aproximadamente $5 \%$ em volume de cada microconstituinte.

O programa AC3 Converter desenvolvido para as análises também permite que o usuário salve a saída da simulação em um arquivo texto para utilização futura, ou que abra um arquivo previamente salvo a fim de gerar novamente a tabela.

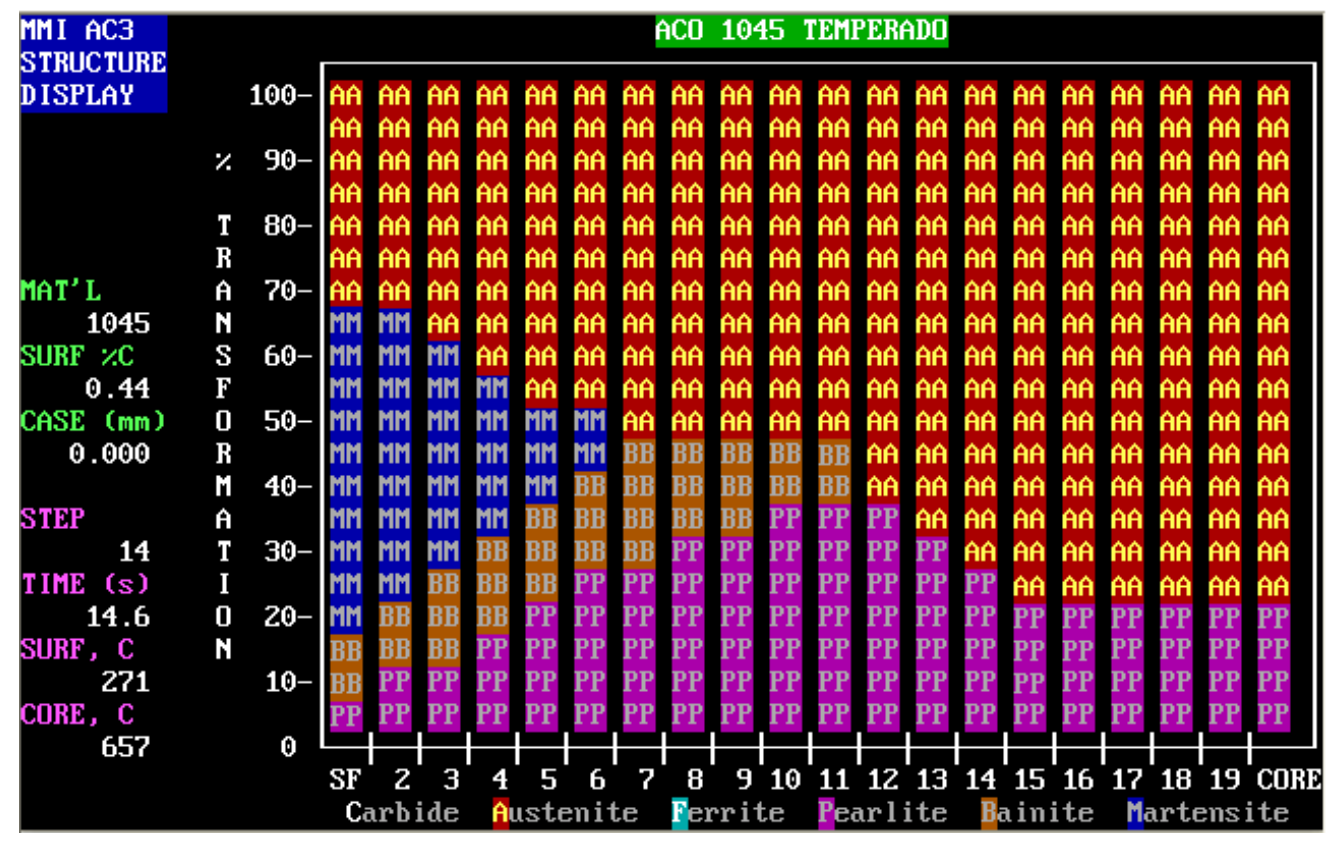

Figura 34 - Imagem de saída do AC3 em um passo (step 14) intermediário da simulação. AA, MM, BB e PP representam austenita, martensita, bainita e perlita, respectivamente. 


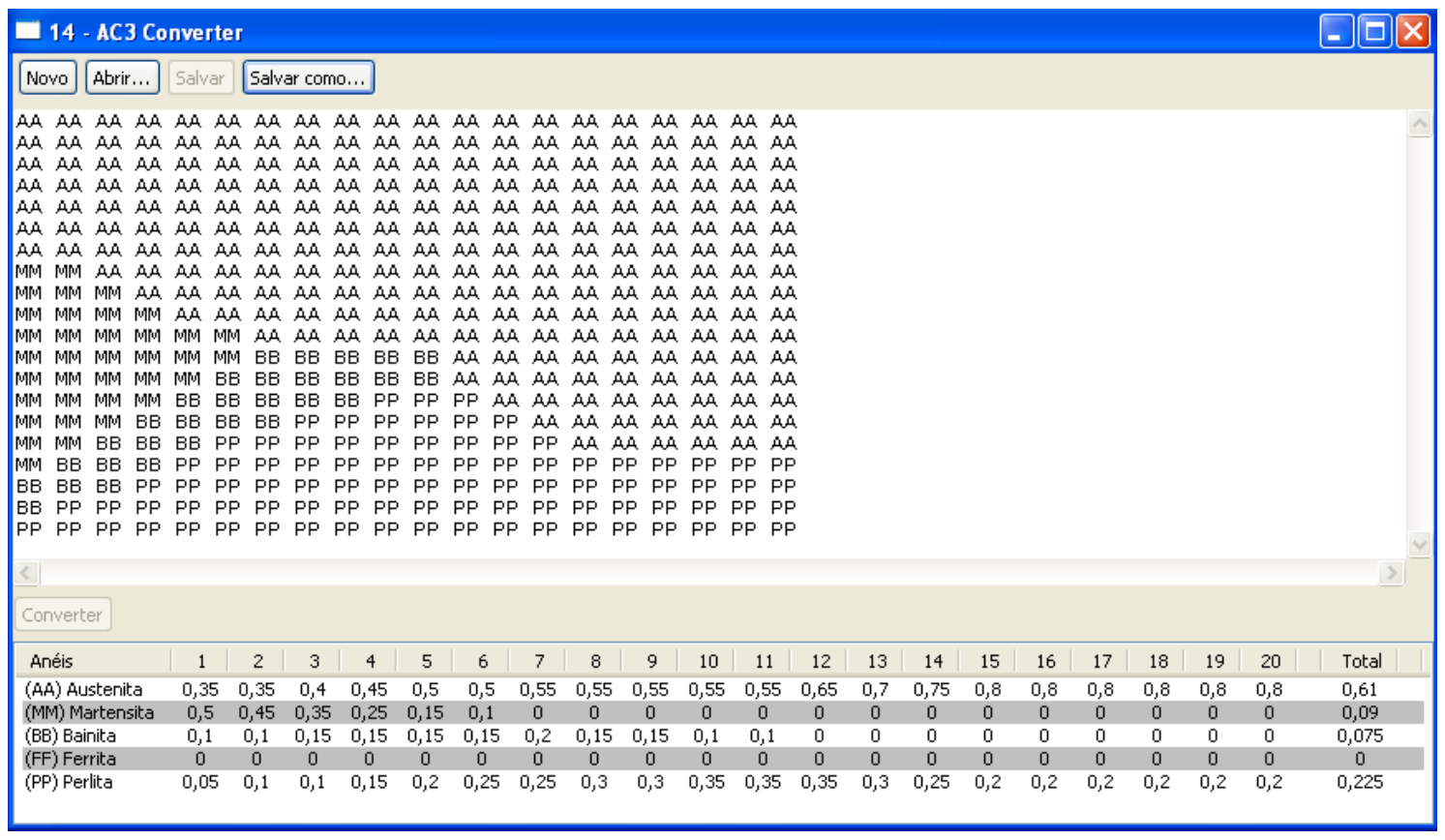

Figura 35 - Programa AC3 Converter

\subsubsection{Modelagem pelo Método dos Elementos Finitos}

A modelagem realizada para previsão dos campos de tensões e deformações foi desenvolvida no software ABAQUS 6.9 de modelação não linear por elementos finitos. De maneira esquemática o modelo no Abaqus pode ser descrito de acordo com a Figura 36. O ABAQUS tem a capacidade de modelar as propriedades elastoplásticas do material em função da temperatura e de resolver o acoplamento da transformação de fase com as variações de temperatura, em função da transferência de calor. 


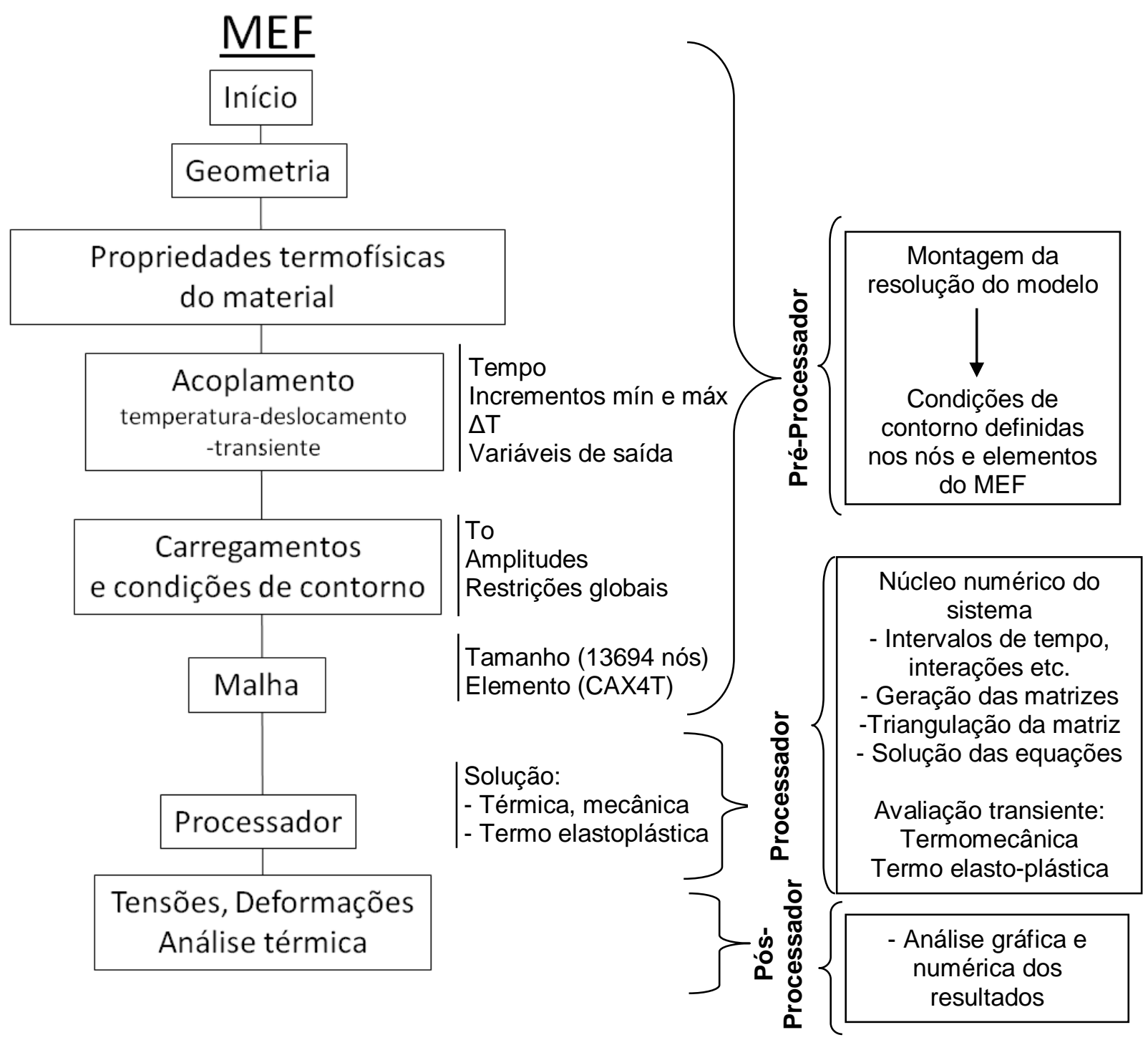

Figura 36 - Fluxograma do modelo de elementos finitos em Abaqus.

$\mathrm{Na}$ formulação por elementos finitos, a equação do problema de transferência de calor transiente não linear é expressa por:

$$
[K]\{T\}+[C]\left\{\frac{\partial T}{\partial t}\right\}=\{Q\}
$$

onde $[K]$ e $[C]$ são as matrizes globais de condutividade térmica e capacidade térmica, construídas por meio das matrizes locais de todos os elementos da malha de elementos finitos, $\{T\}$ é o vetor de temperaturas nodais, $\{\partial T / \partial t\}$ é o vetor da taxa de resfriamento nodal e $\{Q\}$ é o vetor do fluxo de calor. As matrizes e o vetor da equação (47) são calculados, conforme: 


$$
\begin{gathered}
C_{i j}=\sum_{e=1}^{n} \frac{k}{\alpha} \iint_{\Omega_{e}} N_{i} N_{j} d \Omega \\
K_{i j}=\sum_{e=1}^{n} K \iint_{\Omega_{e}}\left(\frac{\partial N_{i}}{\partial r} \frac{\partial N_{j}}{\partial r}+\frac{\partial N_{i}}{\partial \theta} \frac{\partial N_{j}}{\partial \theta}\right) d \Omega \\
Q_{i}=\sum_{e=1}^{n_{c}} \int_{\Gamma} \bar{q} N_{i} d \Gamma-\sum_{e=1}^{n_{f}} \iint_{\Omega_{e}} \dot{q} N_{i} d \Omega
\end{gathered}
$$

onde $i$, $j$, são os graus de liberdade do modelo de elementos finitos; $N_{i}$ e $N_{j}$ são as funções de interpolação (ou funções de forma) associadas com a temperatura nodal; $n$ é o número de elementos do domínio; $k$ e $\alpha$ são a condutividade e difusividade térmica, respectivamente; $n_{c}$ é número de elementos com face(s) no contorno $(\Gamma)$ que têm prescrito o fluxo de calor, $\bar{q} ; n_{f}$ é o número de elementos da região onde a fonte de calor, $\dot{q}$, está sendo aplicada (esta fonte de calor interna está relacionada com o calor latente liberado durante a transformação de fase); $e$ faz referência ao $e$ ésimo elemento da discretização do domínio de integração $(\Omega)$.

As forças externas causadas pelos gradientes térmicos e as mudanças de volume durante a têmpera são aplicados nos incrementos de cada etapa do processo. No Abaqus as temperaturas são integradas utilizando o esquema de regressão diferencial e o sistema não linear acoplado é resolvido usando o método de Newton. Este método envolve uma matriz Jacobiana anti-simétrica como ilustrado na representação matricial da equação (53).

$$
\left[\begin{array}{ll}
K_{u u} & K_{u T} \\
K_{T u} & K_{T T}
\end{array}\right]\left\{\begin{array}{l}
\Delta u \\
\Delta T
\end{array}\right\}=\left\{\begin{array}{l}
R_{u} \\
R_{T}
\end{array}\right\}
$$

onde $\Delta u$ e $\Delta T$ são o deslocamento incremental e a variação de temperatura, respectivamente; $K_{i j}$ são submatrizes da matriz Jacobiana, e $R_{u}$ e $R_{T}$ são os vetores mecânicos e térmicos, respectivamente. Esta matriz Jacobiana, é a matriz que permite através do seu determinante (ou Jacobiano) fazer o mapeamento entre as coordenadas locais e globais do sistema. Neste sistema de equações as equações térmicas e mecânicas são resolvidas simultaneamente. Além disso, o método 
fornece convergência quadrática, quando a solução calculada está dentro do raio de convergência do algoritmo (ABAQUS, 2009).

As deformações e as tensões são computadas dentro de cada elemento usando a relação entre as taxas de deformação e o deslocamento, em seguida, as tensões são calculadas utilizando a taxa de deformação elasto-plástica de cada elemento do modelo. Uma grande vantagem do ABAQUS é que permite realizar o acoplamento de tensão/deformação diretamente.

Os valores para cada elemento são determinados usando os valores de temperatura e a microestrutura avaliada no correspondente ponto nodal, para depois, estes serem usados no cálculo das tensões. Nos cálculos, visto que a geometria analisada é cilíndrica, uma representação axissimétrica (dividida em vinte fatias) foi utilizada na geração da malha de elementos finitos, com 13320 elementos de ordem geométrica quadrática CAX4T, interligados através de 13694 nós.

\subsubsection{Propriedades Físicas e Mecânicas}

O processo de tratamento térmico foi simulado considerando as diferentes propriedades de cada fase e as frações volumétricas transformadas, supondo uma lei de misturas. As equações (54) a (73) apresentam as propriedades mecânicas e físicas necessárias (BHADESHIA, 2002) para o cálculo das tensões residuais de têmpera em função da temperatura. Os sub-índices $A, M, B$ e $P$, representam austenita, martensita, bainita e perlita, respectivamente. Estas equações foram obtidas a partir da interpolação dos resultados obtidos por Schröder (1985), Pietzsch, et al. (2008) e Campbell (1986), tendo como resultados diversos polinômios para temperaturas que variam entre $0^{\circ} \mathrm{C}$ e $900^{\circ} \mathrm{C}$.

Modulo de elasticidade $(E)$ em GPa e $T$ em ${ }^{\circ} \mathrm{C}$ :

$$
\begin{gathered}
E_{A}=-6,20 \times 10^{-9} T^{3}+5,55 \times 10^{-6} T^{2}-0,084 T+200 \\
E_{M}=-5,55 \times 10^{-5} T^{2}-0,033 T+200
\end{gathered}
$$




$$
\begin{gathered}
E_{B}=3,71 \times 10^{-8} T^{3}-2,77 \times 10^{-5} T^{2}+0,045 T+210 \\
E_{P}=2,12 \times 10^{-8} T^{3}-0,0001 T^{2}+0,016 T+200
\end{gathered}
$$

onde $E_{A}, E_{M}, E_{B}, E_{P}$ são os módulos de elasticidade da austenita, martensita, bainita e da perlita, respectivamente.

Coeficiente de Poisson $(v)$ :

$$
\begin{gathered}
v_{A}=8 \times 10^{-11} T^{3}-7 \times 10^{-8} T^{2}+7 \times 10^{-5} T+0,291 \\
v_{M}=8,0 \times 10^{-11} T^{3}-9,0 \times 10^{-8} T^{2}+7 \times 10^{-5} T+0,28 \\
v_{B}=v_{P}=1,9 \times 10^{-11} T^{3}-2,77 \times 10^{-8} T^{2}+6,0 \times 10^{-5} T+0,28
\end{gathered}
$$

Condutividade térmica $(k)$ em $\mathrm{W} / \mathrm{m} .{ }^{\circ} \mathrm{C}$ :

$$
\begin{gathered}
k_{A}=-6,2 \times 10^{-9} T^{3}+9,44 \times 10^{-6} T^{2}+7,72 \times 10^{-3} T+14,85 \\
k_{M}=-1,11 \times 10^{-6} T^{2}-0,021 \times T+43,13 \\
k_{B}=k_{P}=-1,2 \times 10^{-9} T^{3}-1,66 \times 10^{6} T^{2}-0,0239 \times 10^{2} T+49,01
\end{gathered}
$$

Calor específico $\left(C_{p}\right)$ em $\mathrm{J} / \mathrm{kg} \cdot{ }^{\circ} \mathrm{C}$ :

$$
\begin{gathered}
C_{p A}=-3,7 \times 10^{-8} T^{3}+4,44 \times 10^{-5} T^{2}+0,0966 T+531,7 \\
C_{p M}=5,6 \times 10^{-8} T^{3}-8,33 \times 10^{-5} T^{2}+0,306 x T+484 \\
C_{p B}+C_{p P}=4,9 \times 10^{-8} T^{3}-7,78 \times 10^{-5} T^{2}+0,309 T+484
\end{gathered}
$$

Limite de escoamento $\left(\sigma_{e}\right)$ em MPa:

$$
\sigma_{e A}=31,25 \times 10^{-8} T^{3}-42,85 \times 10^{-5} T^{2}+0,0466 T+298,71
$$




$$
\begin{gathered}
\sigma_{e M}=-0,001 T^{2}-0,1 T+1000 \\
\sigma_{e B}=1,29 \times 10^{-9} T^{4}-30,21 \times 10^{-7} T^{3}+18,22 \times 10^{-4} T^{2}+0,654 T+549,9 \\
\sigma_{e P}=3,7 \times 10^{-7} T^{3}+55.56 \times 10^{-5} T^{2}-0,566 T+360
\end{gathered}
$$

No ABAQUS podem ser definidos vários materiais para um único modelo. Em cada definição de material podem ser especificadas várias propriedades com a finalidade de determinar o comportamento completo do mesmo. Para isto, deve ser atribuído um nome que o defina com a finalidade de referenciá-lo a partir das definições das seções usadas para cada região do modelo, o que pode ser feito por meio da linha: ${ }^{*}$ MATERIAL, NAME = nome do material.

Desta maneira, cada material é especificado no bloco de dados, iniciado pela opção *MATERIAL. A definição do material prossegue até que apareça outra opção que não defina mais o comportamento do material, como por exemplo, uma outra linha que especifique *MATERIAL.

Estas propriedades dos materiais podem ser feitas dependentes da temperatura e especificadas em várias temperaturas diferentes. Para isto, é necessário adicionar o valor da temperatura junto ao valor da propriedade especificada, sendo necessário colocá-los em ordem crescente da variável independente. O ABAQUS interpolará linearmente entre os valores indicados. Se os dados do material dependem fortemente da variável independente de forma nãolinear, é possível especificar os pontos de dados suficientes para que uma interpolação linear compreenda o comportamento não-linear com precisão (ABAQUS, 2009).

Cada uma das propriedades enunciadas nas equações 54 a 70, uma vez que são calculadas em função das porcentagens obtidas para cada fase, são inseridas no ABAQUS por meio das linhas: *Elastic, ${ }^{*}$ Conductivity, ${ }^{*}$ Plastic, ${ }^{*}$ Specific heat, *Density para o módulo de elasticidade, condutividade, plasticidade, calor específico e densidade, respectivamente. Assim por exemplo, para incluir a propriedade do 
calor específico do anel perto da superfície variando desde $830^{\circ} \mathrm{C}$ até $24^{\circ} \mathrm{C}$, se especifica de acordo com:

\footnotetext{
* Specific Heat

$491.313,24$.

$491.615,25$.

$492.523,28$.

$494.634,35$.

$498.534,48$.

$505.078,70$.

$515.299,100$.

$525.663,137$.

$538.206,180$.

$550.895,226$.

$562.054,273$.

$568.104,317$.

$570.719,359$.

$574.952,396$.

$578.843,430$.

$582.156,459$.

$585.23,486$.

$588.065,511$.

$590.659,534$.

$593.238,557$.

$595.577,578$.

$621.695,830$.
}

\subsection{Calor Latente de transformação}

No processo de têmpera há liberação de calor latente durante a transformação de fase do aço, devido às diferenças entre entalpias ${ }^{13}$ da fase matriz (austenita) e a fase produto (LEE; LEE, 2008). Dessa forma, um determinado calor latente está relacionado a toda transformação de fase, conforme apresentado nas Tabelas 7 e 8, propostas por Lee e Lee (2008) e Oliveira et al. (2010), cujo trabalho teve base nos estudos de Denis, et al., 1987; Woodward et al., 1999; Stull e Prophet, 1971.

${ }^{13}$ A variação da entalpia de uma transformação de fase é a resposta térmica de um sistema sob pressão constante. Devido à evolução das tensões durante o processo de têmpera, a transformação de fase não ocorre sob pressão constante. No entanto, o efeito da pressão sobre a entalpia é desprezível para os sólidos (SIMSIR, 2008) 
Tabela 7 - Calor latente de transformação. Lee e Lee (2008).

\begin{tabular}{cc}
\hline Transformação & Calor latente $\left(\mathbf{J} / \mathbf{m}^{3}\right)$ \\
\hline Austenita $\rightarrow$ Ferrita & $5,95 \times 10^{8}$ \\
Austenita $\rightarrow$ Bainita & $5,12 \times 10^{8}$ \\
Austenita $\rightarrow$ Perlita & $5,26 \times 10^{8}$ \\
Austenita $\rightarrow$ Martensita & $3,14 \times 10^{8}$ \\
\hline
\end{tabular}

Tabela 8 - Calor latente de transformação. Oliveira et al. (2010).

\begin{tabular}{cc}
\hline Transformação & Calor latente $\left(\mathbf{J} / \mathbf{m}^{3}\right)$ \\
\hline & $1,082 \times 10^{2}-0,162(T+273)+1,118 \times 10^{-4}(T$ \\
Austenita $\rightarrow$ Ferrita & $+273)^{2}-3,000 \times 10^{-8}(T$ \\
& $+273)^{3}-\left(\left(3,501 \times 10^{4}\right) /(T\right.$ \\
Austenita $\rightarrow$ Bainita & $+273)$ \\
Austenita $\rightarrow$ Perlita & $1,560 \times 10^{9}-1,500 \times 10^{6} T$ \\
Austenita $\rightarrow$ Martensita & $1,560 \times 10^{9}-1,500 \times 10^{6} T$ \\
\hline
\end{tabular}

Para incluir estes valores no ABAQUS, já que é necessário definir vários calores latentes para poder modelar diversas mudanças de fase do material, o calor latente pode ser combinado com qualquer outra propriedade do material e definido dentro de um intervalo de temperaturas conhecido.

Para especificar os calores latentes do material no arquivo de entrada do modelo, é necessário definir as seguintes condições:

*Latent Heat (calor latente por unidade de massa)

Temperatura Solidus: Valor inferior do intervalo de temperatura dentro do qual a mudança de fase ocorre.

Temperatura Liquidus: Valor superior do intervalo de temperatura dentro do qual a mudança de fase ocorre.

Estas linhas podem ser repetidas quantas vezes forem necessárias para definir as mudanças de fase do material. 
Assim por exemplo se a transformação de fase é só para martensita, com temperatura de início e fim aos $315^{\circ} \mathrm{C}$ e $100^{\circ} \mathrm{C}$, respectivamente, a linha do arquivo deverá ser:

*Latent Heat

82501.3,100.,315.

Já no casso em que o calor latente evolui durante mais de uma transformação de fase é incorporado no modelo pressupondo uma lei linear de misturas.

\subsection{Expansão térmica}

A determinação da tensão térmica requer o conhecimento dos coeficientes de expansão das várias fases que participam nas transformações durante o tratamento térmico sob consideração. A maioria dos dados disponíveis para a fase austenítica, para temperaturas entre a temperatura de austenitização e a temperatura $M_{S}$, sugerem que o coeficiente de expansão é constante em valores entre $2,1 \times 10^{-5 \circ} \mathrm{C}^{-1}$ e $2,3 \times 10^{-5 \circ} \mathrm{C}^{-1}$ (FLETCHER, 1989). Sjöstrom (1989) e outros trabalhos indicam valores para o coeficiente de expansão da martensita entre $1,1 \times 10^{-5}{ }^{\circ} \mathrm{C}^{-1} \mathrm{e}$ $1,4 \times 10^{-5 \circ} \mathrm{C}^{-1}$. Os coeficientes de expansão térmica $\left(\alpha_{T}\right)$ neste trabalho foram incluídos no modelo de acordo aos seguintes valores:

$$
\begin{gathered}
\alpha_{T A}=2,1 \times 10^{-5} \\
\alpha_{T M}=1,3 \times 10^{-5} \\
\alpha_{T B}=\alpha_{T P}=1,4 \times 10^{-5}
\end{gathered}
$$

\subsection{Expansão volumétrica}

Durante decomposição da austenita em agregados de ferrita e carbonetos ou em martensita, é observado um aumento de volume na região de transformação devido às diferenças de densidades entre a fase matriz (austenita) e a fase produto. 
Desta maneira, na têmpera plena, por exemplo, quando o núcleo se transforma (X segundos após a superfície) ocorre a expansão, forçando a camada dura e frágil de martensita da superfície e podendo dar origem aos seguintes efeitos: distorções, empenamento, criação de tensões residuais e até trincas de têmpera. A Tabela 9 mostra as porcentagens da expansão volumétrica provocadas pelas diversas transformações de fase que ocorrem nos aços AISI 4140, 4340 e 1045.

Tabela 9 - Expansão volumétrica para a composição general e para o aço AISI 4140, 4340 e 1045 em cada fase transformada. Adaptado de Thelning (1975).

\begin{tabular}{cccc}
\hline Transformação de fase & $\begin{array}{c}\text { Variação do } \\
\text { Volume, \% }\end{array}$ & $\mathbf{4 1 4 0 / 4 3 4 0}$ & $\mathbf{1 0 4 5}$ \\
\hline Austenita $\rightarrow$ Martensita & $4,64-0,53(\%$ C) & 4,428 & 4,402 \\
Austenita $\rightarrow$ Bainita inferior & $4,64-1,43(\%$ C) & 4,068 & 3,996 \\
Austenita $\rightarrow$ Bainita superior & $4,64-2,21(\%$ C) & 3,756 & 3,645 \\
Austenita $\rightarrow$ Perlita & $4,64-2,21(\%$ C) & 3,756 & 3,645 \\
\hline
\end{tabular}

$\mathrm{Na}$ transição entre o início e o fim da formação de uma nova fase ou microconstituinte, o modelo leva em conta a contração térmica da porcentagem de fase ou microconstituinte ainda sem transformar e a expansão devida à transformação da porcentagem da nova fase, simultaneamente, como explicado a seguir.

Como a contração térmica é igual a:

$$
\frac{\Delta L}{l_{o}}=\alpha_{T} \cdot \Delta T
$$

onde $\alpha_{T}$ são os coeficientes de expansão térmica relacionados nas equações (71) a (73) e $\Delta T$ é a variação da temperatura. Assim, por exemplo, se o aço transforma só para martensita a variação linear devida à contração térmica será:

$$
\frac{\Delta L}{l_{o}}=\left(2,1 \times 10^{-5} x \% A+1,3 \times 10^{-5} x \% M\right) \cdot \Delta T
$$


onde $\% A$ e $\% M$ representam os percentuais de austenita e de martensita, respectivamente.

Devido ao fato de que a transformação de austenita para martensita se dá com uma expansão do 4,428\% para um aço com 0,4\% C, (Tabela 9) este aumento faz com que o parâmetro de expansão linear por transformação seja igual a 0,013. Desta maneira, a expansão devida à transformação de fase causa uma mudança de volume $\Delta V\left(\gamma \rightarrow \alpha^{\prime}\right)$ expressa por:

$$
\frac{\Delta L}{l_{o}}=0,013 x \Delta \% M
$$

E a variação volumétrica total será:

$$
\frac{\Delta L}{l_{o}}(\text { Total })=\text { transformação }+ \text { contração }
$$

Substituindo (75) e (76) em (77):

$$
\frac{\Delta L}{l_{o}}(\text { Total })=0,013 x \Delta \% M-\left[\left(2,1 \times 10^{-5} x \% A+1,3 \times 10^{-5} x \% M\right) . \Delta T\right]
$$

Da equação (74) o coeficiente de contração térmica equivalente é:

$$
\frac{\Delta L}{l_{o} \Delta T}=\alpha
$$

Assim, para obter o coeficiente de variação volumétrica teremos que:

$$
\frac{\Delta L}{l_{o}} \cdot \frac{1}{\Delta T}=0,013 x \Delta \% M-\left[\left(2,1 \times 10^{-5} x \% A+1,3 \times 10^{-5} x \% M\right) . \Delta T\right] x \frac{1}{\Delta T}
$$

Obtendo-se então, para o caso da transformação de austenita para martensita uma expansão equivalente como representado na equação (81).

$$
\alpha_{\text {equivalente }}=\left(\frac{0,013 x \Delta \% M}{\Delta T}\right)-\left[2,1 \times 10^{-5} x \% A+1,3 x 10^{-5} x \% M\right]
$$


No caso em que estejam presentes as outras fases, as equações (75) e (76) terão os percentuais das frações volumétricas de cada fase gerada a partir da decomposição da austenita.

No Modelo de elementos finitos usando o ABAQUS, a expansão térmica é uma propriedade que pode ser incluída na definição do material.

Como arquivos de entrada são utilizadas as seguintes opções para definir a expansão térmica dos materiais:

* MATERIAL

*EXPANSÃO

Ou é possível também usar a opção Módulo de propriedade - editor de materiais: Mechanical $\rightarrow$ Expansion, para incluir os efeitos de dilatação térmica.

Em ABAQUS podem ser definidas expansão térmica isotrópica, ortotrópica (somente permitida quando utilizada em conjunto com elasticidade e escoamento anisotrópicos ou elasticidade ortotrópica) ou totalmente anisotrópica (ABAQUS, 2009).

No presente trabalho foi definida a condição de expansão isotrópica, uma vez que o coeficiente de expansão térmica é definido diretamente, com um valor de $\alpha$ para cada temperatura. Isto foi feito usando a opção:

* EXPANSÃO, TYPE = ISO.

Desta maneira, uma vez que os cilindros foram divididos em 20 anéis desde a superfície até o centro, a expansão foi definida para cada anel dependendo da porcentagem de cada microconstituinte transformado em função da temperatura. Os cilindros iniciam sua contração (Eq. 74 ) desde a temperatura de austenitização e uma vez atinge a temperatura de início da transformação (seja martensítica, bainítica e/ou perlítica) é utilizado um coeficiente de expansão térmica negativo durante o período de transformação (BORTOLETO et al., 2005) cujo valor depende da 
porcentagem de cada fase transformada conforme a temperatura diminui (Eq. 81). Quando a transição de transformação de fase termina, as peças continuam sua contração térmica dependendo das fases remanescentes após o fim da transformação, segundo as equações (71 a 73 ) e aplicando a lei das misturas.

\subsection{Plasticidade induzida por transformação}

A plasticidade induzida por transformação de fase (conhecida como efeito TRIP do inglês "Transformation Induced Plasticity") é definida segundo Gür e Pan (2009) como a deformação plástica observada quando uma amostra se transforma sob a ação de tensões externas, mesmo para estados de tensão abaixo da tensão de escoamento do material, e Fischer et al. (2000) a definem como o aumento significativo da plasticidade durante uma mudança de fase, mesmo para uma carga externa aplicada na qual a correspondente tensão equivalente é pequena em comparação com a tensão normal de escoamento do material, ocorrendo deformação plástica. Este fenômeno modifica a cinética da transformação (aumento do $M_{s}$ ) e induz uma deformação adicional oriunda da transformação de fase (efeito mecânico) (ABASSI; FLETCHER, 1985). Segundo Camarão (1998) o efeito cinético da variação do $M_{S}$ apresenta apenas uma pequena influência no perfil e magnitude das tensões residuais. Fletcher (1989) comparando os resultados de Sjöstrom (1982), que incluiu em seu modelo o efeito TRIP, e de Inoue (1985) que o ignorou, encontrou que os dois resultados são muito próximos (Figura 37), e afirma que a introdução deste fenômeno não tem um efeito claro nos resultados calculados. Xu et al. (1996) desenvolveram um modelo numérico a fim de analisar as tensões residuais geradas na superfície de barras de aço AISI 4135 (35CrMo), temperadas e encontraram uma influência pequena exercida por esse efeito (TRIP), no estado final de tensão. Esses autores encontraram que o efeito TRIP reduz levemente as tensões finais na superfície. Diante dessas informações, optou-se por desprezar o efeito TRIP sobre as tensões residuais medidas no presente trabalho. 


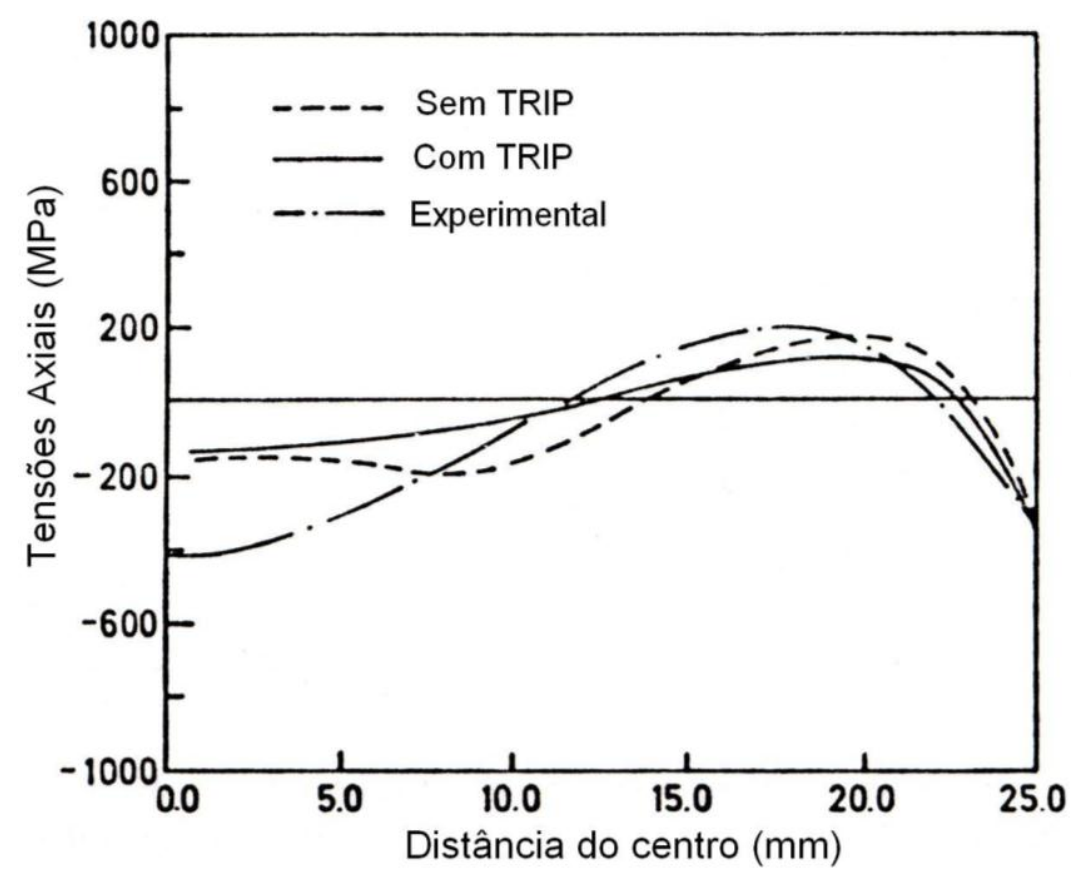

Figura 37 - Distribuição das tensões axiais em um cilindro de aço temperado. Adaptado de Fletcher (1989).

\subsubsection{Análise térmica dos experimentos de têmpera}

Foi feita a análise térmica durante o processo de têmpera a fim de obter o coeficiente de transferência de calor entre a superfície do cilindro e a água refrigerante. Este coeficiente de transferência de calor é necessário para simular a variação dos campos de temperatura durante a têmpera, requerida nas simulações da evolução da microestrutura e na formação das tensões residuais. Para se obter o coeficiente de transferência de calor, as curvas de resfriamento foram medidas pela inserção de termopares tipo $\mathrm{K}$ (Cromel - Alumel) com fios isolados por cerâmica compactada e revestidos por um tubo de aço inoxidável de $1,5 \mathrm{~mm}$ de diâmetro. Estes termopares foram dispostos em dois pontos diferentes da amostra, como mostrado na Figura 38. Estes furos foram feitos cuidadosamente paralelos à superfície do cilindro, uma vez que Luebben et al. (2010) afirmam que se os termopares inseridos na peça não são estritamente paralelos, ocorrerão perturbações nos registros dos campos de temperatura, e como consequência, os resultados da estimativa do coeficiente de transferência de calor poderiam ser errados. 


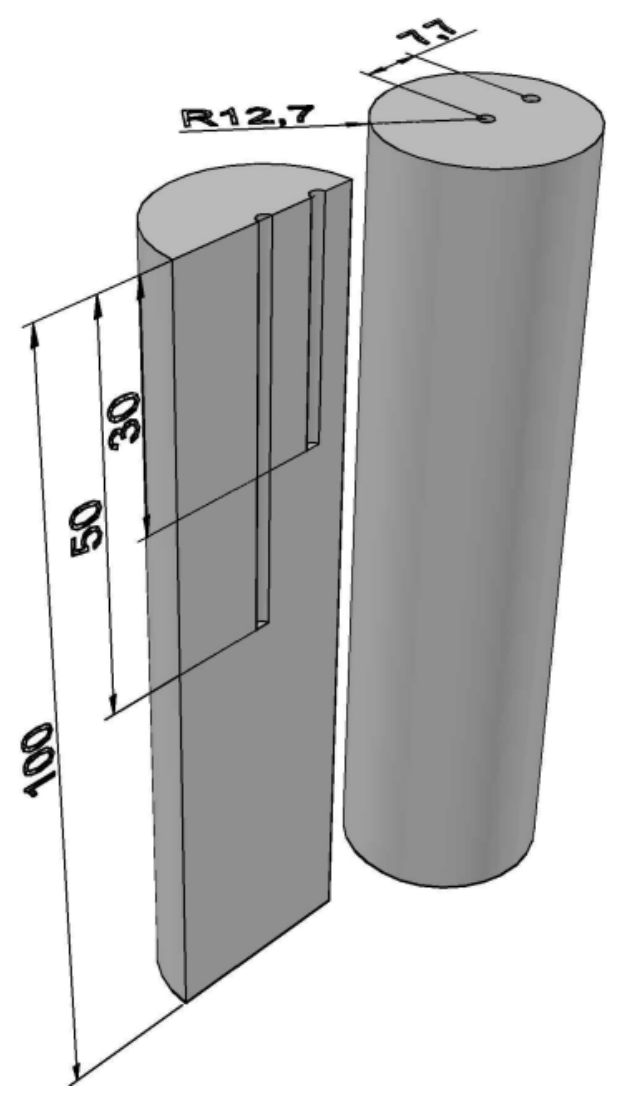

Figura 38 - Disposição dos termopares dentro da amostra para obter as curvas de resfriamento durante o processo de têmpera (dimensões em $\mathrm{mm}$ ).

Os termopares foram conectados a um computador, que através de um sistema SCXI de aquisição de dados, desenvolvido em ambiente de programação gráfica LabVIEW $\Theta$ (National Instruments, 2011), registram os sinais em tempo real a uma taxa de $10 \mathrm{~Hz}$ e converte estes sinais em dados de tempo e temperatura durante o resfriamento. $O$ tempo de resposta do termopar foi de $0,1 \mathrm{~s}$.

As curvas de resfriamento medidas foram utilizadas para resolver inversamente a equação de condução de calor [eq. (26)]. Já que o comprimento dos cilindros é quatro vezes o diâmetro (cilindro semi-infinito ${ }^{14}$ ), a extração de calor pelas extremidades do cilindro pode ser desprezada e avaliada apenas

${ }^{14}$ A necessidade do uso de corpos de prova semi-infinitos, a fim de desprezar a extração de calor através das extremidades do cilindro nos cálculos da transferência de calor, pode ser ilustrada pela comparação dos números de Fourier ou parâmetro de tempo adimensional $\left(t^{*}\right), t^{*}=\alpha t / L^{2}$. Números de Fourier $\leq 0,05$ são considerados aceitáveis (BATES et al., 1993). Sendo $L$, o comprimento do cilindro, $\alpha$ a difusividade térmica e $t$ é o tempo de duração do experimento. Os resultados deste cálculo para o aços usados neste trabalho, na temperatura ambiente, são de 0,055. 
unidimensionalmente no sentido radial. Esta é uma condição comumente usada na maioria dos laboratórios de análise de curvas de resfriamento de peças cilíndricas temperadas por imersão (BABU; PRASANA, 2011). Desta maneira, a transferência de calor dentro do cilindro foi avaliada segundo a equação diferencial de Fourier em coordenadas cilíndricas [eq. (82)]:

$$
\rho C_{p} \frac{\partial T}{\partial t}=\frac{1}{r} \frac{\partial T}{\partial r}\left(r k \frac{\partial T}{\partial r}\right)+\dot{q}
$$

onde $T$ é a temperatura, $t$ é o tempo, $r$ e é a coordenada radial para o sistema de referência cilíndrico; $\rho, C_{p}$ e $k$ são a densidade do aço $\left(7800 \mathrm{~kg} \cdot \mathrm{m}^{-3}\right)$, calor específico e a condutividade térmica, respectivamente, e $\dot{q}$ é o calor latente devido a transformação de fase por unidade de volume e tempo. A condição de contorno na superfície do cilindro foi determinada segundo as equações (29) e (30) como:

$$
-k \frac{\partial T}{\partial t}=h\left(T_{S}-T_{M}\right)
$$

em que $T_{S}$ e $T_{M}$ são as temperaturas da superfície do cilindro e do meio de resfriamento (água a $24^{\circ} \mathrm{C}$ ), respectivamente e $h$ é o coeficiente de transferência de calor entre a superfície da barra e o meio de resfriamento. Para calcular a perda de calor por radiação, foi usada a lei de Stefan-Boltzmann [eq. (84)]:

$$
q_{r}=\varepsilon_{c} \sigma\left[\left(T_{S}-T_{Z}\right)^{4}-\left[\left(T_{M}-T_{Z}\right)^{4}\right]\right.
$$

onde $q_{r}$ é o fluxo de calor devido a radiação $\left(W \cdot m^{-2}\right), T_{z}$ é o valor do zero absoluto na escala de temperatura que está sendo usada, $\varepsilon_{c}$ é o coeficiente de emissividade na superfície do cilindro, igual a 0,76 para uma superfície ferrosa oxidada (OLIVEIRA et al., 2010) e $\sigma$ é a constante de Stefan-Boltzmann $\left(5,6704 \times 10^{-8} W \cdot m^{-2} \cdot K^{-4}\right)$.

As equações 80 a 82 foram resolvidas inversamente utilizando as curvas de resfriamento medidas experimentalmente a fim de obter o coeficiente de transferência de calor. De acordo com este método, as curvas de resfriamento 
medidas são comparadas com as curvas obtidas a partir das equações 80, 81 e 82, resolvidas numericamente pelo método dos elementos finitos.

A estimativa inicial do coeficiente de transferência de calor por convecção foi calculada segundo a equação (85):

$$
h=\frac{k_{f} \cdot N u}{D}
$$

onde $k_{f}$ é a condutividade térmica do fluido, $D$ é a dimensão característica do problema (diâmetro do cilindro) e $\mathrm{Nu}$ é o número de Nusselt, que representa o gradiente de temperatura adimensional na superfície e é função do número de Reynolds $\left(R_{e}\right)$ e do número de Prandlt $\left(P_{r}\right)$, ou seja:

$$
N u=f\left(R_{e}, P_{r}\right)
$$

O número de Reynolds está relacionado com o escoamento do fluido:

$$
R_{e}=\frac{\rho_{f} \cdot V \cdot D}{\mu_{f}}
$$

onde $\rho_{f}$ é a massa específica do fluido, $\mu_{f}$ é a viscosidade dinâmica do fluido e $V$ é a velocidade característica do escoamento.

Já o número de Prandlt, relacionado com as propriedades do fluido é definido como:

$$
P_{r}=\frac{\mu_{f} \cdot C_{p f}}{k_{f}}
$$

onde $C_{p f}$ é o calor específico do fluido.

Para o cálculo do número de Nusselt foi utilizada a correlação de Churchill e Bernstein (1977) para geometrias cilíndricas com regime de fluxo turbulento na superfície, frequentemente utilizada nos cálculos de transmissão de calor por convecção forçada: 


$$
N_{u}=0,3+\frac{0,62 \operatorname{Re}^{1 / 2} \operatorname{Pr}^{1 / 3}}{\left[1+(0,4 / P r)^{2 / 3}\right]^{1 / 4}}\left[1+\left(\frac{R e}{282000}\right)^{5 / 8}\right]^{4 / 5}
$$

para, $10^{2}<R e<10^{7}$ e $\operatorname{Pr}>0,2$.

Levando em conta que o fluido em estudo é água a $24^{\circ} \mathrm{C}, k_{f}=0,609 \mathrm{~W} / \mathrm{m} . \mathrm{K}$; $C_{p f}=4179 \mathrm{~J} / \mathrm{kg} . \mathrm{K} ; \quad \rho=996,6 \mathrm{~kg} / \mathrm{m}^{3} ; \quad \mu_{f}=9,11 \times 10^{-4} \mathrm{~kg} / \mathrm{m} . \mathrm{s} \quad$ (HOLMAN, 2010; INCROPERA, et al., 2011), e que o valor da velocidade do fluido calculado durante a têmpera foi igual a $1,613 \mathrm{~m} / \mathrm{s} \pm 0,08$, da eq. (87) tem-se, $R_{e}=44819,87$ e da eq. (88) $P_{r}=5,52$. Substituindo esses resultados na equação (89), e este resultado na equação (85), chega-se ao valor do coeficiente de transferência de calor dado por:

$$
h=6,676 \times 10^{3} \frac{W}{m^{2} K}
$$

As condições térmicas de resfriamento ou de aquecimento devidas à convecção e/ou radiação de fluidos circundantes na superfície de um material é definido no ABAQUS/CAE a través do coeficiente de transferência de calor, no módulo de interação, através da condição "Film condition". Existem dois tipos de condições que podem ser definidas no ABAQUS, no módulo "Interaction" para utilizar a propriedade de "film condition". Uma é o "Surface film condition" que define o resfriamento por convecção das superfícies no modelo, e a outra é "Concentrated film condition" que define a convecção a partir dos nós ou dos vértices. No presente trabalho, o resfriamento foi definido a través da condição "Surface film condition". Após as primeiras simulações, as curvas de resfriamento calculadas e simuladas foram comparadas e a estimativa do coeficiente de transferência de calor no Abaqus, teve que ser mudada para $7200 \mathrm{~W} / \mathrm{m}^{2} . K$, a fim de melhorar a concordância entre as curvas experimentais e de simulação.

\subsubsection{Difração de raios $X$}

Para a análise das tensões residuais foi empregado o método da difração de raios $X$. Nesse método, a tensão residual é calculada a partir da medição da 
deformação no cristal do agregado policristalino sob estudo, comparada com os parâmetros de rede desse mesmo material sem sofrer deformação.

Para calcular a tensão por este método foi empregado o método do $\operatorname{sen}^{2} \psi$ [eq. (47)] que determina a variação da distância interplanar em função da variação do ângulo $\psi$ (Figura 39).

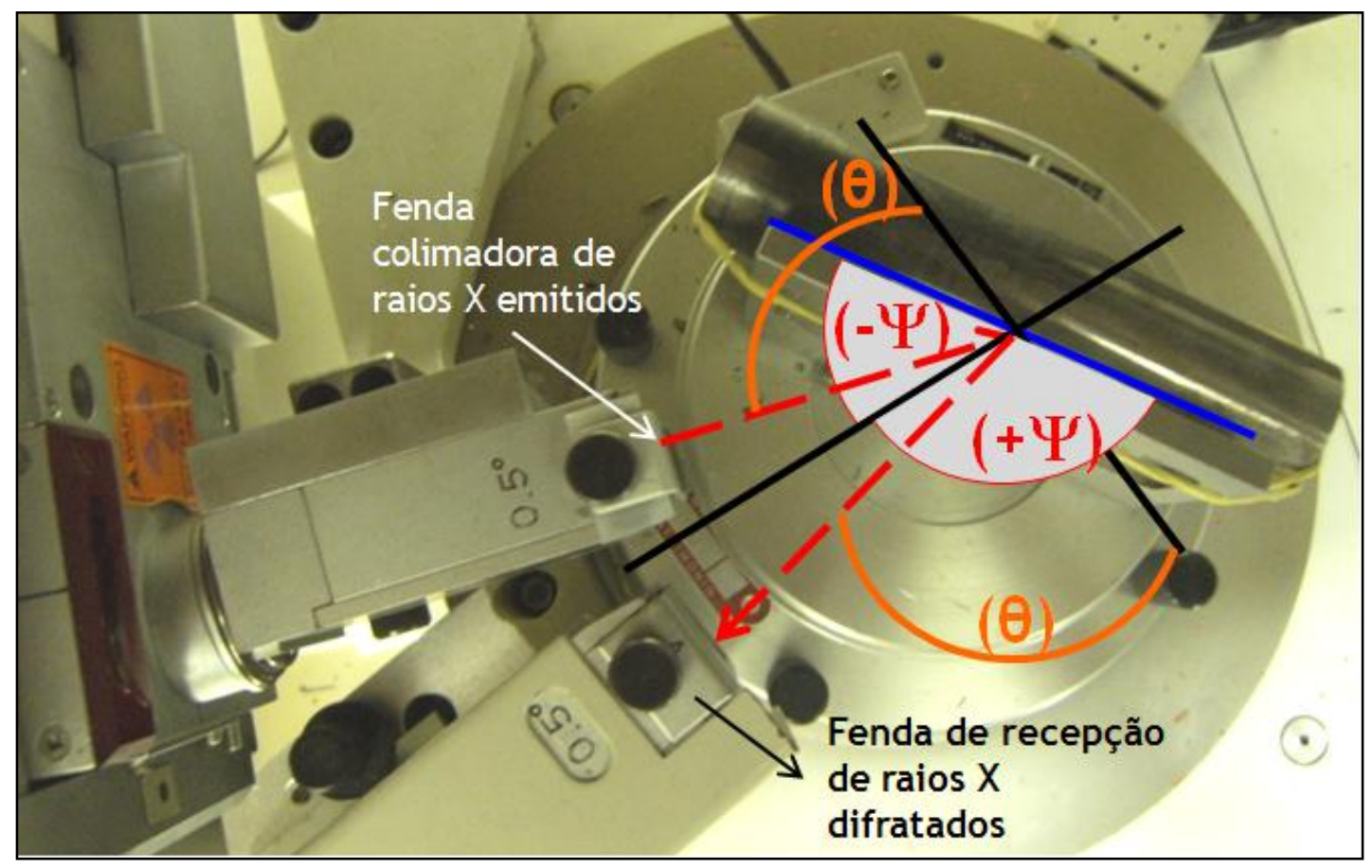

Figura 39 - Montagem da amostra no difratômetro de raios X para análise de tensão residual no sentido axial.

As superfícies das amostras foram lixadas até a grana 1200 antes do tratamento térmico, e somente com grana 1200 após do tratamento, a fim de evitar deslocamentos ou erros na leitura da difração por conta da oxidação ou rugosidade da superfície. No entanto, um dos efeitos que mais afeta a acurácia na determinação de tensão residual por difração de raios $X$ é a existência de orientações cristalográficas preferenciais, ou seja, textura, nos materiais examinados (este efeito não foi quantificado no presente trabalho). A presença de textura, que é causa da oscilação no gráfico de $d \times \operatorname{sen}^{2} \psi$, e é função da relação de orientação entre os tensores de tensão e a orientação cristalográfica, pode levar a erros significativos quando se utilizam as equações derivadas da teoria elástica para materiais isotrópicos na determinação da tensão residual (LIMA, 1992). 
$\mathrm{Na}$ realização das análises foi utilizado um equipamento da marca Rigaku, modelo Rint 2000 com tubo de anodo de cromo $(\operatorname{CrK} \alpha=2,29100 \dot{A})$. Em medida de tensão residual de ferro e aço o plano (211) é frequentemente o usado. Considerando a primeira ordem de difração $(n=1)$, para um $\lambda=2,29100 \dot{A}$ e com radiação $C r K \alpha$ radiando os planos (211) da ferrita $\left(d_{211}=1,1702 \dot{A}\right.$ - aproximação $d_{0} \approx d_{\psi=0}$ ), a posição do pico de difração seria $2 \theta=156.10^{\circ}$. Nas medidas de tensão residual por difração o Scan varreu um ângulo de $154,1^{\circ}$ a $157,7^{\circ}$ caracterizando a medição no plano (211).

Os parâmetros de regulagem do difratômetro utilizados estão descritos na Tabela 10. $A$ área de abrangência do feixe de raios $X$ sobre a superfície do cilindro deve ser de apenas $1 \mathrm{~mm}^{2}$, para isso foi utilizada uma fenda colimadora de raios $X$ com abertura apropriada e o "foco ponto" no difratômetro.

Tabela 10 - Parâmetros de regulagem utilizados no difratômetro de raios X para a medição da tensão residual.

\begin{tabular}{cc}
\hline Parâmetro & Valores \\
\hline Comprimento de onda dos raios X & CrK $\alpha$ \\
Método de cálculo do pico & Peak-top \\
Smooth & Sim \\
Módulo de elasticidade - E (MPa) & 210000 \\
Poisson - $v$ & 0.29 \\
Varredura em $2 \theta$ & $154,1^{\circ}$ a $157,7^{\circ}$ passo $0,2^{\circ}$ \\
Tempo de contagem & $6 \mathrm{~s}$ \\
Plano cristalino de referência & $(211)$ \\
Correção de Ko $\alpha_{2}$ & Sim \\
Variação do $\Psi$ & $-50^{\circ}$ a $50^{\circ}$ passo de $10^{\circ}$ \\
Potência & $40 \mathrm{KV}, 20 \mathrm{~mA}$ \\
\hline
\end{tabular}

As medidas de tensão residual foram feitas tanto no sentido axial quanto no sentido tangencial, como é apresentado na Figura 40. 


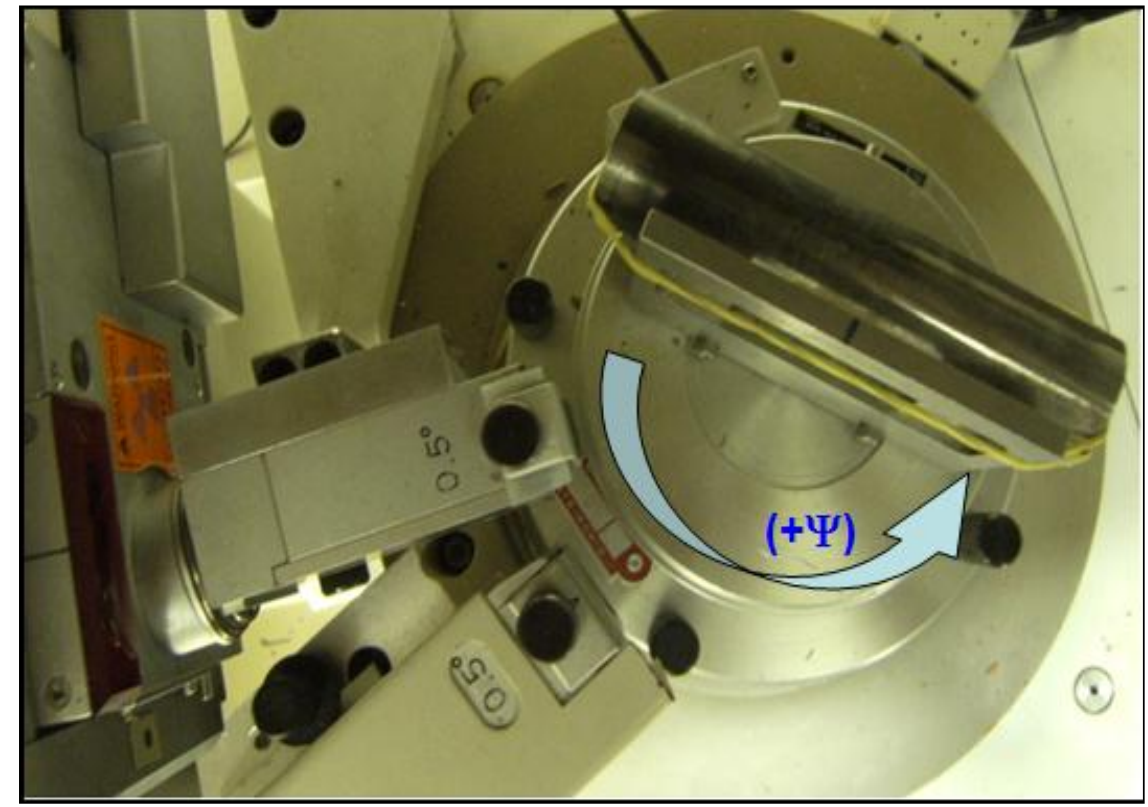

(a)

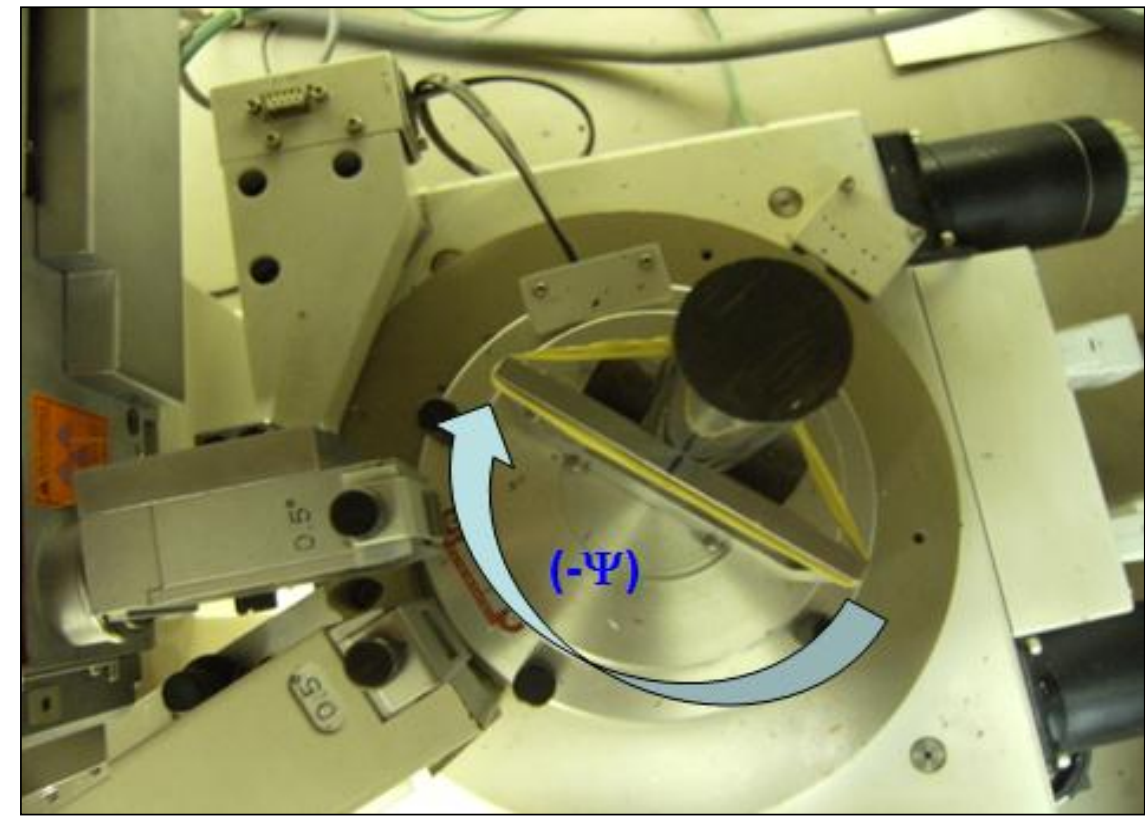

(b)

Figura 40 - Posicionamento dos corpos de prova para medição da tensão residual. (a) Posição para medida de tensão residual axial. (b) Posição para coleta de dados para medição da tensão residual tangencial.

A fim de comprovar se a temperatura de austenitização foi suficiente para eliminar as tensões residuais existentes antes do processo de têmpera (as tensões devidas ao processo de fabricação da barra de aço, por exemplo) e, além disso, comprovar a calibração do difratômetro de raios X, o cilindro de aço AISI 4140 foi austenitizado a $850^{\circ} \mathrm{C}$ durante 60 minutos e deixado no forno, até atingir a temperatura ambiente. 


\section{RESULTADOS E DISCUSSÃO}

\subsection{ANÁLISE TÉRMICA}

\subsubsection{Coeficiente de transferência de calor e fluxo térmico}

O coeficiente de transferência de calor entre a superfície do cilindro e o meio de resfriamento foi calculado pela solução inversa da equação de transferência de calor usando as curvas de resfriamento calculadas em duas posições do cilindro como mostrado na Figura 38. As curvas de resfriamento foram obtidas para três repetições experimentais das condições de têmpera usando cilindros diferentes (AISI 4340 e 1045) com as mesmas dimensões. As curvas de resfriamento obtidas para os três experimentos são mostradas na Figura 41. Nesta figura, são apresentados também os resultados das curvas obtidas através do Abaqus, para as condições de contorno impostas.

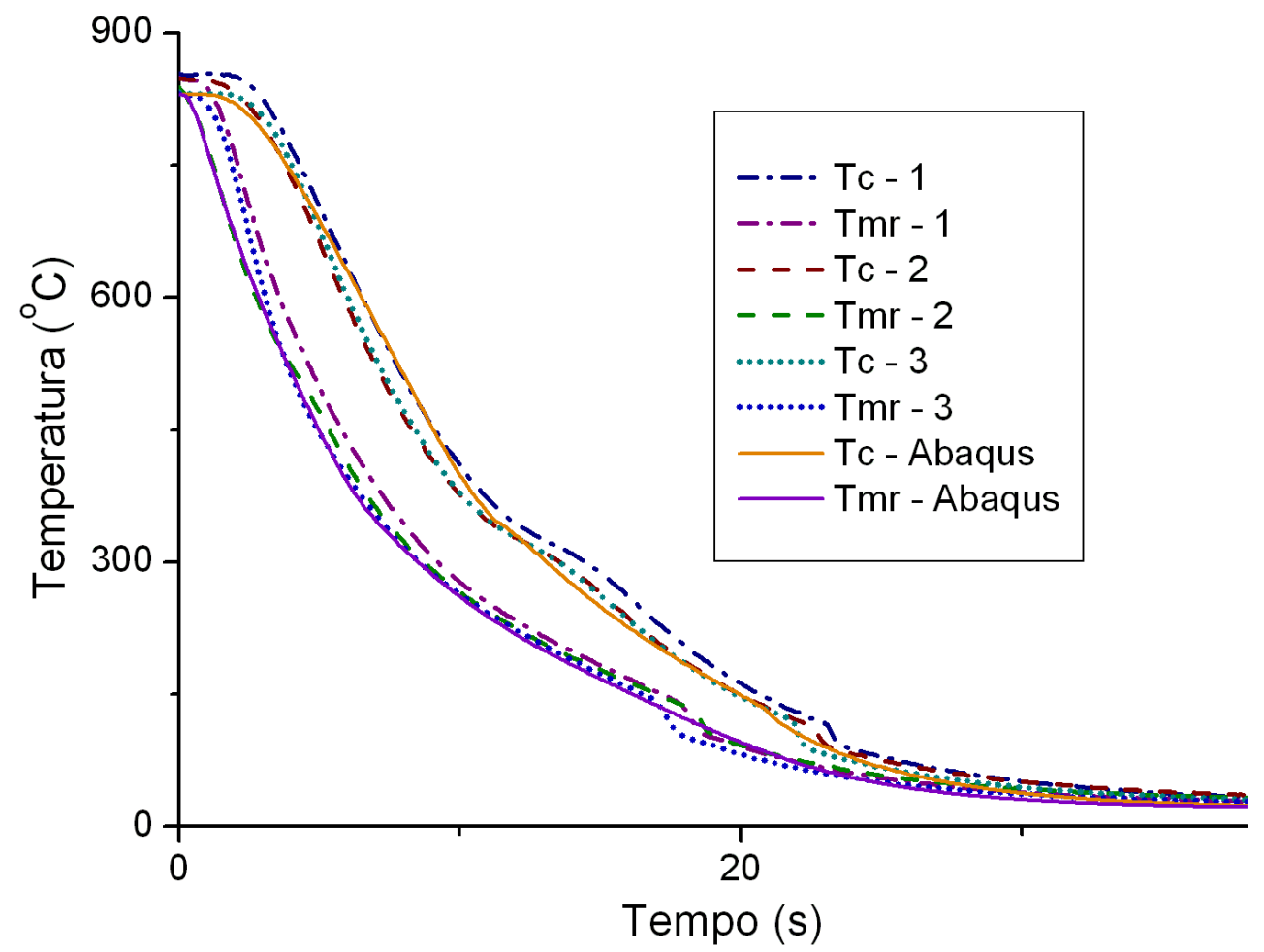

Figura 41 - Curvas de resfriamento experimentais e simuladas em duas posições dentro dos cilindros temperados, para as três experiências realizadas (1 e 3 aço 4340;

2 , aço 1045) e das obtidas através do Abaqus. Tmr e Tc, representam as temperaturas a $3 \mathrm{~mm}$ da superfície e no centro do cilindro, respectivamente. 
Como pode ser observado a partir da Figura 41, em todos os experimentos as curvas obtidas para cada termopar tiveram um comportamento similar, indicando bom controle das condições experimentais. As curvas calculadas com o software de elementos finitos para um coeficiente de transferência de calor igual a $7200 \mathrm{~W} / \mathrm{m}^{2} . K$, o qual foi adotado em todas as simulações, têm boa concordância com as curvas medidas experimentalmente. Esta boa concordância entre as curvas medidas e experimentais indicaram que no presente trabalho um coeficiente de transferência de calor constante pode simular com precisão a transferência de calor dos cilindros temperados em água.

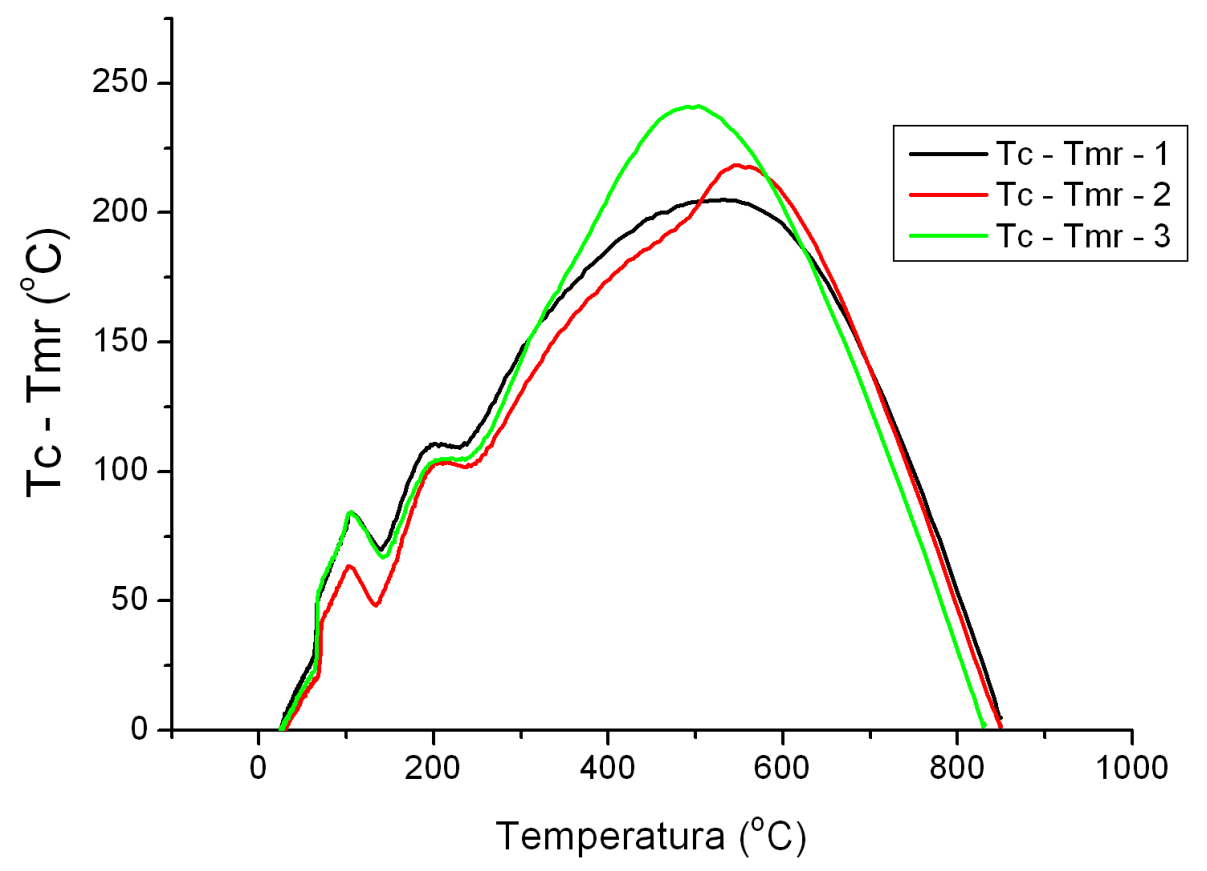

Figura 42 - Diferençaentre as temperaturas medidas experimentalmente no centro (Tc) e perto da superfície (Tmr) dos cilindros (1 e 3, AISI 4340 e 2, 1045) em função da temperatura perto da superfície. Tmr e Tc, representam as temperaturas a $3 \mathrm{~mm}$ da superfície e no centro do cilindro, respectivamente.

O comportamento radial do fluxo de calor na superfície das barras em função da temperatura mostram o regime de ebulição que ocorre na interface sólido-líquido. O fluxo de calor é proporcional ao gradiente de temperatura radial dentro da barra, e pode ser estimado pela diferença entre a temperatura medida no centro e perto da superfície da barra. A Figura 42 mostra o comportamento dessa diferença de temperatura em função da temperatura medida próxima à superfície do cilindro. Inicialmente, a diferença de temperatura é relativamente baixa, indicando um fluxo de calor baixo, e na medida em que a temperatura diminui o fluxo de calor aumenta 
até atingir o máximo valor. Esta parte da curva pode indicar a chamada transição de borbulhamento, que ocorre entre o regime de baixa transferência de calor na camada de vapor (primeiro estágio da têmpera) para o regime de transferência de calor elevado de nucleação de bolhas (segundo estágio). O estágio de nucleação de bolhas provavelmente começa no máximo pico da diferença de temperatura e continua descendo para diferenças de temperatura menores (INCROPERA, et al., 2011; POIRIER; GEIGER, 1994). Na medida em que a temperatura próxima à superfície continua a decrescer, ocorre menos borbulhamento, diminuindo o fluxo de calor, e tornando-se fortemente dependente da convecção natural, perto da superfície do cilindro.

As curvas de resfriamento mostraram algumas mudanças bruscas durante 0 resfriamento, que podem indicar a liberação de calor latente devido a transformações de fase. Para demonstrar este efeito mais claramente, foram derivadas as curvas de resfriamento em função do tempo para uma das experiências (Experimento 1 - aço AISI 4340), como apresentado na Figura 43.

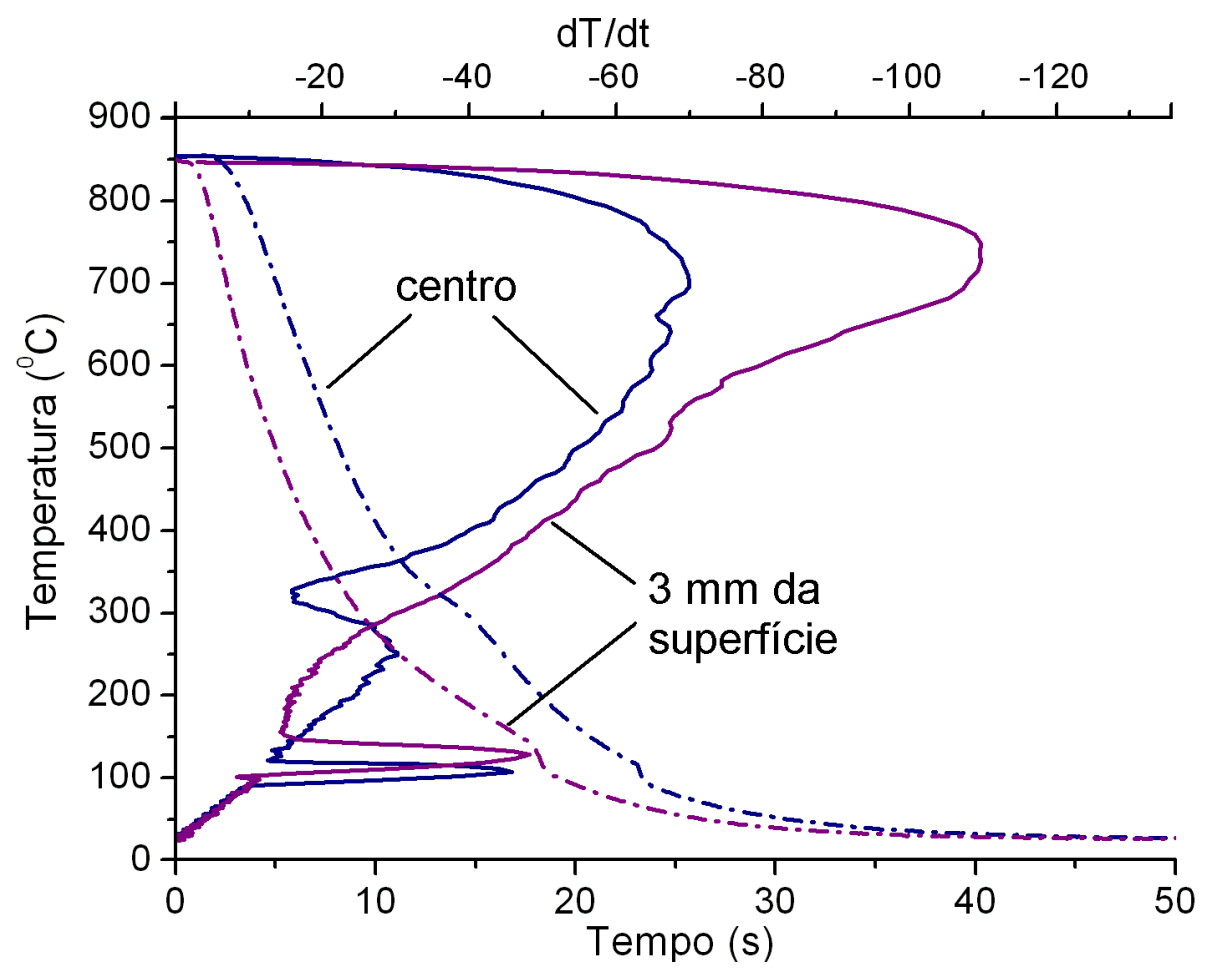

Figura 43 - Derivadasdas curvas de resfriamento para o experimento 1 (AÇO AISI 4340). Tmr e Tc, representam as temperaturas a $3 \mathrm{~mm}$ da superfície e no centro do cilindro, respectivamente. 
A Figura 43 mostra claramente os picos a uma temperatura próxima dos $100^{\circ} \mathrm{C}$, que coincide com as faixas de temperatura propostas na literatura (TROIANO; GRENINGER, 1946; KRAUSS, 1978), para o fim da transformação martensítica $\left(M_{f}\right)$ do aço AISI 4340. As curvas calculadas a partir das temperaturas medidas no centro do cilindro também mostraram um pico cerca aos $320^{\circ} \mathrm{C}$, que estão de acordo com a temperatura de início da transformação martensítica $\left(M_{S}\right)$ para este tipo de aço. Este efeito é provavelmente devido à absorção de calor, que aumenta a taxa de resfriamento, durante a transformação endotérmica de austenita para martensita. Na curva do centro, pode ser observado que a taxa de resfriamento aumenta até $\sim-70{ }^{\circ} \mathrm{C} . \mathrm{s}^{-1}$ próximo dos $700{ }^{\circ} \mathrm{C}$. Para um cilindro de aço de baixa de liga de $38 \mathrm{~mm}$ de diâmetro temperado em água (a $71^{\circ} \mathrm{C}$ ) com agitação, foi observada uma taxa de resfriamento no centro de $\sim-20^{\circ} \mathrm{C} . \mathrm{s}^{-1}$ próximo dos $500^{\circ} \mathrm{C}$ (ASM, 1991). Para esse caso, foi observado um outro patamar na curva da primeira derivada do centro, entre os $800^{\circ} \mathrm{C}$ e os $650^{\circ} \mathrm{C}$, e foi atríbuido à formação da camada de vapor. Quando a temperatura da água de têmpera foi diminuida para 27 ${ }^{\circ} \mathrm{C}$, o patamar e a camada desapareceram, resultando em curvas muito semelhantes às apresentadas no presente trabalho (ASM, 1991).

Quando a água é usada como meio de resfriamento no processo de têmpera, a transferência de calor na superfície é muitas vezes caracterizada com uma curva paramétrica do fluxo de calor versus temperatura da superfície, conhecida como boiling curve. Neste processo, mudanças não-lineares muito rápidas do fluxo de calor ocorrem na medida em que a superfície resfria e o regime de borbulhamento se desenvolve nos três estágios descritos na secção 2.2.6. Os resultados do modelo, da variação na superfície da amostra do fluxo térmico em função do tempo e da temperatura são apresentados na Figura 44. A área sob a curva do transiente de fluxo térmico indica o calor total removido da amostra durante o resfriamento (NARAYAN; PRASAD, 2003). 


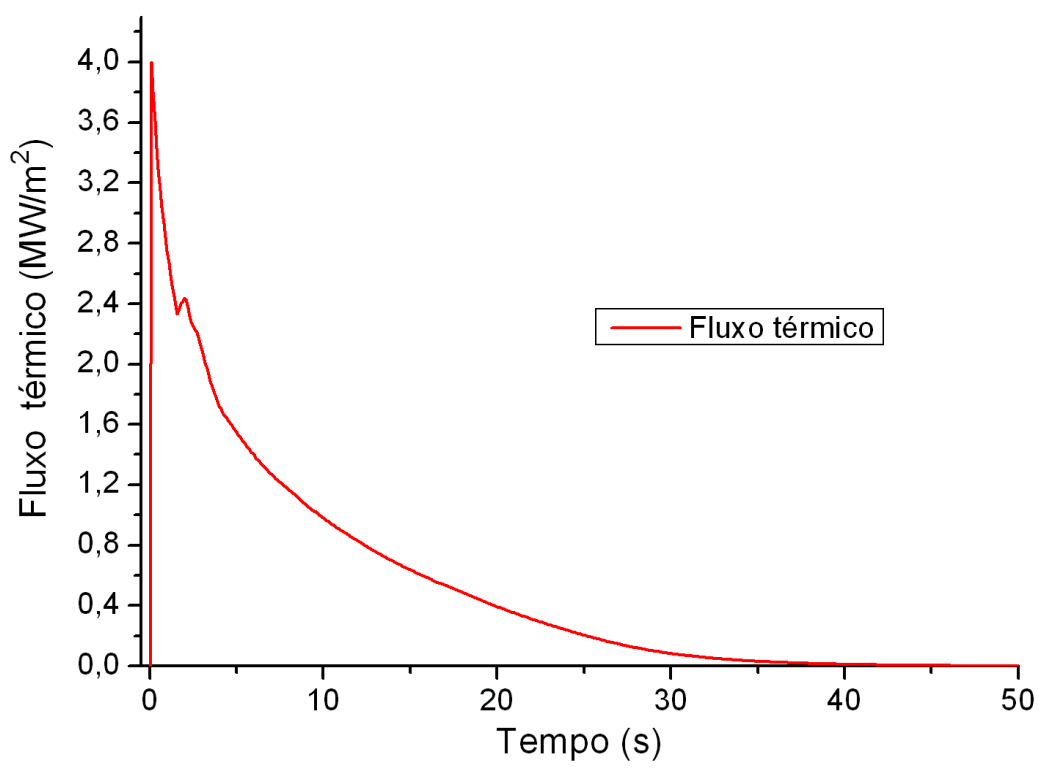

(a)

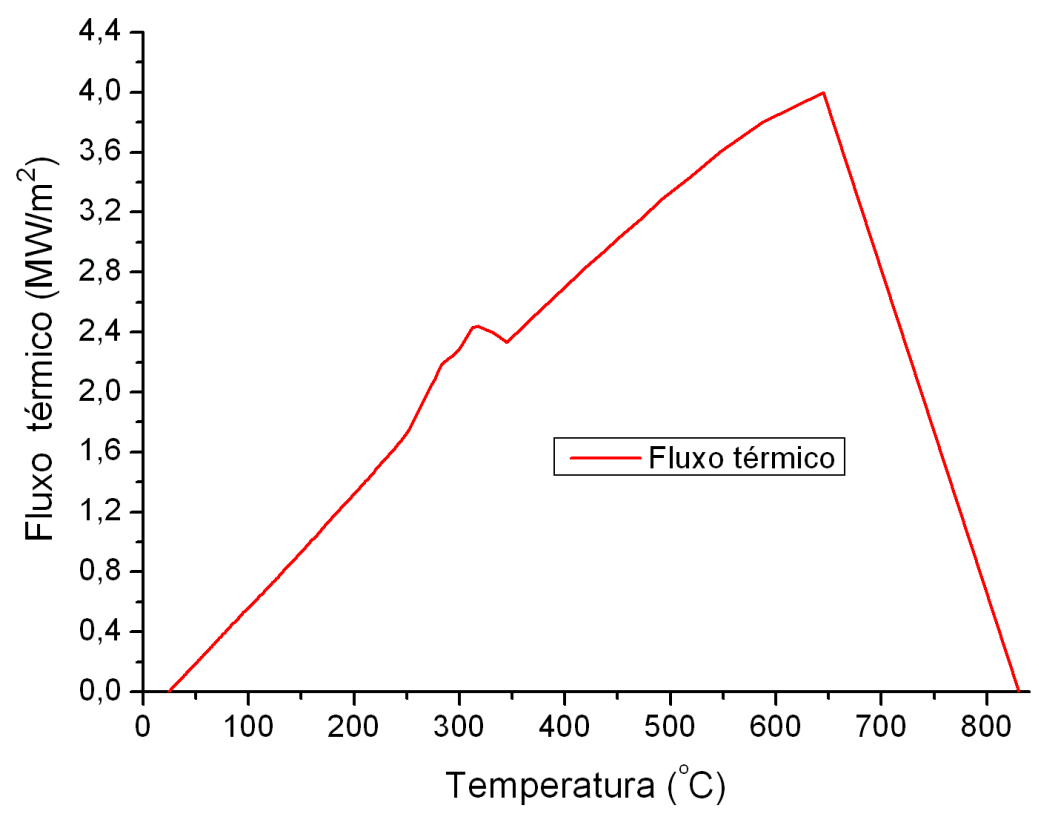

(b)

Figura 44 - Fluxo térmico transiente na superfície do cilindro de aço AISI/SAE 4340, durante a têmpera em água com agitação; (a) em função do tempo; (b) em função da temperatura.

No momento em que o corpo de prova toca a água, esta começa a ferver intensamente com uma elevada taxa de transferência de calor, e o fluxo de calor aumenta rapidamente e se eleva em um curto período de tempo (nos dos primeiros segundos do resfriamento), o que corresponderia com a fase de nucleação de bolhas (segundo estágio de têmpera). Uma vez que o fluxo de calor na superfície atinge o valor crítico (primeiro pico), cai tão rápido quanto aumentou, na medida em 
que os termopares tendem a atingir a temperatura de equilíbrio com o meio de resfriamento, indicando gradientes térmicos desprezíveis no interior do cilindro. Já no final da têmpera, terceiro estágio da têmpera onde a transferência de calor é predominantemente convectiva, a inclinação diminui lentamente. Este perfil complexo do fluxo de calor na superfície é causado pelos diferentes estágios de resfriamento pela água (BABU; PRASANA, 2010). A ocorrência do pico na curva do fluxo térmico pode estar associada com o máximo gradiente térmico existente no interior da amostra temperada (NARAYAN; PRASAD, 2003; FERNANDES; NARAYAN, 2007). Um segundo pico de fluxo de calor formou-se no final do resfriamento, e a magnitude deste pico é pequena se comparado com o do primeiro pico de fluxo de calor, e pode indicar uma reação endotérmica de transformação de fase. Estes picos de fluxo de calor (primeiro pico) aumentarão com o aumento da agitação do meio de têmpera (FERNANDES; NARAYAN, 2007) e depende das temperaturas do meio de resfriamento e das dimensões e condutividade da amostra temperada (BABU; PRASANA, 2010).

\subsubsection{Calor latente}

Com a finalidade de comparar o efeito do calor latente de transformação na evolução da temperatura e das tensões residuais durante a têmpera, foram feitos dois modelos, um incluindo e outro não incluindo o calor latente de transformação.

Para os modelos incluindo o calor latente, foram testados os valores propostos tanto por Lee e Lee (2008), como por Oliveira et al. (2010), apresentados na secção 4.2.6.4.1, tendo obtido resultados mais próximos às curvas experimentais com o segundo trabalho.

Ao comparar dois modelos numéricos desenvolvidos com e sem a inclusão do calor latente de transformação percebe-se uma apreciável diferença na temperatura de resfriamento (inflexões características da liberação de calor quando há transformação) ao redor da temperatura próxima ao início da transformação martensítica para este aço, como pode ser observado na Figura 45. Nessa figura são mostrados os históricos de variação de temperatura calculados a 0 R, 0,23 R e 
0,55 $\mathrm{R}$ (onde $\mathrm{R}$ é o raio do cilindro, $25,4 \mathrm{~mm}$ ). As linhas tracejadas representam os resultados da modelagem em que o efeito do calor latente foi desprezado, enquanto as linhas contínuas são realizadas a partir da modelagem em que o efeito do calor latente de transformação foi incluído. O tempo necessário para o cilindro resfiar até à sua temperatura final é aparentemente maior quando o efeito do calor latente é incluído no cálculo. Ao analisar as curvas no ponto dois da amostra, tem-se que a média da diferença entre a curva sem e com inclusão do calor latente é de $27^{\circ} \mathrm{C}$, sendo a maior diferença de $55^{\circ} \mathrm{C}$, ao redor dos $18 \mathrm{~s}$. Uma vez que os resultados do modelo numérico incluindo o calor latente de transformação se ajustaram melhor às curvas obtidas experimentalmente, se evidência a necessidade de incluir o calor latente associado à transformação de fase no cálculo do histórico de temperatura e das microestruturas produzidas durante a têmpera de cilindros de aço. Os resultados das tensões residuais dos modelos com e sem calor latente, mostraram uma diferença de aproximadamente $20 \mathrm{MPa}$ como será mostrado no item 5.6.

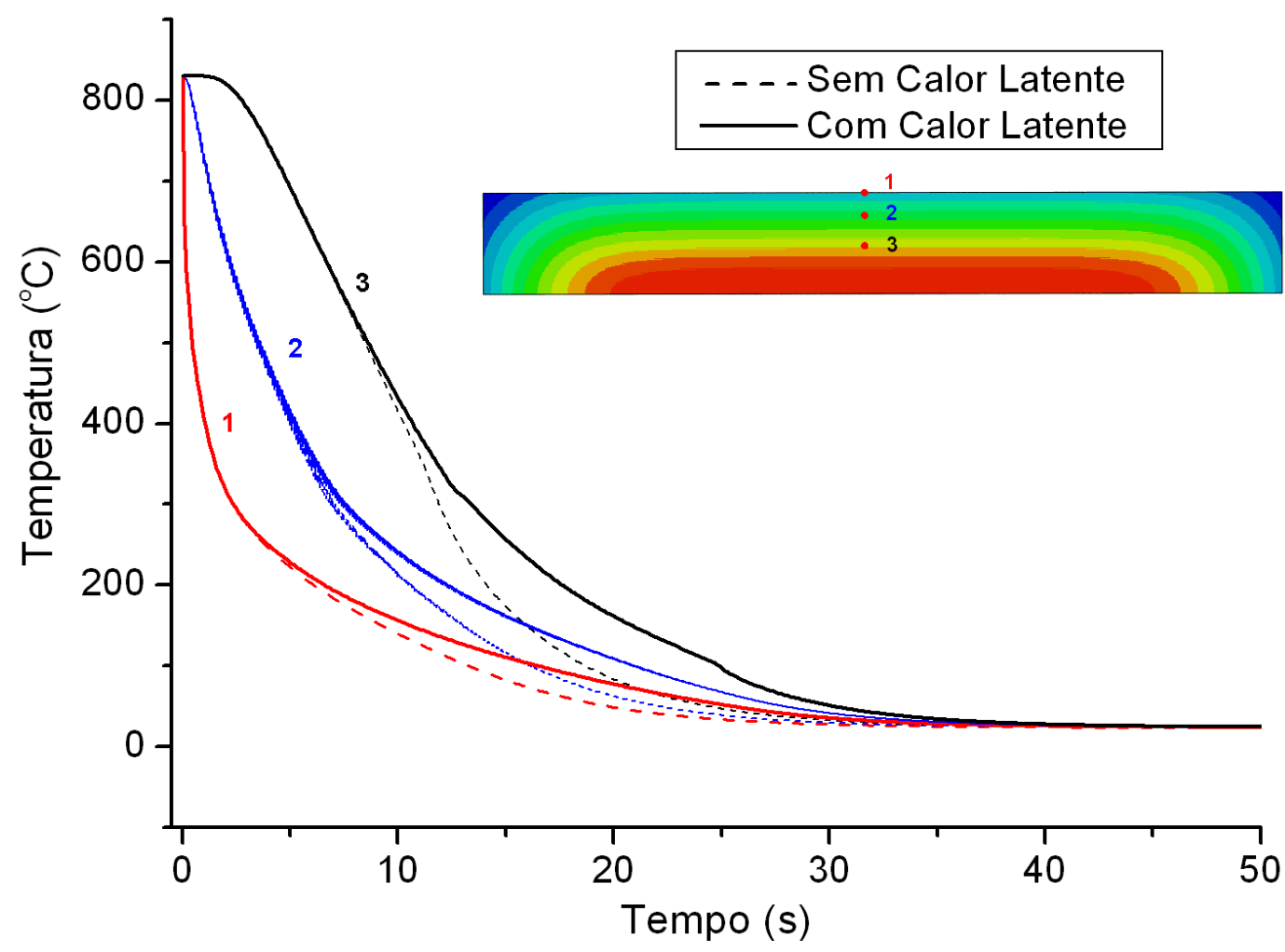

Figura 45 - Curvas de resfriamento temperatura - tempo. As curvas tracejadas indicam as curvas sem a inclusão do calor latente de transformação e as curvas contínuas as que incluíram o calor latente de transformação durante a têmpera em água com agitação para uma barra cilíndrica de $25,4 \mathrm{~mm}$ de diâmetro. Os números 1,2 e 3, indicam os históricos de variação de temperatura calculados em 0 R, 0,23 R e 0,55 $R$, respectivamente (onde $R$ é o raio do cilindro). 


\subsection{ANÁLISE METALOGRÁFICA}

As micrografias da superfície, da região intermediária e do centro dos cilindros de Aço AISI/SAE 4340, 4140 e 1045, resultantes da têmpera em água com agitação, são mostradas nas Figura 46 a 51.

As microestruturas para o aço AISI/SAE 4340 estão mostradas nas Figuras 46, 47 e 48, correspondentes à região superficial, intermediária e central, respectivamente. Estas microestruturas consistem de uma estrutura totalmente martensítica.

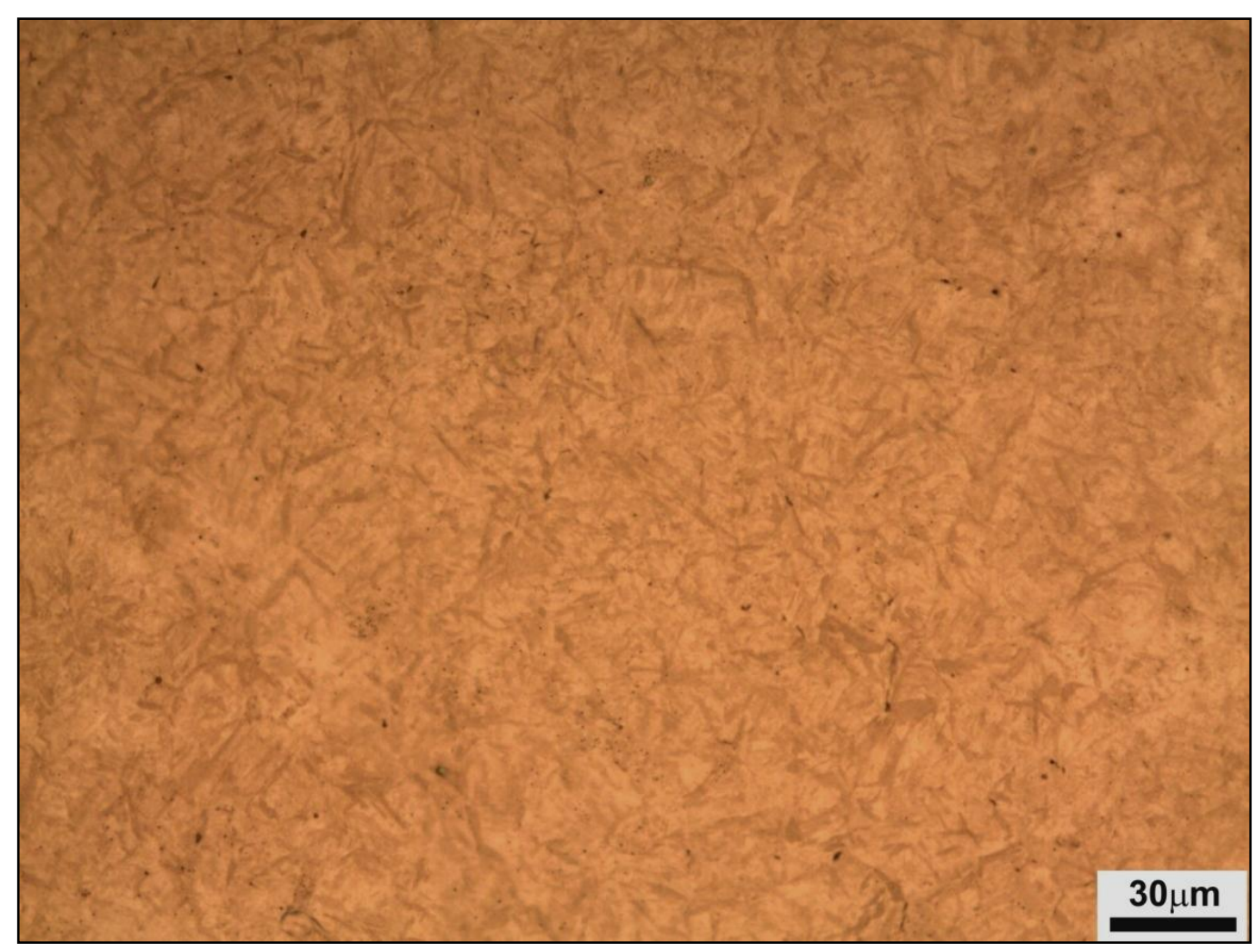

(a) 


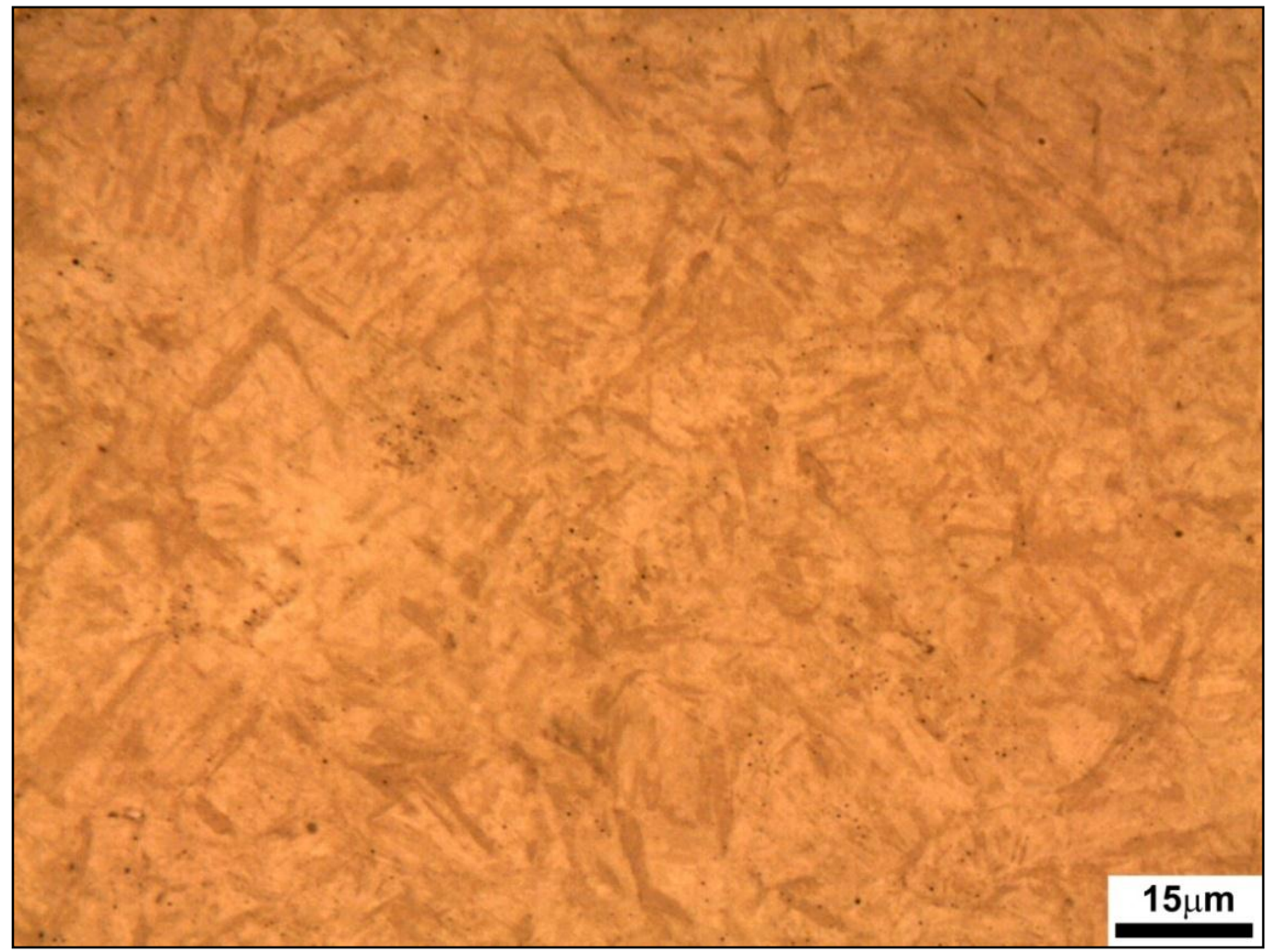

(b)

Figura 46 - Microestruturas da superfície do aço AISI 4340 após tratamento térmico de têmpera em água com agitação. (a) Aumento 500x; (b) Aumento 1000x. Ataque LePera modificado.

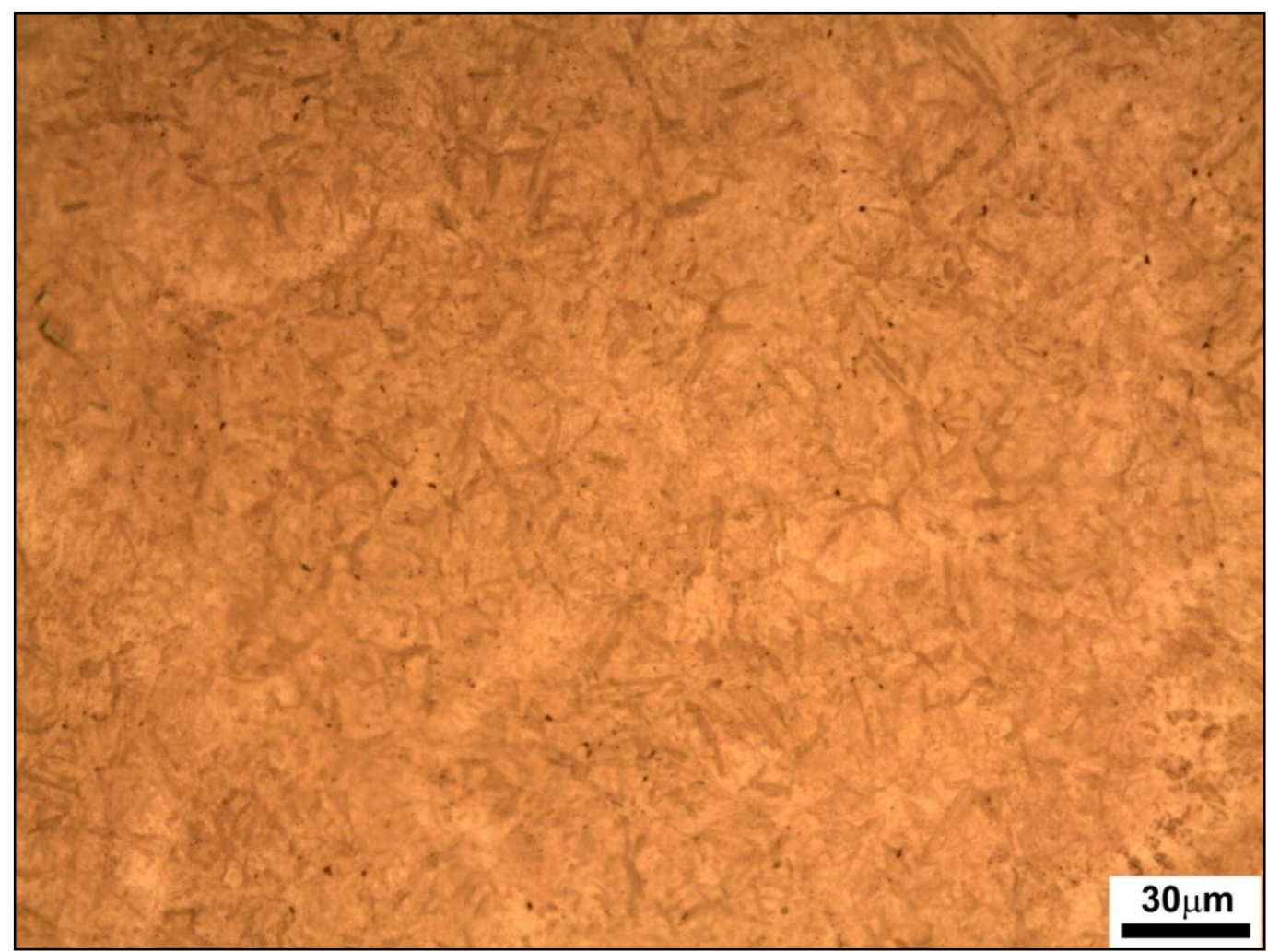

(a) 


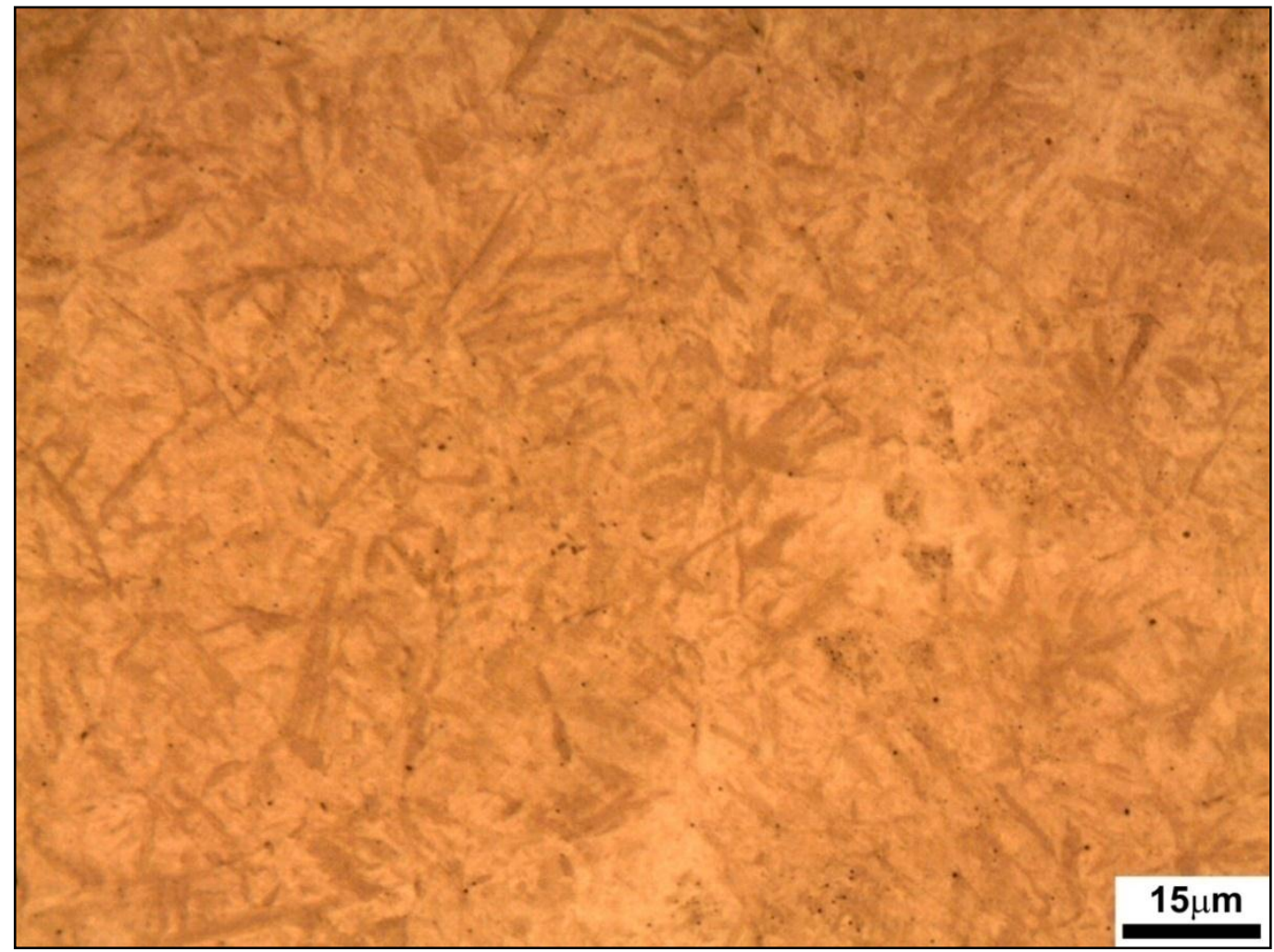

(b)

Figura 47 - Microestruturas da parte intermediária do aço AISI 4340 após tratamento térmico de têmpera em água com agitação. (a) Aumento 500x; (b) Aumento 1000x. Ataque LePera modificado.

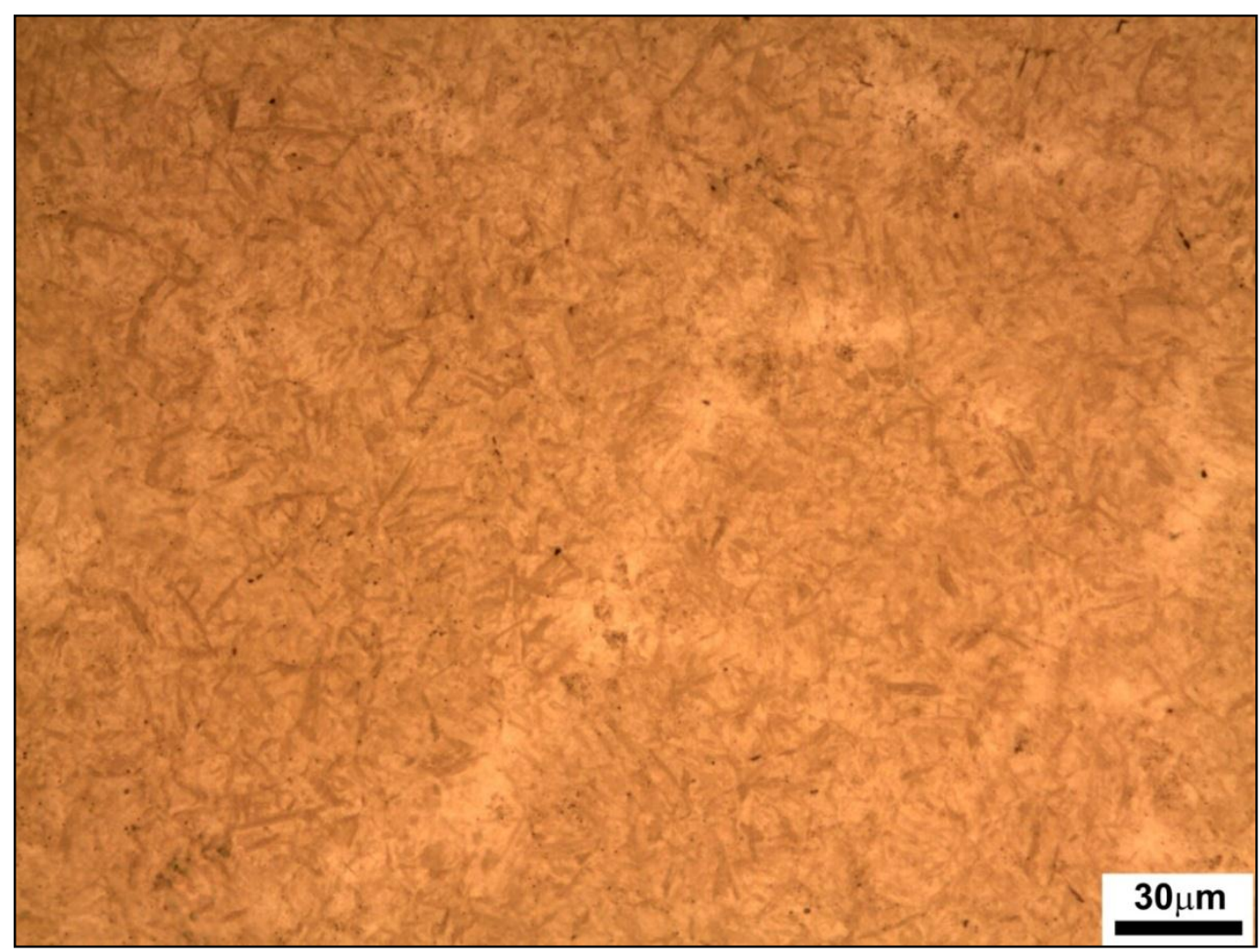

(a) 


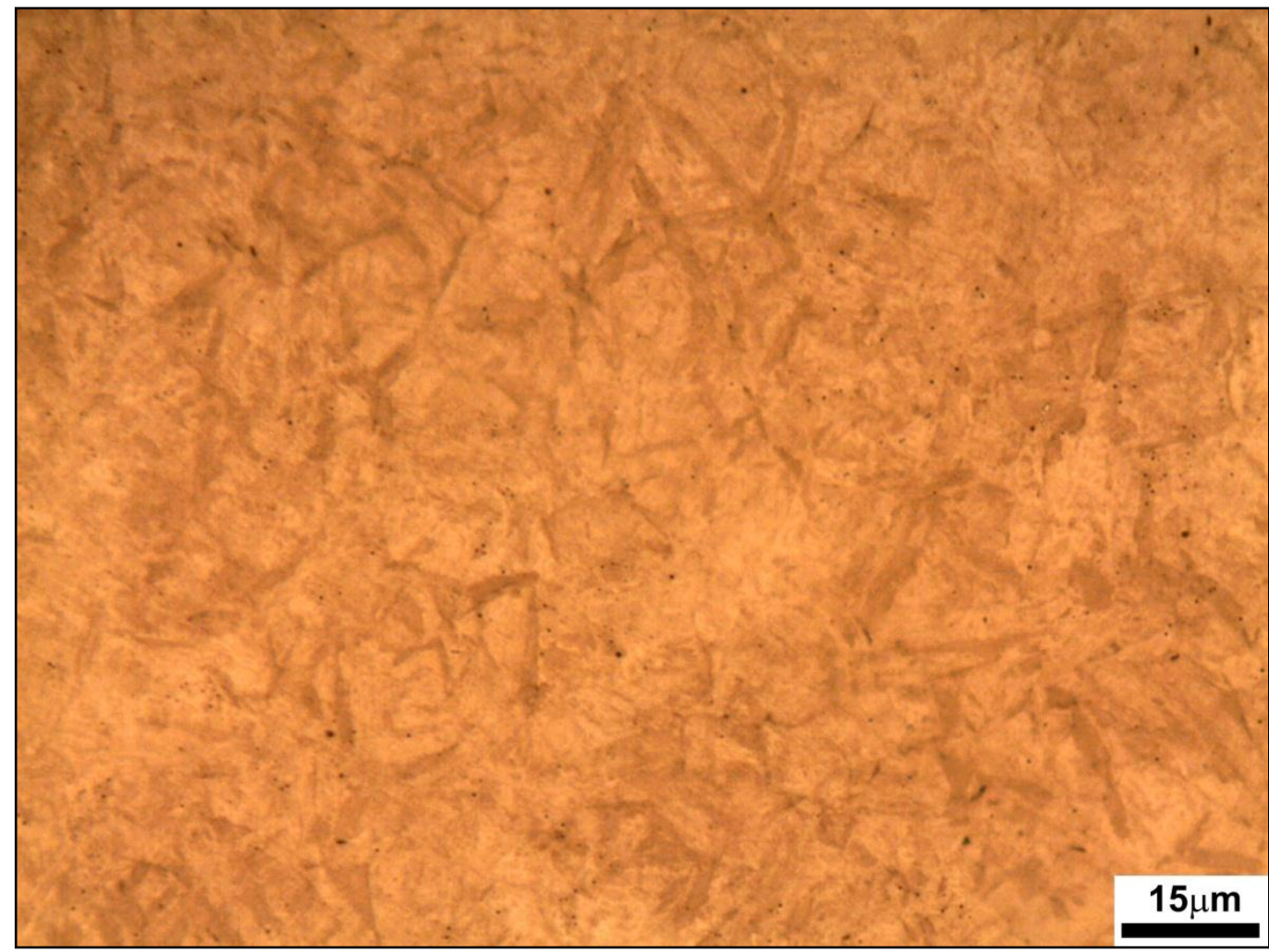

(b)

Figura 48 - Microestruturas da parte central do aço AISI 4340 após tratamento térmico de têmpera em água com agitação. (a) Aumento 500x; (b) Aumento 1000x. Ataque LePera modificado.

As micrografias para o aço AISI 4140 são apresentadas nas Figuras 49, 50 e 51, correspondentes à região superficial, intermediária e central, respectivamente. Estas microestruturas consistem basicamente de martensita com um pouco de bainita, em forma de finas ripas paralelas, com tonalidade marrom escura, possivelmente nucleada a partir dos contornos de grão austeníticos, em diferentes orientações cristalográficas. Nas micrografias da superfície da peça (Figura 49), se observa a maior predominância da estrutura martensítica, com pequenas ripas paralelas de bainita com tonalidade marrom escuro. Nas regiões intermediárias e centrais (Figuras 50 e 51) a mudança da porcentagem de bainita não se mostrou significativa. 


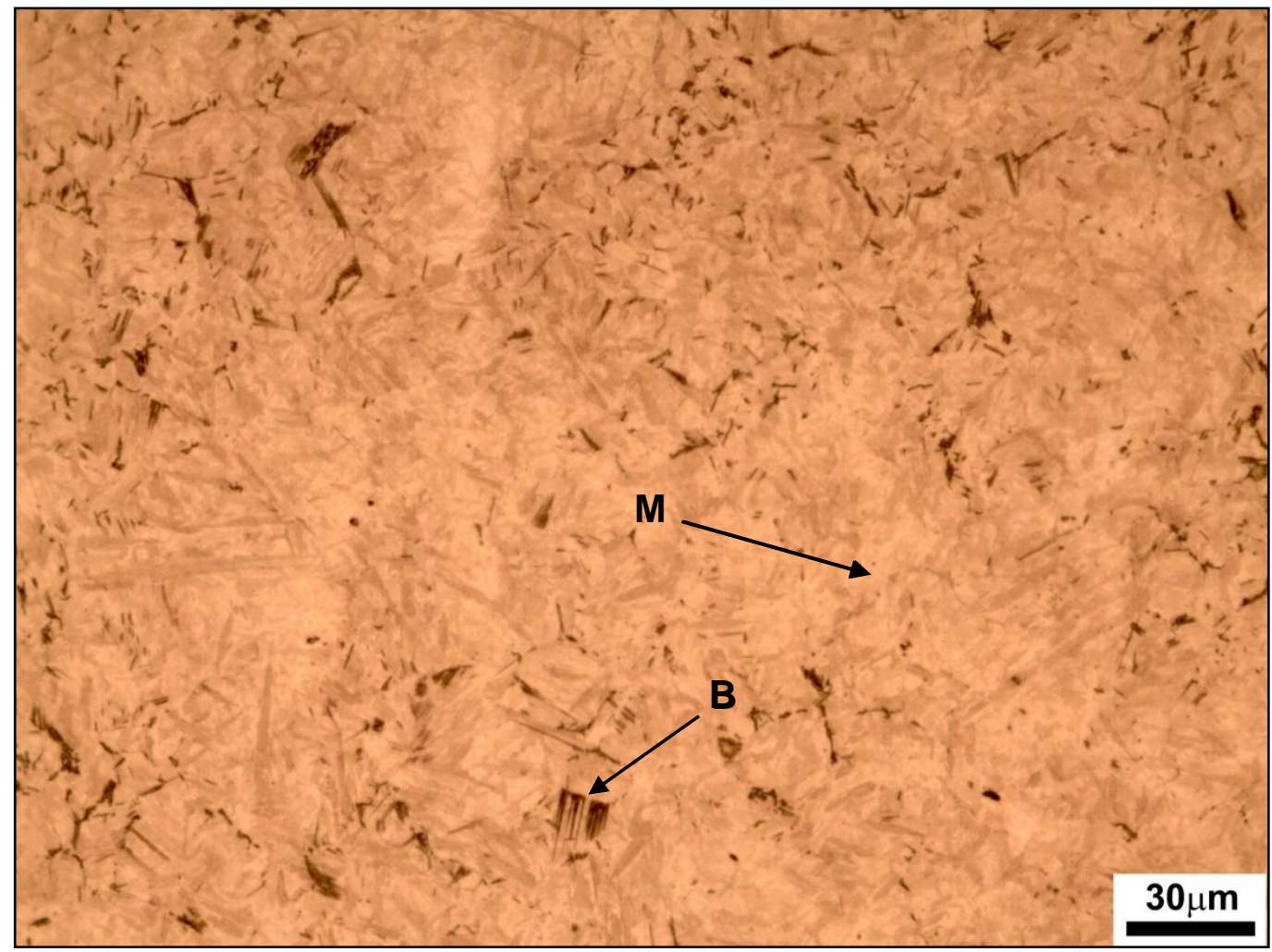

(a)

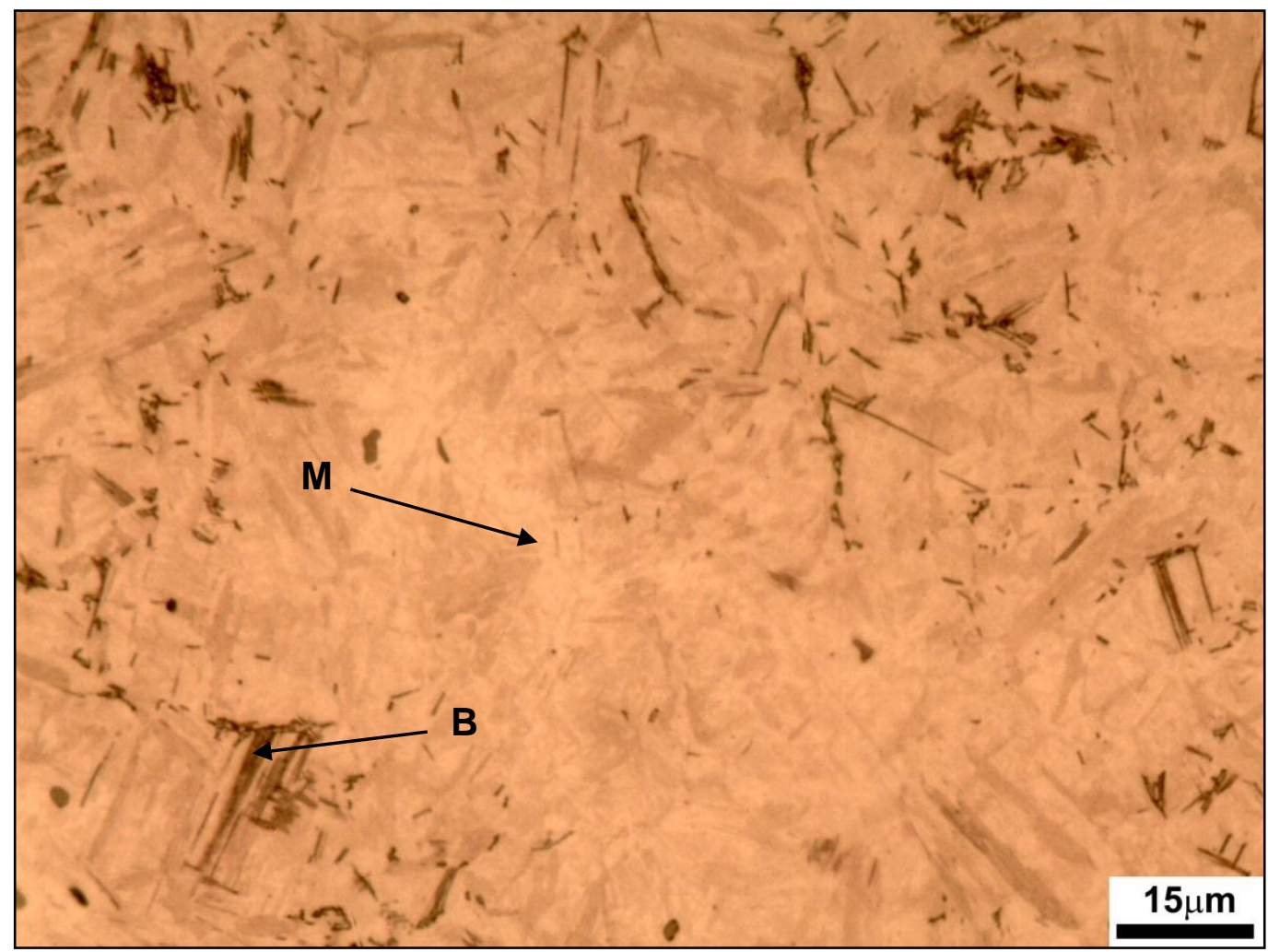

(b)

Figura 49 - Microestruturas da superfície do aço AISI 4140 após tratamento térmico de têmpera em água com agitação. (a) Aumento 500x; (b) Aumento 1000x. Ataque LePera modificado. B (Bainita), M (Martensita). 


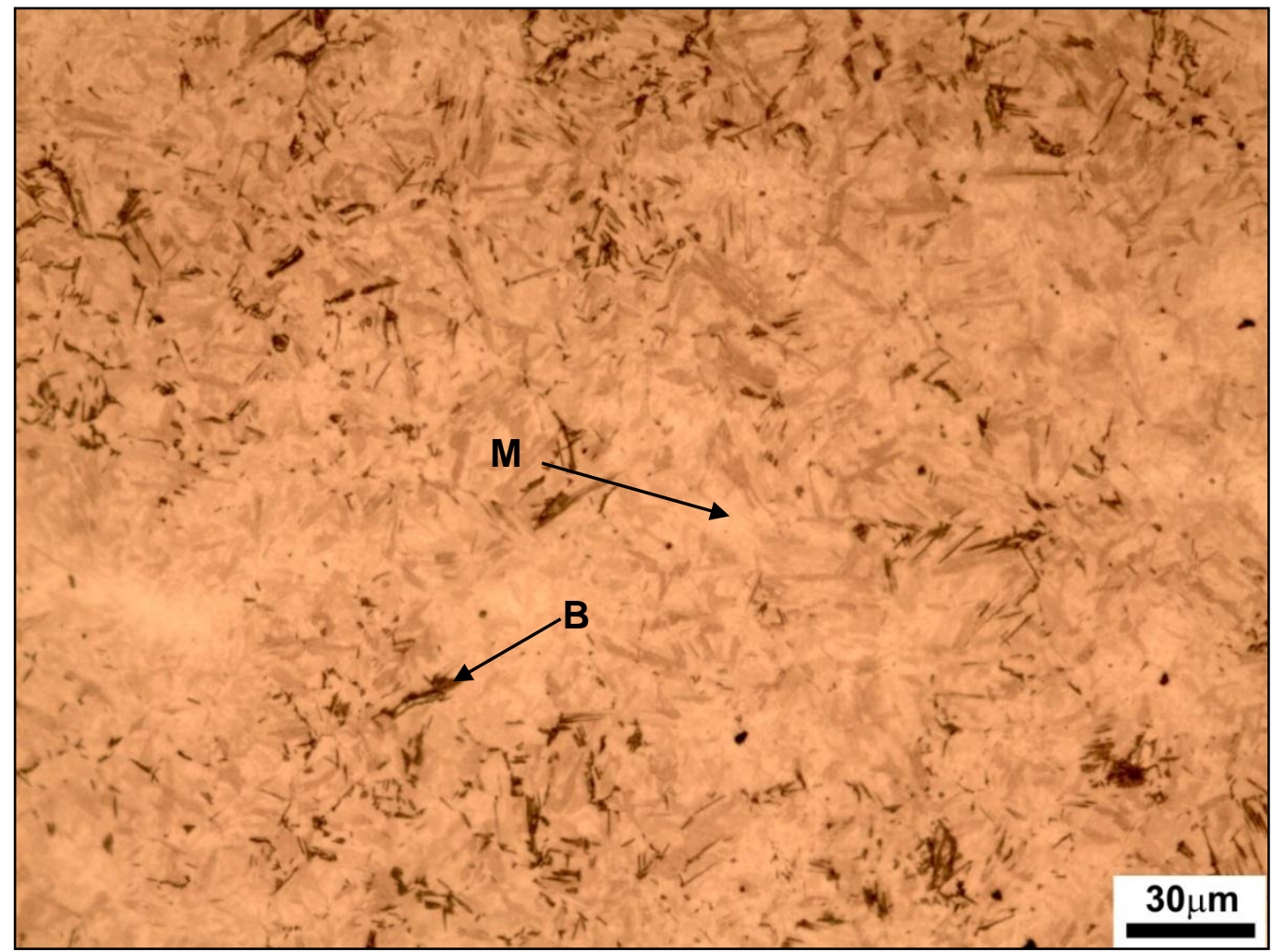

(a)

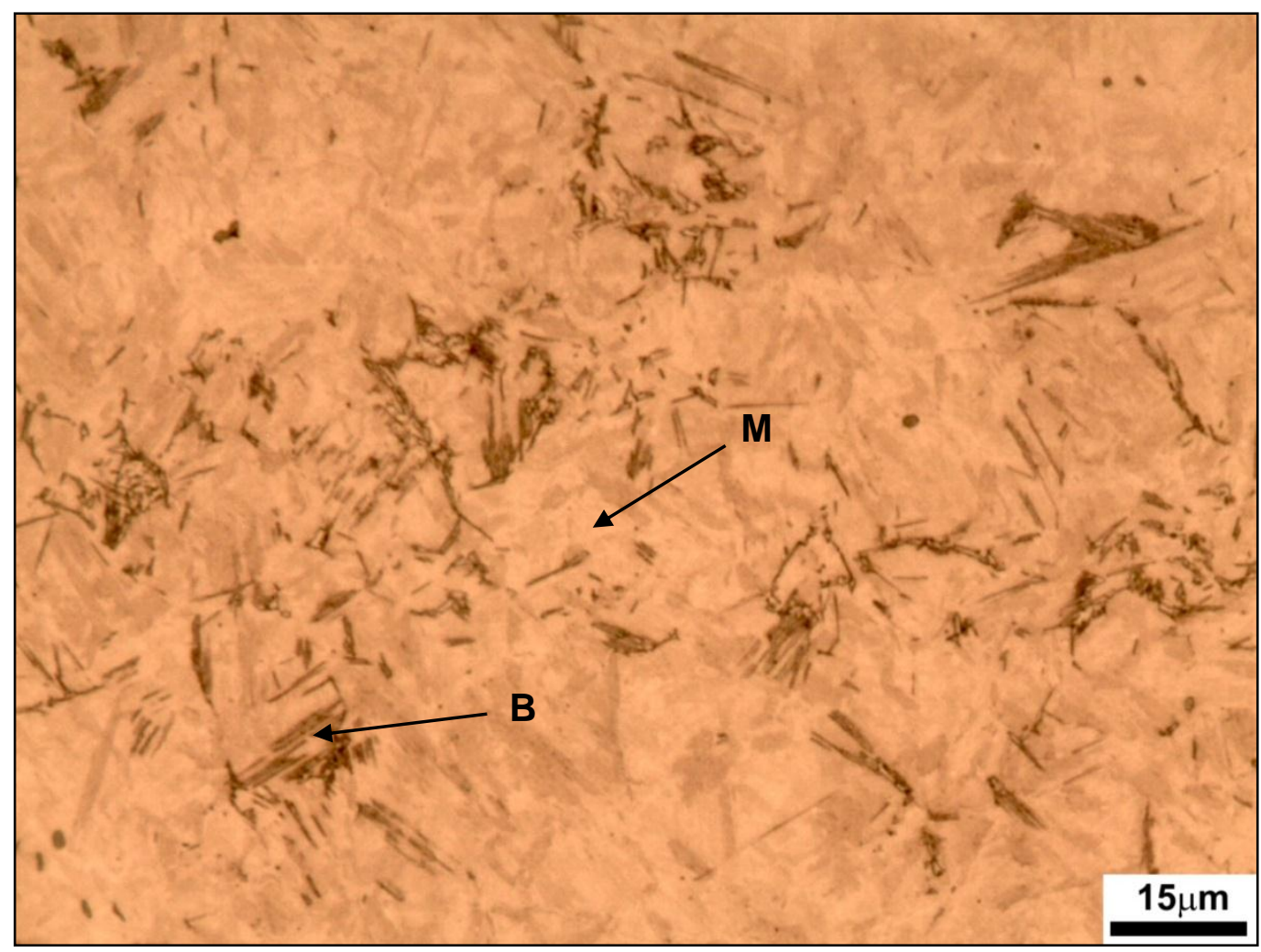

(b)

Figura 50 - Microestruturas da parte intermediária do aço AISI 4140 após tratamento térmico de têmpera em água com agitação. (a) Aumento 500x; (b) Aumento 1000x. Ataque LePera modificado. B (Bainita), M (Martensita). 


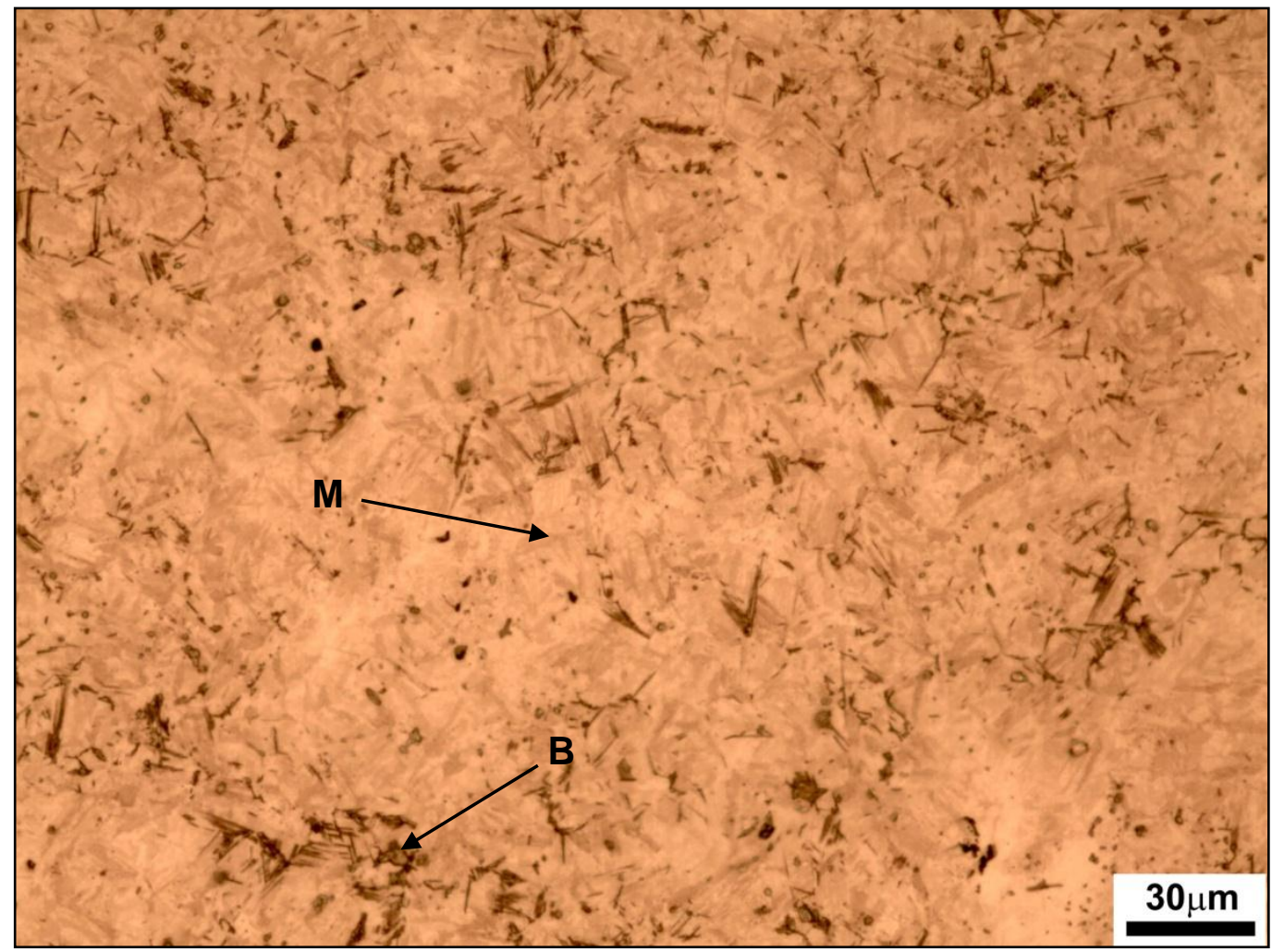

(a)

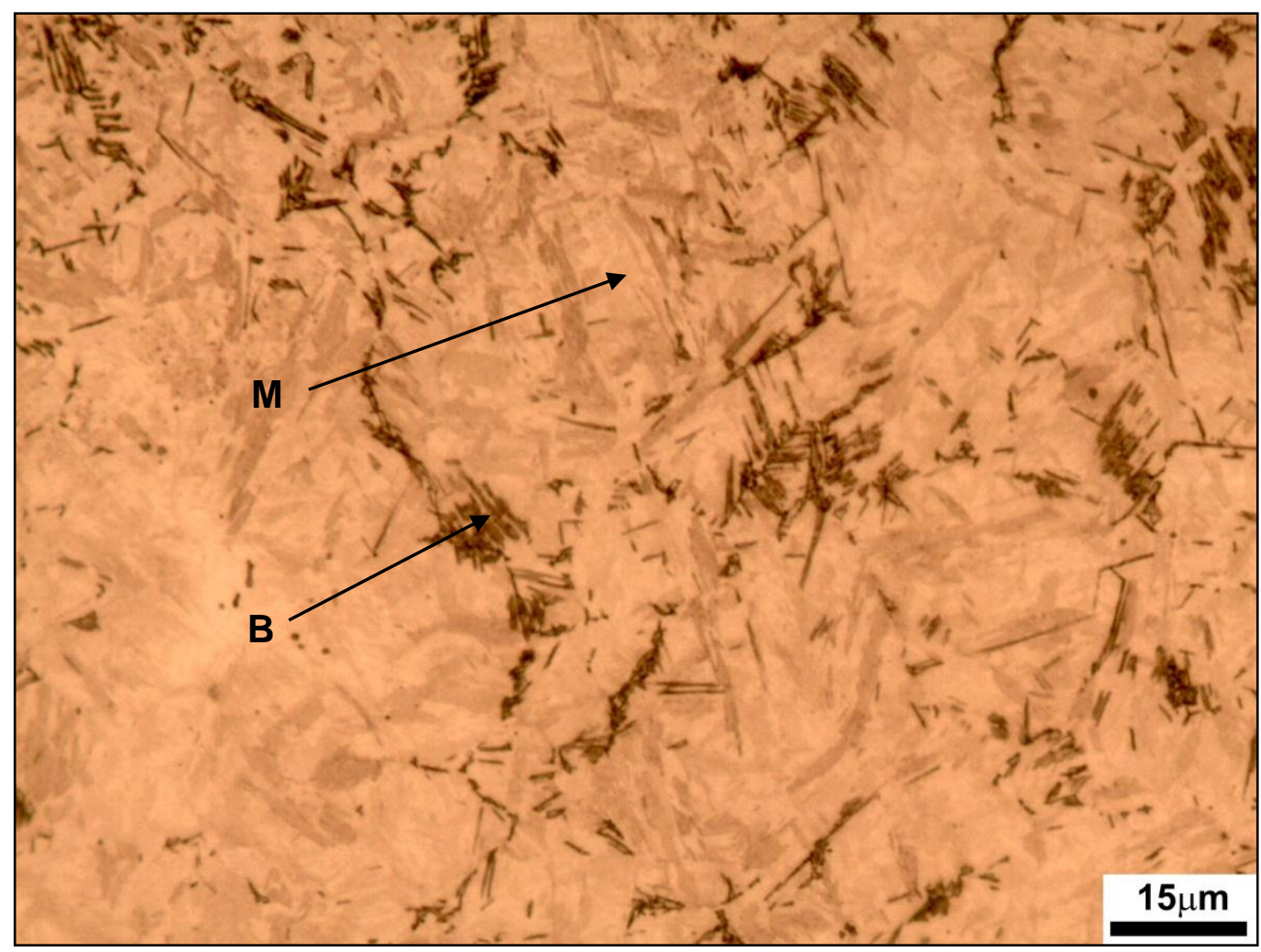

(b)

Figura 51 - Microestruturas da parte central do aço AISI 4140 após tratamento térmico de têmpera em água com agitação. (a) Ampliação 500x; (b) Ampliação 1000x. Ataque LePera modificado. B (Bainita), M (Martensita). 
As micrografias do aço AISI 1045 são apresentadas nas Figuras 52, 53 e 54, correspondentes à região superficial, intermediária e central, respectivamente. Nestas micrografias observa-se matriz martensítica (tonalidade mais clara) e nos contornos observam-se nódulos com tonalidade escura (preta ou marrom escuro) indicando que houve formação de perlita fina. Observa-se também, um produto acicular que se projeta para dentro dos grãos, essa morfologia corresponde à bainita (tonalidade escura em forma de agulha).

A Figura 52 apresenta alta porcentagem de martensita, e nos contornos de grão observam-se pequenas quantidades de perlita muito fina e bainita superior.

Nas Figuras 53 e 54 percebe-se considerável aumento da porcentagem de perlita, enquanto que a estrutura martensítica vai diminuindo notavelmente, nesta mesma direção. Já a estrutura bainítica, não apresenta notáveis modificações ao longo da secção transversal do cilindro.

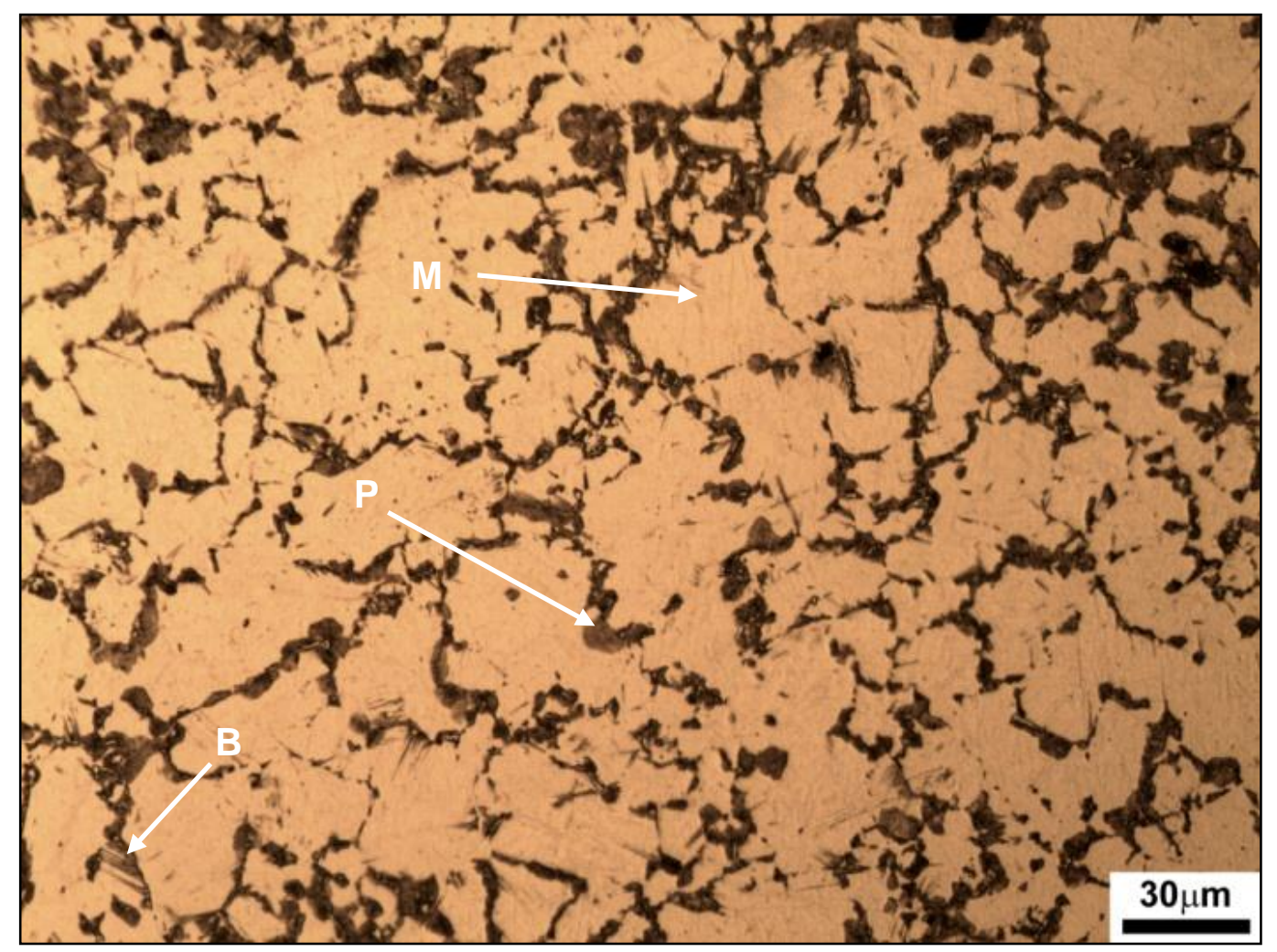

(a) 


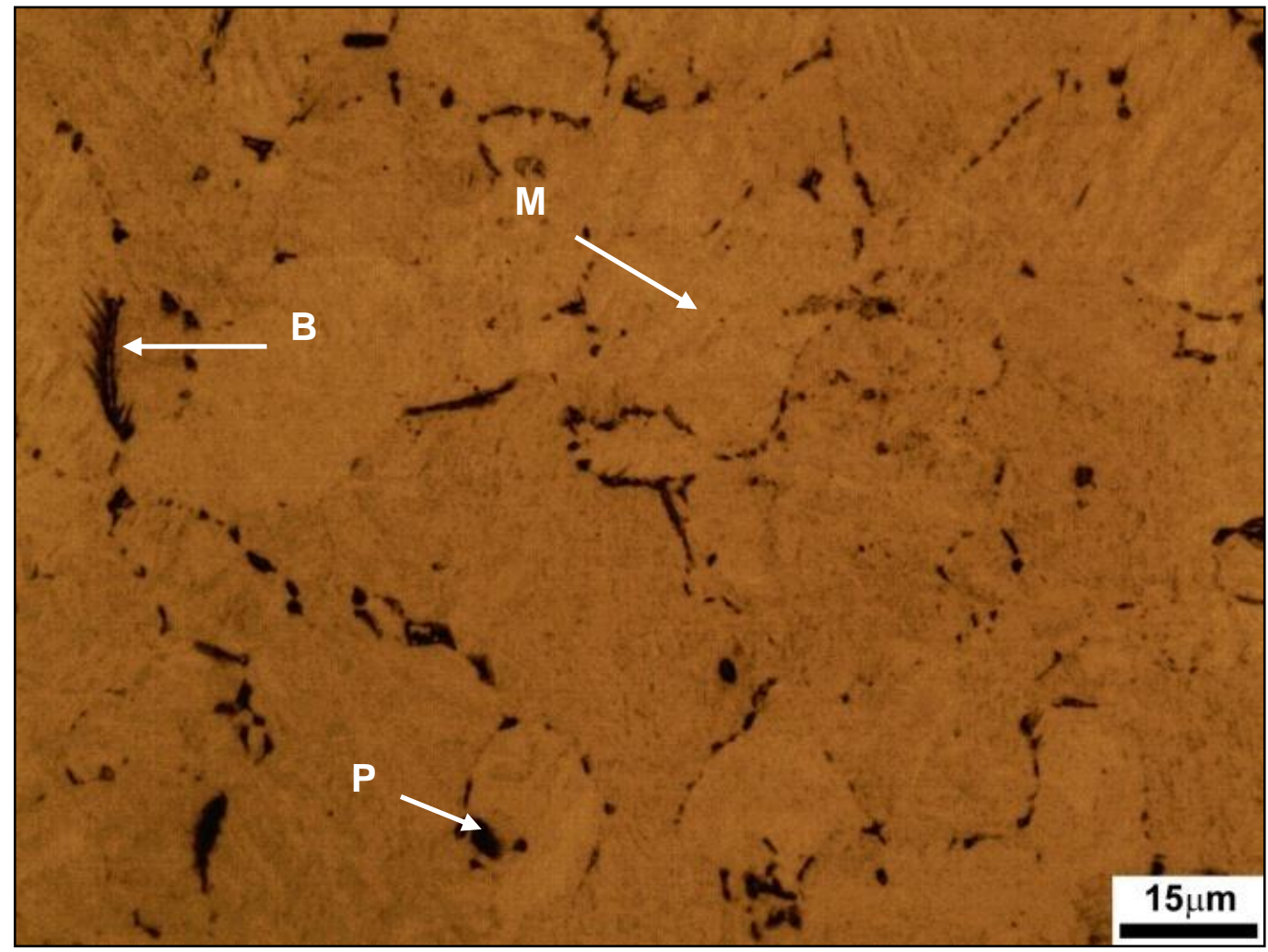

(b)

Figura 52 - Microestruturas da superfície do aço AISI 1045 após tratamento térmico de têmpera em água com agitação. (a)Aumento 500x; (b)Aumento 1000x. Ataque Nital 2\% e Vilella. B (Bainita), M (Martensita), P (Perlita).

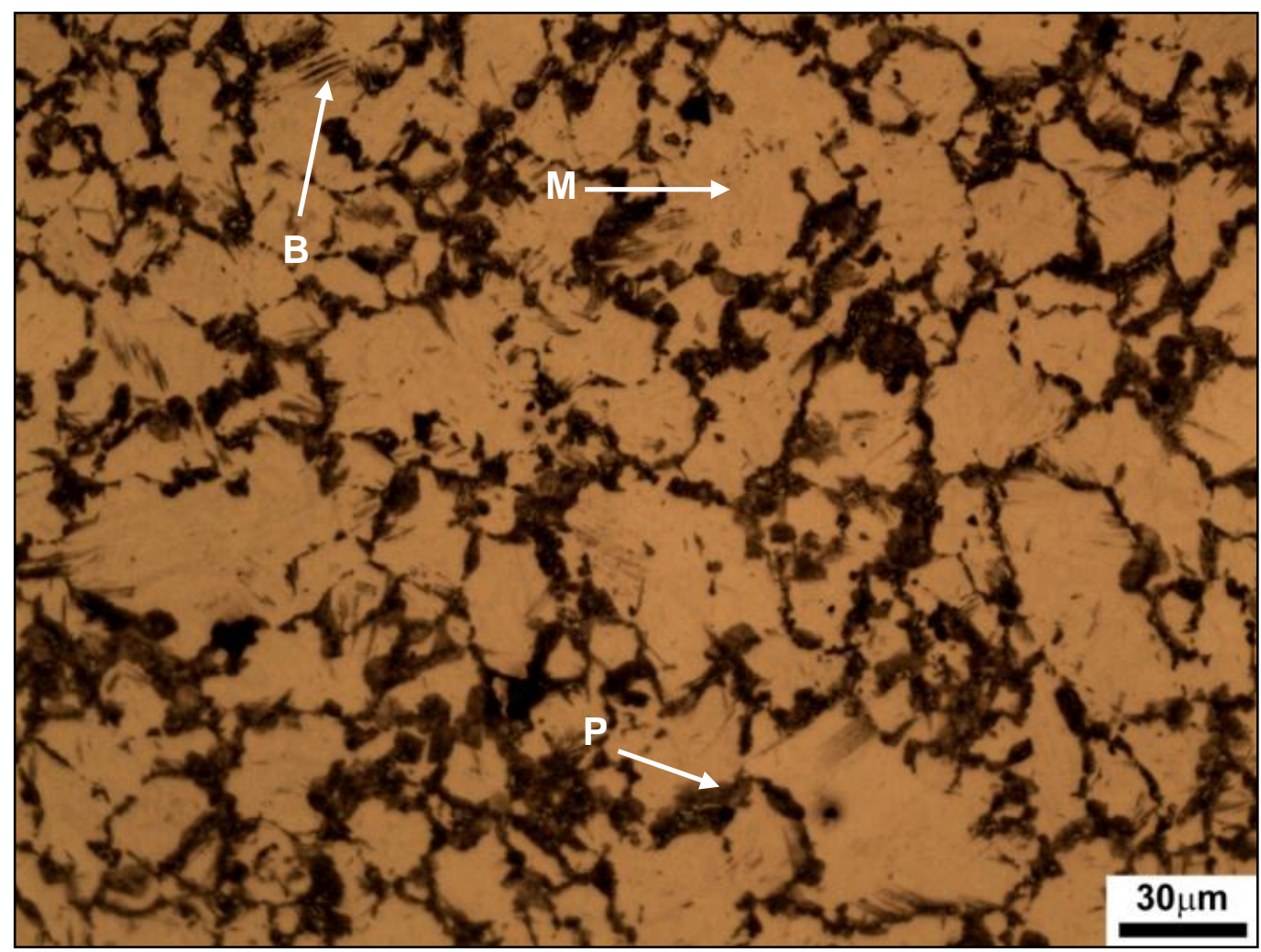

(a) 


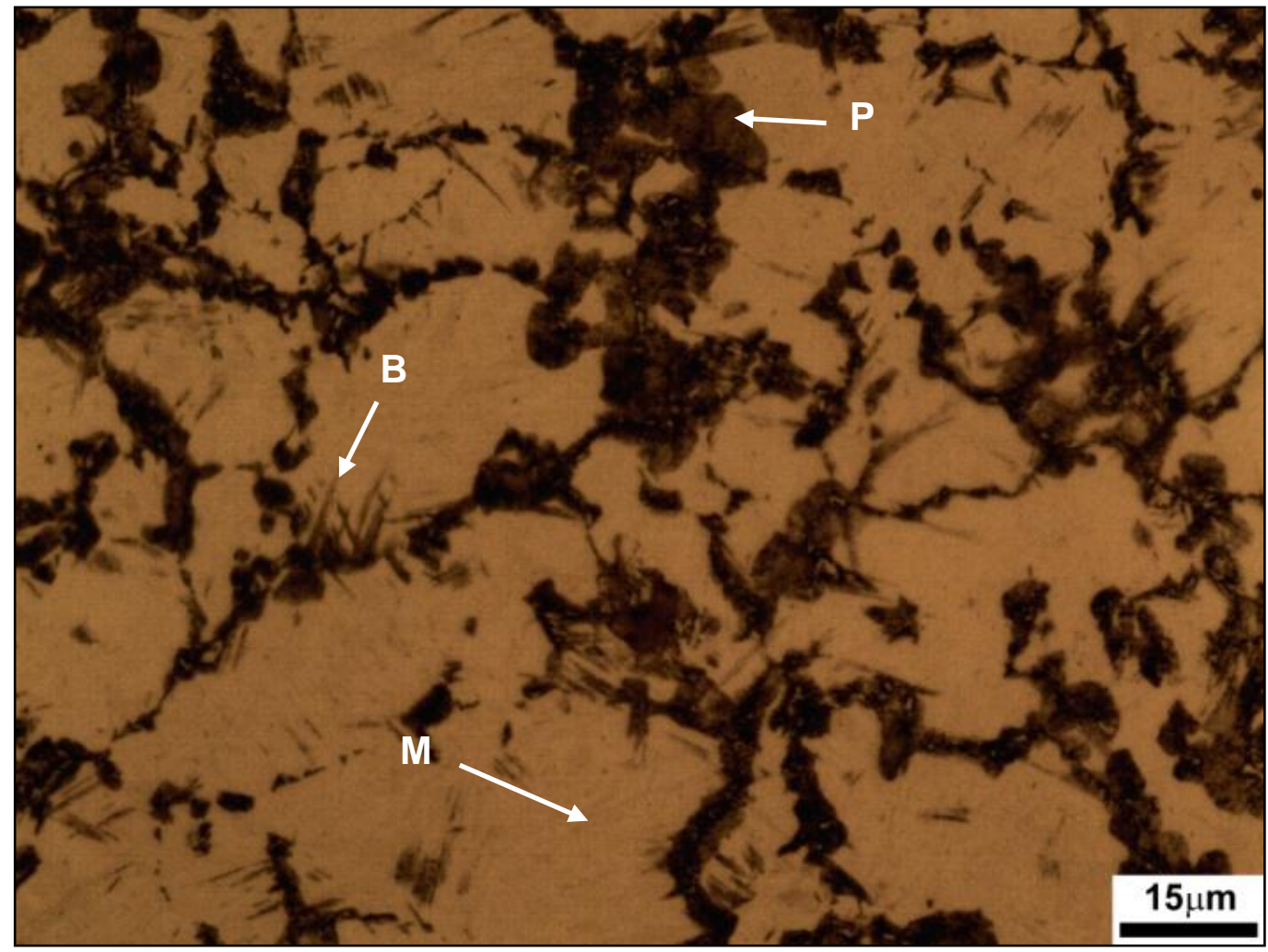

(b)

Figura 53- Microestruturas da parte intermediária do aço AISI 1045 após tratamento térmico de têmpera em água com agitação. (a) Aumento 500x; (b) Aumento 1000x. Ataque Nital 2\% e Vilella. B (Bainita), M (Martensita), P (Perlita).

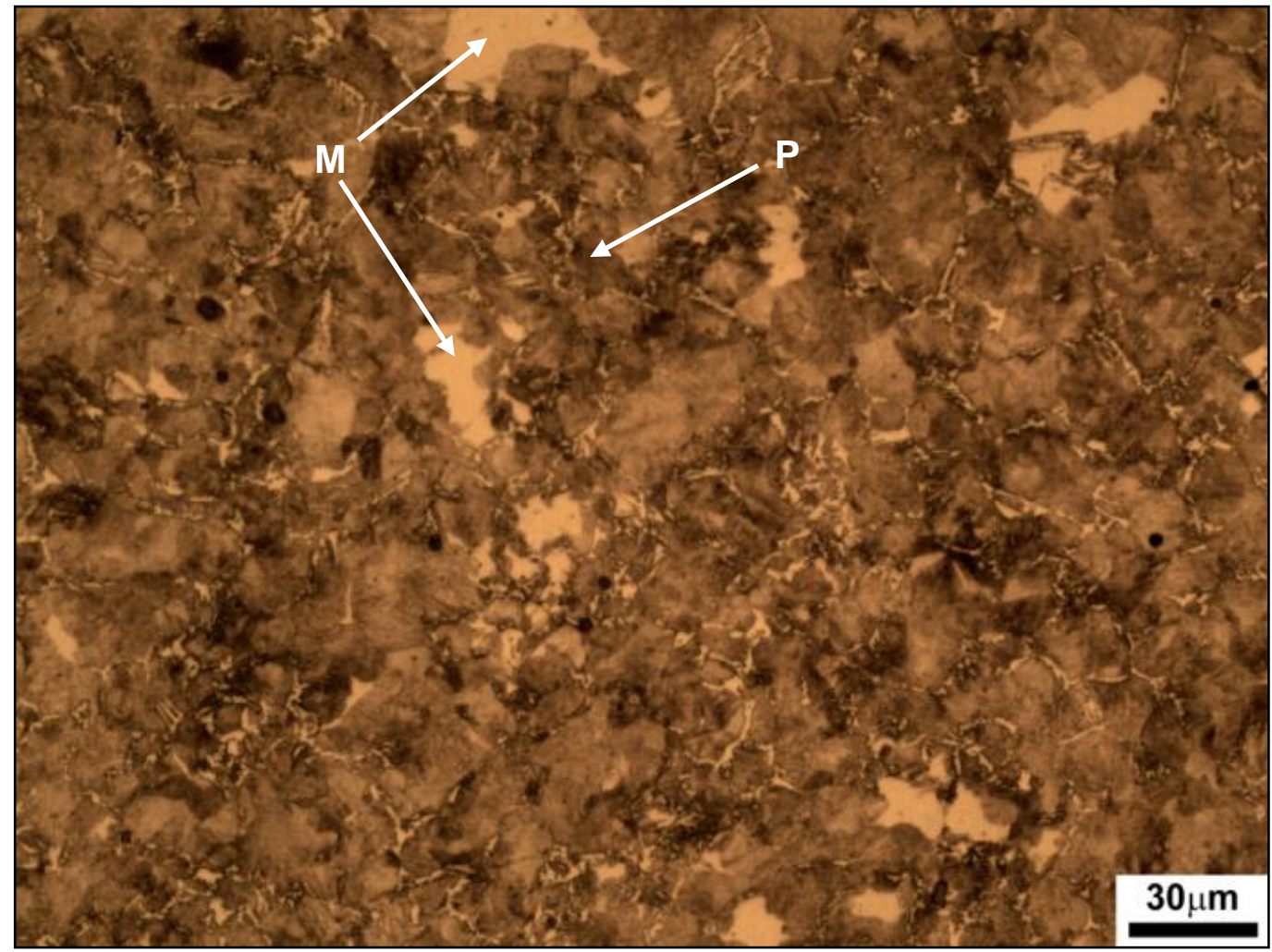

(a) 


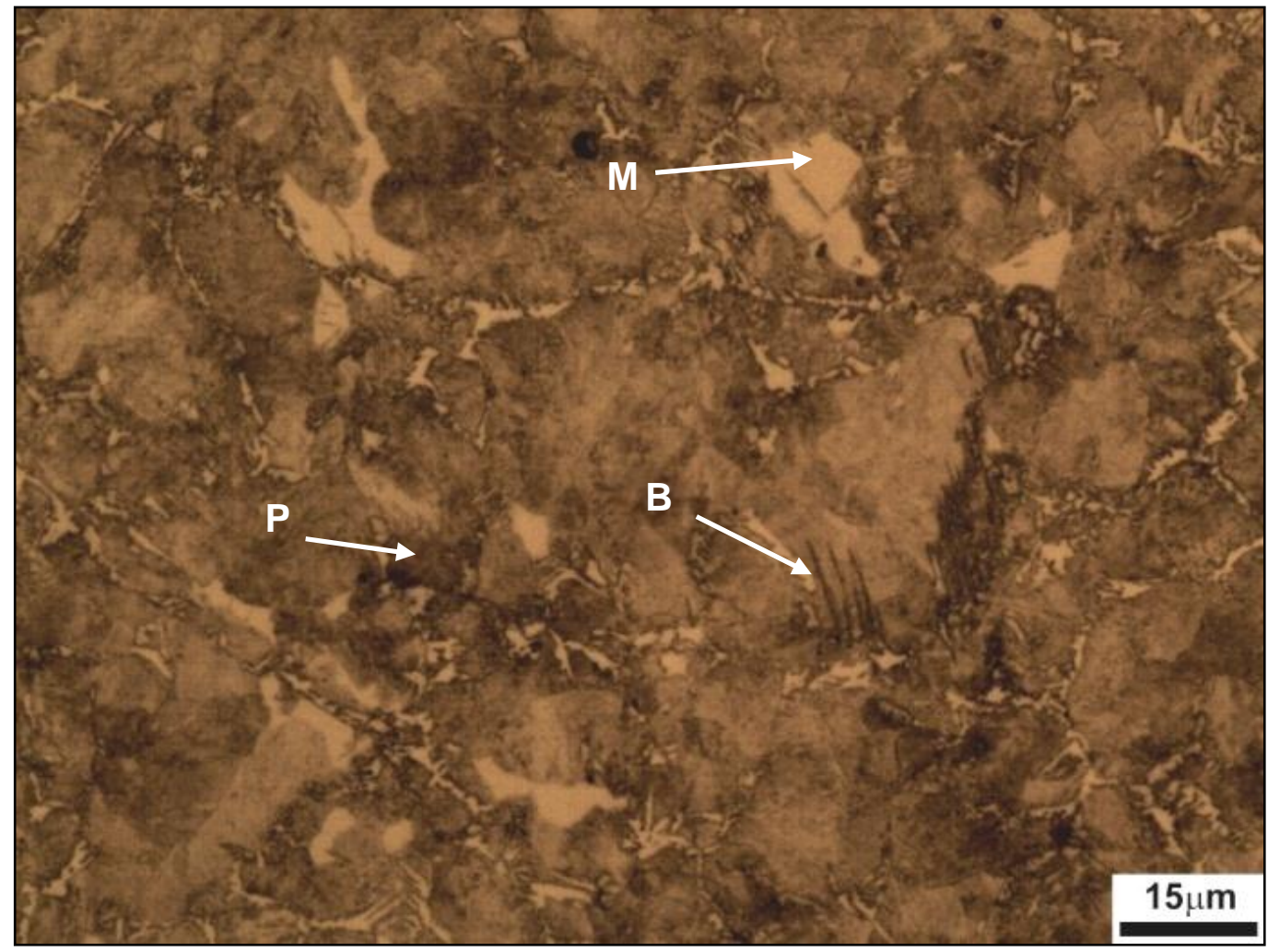

(b)

Figura 54 - Microestruturas da parte central do aço AISI 1045 após tratamento térmico de têmpera em água com agitação. (a) Aumento 500x; (b) Aumento 1000x. Ataque Nital 2\% e Vilella. B (Bainita), M (Martensita), P (Perlita).

A partir da análise das microestruturas resultantes dos tratamentos térmicos pode-se observar que quanto maior a temperabilidade do aço, maior é a quantidade de martensita presente e menor a quantidade de perlita, ferrita e bainita.

É importante ressaltar que nas microestruturas dos aços AISI 4340 e 4140 , foram observadas algumas regiões que apresentaram segregação, como mostrado na Figura 55. Esta segregação é resultante do processo de solidificação do aço, e é uma consequência da rejeição de soluto para determinadas regiões da microestrutura. 


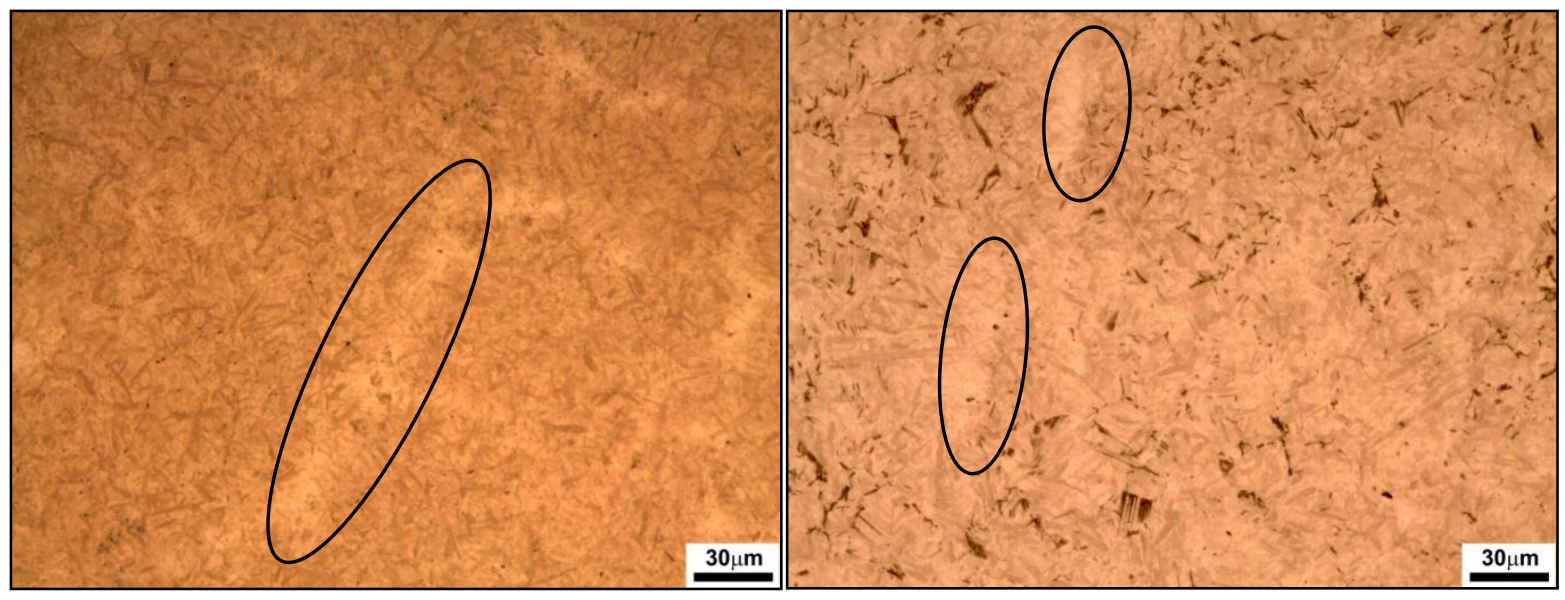

Figura 55 - Micrografias dos aços AISI 4340 (à esquerda) e 4140 (à direita). Os óvalos indicam regiões com indícios de ocorrência de segregação.

A principal consequência dessa segregação é a heterogeneidade na composição do material e, por conseguinte da variação da temperabilidade e das propriedades mecânicas associadas. Além disso, como as zonas segregadas se localizam geralmente no interior das peças (uma vez que os gradientes de composição têm maior concentração de solutos na última porção do líquido solidificada), onde as tensões em nosso caso foram mais altas, estas poderiam ter influência na formação de trincas nessa região.

\subsection{ANÁLISE QUANTITATIVA}

Com o auxílio do processamento digital de imagens através do software Image J, a conversão da imagem original em uma imagem cinza, a utilização de um histograma relacionando os valores máximos e mínimos dos tons de cinza da imagem analisada e, com a determinação da fração volumétrica pela contagem sistemática manual de pontos, foi possível calcular os percentuais de cada microconstituinte na microestrutura, a partir das micrografias obtidas após do tratamento térmico de têmpera e do ataque químico.

Os resultados da análise quantitativa das microestruturas formadas após o processo de têmpera para os aços AISI 4340, 4140 e 1045, estão apresentados nas Tabelas 11,12 e 13, respectivamente. 
Tabela 11 - Análise quantitativa das microestruturas formadas no aço AISI 4340.

\begin{tabular}{ccccccc}
\hline Microconstituinte & \multicolumn{2}{c}{ Superfície } & \multicolumn{2}{c}{ Intermediário } & \multicolumn{2}{c}{ Centro } \\
\hline$(\%)$ & $\begin{array}{c}\text { Contagem } \\
\text { de pontos }\end{array}$ & Image J & $\begin{array}{c}\text { Contagem } \\
\text { de pontos }\end{array}$ & Image J & $\begin{array}{c}\text { Contagem } \\
\text { de pontos }\end{array}$ & Image J \\
Bainita & 0 & 0 & 0 & 0 & 0 & 0 \\
Martensita & 100 & 100 & 100 & 100 & 100 & 100 \\
Desvio padrão & 0 & 0 & 0 & 0 & 0 & 0 \\
\hline
\end{tabular}

Tabela 12 - Análise quantitativa das microestruturas formadas no aço AISI 4140.

\begin{tabular}{ccccccc}
\hline Microconstituinte & \multicolumn{2}{c}{ Superfície } & \multicolumn{2}{c}{ Intermediário } & \multicolumn{2}{c}{ Centro } \\
\hline (\%) & $\begin{array}{c}\text { Contagem } \\
\text { de pontos }\end{array}$ & Image J & $\begin{array}{l}\text { Contagem } \\
\text { de pontos }\end{array}$ & Image J & $\begin{array}{c}\text { Contagem } \\
\text { de pontos }\end{array}$ & Image J \\
Bainita & 8,1 & 11,3 & 11,8 & 14,4 & 15,8 & 16,6 \\
Martensita & 89,9 & 88,7 & 90,2 & 85,6 & 84,2 & 83,4 \\
Desvio padrão & 1,6 & 2,4 & 2,8 & 2,3 & 1,8 & 1,3 \\
\hline
\end{tabular}

Tabela 13 - Análise quantitativa das microestruturas formadas no aço AISI 1045.

\begin{tabular}{cccc}
\hline Microconstituinte (\%) & Superfície & Intermediário & Centro \\
\hline Perlita & 9,8 & 31,0 & 84,1 \\
Bainita & 2,1 & 8,6 & 9,8 \\
Martensita & 88,0 & 60,4 & 6,1 \\
Desvio padrão & 2,2 & 3,6 & 0,5 \\
\hline
\end{tabular}

\subsection{MODELAGEM}

\subsubsection{Modelagem microestrutural utilizando o programa AC3}

A partir dos resultados da análise térmica feita, a fim de determinar 0 coeficiente de transferência de calor, e das análises quantitativas das 
microestruturas formadas em cada região transversal dos cilindros, foi possível calcular o diagrama de resfriamento contínuo mais próximo ao tratamento térmico feito e suas correspondentes percentagens microestruturais, como estão apresentadas nas Figuras 58, 62 e 64. Esta evolução microestrutural ao longo do tempo é calculada pela sobreposição da curva de resfriamento com o diagrama de resfriamento contínuo como mostrado nas Figuras 56, 61 e 63. Nestas figuras é possível observar as temperaturas Ac3 e Ac1 que representam a temperatura mínima de austenitização e o início do intervalo de transformação (temperatura eutetóide), respectivamente, além das temperaturas $M_{s}$ e $M_{f}$, calculadas a partir das equações de Andrews (1965). A curva de resfriamento verde-turquesa corresponde à curva de resfriamento da superfície do cilindro, e a curva roxa à curva de resfriamento do núcleo. As curvas de transformação de cor verde-turquesa, em forma de $\mathrm{C}$, correspondem à formação de bainita, perlita e/ou ferrita. É possível observar que a escala de tempo é logarítmica, para que a ampla faixa de tempo que as transformações ocorrem não faça com que os detalhes dos períodos curtos sejam perdidos, como poderia acontecer em uma escala de tempo linear.

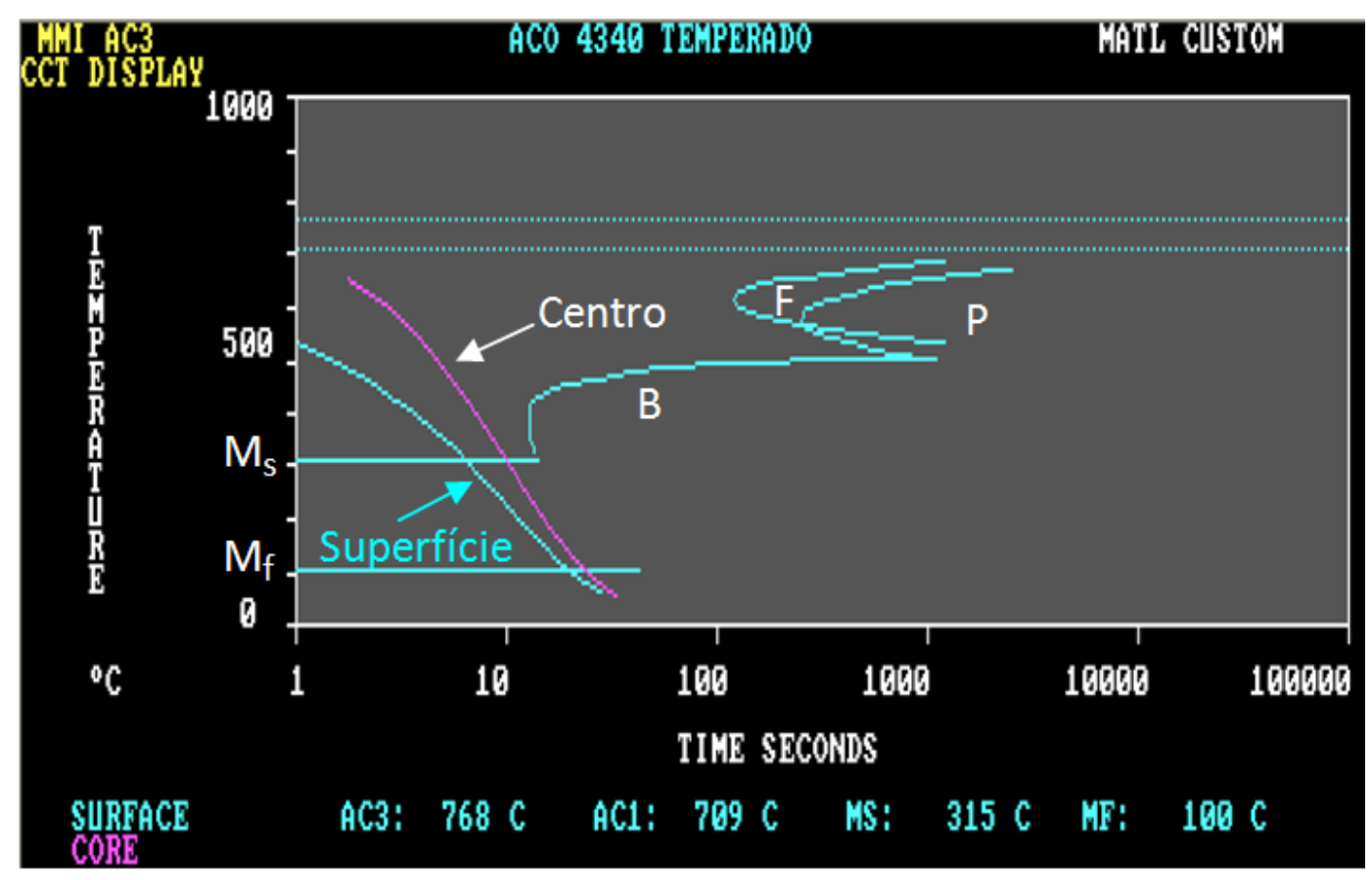

Figura 56 - Curva de resfriamento contínuo para o aço AISI 4340. As linhas $M_{s} e$ $\mathbf{M}_{\mathrm{f}}$ indicam o início e o fim da transformação martensítica, respectivamente. B, F e P indicam o início dos campos bainítico, ferrítico e perlítico, respectivamente. 
De acordo com os diagramas de resfriamento contínuo obtidos, as curvas de resfriamento estão cruzando as curvas de transformação de forma diferente, isto devido às diferenças na composição química de cada aço (diferente temperabilidade), visto que os outros fatores que influenciam a transformação, como o tamanho de grão, condições de austenitização (temperatura e homogeneidade), geometria e meio de têmpera, foram similares para os três aços. No caso dos aços AISI 4140 e 4340 o comportamento das curvas apresentaram uma pequena diferença na formação de bainita, que pode ser atribuída principalmente aos elementos de liga, por exemplo, ao teor de níquel, visto que para o aço 4340 a análise de composição mostrou um resultado de 1,74\% enquanto para o aço 4140 foi de $0,12 \%$, sendo que o níquel é um elemento que aumenta a temperabilidade do aço.

A evolução microestrutural do tratamento térmico de têmpera para o aço AISI 4340 é apresentada na Figura 57. Observa-se que o resultado fornecido pelo programa, divide o cilindro em 20 posições, desde a superfície (esquerda) até o centro (direita). As letras AA e MM, nessa figura, representam austenita e martensita respectivamente, onde cada par de letras corresponde a aproximadamente $5 \%$ em volume de cada microconstituinte. A imagem (a) corresponde aos 6 segundos após o início do resfriamento, quando a microestrutura é ainda totalmente austenítica, e a peça tem uma temperatura de $342^{\circ} \mathrm{C}$ na superfície e $549^{\circ} \mathrm{C}$ no núcleo. Já na imagem (f), aos $35,5 \mathrm{~s}$ a peça tem uma temperatura de $44^{\circ} \mathrm{C}$ na superfície e $57^{\circ} \mathrm{C}$ no núcleo, e uma estrutura martensítica. Uma das grandes vantagens do modelo é que permite acompanhar as porcentagens formadas em cada anel em função da temperatura e do tempo, como mostrado na sequência da Figura 57 (b) à (f). 


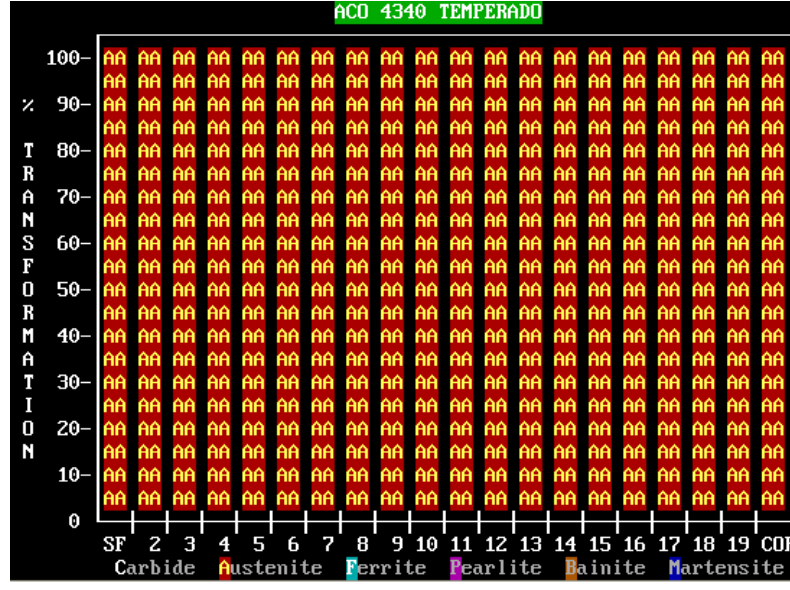

(a)

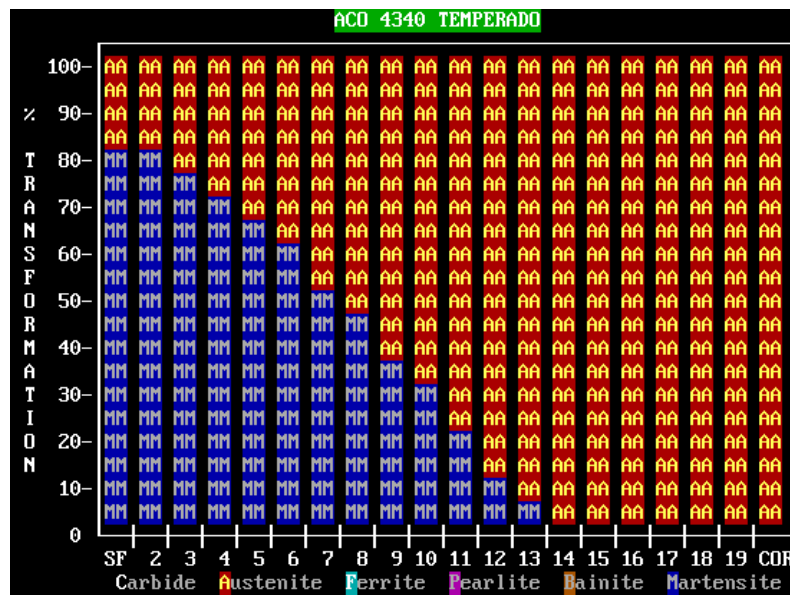

(c)

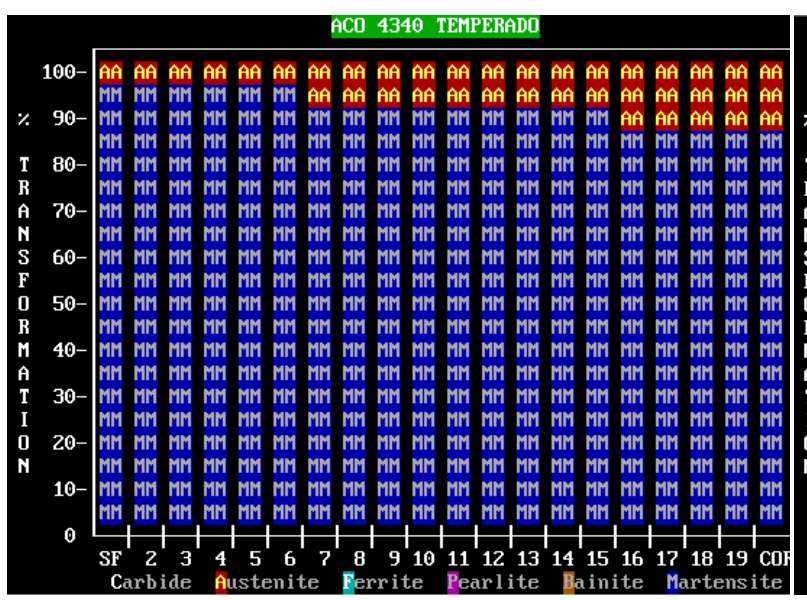

(e)

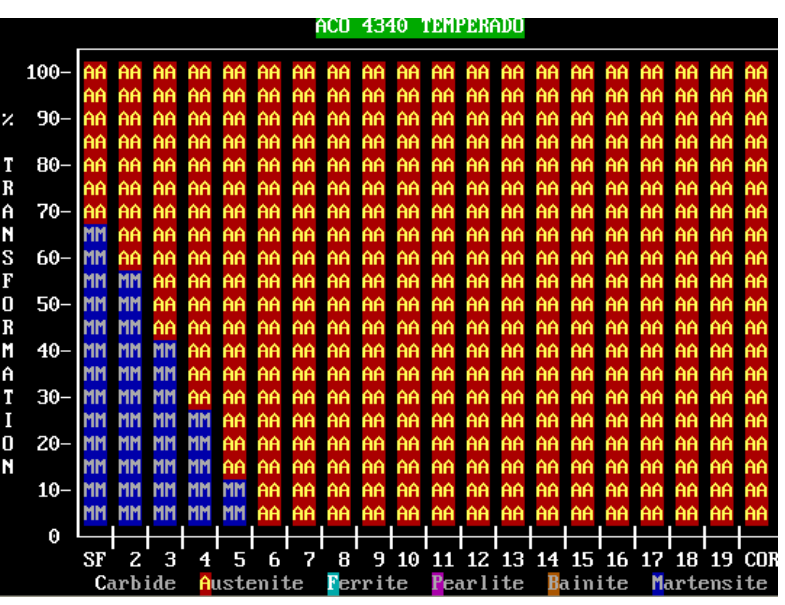

(b)

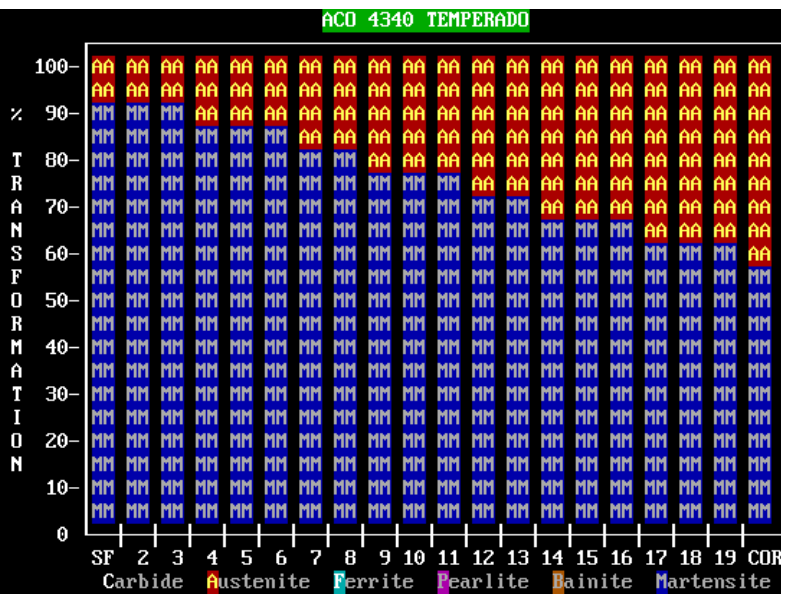

(d)

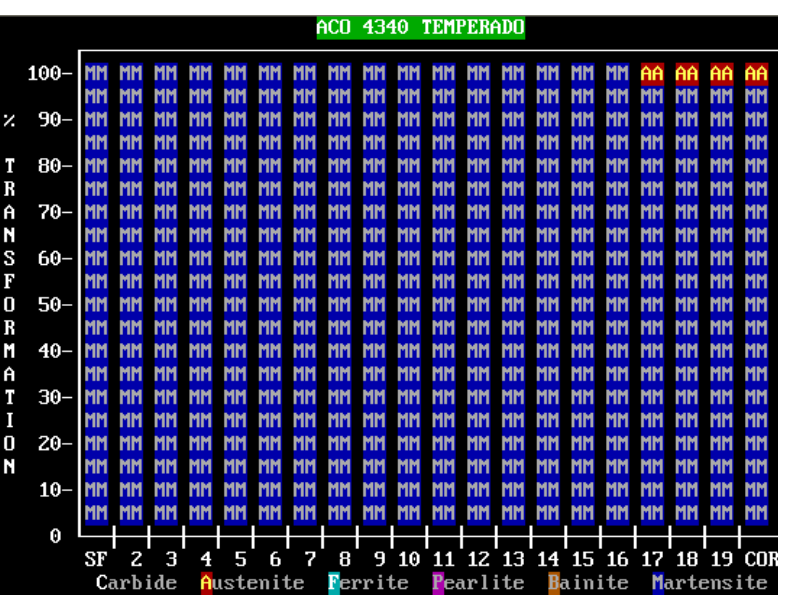

(f)

Figura 57 - Evolução microestrutural do processo de têmpera em água para o aço AISI 4340. (a) $6 \mathrm{~s}$, temperatura da superfície (Ts) $342^{\circ} \mathrm{C}$, temperatura do centro (Tc) $549^{\circ} \mathrm{C}$; (b) $9,3 \mathrm{~s}$, Ts $257^{\circ} \mathrm{C}$, Tc $408^{\circ} \mathrm{C}$; (c) $11,6 \mathrm{~s}$, Ts $212^{\circ} \mathrm{C}$, Tc $333^{\circ} \mathrm{C}$; (d) $14,6 \mathrm{~s}$, Ts $167^{\circ} \mathrm{C}$, Tc $260^{\circ} \mathrm{C}$; (e) $22,7 \mathrm{~s}$, Ts $91^{\circ} \mathrm{C}$, Tc $134^{\circ} \mathrm{C}$; (f) $35,5 \mathrm{~s}$, Ts $44^{\circ} \mathrm{C}$, Tc $57^{\circ} \mathrm{C}$. AA e MM representam austenita e martensita, respectivamente. 
O estado microestrutural final, no interior do aço AISI 4340 (Figura 58) desenvolvido pelo modelo feito através do AC3, apresenta uma estrutura $100 \%$ martensítica ao longo de toda seção transversal, sendo esses valores compatíveis com as análises de microscopia ótica feitas na peça.

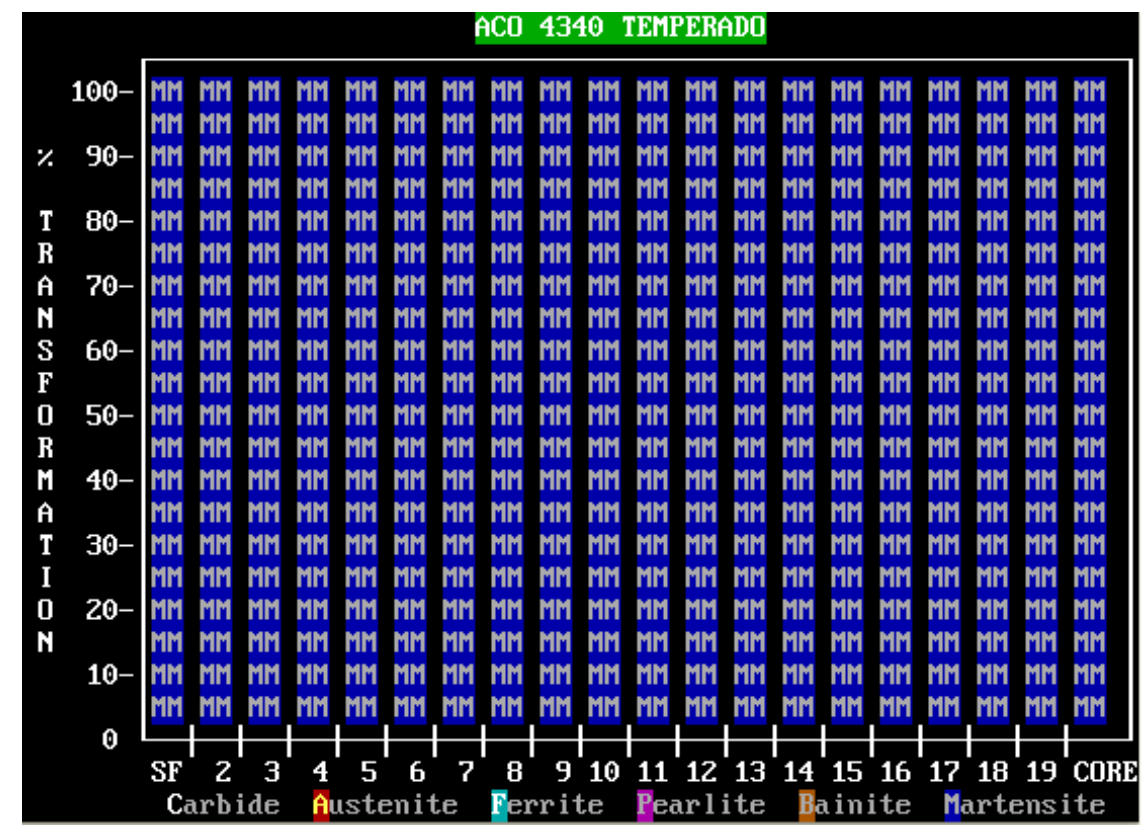

Figura 58 - llustração do estado microestrutural final após tratamento térmico de têmpera em água com agitação, indicando uma microestrutura $100 \%$ martensítica ao longo da secção transversal do cilindro para o aço AISI 4340.

$\mathrm{Na}$ Figura 59 é apresentado o resultado da distribuição da temperatura em função do tempo, ao longo da secção transversal do cilindro AISI 4340, calculados a partir das condições de contorno impostas ao modelo. Nesta figura detalha-se a temperatura de cada nó em uma discretização da variável temporal de 23 intervalos. Para o tempo igual a $0,0 \mathrm{~s}$ todos os nós estão na temperatura de austenitização do aço $\left(830^{\circ} \mathrm{C}\right)$, mostrando que o equilíbrio com o meio de resfriamento $\left(24^{\circ} \mathrm{C}\right)$ é atingido aos $108,4 \mathrm{~s}$.

Os percentuais finais de cada componente, formados após têmpera, e os resultados da simulação numérica da dureza em cada nó (em escala HRC Rockwell C) para o cilindro do aço AISI 4340, em função da profundidade são apresentados na Figura 60. 


\begin{tabular}{|c|c|c|c|c|c|c|c|c|c|c|c|c|}
\hline \multirow[b]{2}{*}{ STEP } & \multirow[b]{2}{*}{ T IME } & \multicolumn{11}{|c|}{$\mathrm{DF}$} \\
\hline & & 1 & 3 & 5 & 7 & 9 & 11 & 13 & 15 & 17 & 19 & 20 \\
\hline 1 & 0.0 & 830 & 830 & 830 & 830 & 830 & 830 & 830 & 830 & 830 & 830 & 830 \\
\hline 2 & 1.0 & 565 & 628 & 681 & 724 & 757 & 782 & 799 & 811 & 817 & 820 & 821 \\
\hline 3 & 1.3 & 543 & 604 & 657 & 701 & 737 & 764 & 784 & 798 & 807 & 811 & 812 \\
\hline 4 & 1.6 & 520 & 579 & 632 & 676 & 713 & 742 & 765 & 781 & 792 & 797 & 797 \\
\hline 5 & 2.0 & 496 & 553 & 604 & 648 & 685 & 716 & 740 & 758 & 770 & 775 & 776 \\
\hline 6 & 2.4 & 471 & 525 & 574 & 617 & 654 & 685 & 710 & 728 & 740 & 747 & 747 \\
\hline 7 & 3.1 & 444 & 495 & 541 & 582 & 618 & 648 & 673 & 691 & 703 & 709 & 710 \\
\hline 8 & 3.8 & 414 & 461 & 504 & 543 & 577 & 605 & 629 & 646 & 658 & 664 & 664 \\
\hline 9 & 4.8 & 380 & 423 & 463 & 499 & 530 & 556 & 577 & 594 & 604 & 610 & 611 \\
\hline 10 & 6.0 & 342 & 381 & 417 & 449 & 476 & 500 & 519 & 534 & 544 & 548 & 549 \\
\hline 11 & 7.5 & 301 & 335 & 366 & 394 & 418 & 438 & 455 & 468 & 476 & 481 & 481 \\
\hline 12 & 9.3 & 257 & 285 & 311 & 335 & 355 & 372 & 386 & 397 & 404 & 408 & 408 \\
\hline 13 & 11.6 & 212 & 234 & 255 & 274 & 291 & 305 & 316 & 324 & 330 & 333 & 333 \\
\hline 14 & 14.6 & 167 & 185 & 200 & 215 & 227 & 238 & 247 & 253 & 257 & 260 & 260 \\
\hline 15 & 18.2 & 126 & 138 & 150 & 160 & 169 & 176 & 183 & 187 & 190 & 192 & 192 \\
\hline 16 & 22.7 & 91 & 99 & 106 & 113 & 119 & 124 & 128 & 131 & 133 & 134 & 134 \\
\hline 17 & 28.4 & 63 & 68 & 73 & 76 & 80 & 83 & 85 & 87 & 88 & 89 & 89 \\
\hline 18 & 35.5 & 44 & 47 & 49 & 51 & 53 & 54 & 56 & 57 & 57 & 57 & 57 \\
\hline 19 & 44.4 & 33 & 34 & 35 & 36 & 37 & 37 & 38 & 38 & 38 & 39 & 39 \\
\hline 20 & 55.5 & 27 & 28 & 28 & 28 & 28 & 29 & 29 & 29 & 29 & 29 & 29 \\
\hline 21 & 69.4 & 25 & 25 & 25 & 25 & 25 & 25 & 25 & 25 & 25 & 25 & 25 \\
\hline 22 & 86.7 & 24 & 24 & 24 & 24 & 24 & 24 & 24 & 24 & 24 & 24 & 24 \\
\hline 23 & 108.4 & 24 & 24 & 24 & 24 & 24 & 24 & 24 & 24 & 24 & 24 & 24 \\
\hline
\end{tabular}

Figura 59 - Variação da temperatura no processo de têmpera em água para o cilindro de aço AISI 4340.

As variações da dureza nos modelos desenvolvidos tiveram boa aderência em relação aos valores medidos experimentalmente (seção 5.4.3), tanto em relação ao valor máximo quanto em relação à distribuição ao longo da secção transversal do cilindro, como será discutido posteriormente.

$\begin{array}{rrrrrrrrrr}\text { NODE } & \begin{array}{r}\text { DEPTH } \\ (\mathbf{m m})\end{array} & \% \text { FE3C } & \text { MART } & \text { BAIN } & \text { PEARL } & \text { FERR } & \text { AUST } & \begin{array}{r}\text { ASQU } \\ \text { (RC) }\end{array} \\ --- & ----- & ---- & ---- & ---- & ---- & ---- & ---- & ---- & ----- \\ \mathbf{1} & 0.000 & 0.40 & 0.0 & 99.5 & 0.0 & 0.0 & 0.0 & 0.5 & 57.9 \\ \mathbf{2} & 0.668 & 0.40 & 0.0 & 99.5 & 0.0 & 0.0 & 0.0 & 0.5 & 57.9 \\ \mathbf{3} & \mathbf{1 . 3 3 7} & 0.40 & 0.0 & 99.5 & 0.0 & 0.0 & 0.0 & 0.5 & 57.8 \\ \mathbf{4} & 2.005 & 0.40 & 0.0 & 99.5 & 0.0 & 0.0 & 0.0 & 0.5 & 57.8 \\ \mathbf{5} & 2.674 & 0.40 & 0.0 & 99.5 & 0.0 & 0.0 & 0.0 & 0.5 & 57.7 \\ \mathbf{6} & 3.342 & 0.40 & 0.0 & 99.5 & 0.0 & 0.0 & 0.0 & 0.5 & 57.5 \\ \mathbf{7} & 4.011 & 0.40 & 0.0 & 99.5 & 0.0 & 0.0 & 0.0 & 0.5 & 57.4 \\ \mathbf{8} & 4.679 & 0.40 & 0.0 & 99.5 & 0.0 & 0.0 & 0.0 & 0.5 & 57.4 \\ \mathbf{9} & 5.347 & 0.40 & 0.0 & 99.5 & 0.0 & 0.0 & 0.0 & 0.5 & 57.4 \\ \mathbf{1 0} & \mathbf{6 . 0 1 6} & 0.40 & 0.0 & 99.5 & 0.0 & 0.0 & 0.0 & 0.5 & 57.3 \\ \mathbf{1 1} & \mathbf{6 . 6 8 4} & 0.40 & 0.0 & 99.5 & 0.0 & 0.0 & 0.0 & 0.5 & 57.3 \\ \mathbf{1 2} & 7.353 & 0.40 & 0.0 & 99.5 & 0.0 & 0.0 & 0.0 & 0.5 & 57.3 \\ \mathbf{1 3} & \mathbf{8 . 0 2 1} & 0.40 & 0.0 & 99.5 & 0.0 & 0.0 & 0.0 & 0.5 & 57.3 \\ \mathbf{1 4} & \mathbf{8 . 6 8 9} & 0.40 & 0.0 & 99.5 & 0.0 & 0.0 & 0.0 & 0.5 & 57.3 \\ \mathbf{1 5} & 9.358 & 0.40 & 0.0 & 99.5 & 0.0 & 0.0 & 0.0 & 0.5 & 57.3 \\ \mathbf{1 6} & \mathbf{1 0 . 0 2 6} & 0.40 & 0.0 & 99.5 & 0.0 & 0.0 & 0.0 & 0.5 & 57.3 \\ \mathbf{1 7} & \mathbf{1 0 . 6 9 5} & 0.40 & 0.0 & 99.5 & 0.0 & 0.0 & 0.0 & 0.5 & 57.3 \\ \mathbf{1 8} & \mathbf{1 1 . 3 6 3} & 0.40 & 0.0 & 99.5 & 0.0 & 0.0 & 0.0 & 0.5 & 57.3 \\ \mathbf{1 9} & \mathbf{1 2 . 0 3 2} & 0.40 & 0.0 & 99.5 & 0.0 & 0.0 & 0.0 & 0.5 & 57.3 \\ \mathbf{2 0} & \mathbf{1 2 . 7 0 0} & 0.40 & 0.0 & 99.5 & 0.0 & 0.0 & 0.0 & 0.5 & 57.3\end{array}$

Figura 60 - Resultado final da porcentagem de cada microestrutura formada e da predição de dureza em função da profundidade, na simulação numérica desenvolvida através do AC3. FE3C, MART, BAIN, PEARL, FERR, AUST, ASQU (RC) representam cementita, martensita, bainita, perlita, ferrita, austenita retida e dureza (em escala Rockwell C), respectivamente. 
O diagrama RC relacionado à analise de têmpera para o aço AISI 4140 é apresentado na Figura 61. Nesse diagrama, percebe-se um comportamento similar ao apresentado pelo aço AISI 4340, porém com um gradiente térmico um pouco menor no início do resfriamento e com um corte no campo de formação de bainita. As diferenças nas temperaturas $M_{s}$ e $M_{f}$, para esses dois aços, foram de $\sim 32^{\circ} \mathrm{C}$, sendo maiores no caso do aço AISI 4140. Como foi exposto na secção 2.2 .5 a temperatura $M_{S}$ é dependente dos elementos de liga adicionados aos aços, mas também cabe ressaltar que as transformações difusionais precedentes também afetam a temperatura $M_{S}$, devido ao enriquecimento de carbono da austenita durante a transformação. No entanto, este efeito não é incorporado em nenhum dos modelos de têmpera atual.

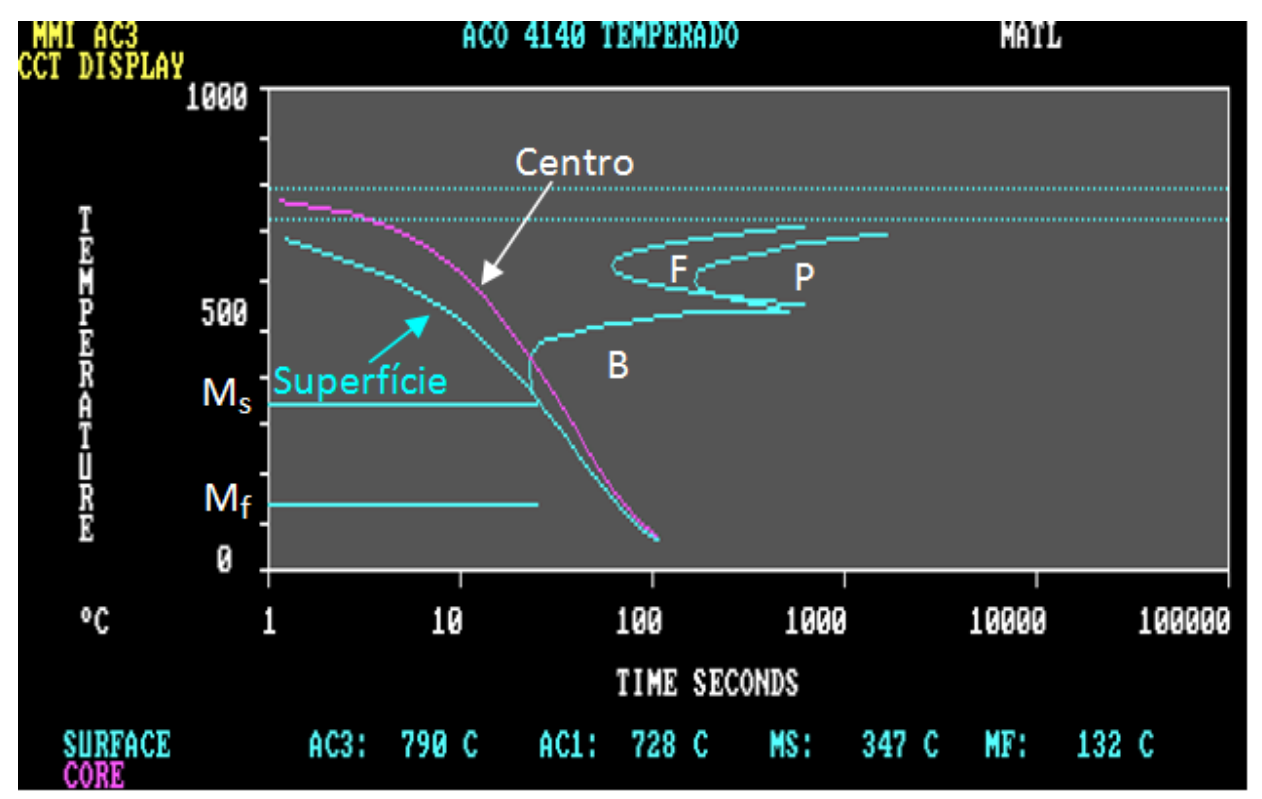

Figura 61 - Curva de resfriamento contínuo para o aço AISI 4140. As linhas $M_{s}$ e $M_{f}$ indicam o início e o fim da transformação martensítica, respectivamente. B, F e P indicam os campos bainítico, ferrítico e perlítico, respectivamente.

O resultado quantitativo de cada constituinte no interior do aço AISI 4140 é mostrado na Figura 62. O resultado mostra uma distribuição radial com variação leve de martensita ao longo da secção transversal do cilindro, com 95\% de martensita e $5 \%$ de bainita na região superficial e uma estrutura com $85 \%$ de martensita e $15 \%$ de bainita nas regiões intermediária e central. 
Uma análise similar à aplicada nos aços 4340 e 4140 foi feita para o aço 1045, a fim de calcular a curva de resfriamento mais próxima aos resultados obtidos da análise metalográfica. Na Figura 63 é apresentado o diagrama de resfriamento contínuo relacionado à analise de têmpera para esse aço. A partir desse diagrama pode-se observar o início da transformação de austenita para perlita em uma temperatura próxima aos $600^{\circ} \mathrm{C}$, em aproximadamente 6 segundos após o início do resfriamento. Visto que a queda de temperatura na superfície é maior que no centro, a transformação de austenita para bainita na superfície inicia-se quase ao mesmo tempo em que foi registrado pelo centro.

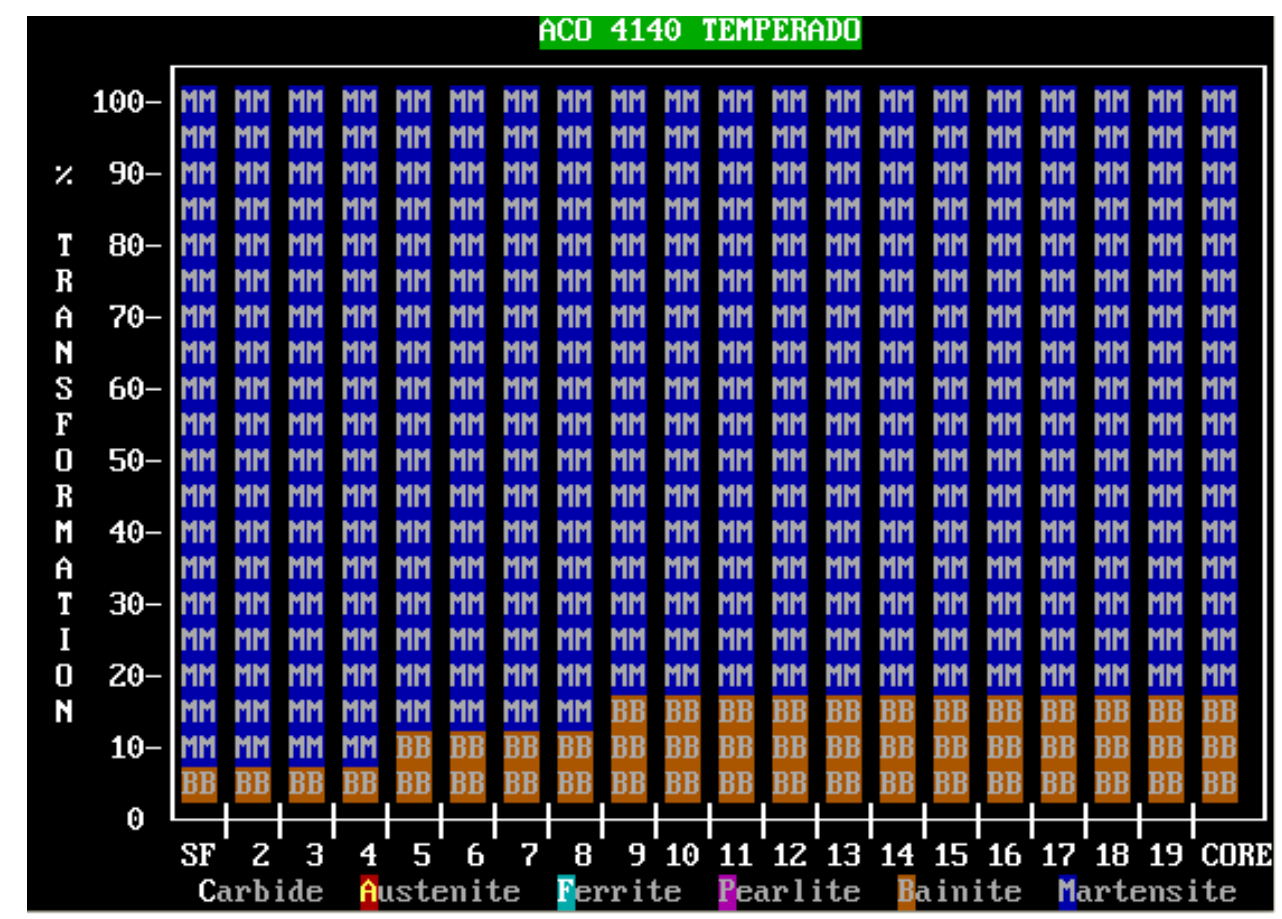

Figura 62- llustração do estado final da microestrutura após tratamento térmico de têmpera, indicando as porcentagens de cada microestrutura ao longo da secção transversal do cilindro para o aço AISI 4140. MM e BB representam martensita e bainita, respectivamente.

As diferenças nas temperaturas $M_{s}$ e $M_{f}$, para os aços AISI 4140 e 1045, não foram representativas, sendo somente $1^{\circ} \mathrm{C}$ a mais, para o caso do aço AISI 1045.

Se comparados os resultados das curvas de início da transformação para os aços deste estudo, é comprovada a influência da composição química (teores de elementos de liga) no deslocamento das curvas (seção 2.2.5). Observa-se, o deslocamento para esquerda das curvas de início de transformação para o aço 1045 
quando comparado com as curvas dos aços 4140 e 4340, o que explica sua baixa temperabilidade.

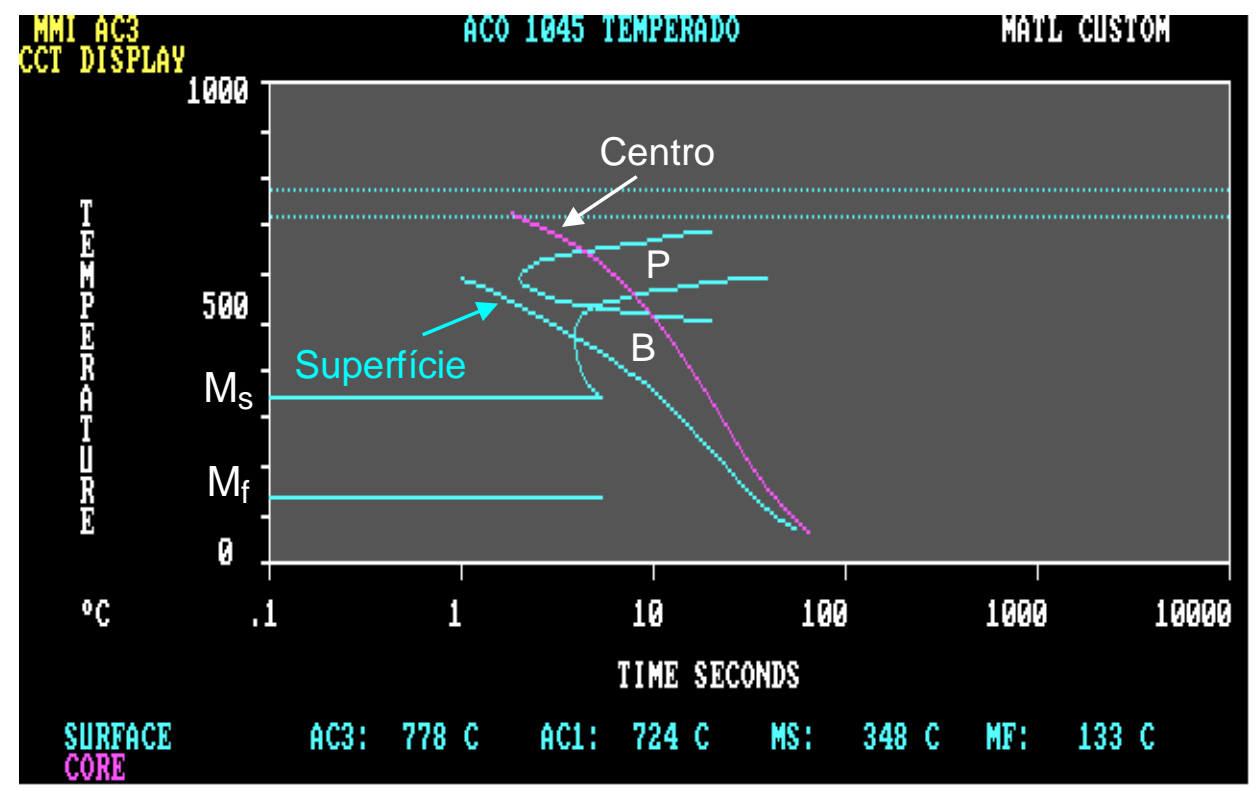

Figura 63 - Curva de resfriamento contínuo para o aço AISI 1045. As linhas $M_{s}$ e $M_{f}$ indicam o início e o fim da transformação martensítica, respectivamente. B, F e P indicam os campos bainítico, ferrítico e perlítico, respectivamente.

O resultado microestrutural do processo de têmpera em água para o aço 1045 é apresentado na Figura 64. As microestruturas formadas mostram uma intensa modificação entre a superfície e o centro do cilindro, sendo a superfície predominantemente martensítica e o centro predominantemente perlítico. Observase que a quantidade de martensita diminui da superfície ao centro, sendo substituída por perlita e bainita. Os resultados obtidos pela modelagem mostraram-se coerentes com as análises metalográficas feitas na secção 5.2.

A análise quantitativa da Figura 64 indica que a microestrutura final é constituída na superfície por $85 \%$ de martensita e $15 \%$ de bainita, na região intermediária tem-se uma variação entre 15 e $25 \%$ de martensita, 20 e $35 \%$ de bainita e 40 e $65 \%$ de perlita, já na região central apresenta-se uma microestrutura formada por $10 \%$ de martensita, $10 \%$ de bainita e $80 \%$ de perlita. 


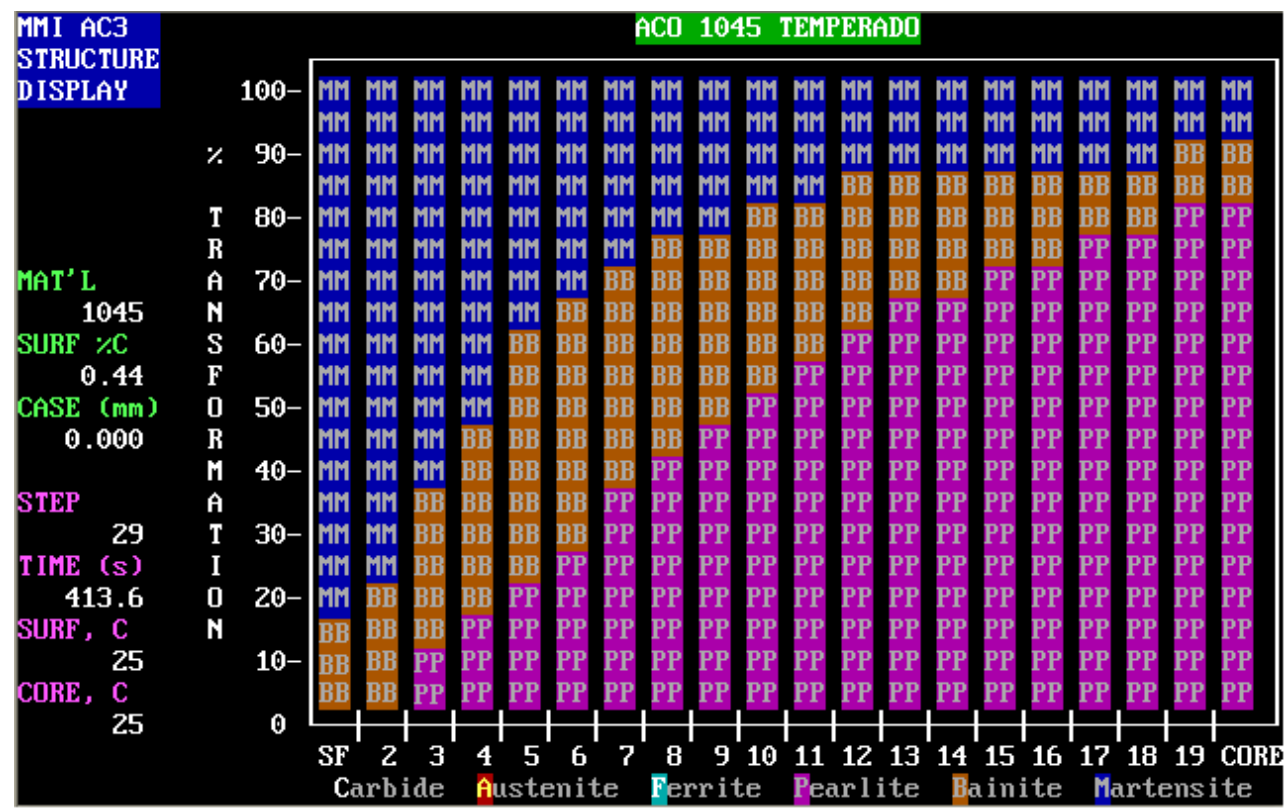

Figura 64- llustração do estado microestrutural final após tratamento térmico de têmpera, indicando as porcentagens de cada microestrutura ao longo da secção transversal do cilindro para o aço AISI 1045. MM, BB e PP representam martensita, bainita e perlita, respectivamente.

A partir dos resultados das distribuições microestruturais em cada nó, ao longo do tempo e da temperatura, obtidas pelo modelo desenvolvido no AC3 na secção transversal de cada cilindro, é possível determinar as propriedades termofísicas e mecânicas apresentadas nas equações (54) a (73), para alimentar o modelo de elementos finitos.

\subsubsection{Modelagem da dureza utilizando o programa AC3}

As curvas de predição de dureza do modelo no programa AC3, a partir das microestruturas obtidas, resultam em valores de dureza que podem ser observados nas Figuras 65, 66 e 67.

Nas Figuras 65 e 66, nota-se que há equivalência entre as curvas dos aços AISI 4140 e 4340, porém existe uma pequena diferença nos valores, sendo os resultados levemente menores para o aço 4140, o que pode ser explicado pela diferença no volume de bainita presente nesse aço, visto que a bainita tem dureza bastante menor quando comparada com a dureza da martensita. 


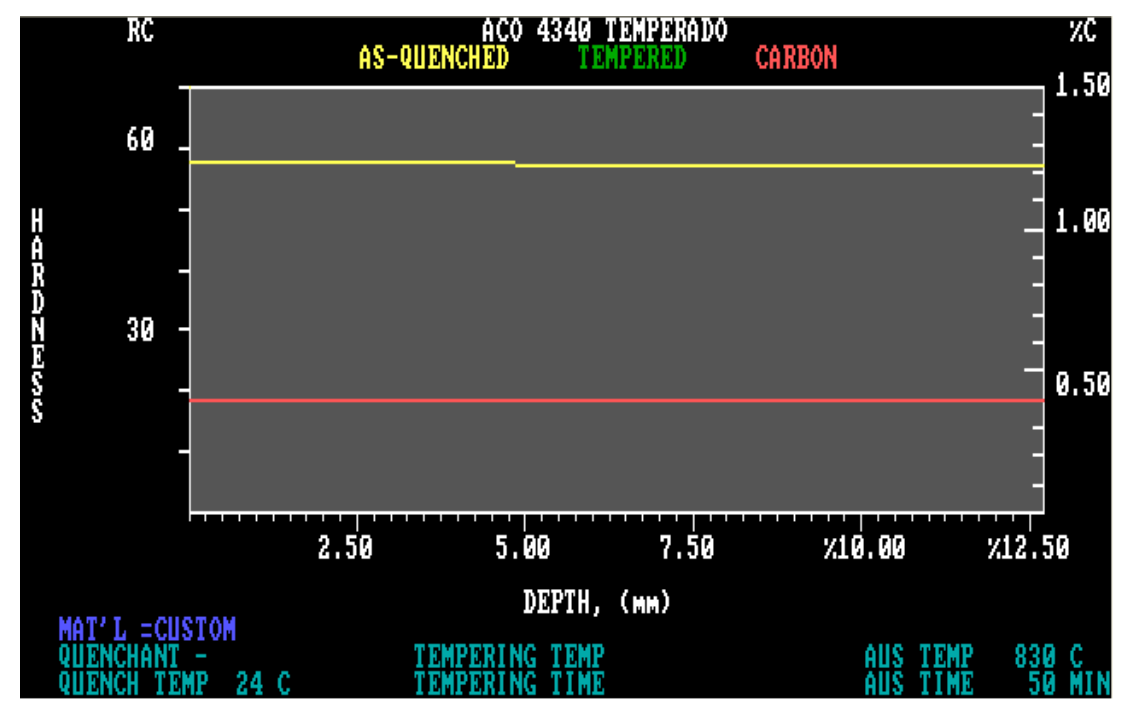

Figura 65 - Perfil de dureza (HRC) do aço AISI 4340. Resultados calculados pela modelagem no AC3.

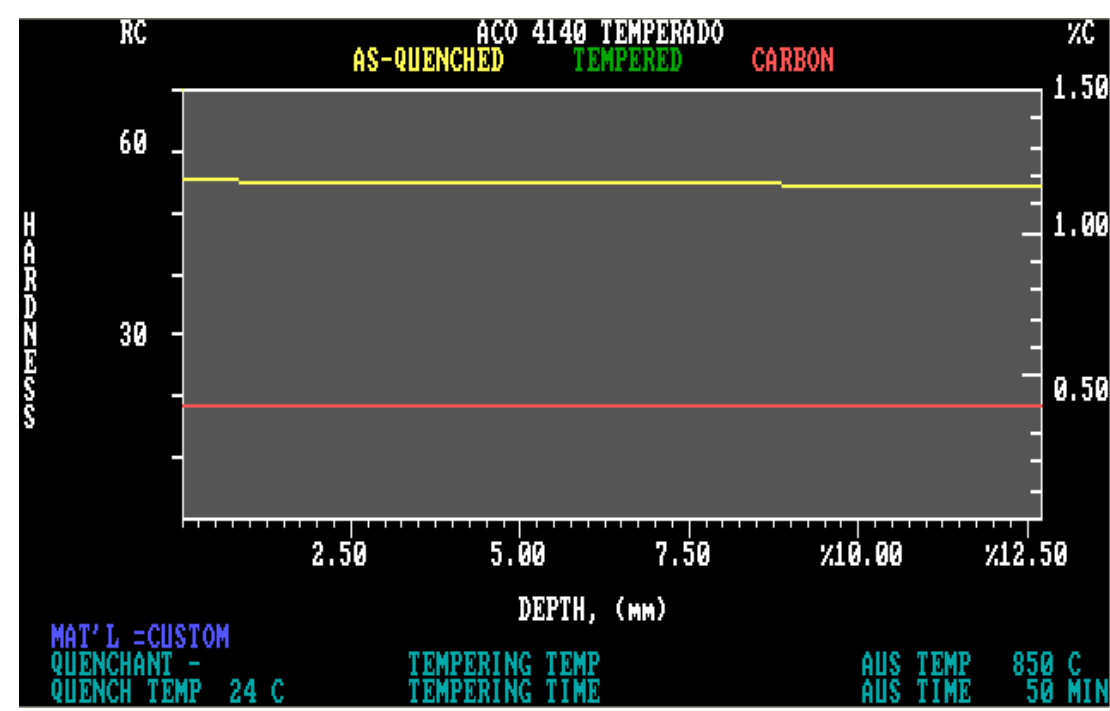

Figura 66 - Perfil de dureza (HRC) do aço AISI 4140. Resultados calculados pela modelagem no AC3.

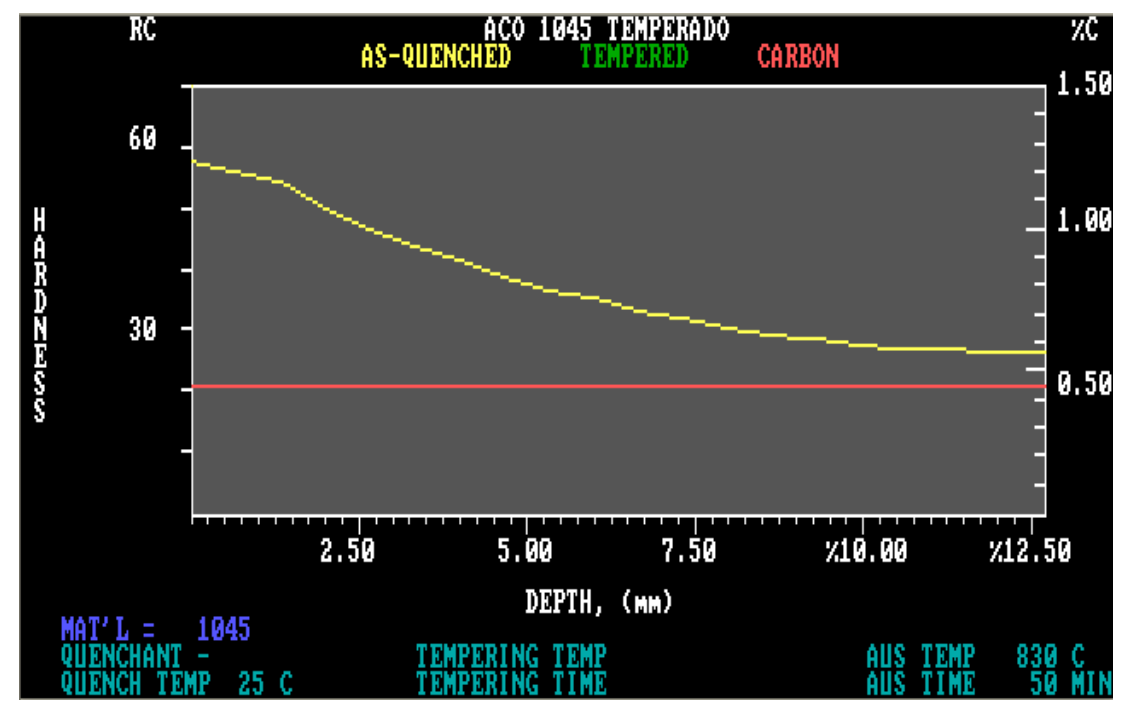

Figura 67 - Perfil de dureza (HRC) do aço AISI 1045. Resultados calculados pela modelagem no AC3. 
Segundo os resultados obtidos no AC3, após a têmpera, o cilindro de aço AISI 4340 terá uma dureza de aproximadamente 57 HRC, ao longo da secção transversal do cilindro, o aço AISI 4140 terá aproximadamente 56 HRC na superfície e cerca de 53 HRC no centro, já o aço 1045 terá aproximadamente 58 HRC na superfície e 28 HRC no centro.

A partir dos resultados de dureza apresentados para o aço AISI 1045, observa-se que há uma queda acentuada de penetração de dureza devido à sua baixa temperabilidade.

\subsection{DUREZA CALCULADA EXPERIMENTALMENTE}

A Figura 68 apresenta os valores medidos experimentalmente das durezas obtidas ao longo dos raios, da secção transversal dos cilindros de aço 4340, 4140 e 1045 , desde o ponto 1 , perto da superfície, até o ponto 7 no centro, com uma distância aproximada de 1,8 mm entre os pontos. Os resultados apresentados nesta figura mostram que, na superfície os maiores resultados de dureza são para os aços 1045 e 4340, sendo esses valores 57,5 e 57 HRC, respectivamente. Para o aço 4340 isto pode ser compreendido pela maior fração de volume de martensita presente nesse aço. Embora os aços 4140 e 1045 tenham apresentado quantidades similares de martensita na superfície, a pequena diferença de dureza na superfície poderia ser explicada pela diferença de carbono entre esses dois aços. Outra notória diferença está no gradiente do perfil de dureza da secção transversal do cilindro de aço 1045, tanto na simulação quanto na medida experimental, a qual reflete a formação de maiores quantidades de outros produtos de decomposição da austenita que não a martensita, condizentes com as quantidades de perlita, bainita $\mathrm{e}$ martensita, encontrados na análise metalográfica (Tabela 12). Já os resultados para os aços 4340 e 4140 , mostraram que a dureza cai suavemente com a profundidade, sendo então coerentes com as microestruturas apresentadas nesses pontos e apresentando boa aderência com as curvas de predição de dureza do modelo. 


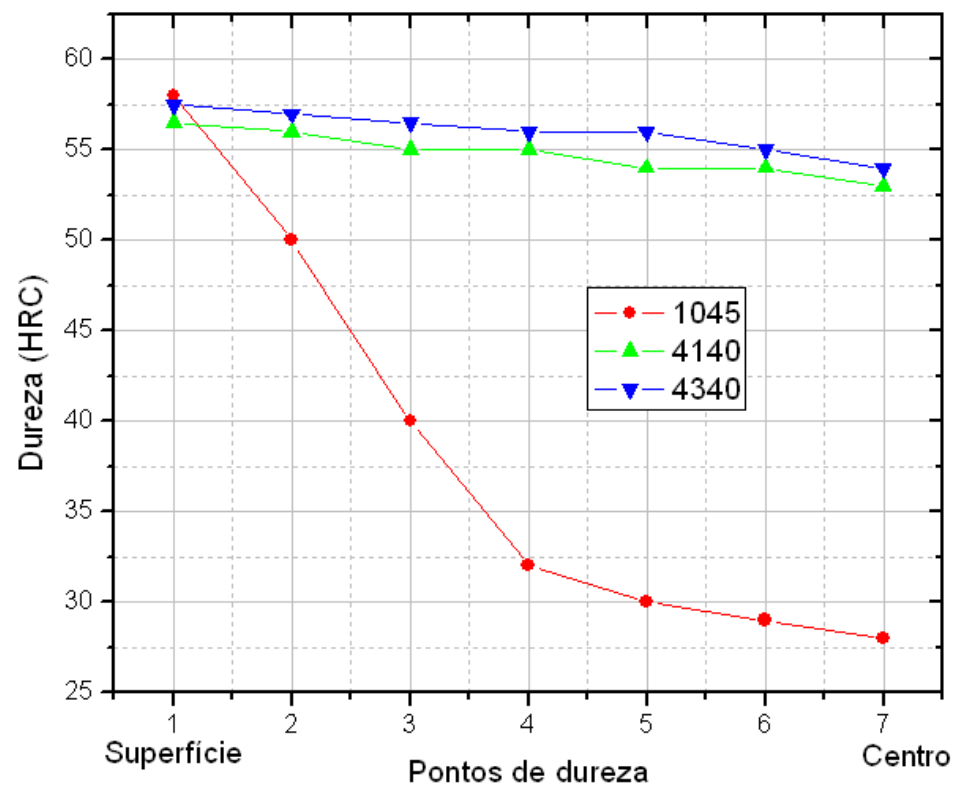

Figura 68 - Resultados da dureza em função da distância do centro da amostra para os aços 4340, 4140 e 1045.

Os resultados de dureza obtidos através da simulação e as medições experimentais mostram-se equivalentes com os resultados existentes na literatura (COLPAERT, 1992; PALANIRADJA et al., 2010), como pode ser visto a partir da Figura 69 para barras de aços SAE 1040, 4140 e 3340, com diversos diâmetros temperados em água, os quais, numa secção transversal, se efetuaram medidas de dureza resultando em uma curva "U".

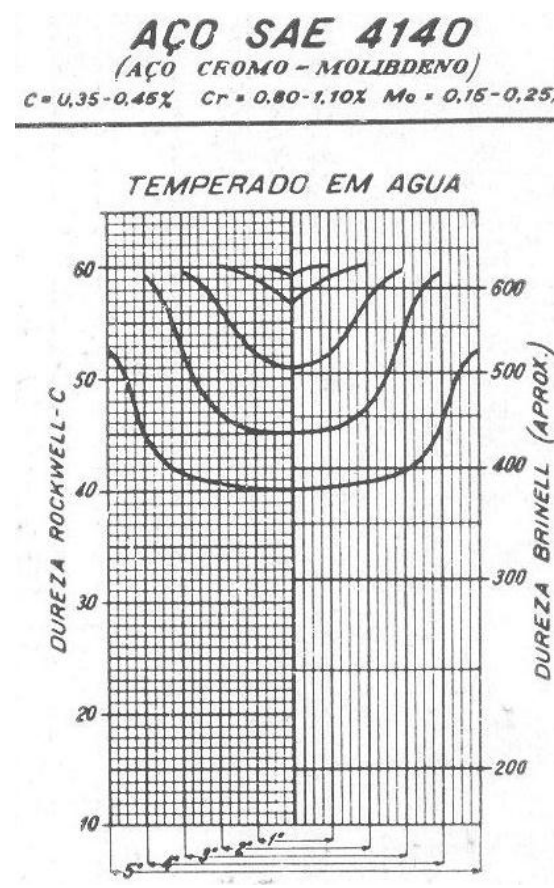

(a)
ACO SAE 1040

(ACO COMUIA. AO CARBONO) $c=0.35-0.45 \%$

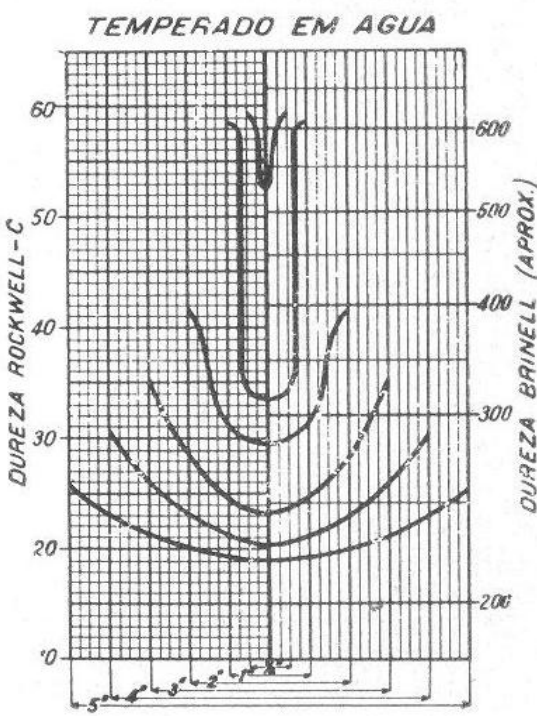

(b) 


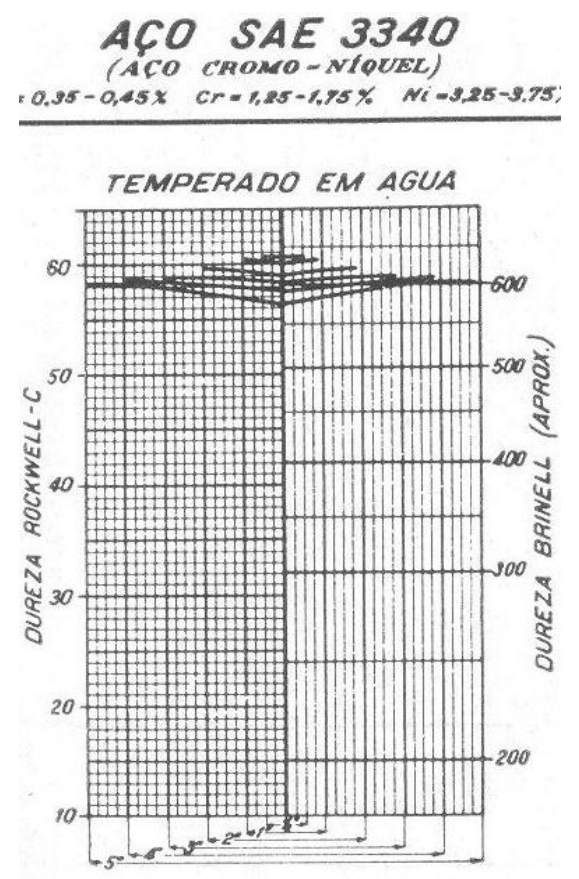

(c)

Figura 69 - Dureza da superfície até o centro de barras de aço temperado. (a) 4140, (b) 1040 e (c) 3340. Colpaert (1992).

\subsection{TENSÕES RESIDUAIS POR DIFRAÇÃO DE RAIOS X}

A verificação e calibração do modelo computacional desenvolvido pelo método dos elementos finitos foram efetuadas através da medição das tensões residuais na superfície dos cilindros com o emprego de difração de raios $X$ usando o método do $\operatorname{sen}^{2} \psi$ [eq. (47)]. Para os três aços foram avaliadas as tensões residuais nos sentidos axiais e tangenciais. No sentido radial não foram tomadas as medidas de tensão residual por difração de raios $X$, visto que as simulações prévias e a revisão da literatura apresentavam resultados pouco significativos nessa direção.

Nas Figuras 71 a 73 estão apresentados os resultados da tensão residual axial e tangencial, para os aços AISI 4340, 4140 e 1045. Os ângulos $2 \theta$ são lançados nas ordenadas e o $\operatorname{sen}^{2} \psi$ na abscissa dos gráficos.

Nos gráficos dos resultados da difração observa-se a distribuição dos valores de $\psi$, em onze posições (cinco à direita para a determinação dos valores de $+\psi$, 
cinco à esquerda para determinação dos valores de $-\psi$ e um valor em $\psi=0$ ), na parte inferior esquerda do gráfico (Figura 70) têm-se três colunas que relacionam os valores de $\psi_{n}, \operatorname{sen}^{2} \psi_{n}$ e os valores angulares das reflexões dos planos cristalinos com normais caracterizadas por ângulos $\psi_{n}$. Na parte inferior intermediária estão relacionadas às condições iniciais do aço, impostas ao difratômetro para a medição da tensão residual (a família de planos para medida da tensão residual e o módulo de elasticidade e coeficiente de Poisson do aço). Já em cor vermelha (resultados para os valores de $-\psi$ ) e azul (resultados para os valores de $+\psi$ ) estão relacionados os resultados dos cálculos da tensão residual (em MPa) obtidos pelo software (Residual Stress Measurement) do difratômetro Rigaku Rint 2000, fator de segurança, coeficiente angular das curvas de tensão e o valor obtido de $2 \theta$ em $\psi=0$. A tensão residual é descrita em termos das tensões de tração e de compressão. A tensão de tração recebe o sinal positivo $(+\sigma)$ e a de compressão recebe o sinal negativo $(-\sigma)$.

A Figura 70 apresenta os resultados da tensão residual axial e tangencial, respectivamente, para o cilindro de aço AISI 4140 após ser austenitizado durante 50 minutos e resfriado dentro do forno. Esses resultados mostraram que a temperatura de austenitização foi suficiente para relaxar as tensões residuais existentes, antes do processo de têmpera, visto que os resultados das tensões residuais calculadas na superfície são de $\sim 25 \mathrm{MPa}$ no sentido axial e $\sim 16 \mathrm{MPa}$ na direção tangencial. Segundo Cullity (2001) um desvio de \pm 15 a $\pm 20 \mathrm{MPa}$ são estimativas conservadoras para medição de tensão residual através da difração de raios $X$. 


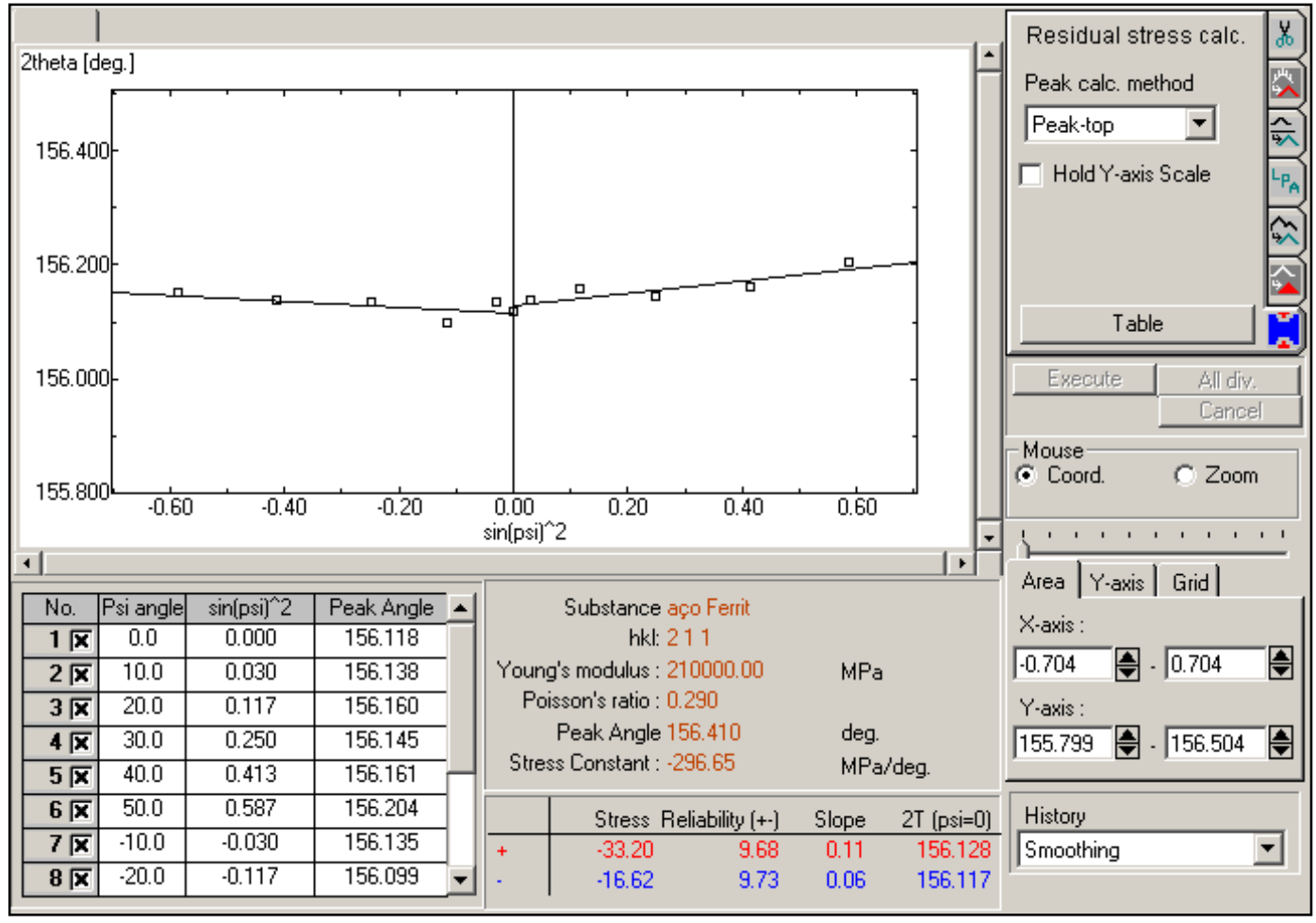

(a)

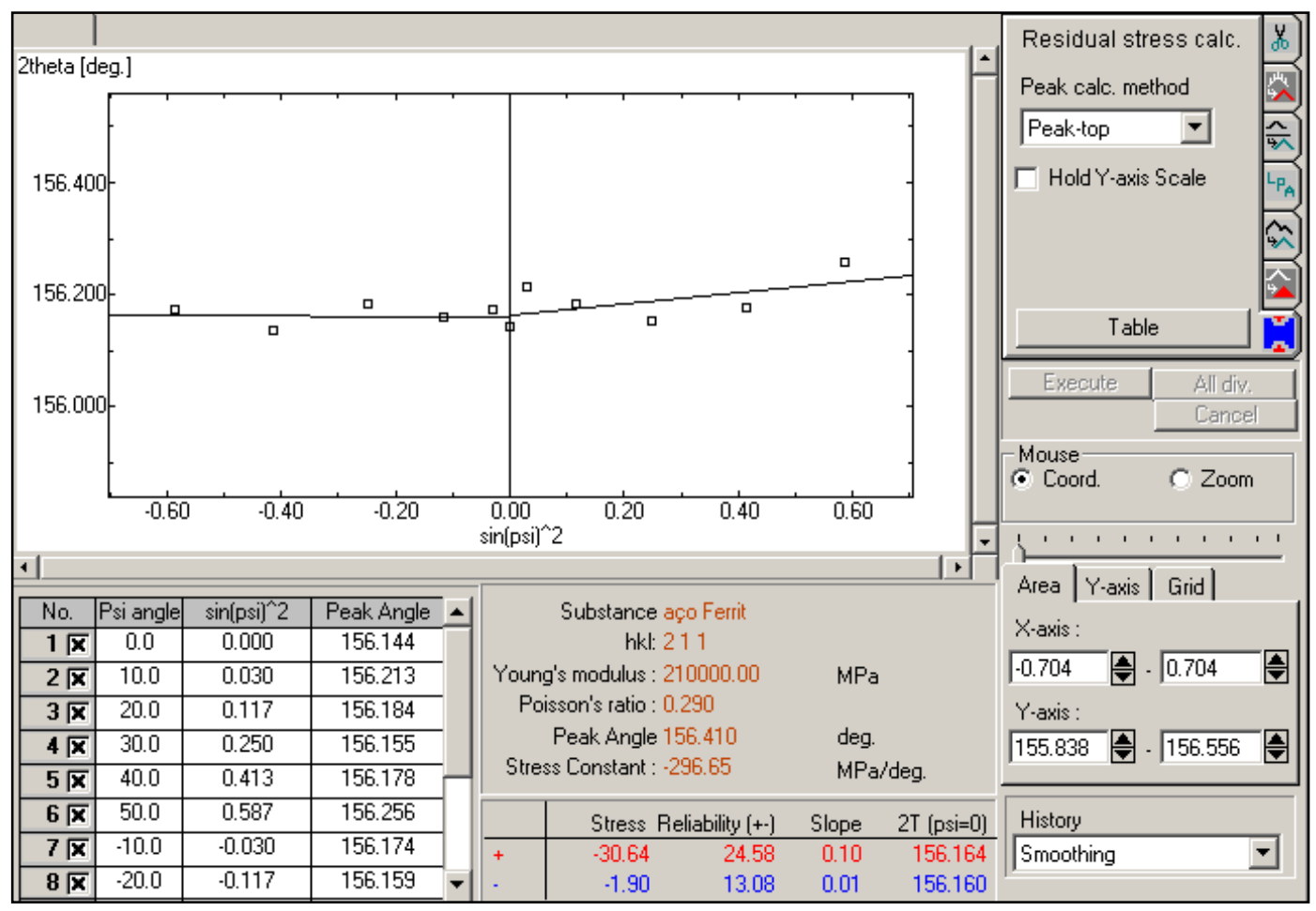

(b)

Figura 70 - Tensão residual para o aço AISI 4140, austenitizado e resfriado dentro do forno. Gráfico gerado pelo difratômetro de raios X Rigaku Rint 2000. As linhas de cor vermelha e azul representam os resultados para os valores de $-\psi$ e de $+\psi$, respectivamente. (a) Resultados das tensões no sentido axial (b) Resultados das tensões no sentido tangencial. 
As Figuras 71, 72 e 73 apresentam os resultados das tensões residuais axiais e tangenciais, para os cilindros AISI 4340, 4140 e 1045, respectivamente, após têmpera em água.

Observa-se através dessas figuras a distribuição das curvas de $(+\psi)$ e $(-\psi)$ dispostas simetricamente, indicando uma distribuição homogênea da tensão residual para ambos os lados, o que pode ser atribuído à preparação superficial da amostra antes e depois do tratamento térmico, e, além disso, ao correto alinhamento do feixe de difração incidido sobre a amostra.

A disposição das curvas (71 a 73) está mostrando que a distância interplanar está sofrendo variações de acordo com a orientação (ângulo $\psi$ ) da família de planos $h k l$ e da tensão aplicada. Pela lei de Bragg [eq. (33)], é possível afirmar que a disposição das curvas em forma de "V" é devida ao estado de tensão compressivo do componente, visto que $2 \theta$ está aumentando com $\psi$ o qual é causado pela diminuição da distância interplanar. Um estado de tensão em tração, segundo a lei de Bragg, seria descrito em forma de " $\wedge$ ".

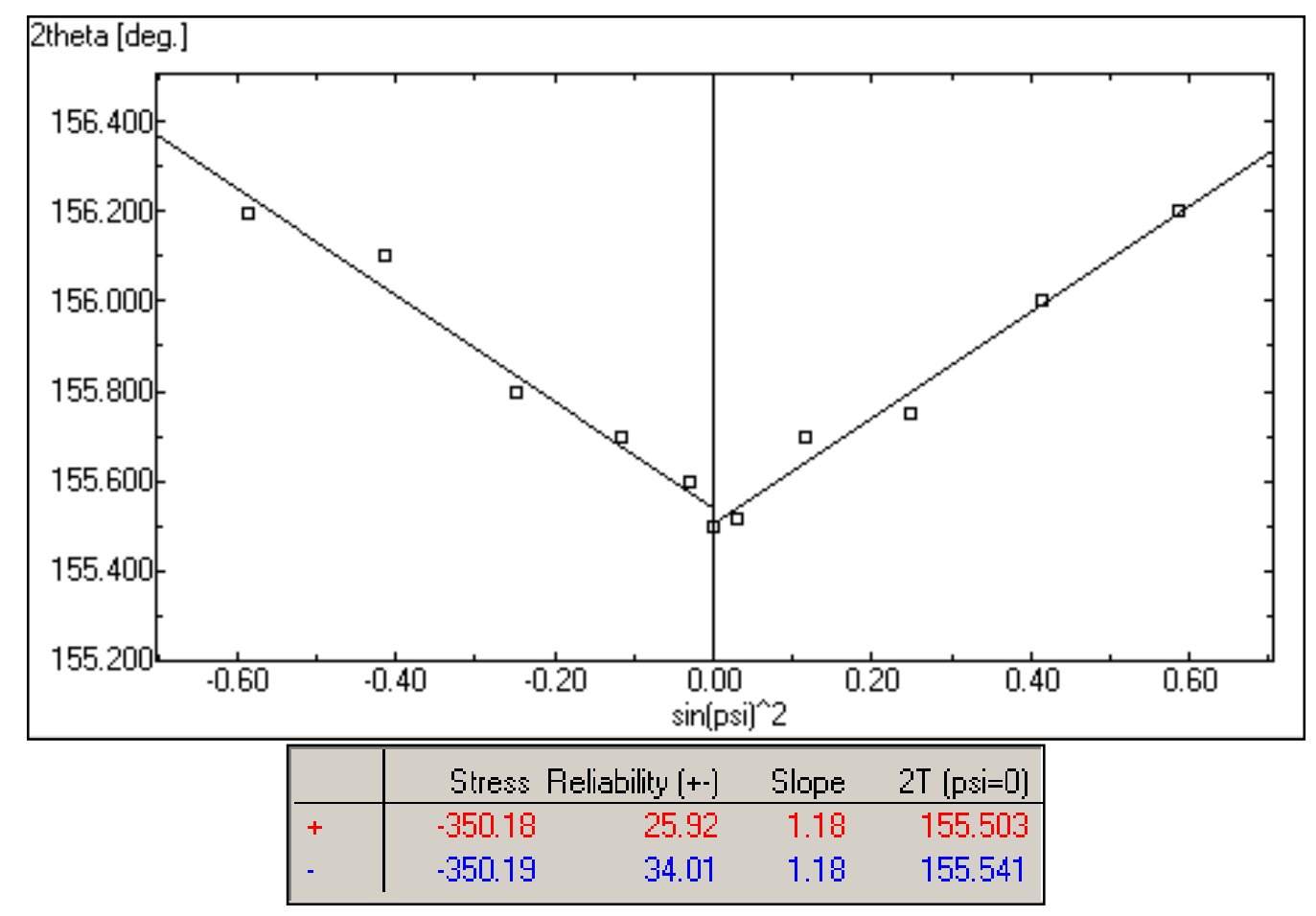

(a) 


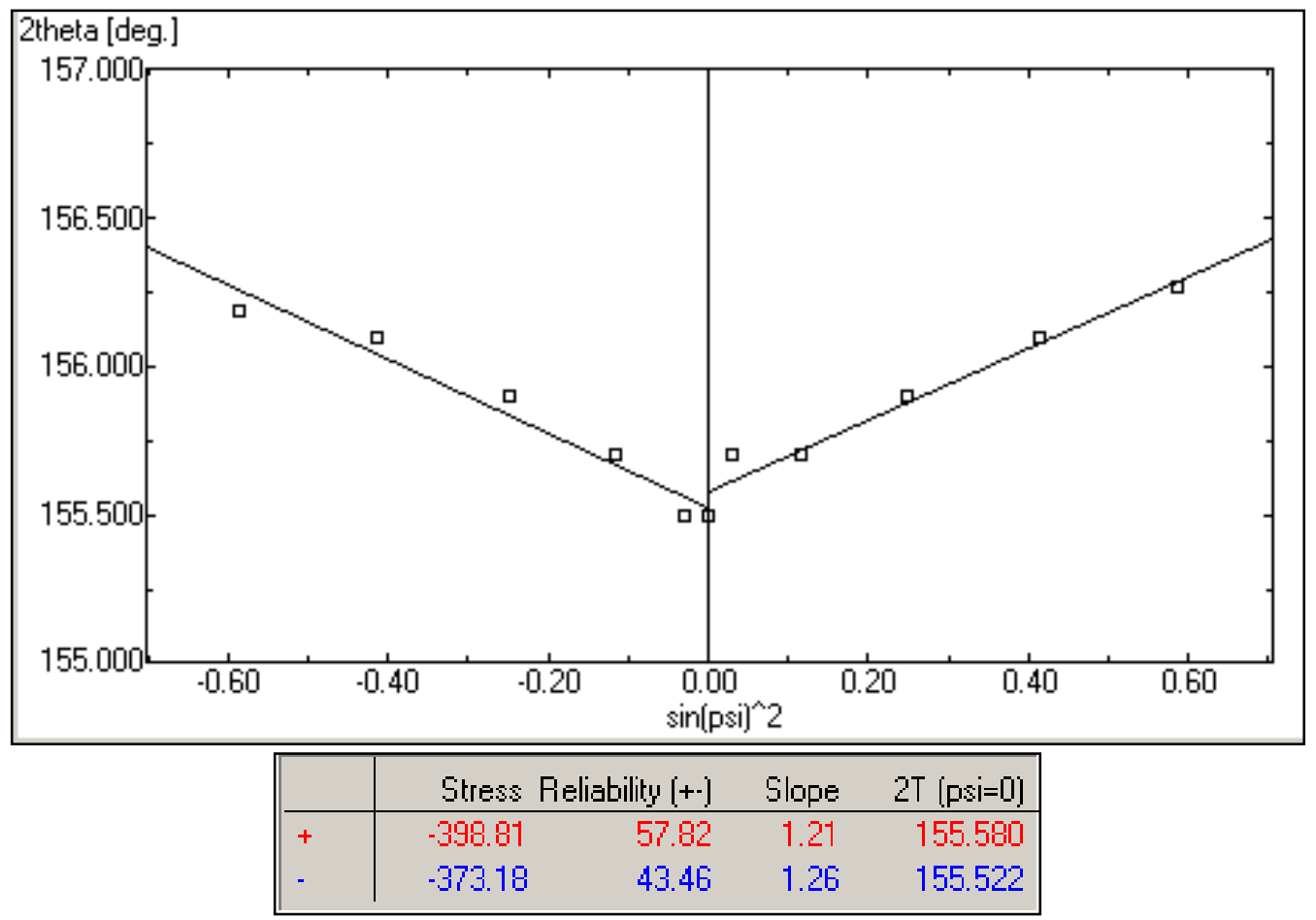

(b)

Figura 71 - Gráfico gerado pelo difratômetro de raios X Rigaku Rint 2000 da distribuição da tensão residual na superfície do aço AISI $\mathbf{4 3 4 0}$ (a) axialmente e (b) tangencialmente. As linhas de cor vermelha e azul representam os resultados para os valores de $-\psi$ e de $-\psi$, respectivamente. As quatro colunas inferiores descrevem, de esquerda à direita, o resultado da tensão, o fator de segurança, o coeficiente angular $\mathrm{e}$ o valor obtido de $2 \theta$ em $\psi=0$, respectivamente.

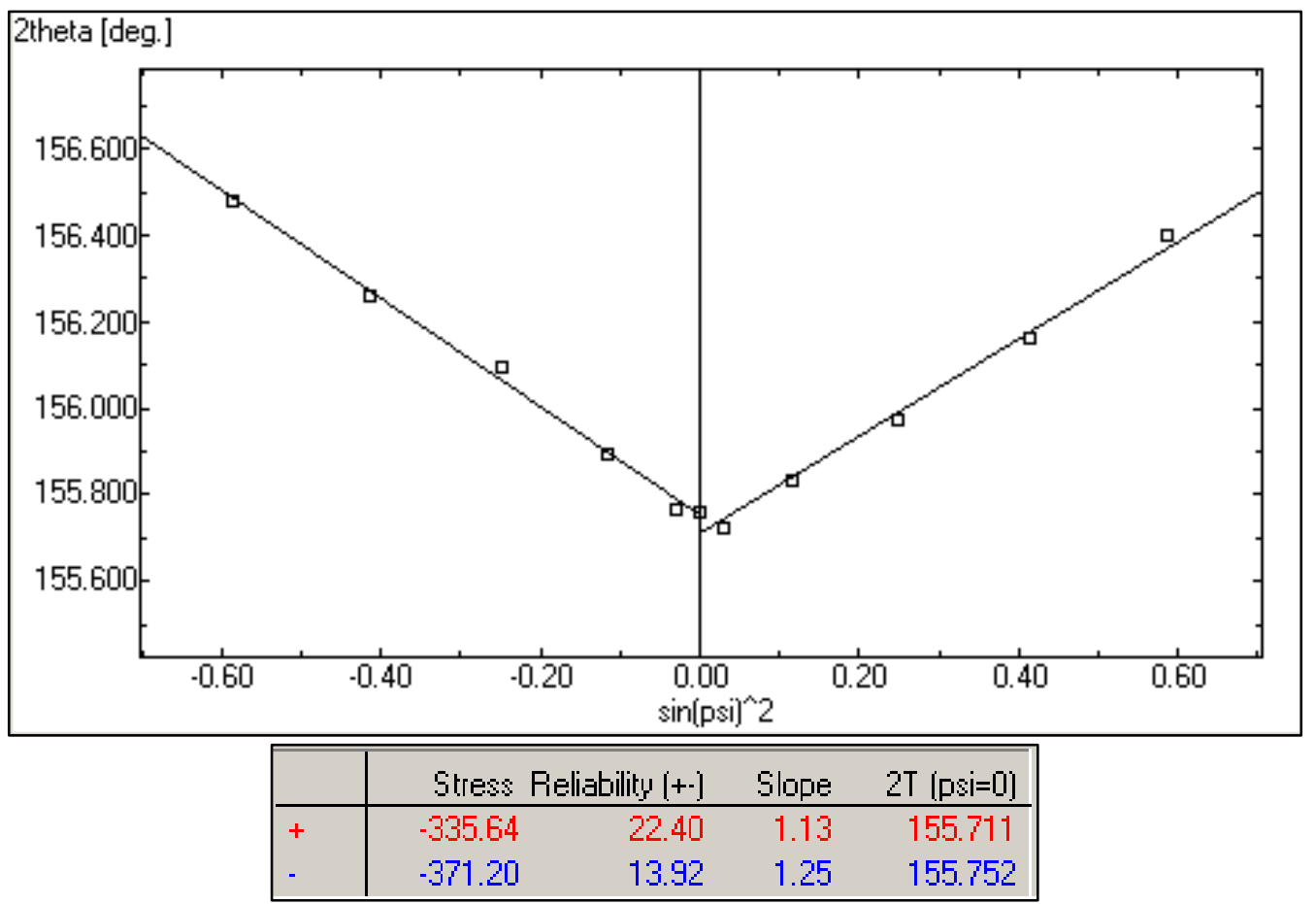

(a) 


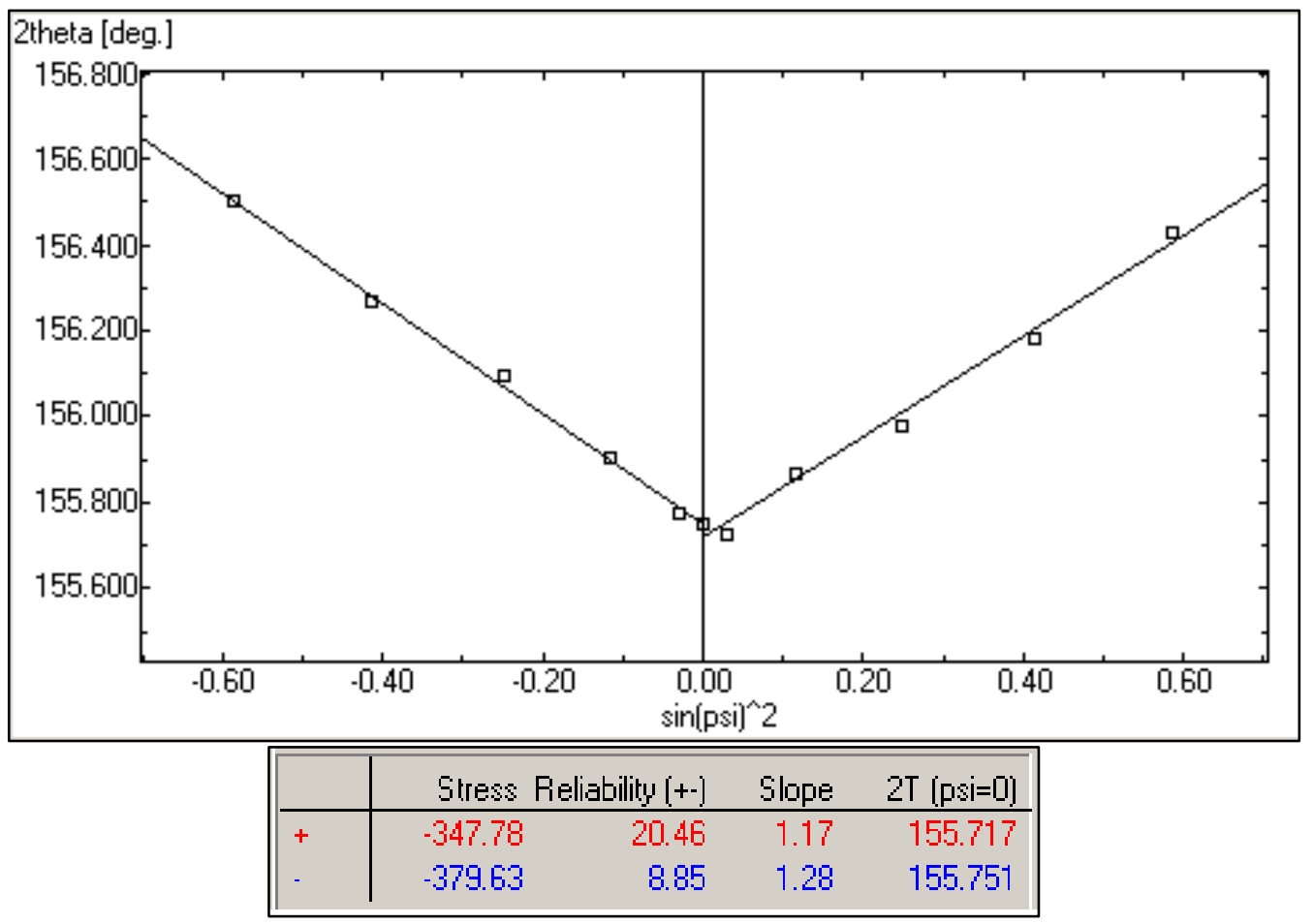

(b)

Figura 72 - Gráfico gerado pelo difratômetro de raios X Rigaku Rint 2000 da distribuição da tensão residual na superfície do aço AISI 4140 (a) axialmente e (b) tangencialmente. As linhas de cor vermelha e azul representam os resultados para os valores de $-\psi$ e de $-\psi$ respectivamente. As quatro colunas inferiores descrevem, de esquerda à direita, o resultado da tensão, o fator de segurança, o coeficiente angular $e$ o valor obtido de $2 \theta$ em $\psi=0$, respectivamente.

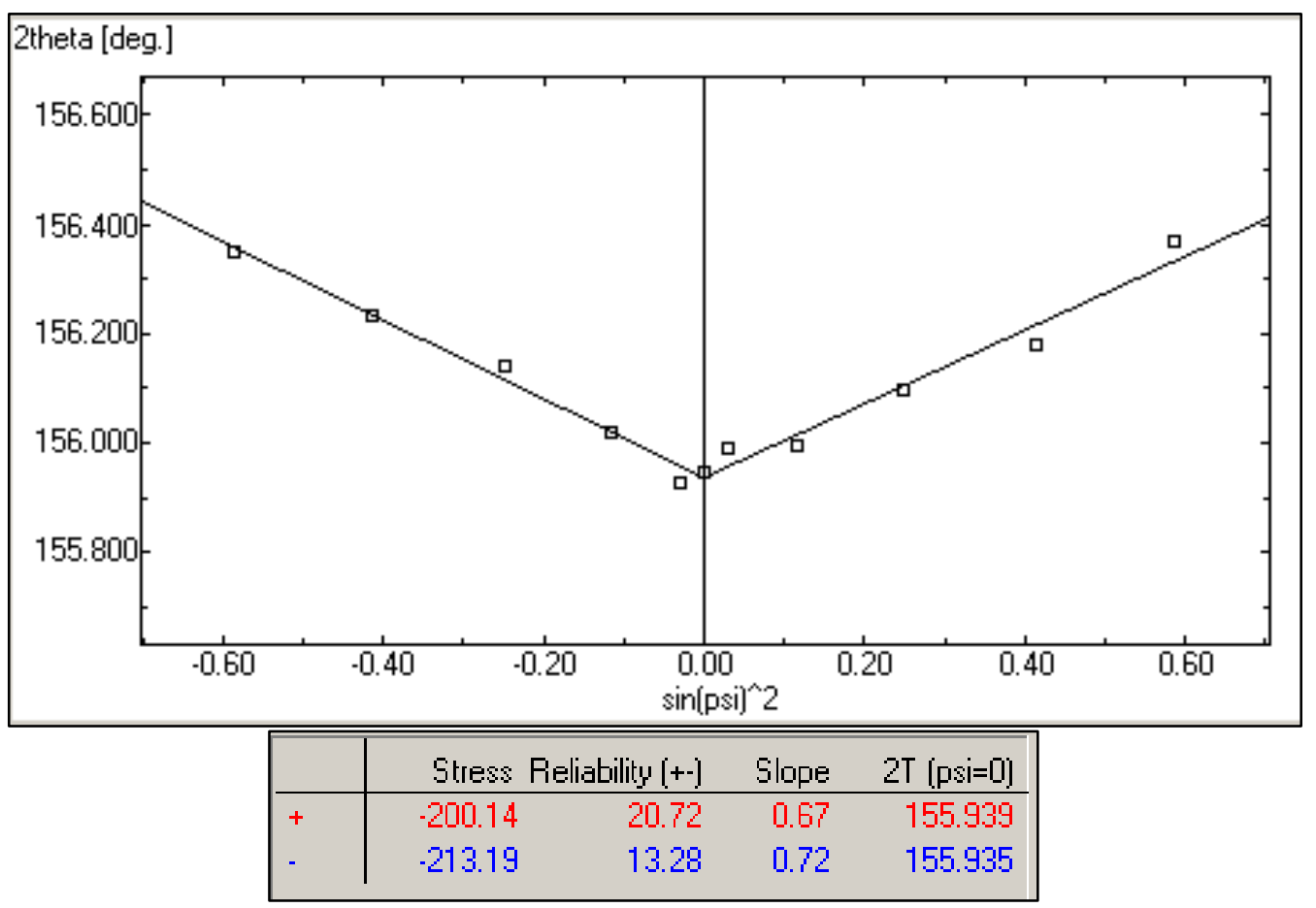

(a) 


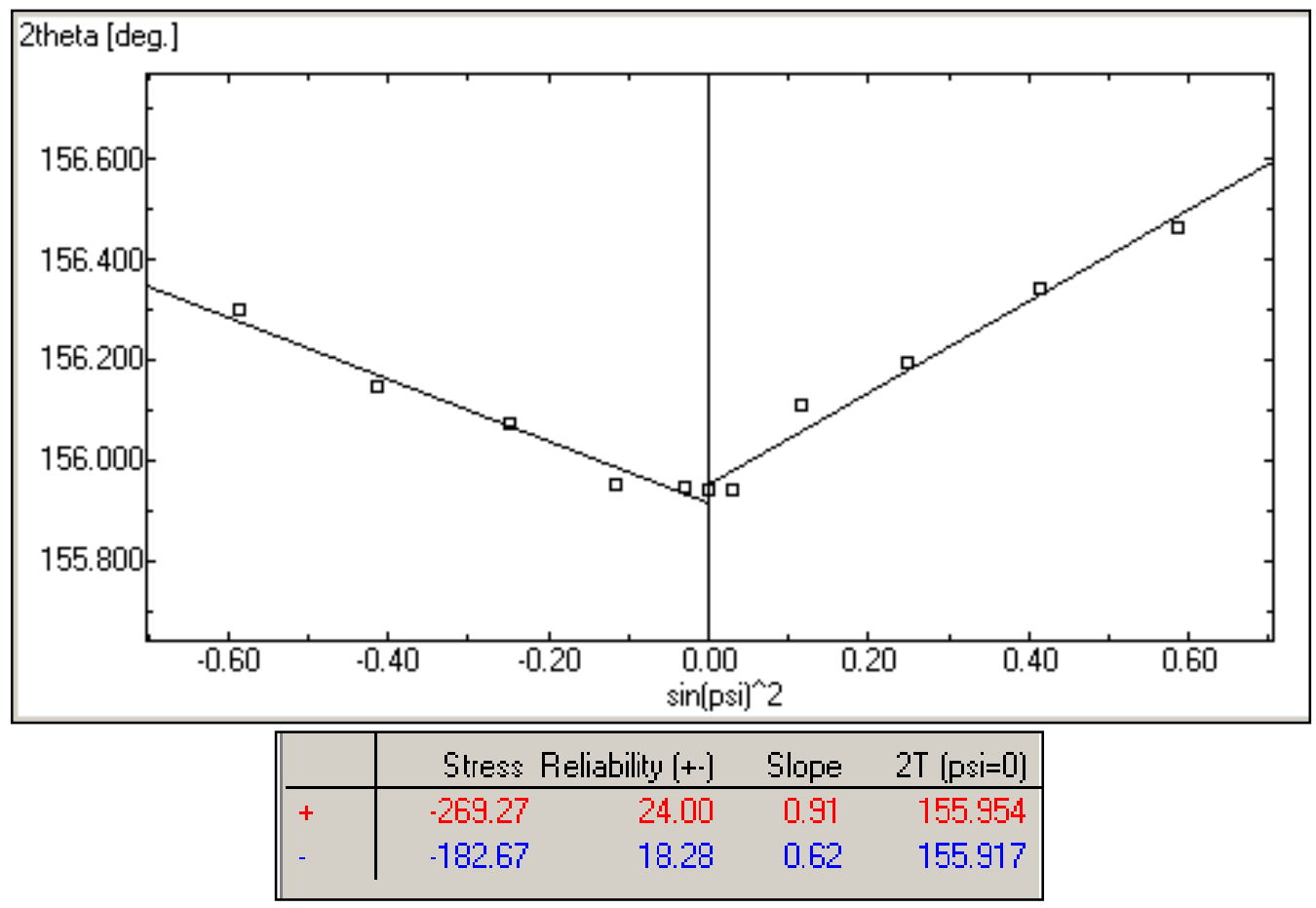

(b)

Figura 73- Gráfico gerado pelo difratômetro de raios X Rigaku Rint 2000 da distribuição da tensão residual na superfície do aço AISI 1045 (a) axialmente e (b) tangencialmente. As linhas de cor vermelha e azul representam os resultados para os valores de $-\psi$ e de $-\psi$, respectivamente. As quatro colunas inferiores descrevem, de esquerda à direita, o resultado da tensão, o fator de segurança, o coeficiente angular $e$ 0 valor obtido de $2 \theta$ em $\psi=0$, respectivamente.

Os resultados das medições e as médias dos valores de tensão residual para os três aços estudados estão descritos na Tabela 14. Em todos os casos os resultados de tensão residual foram de compressão na superfície, com resultados de tensão residual maiores no sentido tangencial. Os resultados para os aços AISI 4340 e 4140 foram muito próximos, tanto axial como tangencialmente. Quando comparados os três aços, os menores valores de tensão residual foram obtidos para o aço AISI 1045 tanto no sentido axial como tangencial. 
Tabela 14 - Resultados das medições de tensão residual pelo método de difração de raios $X$.

\begin{tabular}{|c|c|c|c|c|}
\hline Amostra & & liçõe & & $\begin{array}{c}\text { Média entre }(+\psi) \text { e }(-\psi) \\
(\mathrm{MPa})\end{array}$ \\
\hline \multirow{4}{*}{ Amostra recozida } & \multirow{2}{*}{ Axial } & $+\psi$ & $-33 \pm 10$ & \multirow{2}{*}{$24 \pm 10$} \\
\hline & & $-\psi$ & $-16 \pm 10$ & \\
\hline & \multirow{2}{*}{ Tangencial } & $+\psi$ & $-31 \pm 25$ & \multirow{2}{*}{$16 \pm 19$} \\
\hline & & $-\psi$ & $-2 \pm 13$ & \\
\hline \multirow{4}{*}{4340} & \multirow{2}{*}{ Axial } & $+\psi$ & $-350 \pm 26$ & \multirow{2}{*}{$-350 \pm 30$} \\
\hline & & $-\psi$ & $-350 \pm 34$ & \\
\hline & \multirow{2}{*}{ Tangencial } & $+\psi$ & $-398 \pm 57$ & \multirow{2}{*}{$-386 \pm 50$} \\
\hline & & $-\psi$ & $-373 \pm 43$ & \\
\hline \multirow{4}{*}{4140} & \multirow{2}{*}{ Axial } & $+\psi$ & $-336 \pm 22$ & \multirow{2}{*}{$-353 \pm 18$} \\
\hline & & $-\psi$ & $-371 \pm 14$ & \\
\hline & \multirow{2}{*}{ Tangencial } & $+\psi$ & $-347 \pm 20$ & \multirow{2}{*}{$-363 \pm 14$} \\
\hline & & $-\psi$ & $-380 \pm 9$ & \\
\hline \multirow{4}{*}{1045} & \multirow{2}{*}{ Axial } & $+\psi$ & $-200 \pm 21$ & \multirow{2}{*}{$-206 \pm 17$} \\
\hline & & $-\psi$ & $-213 \pm 13$ & \\
\hline & \multirow{2}{*}{ Tangencial } & $+\psi$ & $-269 \pm 24$ & \multirow{2}{*}{$-226 \pm 21$} \\
\hline & & $-\psi$ & $-182 \pm 18$ & \\
\hline
\end{tabular}

\subsection{TENSÕES CALCULADAS PELO MÉTODO DOS ELEMENTOS FINITOS}

A análise numérica desenvolvida pelo método dos elementos finitos permitiu calcular as tensões térmicas e de transformação resultantes do processo de têmpera em função do tempo de resfriamento, da distribuição da temperatura ao longo do raio, da fração de cada fase transformada e das propriedades do material dependentes da temperatura.

As curvas de resfriamento, relacionando tempo-temperatura para um nó da superfície (curva azul) e um nó do núcleo (curva laranja) do cilindro de aço AISI/SAE 4340 são mostradas na Figura 74, a partir da qual se observa que a maior diferença de temperatura ocorre entre os 5 e os 10 segundos, aproximadamente, e diminui na medida que o campo de temperatura torna-se mais uniforme no interior do cilindro. Essas curvas não apresentam a formação do primeiro estágio da têmpera, uma vez 
que o coeficiente de transferência de calor usado no modelo é constante. Nota-se na mesma Figura 74, que o resfriamento foi bem mais lento no centro que na superfície.

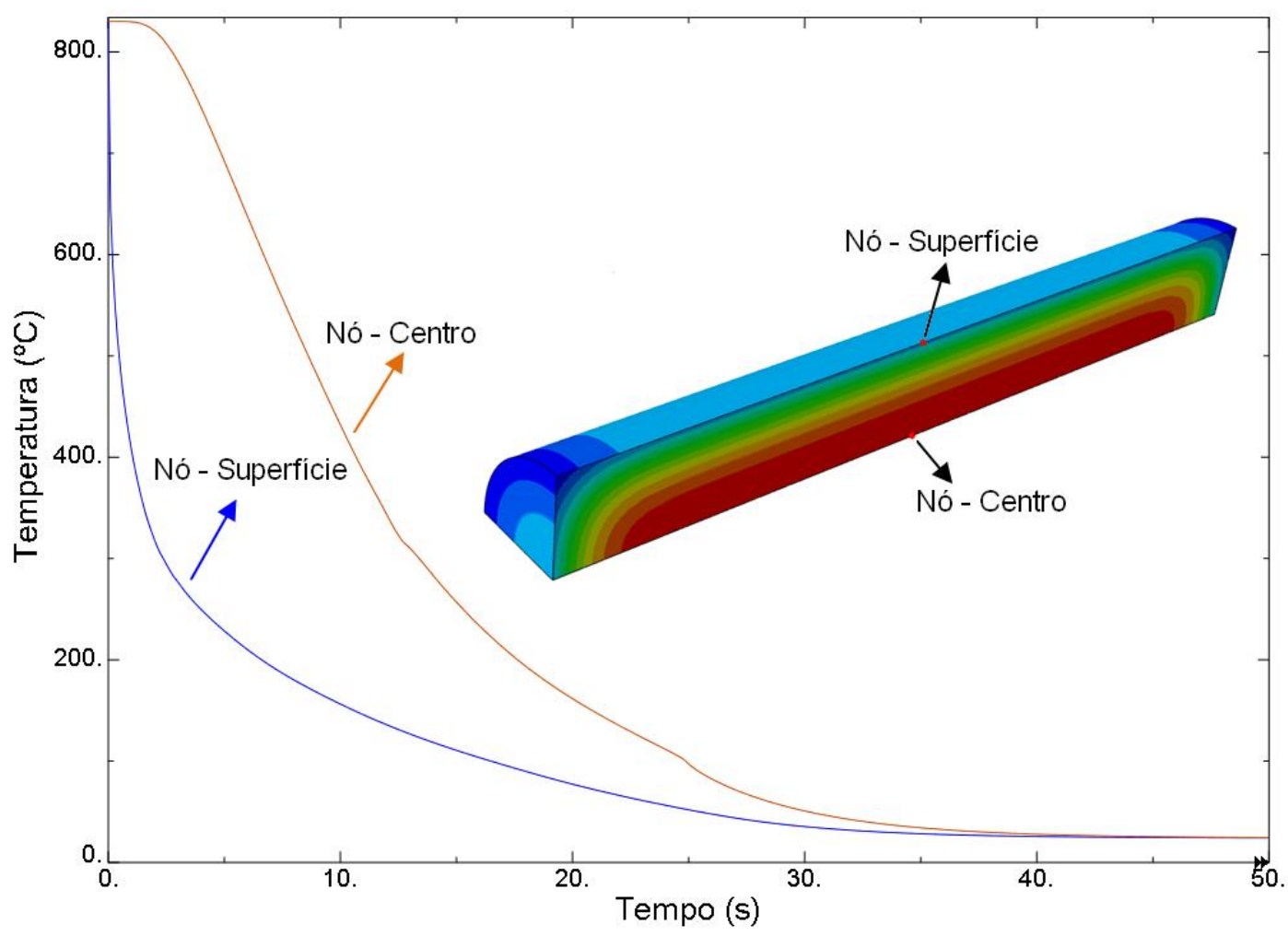

Figura 74 - Variação da temperatura durante a têmpera para um nó da superfície e um nó do centro.

As Figuras 75, 76 e 77 mostram os campos de tensões residuais (térmicas e de transformação) resultantes na direção axial, tangencial e radial, em um setor de um quarto de cada cilindro temperado. Esses resultados mostram que em todos os casos estudados os resultados das tensões residuais axiais e tangenciais são de tração no centro e de compressão na superfície. Nota-se de maneira qualitativa e quantitativa, que na superfície, os resultados das tensões mais significativas são tangenciais. Ainda nessas figuras, é possível observar que devido ao princípio de equilíbrio, as tensões de compressão na superfície e de tração no centro se contrabalançam, resultando em somatória de tensões iguais a zero em todo o cilindro. Da mesma forma que na medição das tensões residuais pelo método de difração de raios $X$, a tensão de tração recebe o sinal positivo $(+\sigma)$ e a de compressão recebe o sinal negativo $(-\sigma)$. 


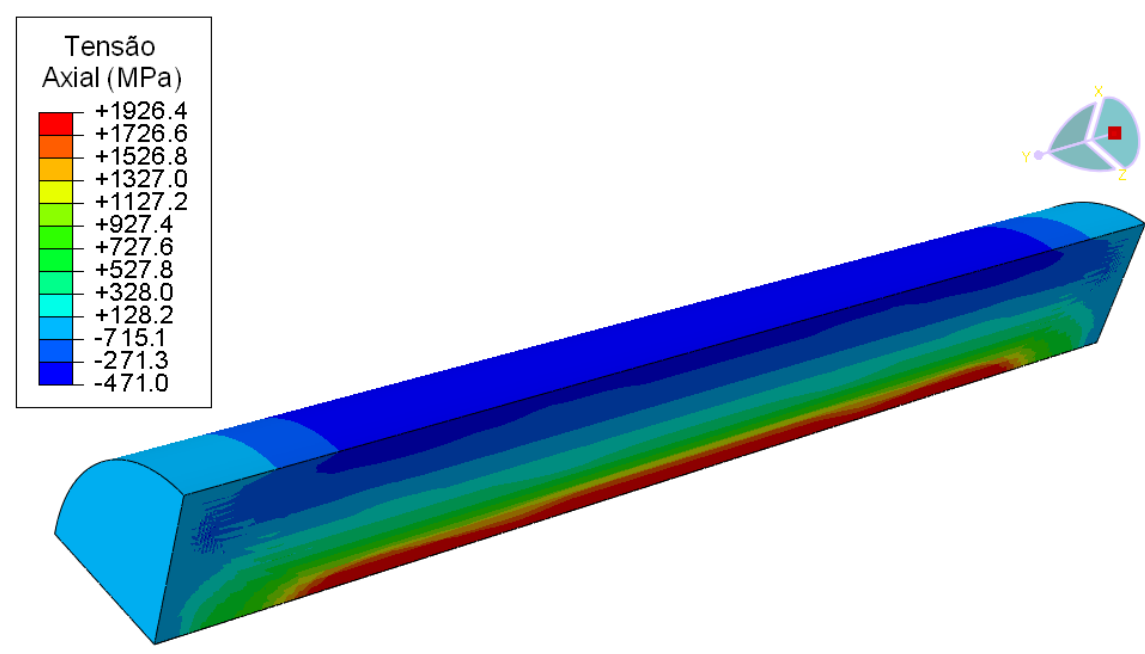

(a)

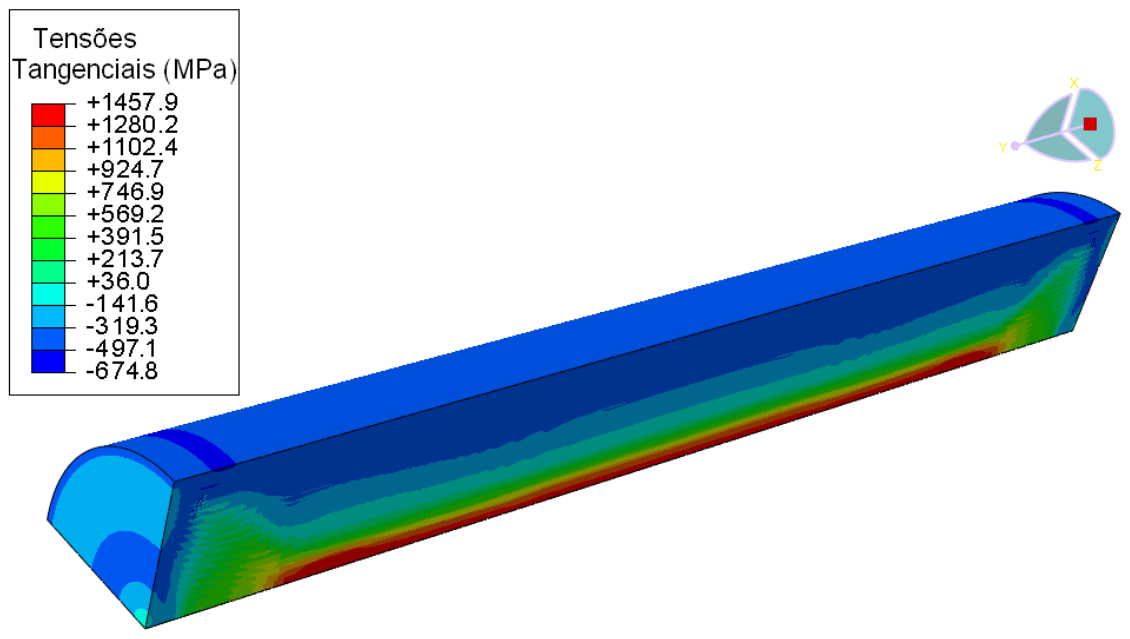

(b)

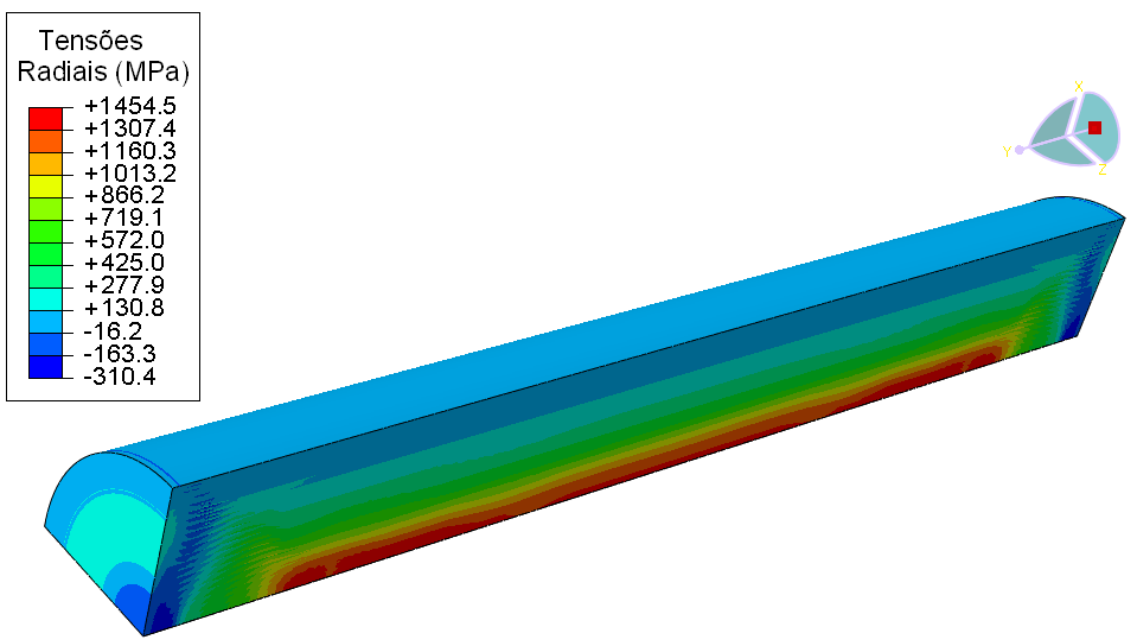

(c)

Figura 75 - Distribuição das tensões residuais calculadas pelo MEF para o cilindro de aço AISI/SAE 4340 após têmpera em água com agitação. (a) Axiais (b) Tangenciais (c) Radiais. 


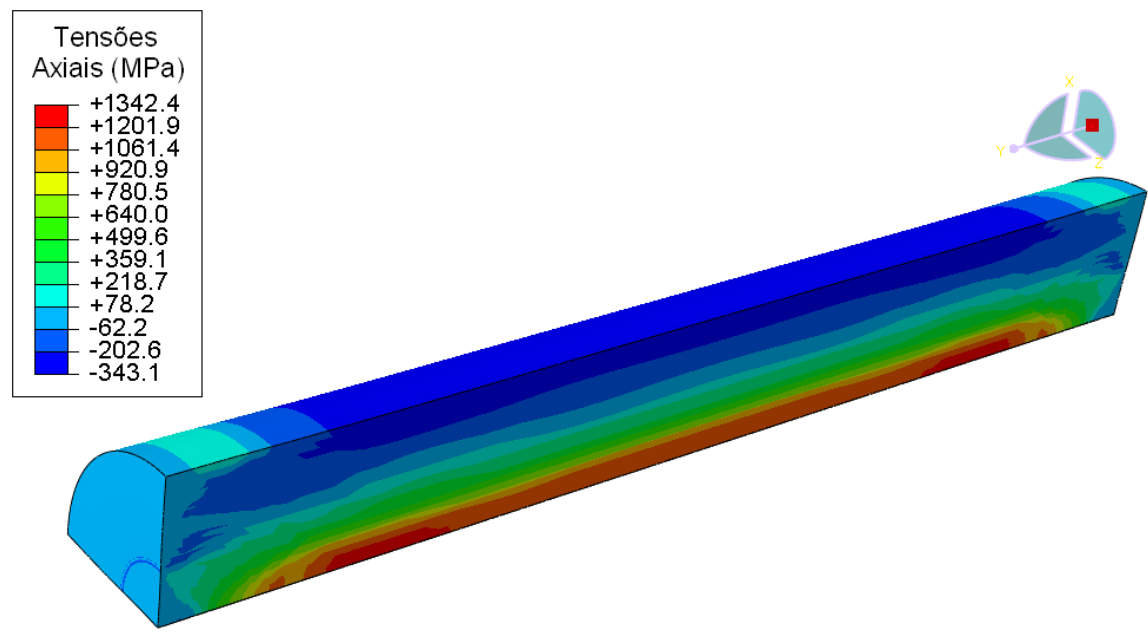

(a)

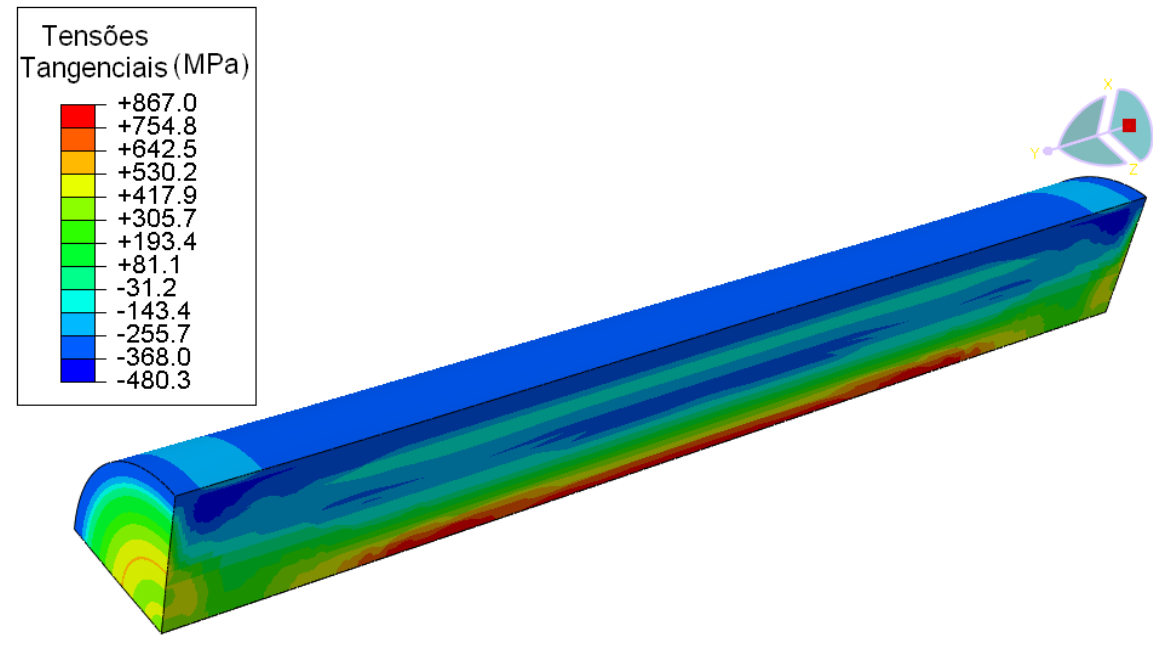

(b)

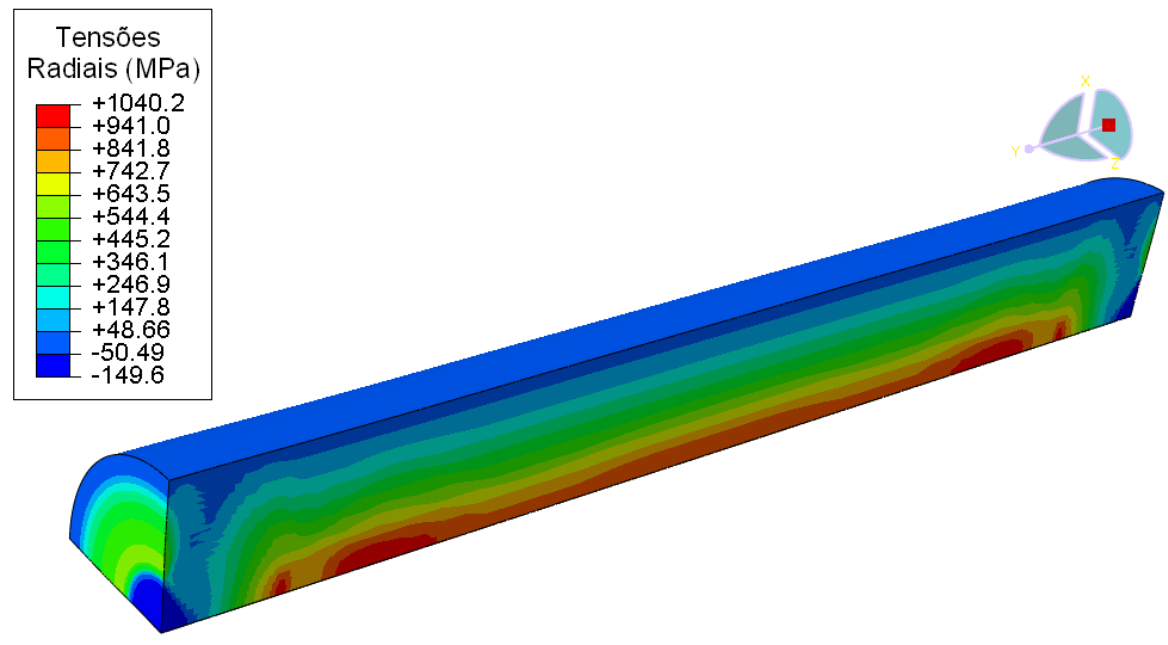

(c)

Figura 76 - Distribuição das tensões residuais calculadas pelo MEF para o cilindro de aço AISI 4140após têmpera em água com agitação. (a) Axiais (b) Tangenciais (c) Radiais. 


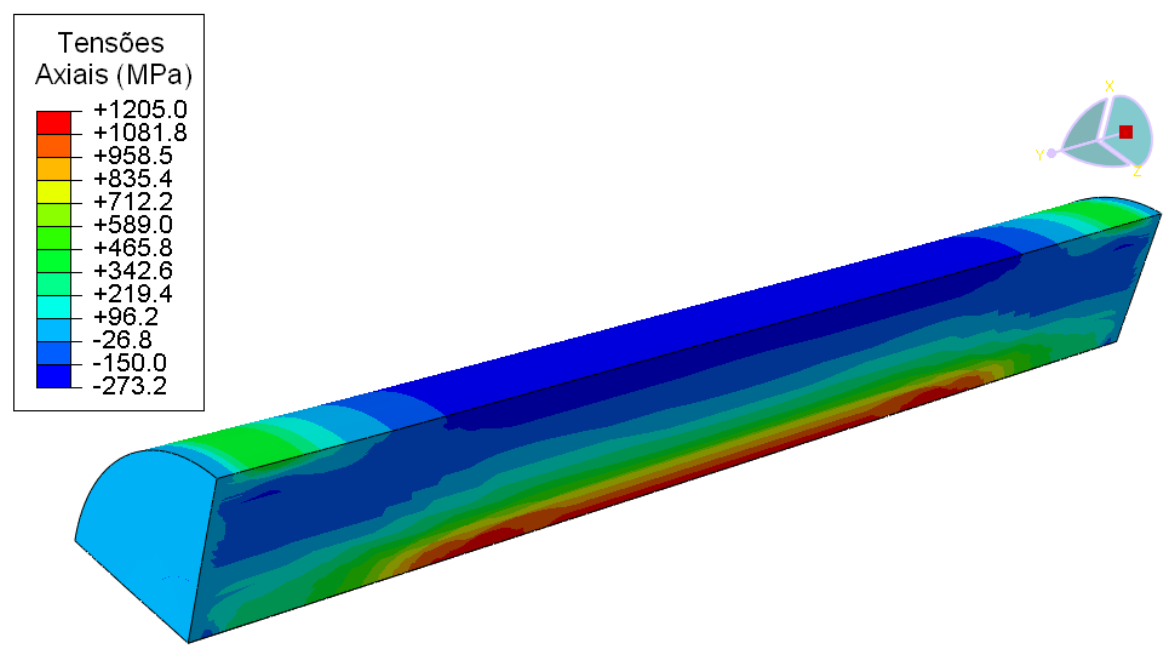

(a)

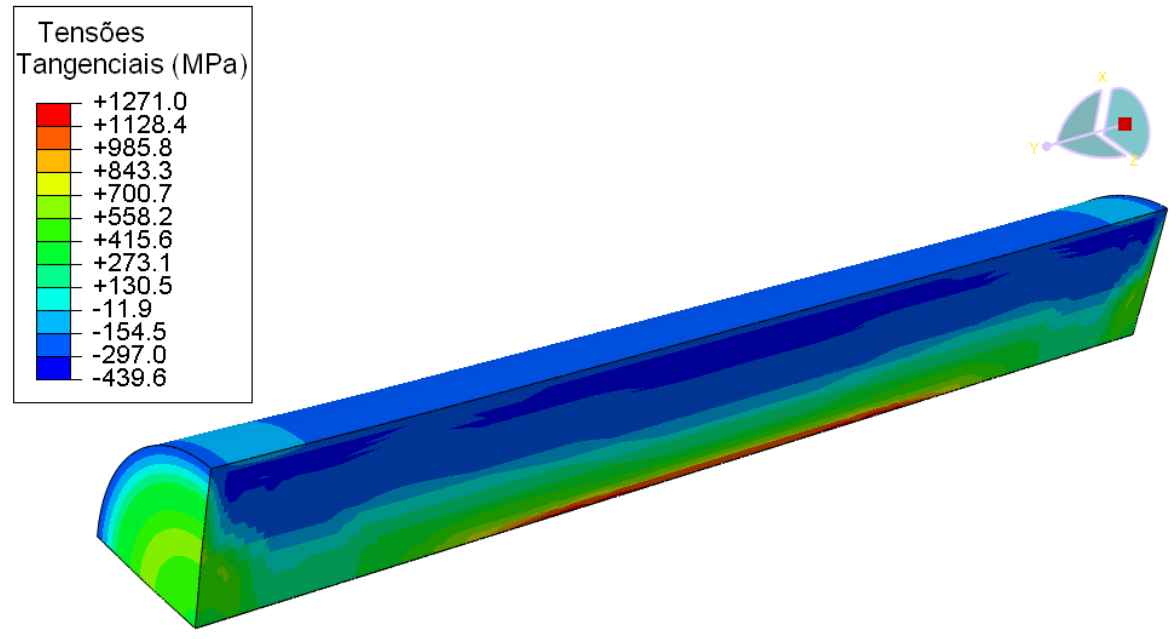

(b)

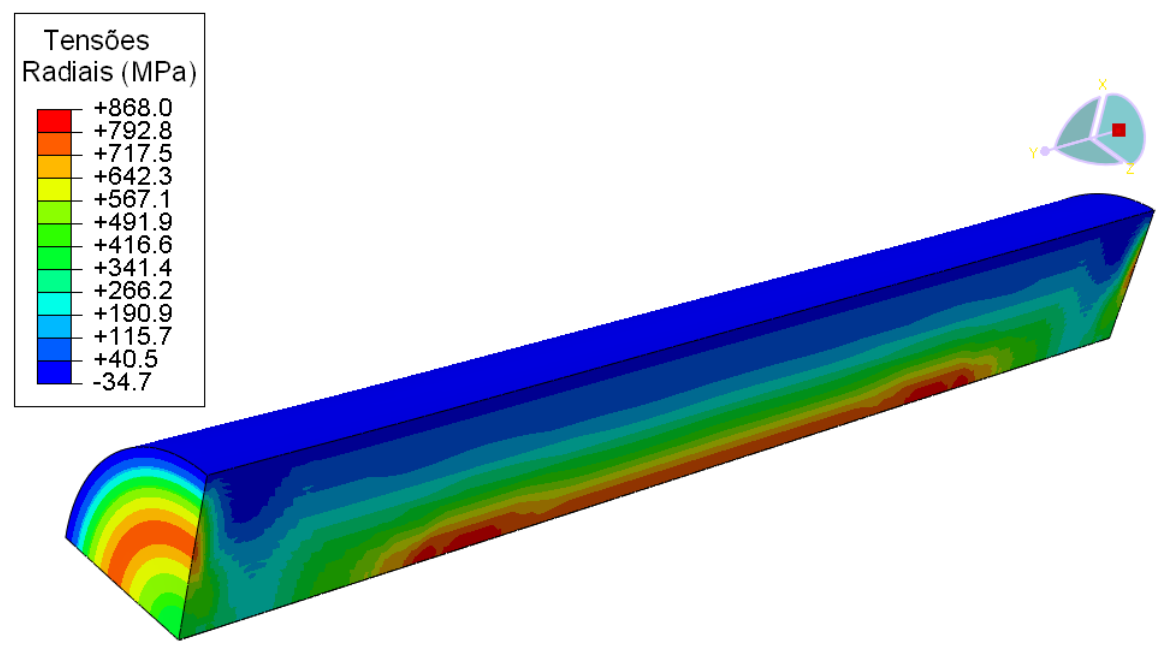

(c)

Figura 77 - Distribuição das tensões residuais calculadas pelo MEF para o cilindro de aço AISI 1045 após têmpera em água com agitação. (a) Axiais (b) Tangenciais (c) Radiais. 
Dada a importância que representam os campos de tensões através da seção transversal do componente, foram levantados os perfis de tensão residual através de um caminho intermediário dos cilindros (Figura 78). Os resultados das tensões axial, tangencial e radial, para esse caminho, nos aços 4340, 4140 e 1045 são mostrados nas Figuras 79, 80 e 81 . Os resultados dessas figuras mostraram um estado predominante de compressão na superfície tanto para a tensão axial, quanto para a tensão tangencial, com valores de $-323 \pm 10 \mathrm{MPa}$ e $-391 \pm 3 \mathrm{MPa}$ para o aço 4340; de $-329 \pm 8 \mathrm{MPa}$ e $-347 \pm 5 \mathrm{MPa}$ para o aço 4140 ; e de $-228 \pm 3$ e $-286 \pm 6 \mathrm{MPa}$ para o aço 1045, respectivamente. Já no caso da tensão radial, esta é nula na superfície. Os comportamentos dessas tensões concordam de forma qualitativa com o relatado na literatura (DENIS et al., 2002; FLETCHER; SOOMRO, 1986; HERNANDEZ, 1996; LI et al., 2008; ROHDE; JEPPSSON, 2000).

Já no caso dos resultados na parte interna dos cilindros houve um comportamento oposto ao obtido na parte superficial, sendo que todos os resultados foram em tração. Além disso, na região superficial os resultados maiores foram no sentido tangencial e na região central foram no sentido axial, para os três aços, com valores de $1848 \pm 11,1189 \pm 7$ e $1128 \pm 4$, para os aços 4340,4140 e 1045 , respectivamente. Já no sentido tangencial e radial foram obtidos resultados de 1321 \pm 4 e $1319 \pm 3$ para o aço 4340; $784 \pm 5$ e $892 \pm 7$ para o 4140 e $1117 \pm 5$ e $778 \pm 5$ para o aço 1045, respectivamente.

Os resultados das altas tensões residuais em tração no centro, obtidas por meio do modelo foram constatados experimentalmente pela formação de uma trinca nessa região em uma das experiências, como mostrado na Figura 84. 


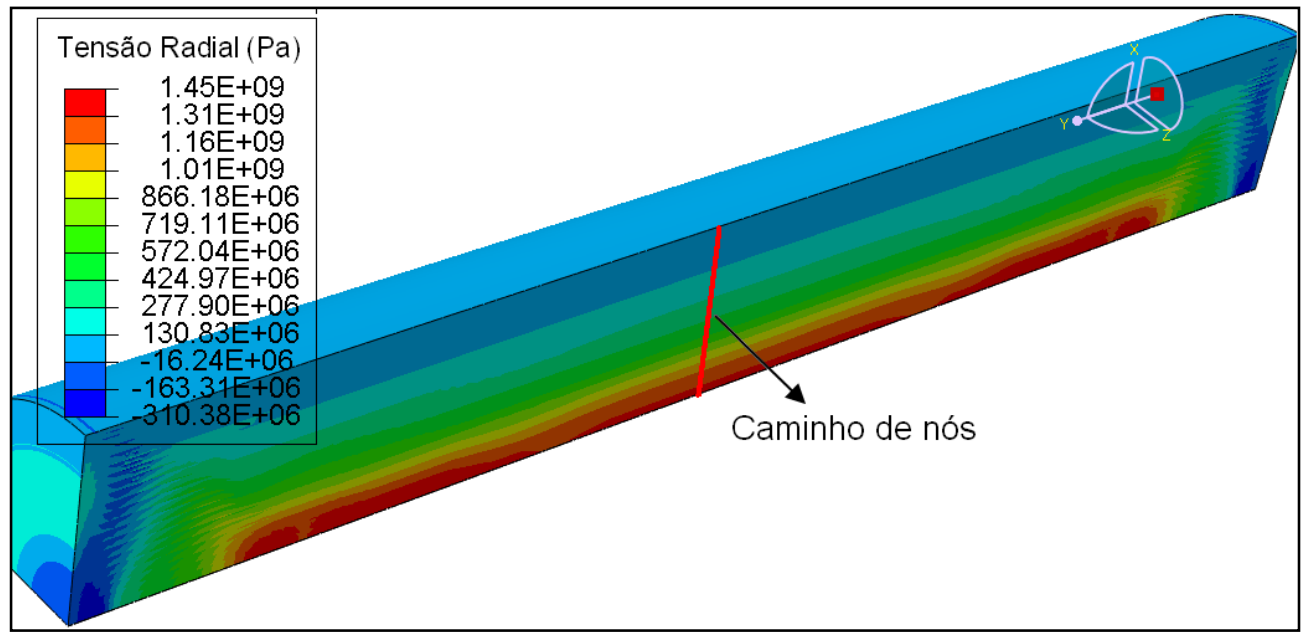

Figura 78 - Caminho de nós para determinação do perfil de tensão residual.

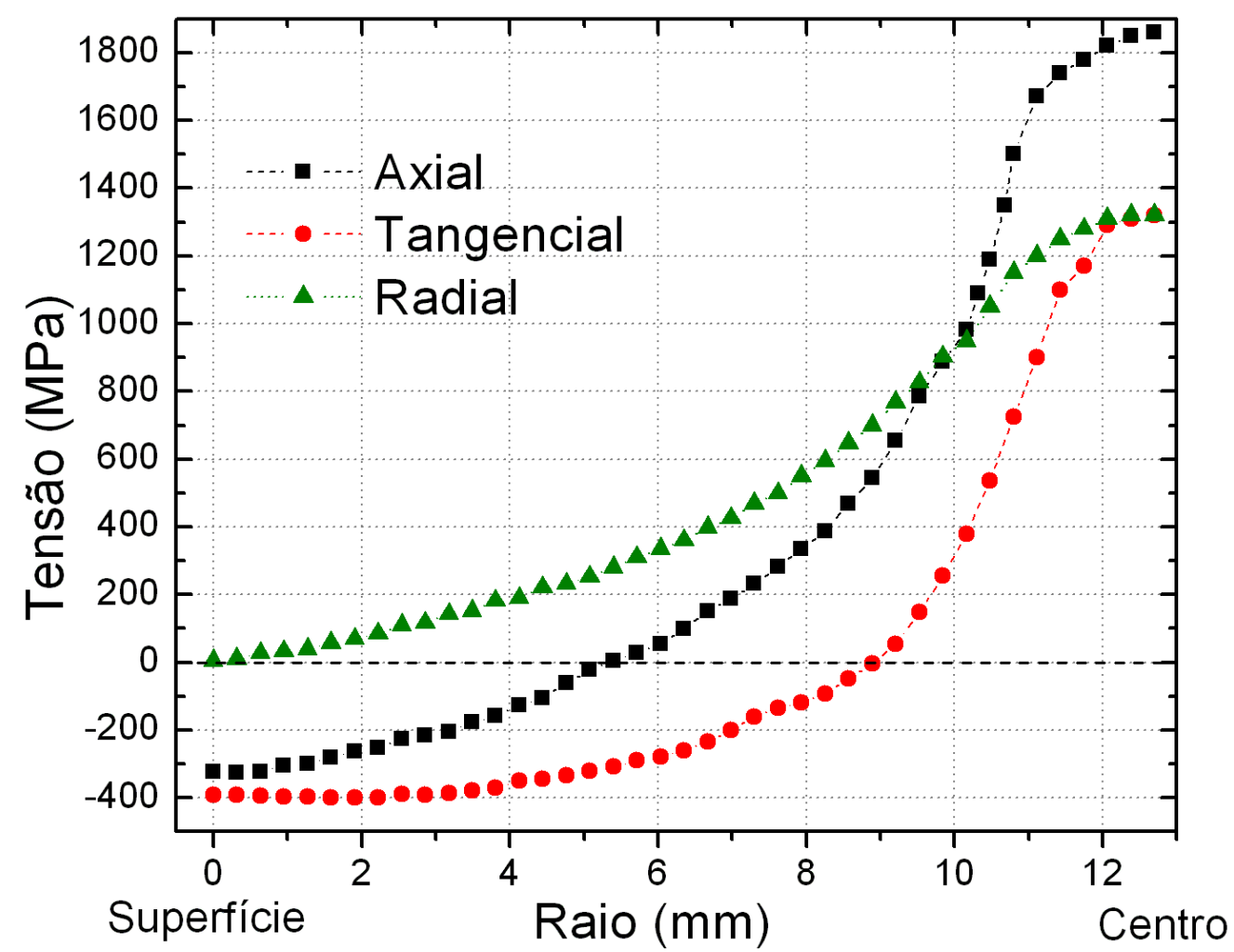

Figura 79 - Distribuição das tensões residuais ao fim da têmpera, calculadas pelo MEF ao longo da secção transversal do cilindro de aço AISI 4340. 


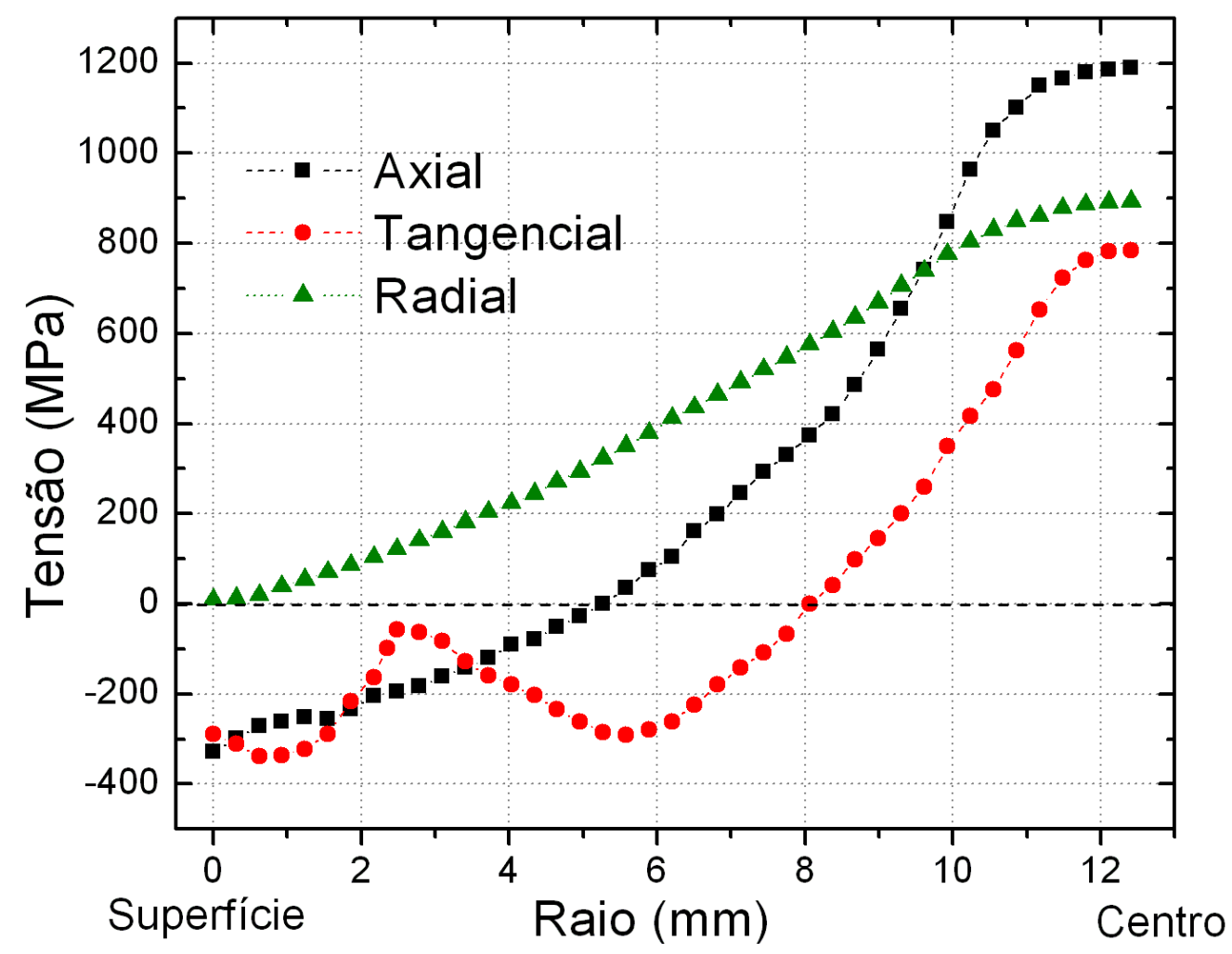

Figura 80 - Distribuição das tensões residuais ao fim da têmpera, calculadas pelo MEF ao longo da secção transversal do cilindro de aço AISI 4140.

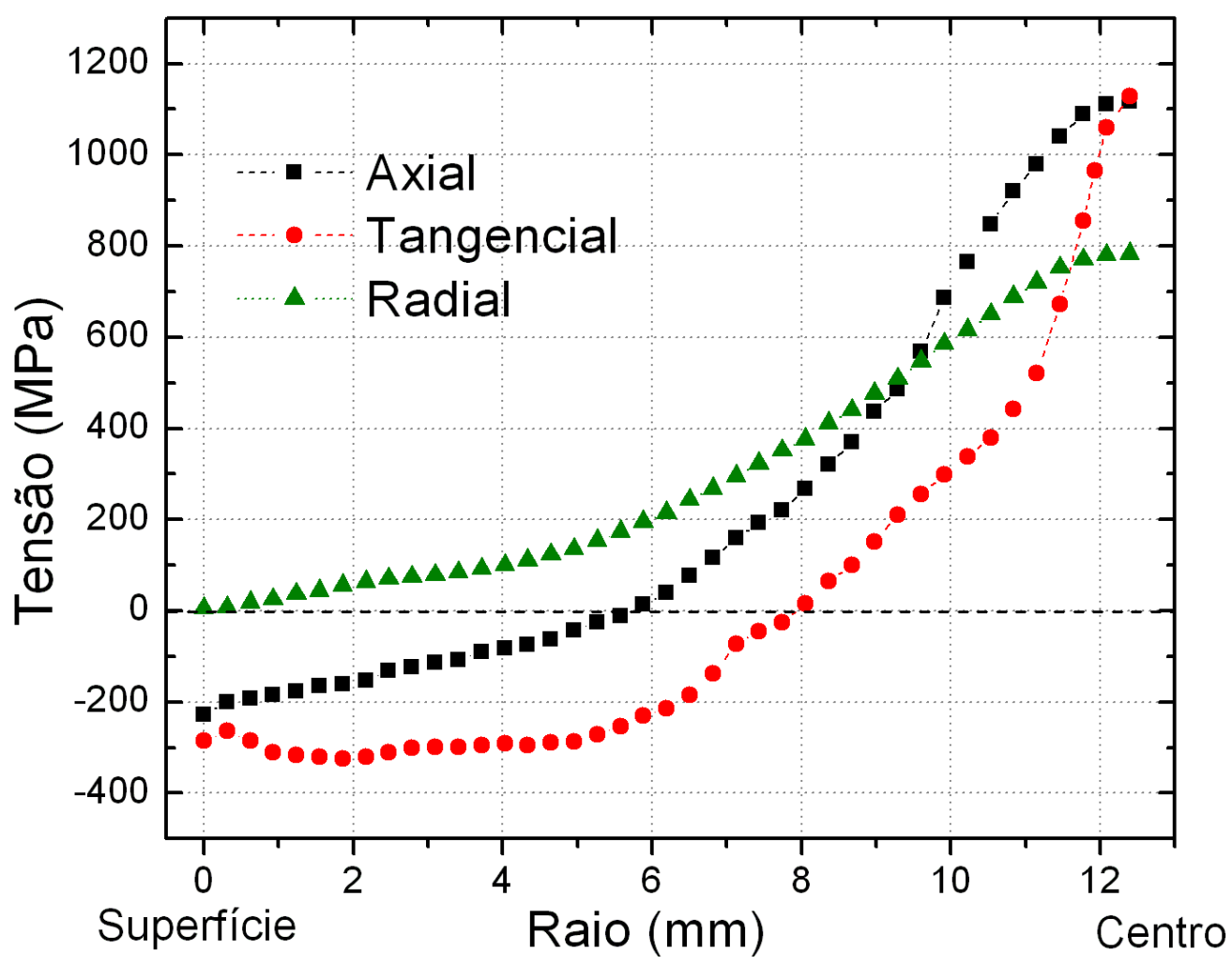

Figura 81- Distribuição das tensões residuais ao fim da têmpera, calculadas pelo MEF ao longo da secção transversal do cilindro de aço AISI 1045. 
As análises dessas figuras permitiram visualizar quantitativa e qualitativamente a magnitude da tensão máxima residual de tração e determinar os valores precisos das tensões residuais na superfície a fim de poder fazer uma comparação com os valores obtidos pela difração de raios $X$, como relacionado na Tabela 15.

Tabela 15 - Comparação entre as tensões tangenciais e axiais numéricas e por difração de raios X para os aços AISI/SAE 4340, 4140 e 1045.

\begin{tabular}{c|cc|cc}
\hline AÇOS & \multicolumn{2}{c|}{$\sigma$ Tangencial (MPa) } & \multicolumn{2}{c}{$\sigma$ Axial (MPa) } \\
\hline AISI/SAE & Modelo Matemático & DRX & Modelo Matemático & DRX \\
4340 & $-391 \pm 3$ & $-386 \pm 50$ & $-323 \pm 10$ & $-350 \pm 34$ \\
4140 & $-347 \pm 5$ & $-363 \pm 14$ & $-329 \pm 8$ & $-353 \pm 18$ \\
1045 & $-286 \pm 6$ & $-226 \pm 21$ & $-228 \pm 3$ & $-206 \pm 17$ \\
\hline
\end{tabular}

Comparando os resultados de tensão residual da Tabela 15, pode-se afirmar que as tensões residuais na superfície foram sempre compressivas para a direção axial e tangencial, com magnitudes próximas entre os resultados numéricos e experimentais. As tensões residuais tangenciais na superfície foram superiores às axiais nos três casos estudados. Os maiores valores de tensão residual no sentido tangencial foram obtidos para o aço AISI 4340 e os menores valores para o aço AISI 1045, tanto numérica como experimentalmente, o que poderia ser explicado pela formação de uma estrutura completamente martensítica (expansão volumétrica associada maior) no aço AISI 4340 e pela alta formação de perlita no aço AISI 1045, que é um produto de transformação relativamente mole e de menor expansão volumétrica. No sentido axial os resultados para os aços AISI 4340 e 4140 foram bastante similares. Já no sentido tangencial os resultados para o aço AISI 4340 foram um pouco maiores ( 40 MPa para o modelo numérico e $\sim 30 \mathrm{MPa}$ experimentalmente), se comparado com o aço AISI 4140, o que pode estar relacionado com a maior fração volumétrica de martensita formada no aço 4340.

De uma maneira geral, pode-se afirmar que existe uma boa correlação entre os resultados de tensões residuais obtidos a partir do método dos elementos finitos e aqueles obtidos através de difração de raios X. Não entanto cabe ressaltar, que as constantes elásticas na medição de tensão residual por difração de raios $\mathrm{X}$, foram 
iguais para os três aços estudados $\left(E_{211}=210 \mathrm{GPa}\right)$ o que pode causar algumas discrepâncias entre os resultados do modelo e os experimentais.

Os resultados das tensões residuais dos modelos com e sem calor latente, mostraram uma diferença de aproximadamente $20 \mathrm{MPa}$, sendo menores os resultados no caso em que não foi levado em conta o calor latente de transformação. O que evidencia a importância de ter em conta esta variável nos modelos desenvolvidos.

Essa leve diferença é equivalente ao trabalho apresentado por Lee e Lee (2009). Esses autores avaliando a têmpera de um cilindro de aço AISI 4340 de 100 $\mathrm{mm}$ de comprimento e $10 \mathrm{~mm}$ de diâmetro, concluíram que a média da diferença de temperatura considerando o calor latente é de $43^{\circ} \mathrm{C}$. Por outro lado, ao tratar o comportamento do calor latente na predição das tensões residuais, Xu et al. (1995) desenvolveram um modelo de elementos finitos para barras de aço (AISI 4135) temperadas, afirmando que não há um efeito significativo do calor latente nas tensões residuais produzidas pelo processo de têmpera.

Dessa maneira, uma vez que a evolução microestrutural é acoplada não linearmente ao cálculo da temperatura, ao calor latente e às propriedades do material, pequenas alterações no histórico de temperatura podem causar alterações substanciais na microestrutura e no estado final de tensão residual dos componentes.

\subsubsection{Formação das tensões residuais de compressão na superfície}

O desenvolvimento da formação de tensões residuais de compressão na superfície durante o processo de têmpera foi detalhado na secção 2.3.4.3, em que foi descrito como o aumento de volume associado às transformações de fase (secção 4.2.6.4.3) sempre desloca as tensões existentes (independentemente do seu sinal) para valores mais negativos, e como reação, por razões de equilíbrio, as zonas do material não afetado diretamente pela transformação reagem com valores de tensão positivas. Isto quer dizer, que as transformações que ocorrem em regiões do material que estão em tensão de tração inevitavelmente reduzem as tensões, 
enquanto as transformações que ocorrem em zonas que estão em compressão aumentarão os valores das tensões existentes, no momento em que acontece a transformação.

A Figura 82 apresenta a evolução das tensões residuais térmicas (sem transformação) tangenciais ao longo do tempo na superfície e no centro do aço 4140. A descrição qualitativa da sequência que leva a esse comportamento, já foi detalhada nos itens 2.3.4.1 e 2.3.4.2, mas é importante ressaltar que esse resultado indica claramente a inversão do estado tensional sofrido pelo componente durante 0 resfriamento. Nessa figura é ressaltado o tempo $t(u)$, o qual indica o ponto em que são invertidos os sinais das tensões térmicas na superfície e no centro da peça.

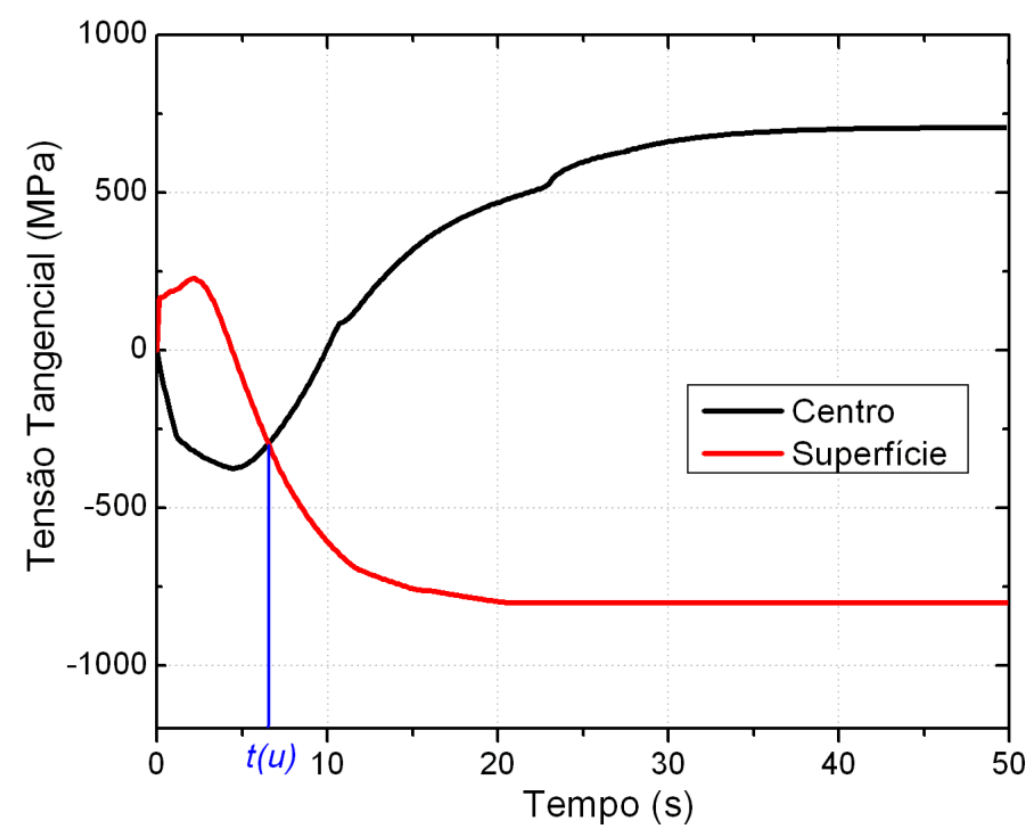

Figura 82 - Tensões residuais tangenciais térmicas ao longo do tempo desenvolvidas durante o tratamento térmico de têmpera do aço 4140.

Como foi detalhado na secção 2.3.4.2 além das tensões térmicas devem ser consideradas as tensões devidas à transformação de fase, já que durante o resfriamento surgem mudanças não homogêneas no volume, associadas com a formação da nova fase. Na Figura 83, é mostrada a evolução das tensões residuais térmicas e de transformação ao longo do tempo. Este resultado indica a condição em que a transformação acontece depois da mudança de sinal das tensões térmicas $\left(t_{u}\right)$. Neste caso o aumento de volume devido à transformação da superfície adiciona 
tensões compressivas à superfície (na transição da transformação, entre aproximadamente os 10 e os 20 s) e uma vez que as tensões são balanceadas, há um correspondente aumento das tensões de tração no núcleo. Após a transição de transformação o cilindro começa a contrair, levando a uma redução do estado de tensões.

Deste modo as transformações que ocorrem em regiões do material que estão em tensão de tração inevitavelmente reduzem as tensões, enquanto as transformações que ocorrem em zonas que estão em tensão de compressão aumentarão os valores destas tensões, como mostrado na Figura 83. Esses resultados mostram que a variação do resfriamento pode apresentar comportamentos complexos em relação à estabilidade do efeito dimensional. Assim, devido ao comportamento das tensões térmicas no núcleo e da mudança do sinal das tensões na superfície durante o resfriamento, as posições do início da transformação na superfície e no núcleo são de fundamental importância para compreensão do estado final de tensões residuais no processo de têmpera.

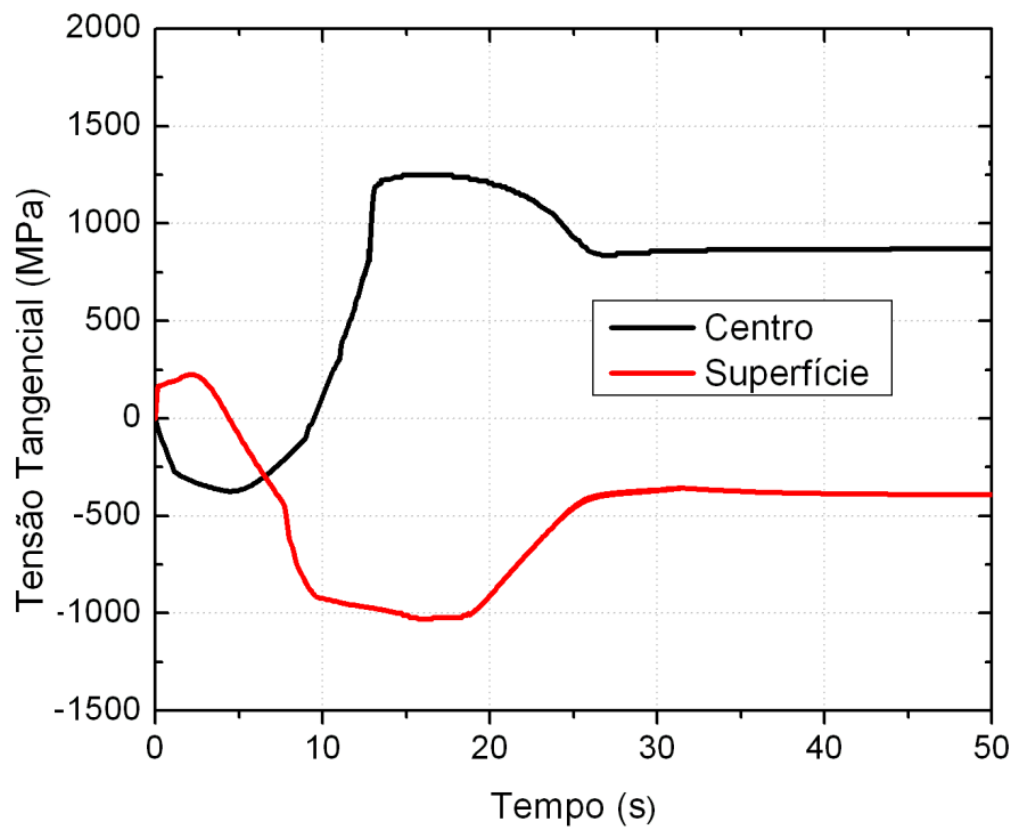

Figura 83 - Tensões residuais tangenciais térmicas e de transformação ao longo do tempo desenvolvidas durante o tratamento térmico de têmpera do aço 4140.

Os resultados das altas tensões residuais em tração no centro, obtidas por meio do modelo, foram constatados experimentalmente pela formação de uma trinca 
nessa região, ao final de uma das experiências, como mostrado na Figura 84. $\mathrm{Na}$ fase inicial da têmpera, uma vez que toda a peça é composta por austenita que possui alta ductilidade, a possibilidade de sofrer grandes deformações plásticas ou trincamento é pequena, mas na fase posterior, a formação súbita de martensita (coeficiente de expansão por transformação, muito maior que o coeficiente de expansão térmica) induz tensões internas que podem levar a grandes deformações e até trincamento.

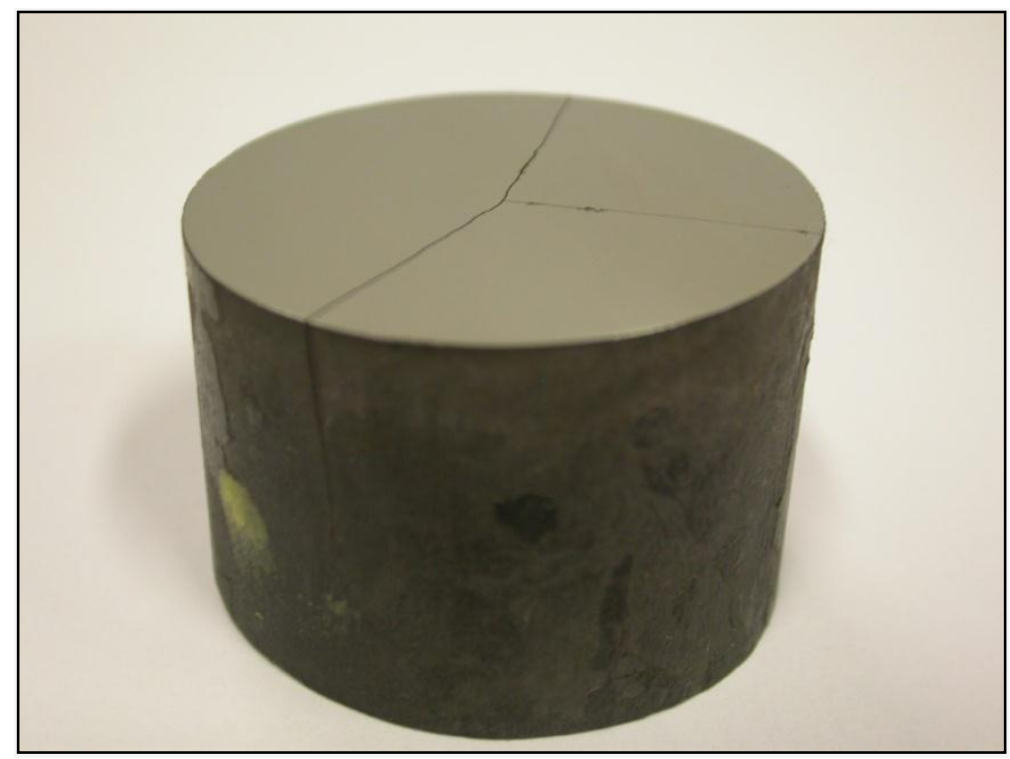

(a)

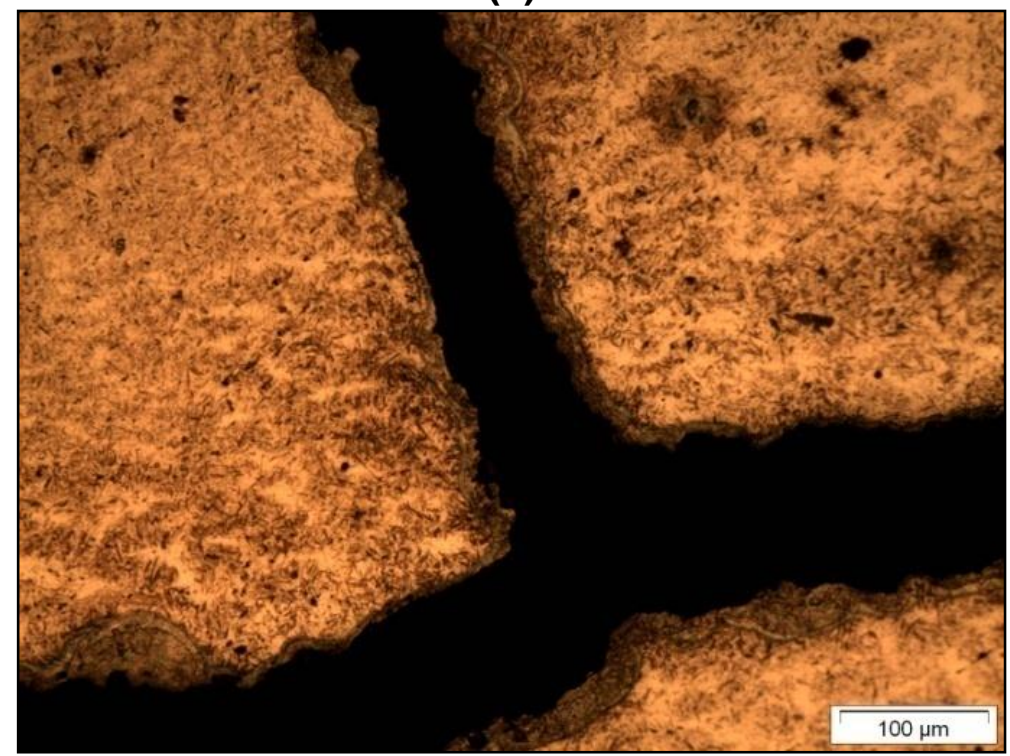

(b)

Figura 84 - Trinca de têmpera iniciada na parte central após têmpera em água com intensa agitação. Aço 4340. (a) Fotografia da peça evidenciando as duas trincas formadas. (b) Micrografia da trinca na região de interseção; aumento 100x. 
A ruptura localizada na forma de trincas de têmpera ocorre quando a quantidade de tensão desenvolvida excede a tensão de fratura, é dizer, essas fissuras ocorrem quando a deformação plástica não consegue absorver as tensões geradas. Uma vez que, as tensões residuais obtidas pelo modelo numérico nos três casos na região central foram acima dos $1300 \mathrm{MPa}$ para o aço 4340, dos $800 \mathrm{MPa}$ para aço 4140 e ao redor dos $1000 \mathrm{MPa}$ para o 1045, e as tensões de ruptura são, segundo a dureza (Normas Técnicas: DIN. 50150, 2000 e ASTM A370-09, 2009) obtidas nessa região (de $~ 55 \mathrm{HRC}$ para os aços 4340 e 4140 e de $\sim 30 \mathrm{HRC}$ para o aço 1045), de 1900 MPa para os aços 4340 e 4140 e de 1100 MPa para o 1045, se torna possível o desenvolvimento de trincas na região central dos mesmos, como foi observado ao final de um dos processos de têmpera realizados no cilindro AISI 4340 (Figura 84). Desta maneira, dependendo do estado de tensão residual e da natureza da perda de ductilidade durante a têmpera desde temperatura elevadas, podem resultar trincas de têmpera devidas às tensões residuais de tração somadas às evidências de segregação química nessa região.

Para medir a tensão residual por métodos não destrutivos podem ser utilizados diferentes tipos de radiação: raios $X$ (interação eletrônica), nêutrons (interação nuclear) ou radiação sincrotron, todos eles baseados na lei de Bragg (secção 2.3.5). No caso da difratometria de raios $X$ convencional, devido à sua baixa intensidade, a penetração em aços é da ordem de 10 a $15 \mu \mathrm{m}$ e no caso dos nêutrons ou da radiação sincrotron, devido a sua alta energia $(>80 \mathrm{KeV})$, a penetração é $10 \mathrm{~mm}$, cerca de 1000 vezes maior. Portanto, existem barreiras para determinar o comportamento das tensões em profundidades maiores; além disso, as tecnologias de alta energia não são de fácil acesso. Portanto, torna-se necessário o desenvolvimento de modelos numéricos de previsão de tensões residuais para se evitar trincas, distorções, descartes e retrabalhos de peças tratadas termicamente. 


\section{CONCLUSÕES}

O modelo não linear elasto-plástico proposto neste trabalho requer a inclusão das propriedades mecânicas e físicas, porcentagens de cada fase transformada em função da temperatura, acoplamento termo-mecânico e análises precisas das principais interações, para prever o estado de tensões residuais que se desenvolve no tratamento térmico de têmpera. A incorporação desses requisitos permitiu obter os seguintes resultados:

- Resultados numéricos de tensão residual, com aderência significativa, entre os dados obtidos através da modelagem por elementos finitos (-391 $\pm 3,-347 \pm 5$ e -286 $\pm 6 \mathrm{MPa}$, no sentido tangencial e de $-323 \pm 10,-329 \pm 8$ e $-228 \pm 3 \mathrm{MPa}$ no sentido axial, para os aços 4340, 4140 e 1045, respectivamente) e os obtidos experimentalmente por difração de raios X (-386 $\pm 50,-363 \pm 14$ e -226 $\pm 21 \mathrm{MPa}$, no sentido tangencial e de $-350 \pm 34$, $-353 \pm 18$ e $-206 \pm 17 \mathrm{MPa}$ no sentido axial, para os aços 4340, 4140 e 1045, respectivamente). Com uma diferença numérica no sentido tangencial de 5, 16 e $60 \mathrm{MPa}$; e no sentido axial de 27, 24 e $22 \mathrm{MPa}$, para os aços 4340, 4140 e 1045, respectivamente, sendo que alguns desses valores estão dentro do desvio padrão dos resultados experimentais.

- Os perfis de tensões residuais na direção axial e tangencial têm distribuições semelhantes na superfície, com predominância de compressão, e resultados quantitativos maiores no sentido tangencial, para os três casos estudados. Com uma diferença média de $\sim 40 \mathrm{MPa}$ para o modelo numérico e de $22 \mathrm{MPa}$ na medida experimental.

- Observou-se através do modelo que a distribuição de tensões residuais na direção radial é quase nula na superfície. Porém, crescem em direção ao núcleo atingindo valores de $1319 \pm 4,892 \pm 7$ e $778 \pm 5 \mathrm{MPa}$, para o aço 4340, 4140 e 1045, respectivamente.

- Os maiores valores de tensão residual obtidos tanto experimentalmente como no modelo numérico desenvolvido, para o sentido tangencial foram para o aço AISI 
4340 (- $391 \pm 3 \mathrm{MPa}$ para o modelo numérico e - $386 \pm 50 \mathrm{MPa}$, por difração de raios $\mathrm{X}$ ) e os menores valores para o aço AISI 1045 (- $286 \pm 6 \mathrm{MPa}$ para o modelo numérico e - $226 \pm 21 \mathrm{MPa}$, por difratometria)

- No sentido axial os resultados para os aços AISI 4340 e 4140 foram bastante similares, se mostrando um pouco acima ( $\sim 28 \mathrm{MPa}$ ) para as medidas experimentais se comparadas com o modelo numérico. Já no sentido tangencial os resultados para o aço AISI 4340 foram um pouco maiores ( 40 MPa para o modelo numérico e $~ 30$ $\mathrm{MPa}$ experimentalmente), se comparado com o aço AISI 4140, o que pode estar relacionado com a maior fração volumétrica de martensita formada no aço 4340 .

- A modelagem, combinando os resultados microestruturais fornecidos pelo programa AC3 com o programa de modelamento de elementos finitos ABAQUS/Standard $\AA$, permitiu obter tendências similares nas tensões residuais resultantes do tratamento de têmpera em água para os aços AISI 4340, 4140 e1045

- As medidas de difração de raios $X$ indicaram que o efeito da rugosidade superficial da amostra não pode ser desprezado durante a medição.

- Os resultados mostram que a utilização dos resultados obtidos no software AC3 podem ser implementados, conjuntamente com o programa ABAQUS $\AA$, no cálculo das frações volumétricas, distorções e tensões residuais que surgem em um tratamento térmico de têmpera.

- A previsão da dureza obtida por meio da simulação numérica desenvolvida no programa AC3 levou a resultados bastante consistentes com as medidas experimentais. Sendo que os resultados experimentais na superfície mostraram resultados de $57,57,5$ e $56 \mathrm{HRC}$, e os resultados através do modelo foram de 58,57 e 56 HRC, para os aços 4340, 1045 e 4140, respectivamente.

- Para analisar as tensões residuais que permanecem no componente após o processo de têmpera (onde houve transformação) devem ser consideradas tanto as tensões térmicas quanto as tensões de transformação. Mas é importante salientar, que o estado final dessas tensões não pode ser descrito simplesmente pela 
sobreposição das tensões térmicas e as tensões de transformação, uma vez que a posição da inversão do sinal das tensões térmicas durante a têmpera é de fundamental importância na compreensão do estado final das tensões residuais.

- O calor latente de transformação afeta o campo de temperatura e de transformação através do transiente térmico, e se estende ao longo da secção transversal da amostra, mesmo em posições distantes do meio de resfriamento, o qual implica mudanças dos resultados de tensão residual. 


\section{REFERÊNCIAS}

ABAQUS 6.9. User's Manual (6.9), ABAQUS Inc, USA, 2009.

ABASSI, F.; FLETCHER, A. J. Effect of Transformation Plasticity on Generation of Thermal Stress and Strain in Quenched Steel Plates. Materials Science and Technology, v. 1, 1985, p. $49-55$.

AC3 Heat Treatment Software Operating Manual. Marathon Monitors Inc. Ohio, 1994.

ALVES, G. Caracterização microestrutural de um aço médio carbono e baixa liga (com estrutura bainítica/martensítica) via microscopia óptica. Dissertação (Mestrado em Engenharia na área de Projetos e Materiais). Faculdade de Engenharia de Guaratinguetá, 2008.

ANDREWS, K.W. Empirical formulae for calculation of some transformation temperatures. Journal of the Iron and Steel Institute 203. 1965, p. 721-727. Em: ISHIDA, K. Calculation of the effect of alloying elements temperature in steels. Journal of Alloys and Compounds, v. 220, 1995, p. $126-131$.

ASM. Metals Handbook. Heat Treating of Steel. ASM International, Materials Park, Oh, v. 4, 1991, p. $67-121$.

ASM. Metals Handbook. Failure Analysis and Prevention. ASM International, Materials Park, Oh, v. 11, p 2899, 2002.

ASSIS, J. T; MONIN, V. I.; SOUZA, P. S.; WEIDLICH, M. C.; GUROVA, T.; TEODOSIO, J. R.; Processamento dos dados de difração de raios $X$ para medição de tensões: Disponível em: <http://www.sbmac.org.br/bol/boletim 2002/assismonim-souza-weidlich-4emc.pdf>. Acessado em: 10 jun. 2011.

ASTM. Norma ASTM E 562-02.Standard Test Method for Determining Volume Fraction by Systematic Manual Point Count. American Society for Testing and Materials, 2002.

ASTM. Norma ASTM E3-01.Standard Guide for Preparation of Metallographic Specimens. Current edition approved July 1, 2007. Published September 2007. Originally approved in 1921. Last previous edition approved in 2001 as E3-01.

ASTM. Norma ASTM E 562-02.Standard Test Method for Determining Volume Fraction by Systematic Manual Point Count. American Society for Testing and Materials, 2002.

ASTM. Norma ASTM A 370-09. Standard Test Methods and Definitions for Mechanical Testing of Steel Products. American Society for Testing and Materials, 2009. 
AVRAMI, M. Kinetics of Phase Change. I. General Theory. Journal of Chemical Physics, v. 7, 1939, p. $1103-1112$.

BABU, K.; PRASANA-KUMAR, T. S. Mathematical Modeling of Surface Heat Flux During Quenching. Metallurgical and Materials Transactions B, v. 41, 2010, p. 214224.

BABU, K.; PRASANNA-KUMAR, T. S. Estimation and Analysis of Surface Heat Flux During Quenching in CNT Nanofluids. Journal of Heat Transfer, v. 133, 2011, p. 106-117.

BAILEY, N. S.; TAN, W.; SHIN, Y. C. Predictive modeling and experimental results for residual stresses in laser hardening of AISI 4140 steel by a high power diode laser. Surface \& Coatings Technology, v. 203, 2009, p. $2003-2012$.

BARBOSA, M. Influência das Tensões Residuais no Comportamento em Fadiga e Fratura de ligas Metálicas. 1998. 116 f. Tese de doutorado (Doutorado em Ciências - Área de Reatores Nucleares de Potência e Tecnologia do Combustível Nuclear) - Universidade de São Paulo, 1998.

BATES, C. E; TOTTEN, G.E.; CLINTON, N. A. Handbook of Quenchants and Quenching Technology.ASM International Park, Oh, v. 4, 1993, p. 69-129.

BATHE, K. J. Finite Element Procedures. Upper Saddle River. Prentice-Hall. 1996. $1037 \mathrm{p}$.

BERNS, H. Distortion and Crack Formation by Heat Treatment of Tools. Radex Rundsch, v. 1, 1989, p. 40-57. Em: TOTTEN, G. E. Steel Heat Treatment Metallurgy and Technologies. 2 ed. Taylor \& Francis Group. U.S, 2007, p. 249.

BHADESHIA, H. K. D. Bainite in Steels. Institute of Materials, Minerals and Mining. 2 ed. UK, 2001. 464 p.

BHADESHIA, H. K. D.; HONEYCOMBE, R. Steels: Microstructure and Properties. 3 ed. Edward Arnold, 2006.344 p.

BHADESHIA, H.K.D. Material factors. Em: Handbook of Residual Stress and Deformation of Steel. ASM International, eds G. Totten, M. Howes and T. Inoue, ASM International, Materials Park, Ohio, 2002.

BORTOLETO, E. M. Modelamento Numérico-Computacional das Transformações de Fase nos Tratamentos Térmicos de Aços. 2010. $134 \mathrm{f}$. Dissertação (Mestrado em Engenharia Mecânica) - Universidade de São Paulo, São Paulo, 2010.

BORTOLETO, E. M.; LAGATTA, C. F. SOUZA, R. M. Simulação e Análise de Tensões Residuais em Cilindros. Em: XII Congresso Nacional de Estudantes de Engenharia Mecânica - CREEM 2005. Ilha Solteira, São Paulo. 2005. 
BRINGAS, J. E. Handbook of Comparative World Steel Standards. ASTM International. USA, $2007.840 \mathrm{p}$.

BROOKS, C. R. Heat Treatment of Plain Carbon and Low Alloy Steels. ASM International Park, Oh, v. 4, 1996, p. $87-127$.

CALLISTER, W. D. Ciência e Engenharia de Materiais: Uma Introdução. 7. ed. Utah. John Willey \& Sons, 2008.

CAHN, J. W. The Kinetics of Grain Boundary Nucleated Reactions. Acta Metall, v. 4,1956, p. $449-459$.

CAMARÃO, A. F. Um modelo para previsão de tensões residuais em cilindros de aço temperados por indução. 1998. $107 \mathrm{f}$. Tese de doutorado (Doutorado em Engenharia Mecânica) - Universidade de São Paulo, 1998.

CAMPBELL, F. C. Elements of metallurgy and engineering alloys. ASM International. Materials Park, Ohio, 2008.

CAMPBELL, P. C. Application of Microstructural Engineering to the Controlled Cooling of Steel Wire. 1989. $350 \mathrm{f}$. Tese de Doutorado (Doutorado em Engenharia de Materiais e Metais) - University of British Columbia, Vancouver, 1989.

CANALE, L.; TOTTEN, G. E. Quenching Technology: a selected overview of the current state of the art. Materials Research, v. 8, 2005, p. $461-467$.

CANALE, L.; NARAZAKI, M. Quenching and Cooling, Residual Stress and Distortion Control. ASTM International. 2010.

CHRISTIAN, J. W. The Theory Transformations in Metals and Alloys. Pergamon Press, Oxford. 1965.

CHURCHILL, S. W.; BERNSTEIN, M. A Correlating Equation for Forced Convection from Gases and Liquids to a Circular Cylinder in Cross flow. Journal Heat Transfer, v. 99, 1977, p. 300 - 306. Em: Holman, J. P. Heat Transfer. 10 ed. McGraw Hill. 2010, p. 237.

COLPAERT, H. Metalografia dos Produtos Siderúrgicos Comuns. 3 ed. Edgard Blücher Ltda. São Paulo, 1992.

CULLITY, B. D. Elements of X-Ray Diffraction. Addison-Wesley, Massachusetts, 1956.

CULLITY, B. D.; STOCK, S. R. Elements of X-Ray Diffraction 3 ed. Upper Saddle River, New Jersey: Prentice Hall, 2001, p.435 - 469.

DENIS, S.; SJÖSTRÖM, S.; SIMON, A. Coupled Temperature, Stress, Phase Transformation Calculation Model Numerical Illustration of the Internal Stresses Evolution during Cooling of a Eutectoid Carbon Steel Cylinder. Metallurgical Transactions A, v.18 A, 1987, p. $1203-1212$. 
DENIS, S. et al. Prediction of Residual Stress and Distortion of Ferrous and Non-Ferrous Metals: Current Status and Future Developments. Journal of Materials Engineering and Performance, 2002, p. 92 - 102.

DIN. 50150. Testing metallic materials - Conversion of hardness values. Edição 2000.

DOS SANTOS, A. A. Modelamento da transformação de fases de aços de alta resistência microligados ao $\mathbf{N b}$ durante resfriamento após laminação em tiras a quente. 2007. 335 f. Tese de doutorado (Doutorado em Engenharia Metalúrgica e de Minas) - Universidade Federal de Minas Gerais, Belo horizonte, 2007.

DUFOUR, J.D. An Introduction to Metallurgy. 4 ed. Houston-TX, Cooper Cameron Corporation, 2002. Em: BARROS, F. L. Microestrutura e tenacidade de aços baixa liga tipo 41xx - uma abordagem quantitativa. 2006. $200 \mathrm{f}$. Dissertação (Mestrado em Ciências). Faculdade de Engenharia Metalúrgica e de Materiais, Universidade Federal de Rio de Janeiro, Rio de Janeiro, 2006.

EBERT, L. J. Role of residual-stresses in mechanical performance of case carburized steels. Metallurgical and Materials Transactions, v. 9, 1978, p. 1537 1151.

ECKEL, B. Thinking in Java. 4 ed. Prentice Hall, 2006.

EIGENMANN, B.; MACHERAUCH, E. Röntgenographische Untersuchung von Spannungszuständen in Werkstoffen. Materialwissenschaft und Werkstofftechnik, v. 27, 1996, p. 426 - 437. Em: SILVA, et al. Aplicação da Difração de Raios-X para Inspeções de Campo-Avaliação de Tensões Residuais em Tubulações. 4 PPDPETRO, Campinas, SP. 2007.

ERICSSON, T. Residual stresses caused by thermal and thermochemical surface treatments. Advances in surface treatments, v 4, 1987, p. $87-113$.

FANG, L.; WOOD, W. E.; ATTERIDGE, D. G. Identification and Range of Quantification of Steel Transformation Products by Transformation Kinetics. Metallurgical and Materials Transactions, v. 28A, 1997, p. 5- 14.

FERNANDES, F. M. B.; DENIS, S.; SIMON, A. Mathematical model coupling phase transformation and temperature evolution during quenching of steels. Materials Science and Technology, v. 1, 1985, p. 838 - 844.

FERNANDES, P.; NARAYAN, K. Effect of section size and agitation on heat transfer during quenching of AISI 1040 Steel. Journal of Materials Processing Technology, v. 183, 2007, p. $1-5$.

FISCHER, F. et al. A New view on transformation induced plasticity (TRIP). International Journal of Plasticity, v. 16, 2000, p. $723-748$.

FLETCHER, A. J. Thermal Stress and Strain Generation in Heat Treatment. Elsevier Applied Science. London, 1989. 246 p. 
FLETCHER, A. J.; SOOMRO, A. B. The Effect of Stress Relaxation Rate on the Generation of Thermal Stress during Quenching. Materials Science and Engineering, v. 82, 1986, p. $101-115$.

GALLAGHER, R. H. Finite Element Analysis: Fundamentals. Prentice - Hall, Englewood. 1975.

GHOSH, G.; OLSON, G. B. Computational Thermodynamics and the Kinetics of Martensitic Transformation. Journal of Phase Equilibria, v. 22, 2001, p. 199 - 207.

GOTTFRIED, B. S.; LEE, C. J.; BELL, K. J. The Leidenfrost Phenomenon: Film Boiling of Liquid Droplets on a Flat Plate. Journal Heat Mass Transfer, v. 9,1966, p. $1167-1187$.

GÜR, C. H.; PAN, J. Handbook of Thermal Process Modeling of Steels. CRC Press, London, 2009. 739 p.

GÜR, C. H.; SIMSIR, C. 3D FEM simulation of steel quenching and investigation of the effect of asymmetric geometry on residual stress distribution. Journal of Materials Processing Technology, v. 207, 2008, p. $211-221$.

HAWBOLT, E. B.; CHAU, B.; BRIMACOMBE, J. K. Kinetics of Austenite-Ferrite and Austenite - Pearlite Transformations in a 1025 Carbon Steel. Metallurgical and Materials Transactions A, 1985, p. $565-578$.

HE, B. B. Two-Dimensional X-Ray Diffraction. John Wiley \& Sons. New Jersey, 2009.

HERNANDEZ, J. B. Heat Transfer and Stress Generation during Forced Convective Quenching of Steel Bars. 1996. $408 \mathrm{f}$. Tese de doutorado (Doutorado em Engenharia de Materiais e Metais) - University of British Columbia, Vancouver, 1996.

HOLMAN, J. P. Heat Transfer. 10 ed. McGraw Hill. 2010, p. 237

HORNBOGEN, E. The Effect of Variables on Martensitic Transformation

Temperatures. Acta Metall, v. 33, n. 4, 1985, p. 595 - 601.

HUGHES, T. J. R. The Finite Element Method. Englewood Cliffs. Prentice - Hall. 1987. $803 \mathrm{p}$.

INCROPERA, F. P.; DEWITT, D. P.; BERGMAN, T. L.; LAVINE, A. S.

Fundamentals of Heat and Mass Transfer. 7. ed. John Wiley \& Sons, Inc. USA. 2011.

INOUE, T.; WANG, Z. Coupling between stress, temperature, and metallic structures during processes involving phase transformations. Materials Science and Technology, v. 1, 1985, p. $845-850$. 
KAMAMOTO, S.; NISHIMORI, T.; KINOSHITA, S. Analysis of residual stress and distortion resulting from quenching in large low-alloy steels shafts. Materials Science and Technology, v. 1, 1985, p. $798-804$.

KANG, S. H.; IM, Y. T. Three-Dimensional Finite Element Analysis of the Quenching Process of Plain-Carbon Steel with Phase Transformation. Metallurgical and Materials Transactions A, v. 36, 2005, p. $2315-2325$.

KANG, S.H.; IM, Y.T. Finite element investigation of multi-phase transformation within carburized carbon steel. Journal of Materials Processing Technology, v. 183,2007 , p. $241-248$.

KIRKALDY, J. S.; THOMSON, B. A.; BARGANIS, E. Hardenability Concepts with Applications to Steel. Em: DOANE, D.V.; KIRKALDY, J.S. Editors, AIME, p. 82. 1978.

KISSINGER, H. E. Reaction Kinetics in Differential Thermal Analysis. Analytical Chemistry, v.29, 1957, p. $1702-1706$.

KLUG, H.P.; ALEXANDER, L.E. X-Ray Diffraction Procedures For Polycrystalline and Amorphous Materials. 2. ed. Wiley - Interscience, New York, 1974.

KOISTINEN, D. P.; MARBURGER, R. E.A General Equation Prescribing the Extent of the Austenite - Martensite Transformation in Pure Iron - Carbon Alloys and Plain Carbon Steel. Acta Metall, v. 7, 1959, p. 59-60.

KRAUSS, G. Martensitic Transformation, Structure and Properties in Hardenable Steels. Metallurgical Society AIME, 1978, p. $229-248$.

KRAUSS, G. Steels Processing, Structure, and Performance. ASM International. Materials Park, Ohio, 2005.614 p.

LEE, S. J.; LEE, Y.K. Finite element simulation of quench distortion in a lowalloy steel incorporating transformation kinetics. Acta Materialia 56, 2008, p. $1482-1490$.

LEE, S.J.; PAVLINA E.J.; VAN TYNE C.J. Kinetics Modeling of Austenite Decomposition for an End-Quenched 1045 Steel. Materials Science and Engineering A, 2010.

LI, D. Boiling Water Heat Transfer during Quenching of Steel Plates and Tubes.2003. $201 \mathrm{f}$. Tese de Doutorado (Doutorado em Engenharia de Materiais e Metais) - University of British Columbia, Vancouver, 2003.

LI, H.; ZHAO, G.; HE, L. Finite element method based simulation of stress-strain field in the quenching process. Materials Science and Engineering A, v. 478, 2008, p. $276-290$. 
LIMA, N. B. Influência da textura em medidas de tensão residual. 1992. 105 f. Tese de doutorado (Doutorado em Tecnologia Nuclear) - Universidade de São Paulo, 1992.

LISCIC, B.; TENSI, H. M.; LUTY, W. Theory and technology of quenching. New York, Springer Verlag, 1992. Em: TOTTEN, G. E. Steel Heat Treatment - Metallurgy and Technologies. 2 ed. Taylor \& Francis Group. U.S, 2007. 820 p.

LISCIC, B. Steel Heat Treatment. Em: TOTTEN, G. E. Steel Heat Treatment Metallurgy and Technologies. 2 ed. Taylor \& Francis Group. U.S, 2007, p. 289 426.

LISCIC, B.; TENSI, H. M.; CANALE, L. C.; TOTTEN, G. E. Quenching Theory and Technology. 2 ed. Taylor \& Francis Group. 2010.

LUEBBEN, T.; LOHRMANN, M.; SEGERBERG, S.; SOMMER, P. Formulation of a Guideline for the Determination of Heat Transfer Coefficient during Gas Quenching. Em: CANALE, L.; NARAZAKI, M. Quenching and Cooling, Residual Stress and Distortion Control. ASTM International. 2010, p. $63-83$.

LUSK, M. T.; LEE, Y. K. A Global Material Model for Simulating the Transformation Kinetics of Low Alloy Steels. Proceedings of the 7th International Seminar of the International IFHT, Budapest, Hungary: IFHT, 1999. p. 273-282. Em: Quenching and Cooling, Residual Stress and Distortion Control. ASTM International, 2010, p 130.

MACHERAUCH, E.; KLOSS, K. H. Origin Measurements and Evaluation of Residual Stresss. Proceedings of the International Conference on Residual Stress, 1986, p. 3-26.

MACHERAUCH, E.; WOHLFAHRT, H.; WOLFSTIEG, U.; ZWECKMÄBIGEN, Z. Definition von Eigenpannungen. Härterei - Tech. Mitt 28, p. 201 - 211. Em: HAUK, V. Structural and Residual Stress Analysis by Nondestructive Methods. Elsevier Science, 1997, p. 59.

MAYR, P. Dimensional alteration of parts due to heat treatment. Residual Stress in Science and Technology, v. 1, Garmisch-Partenkirschen, 1987, p. $57-77$.

MELANDER, A. A finite element study of the notch effect at surface inclusions. International Journal of Fatigue, v. 12, n. 3, 1990, p. $154-164$.

MELANDER, A. A finite element study of short cracks with different inclusion types under rolling contact fatigue load. International Journal of Fatigue, v. 19, 1997 , p. $13-24$.

McCOOL, J. I. Analysis of sets of two-parameters Weibull data arising in rolling contact endurance testing. Em: HOO, J. J. C. Rolling contact fatigue testing of bearing steels. ASTM, Pennsylvania, USA. 1982, p. 293-319 
MOYER, J. M.; ANSELL, G. S. The Expansion Accompanying the Martensite Transformation in Iron - Carbon Alloys. Metallurgical and Materials Transactions A, v. 6, 1975, p. $1975-1785$.

NARAZAKI, M.; TOTTEN, G. E.; WEBSTER, G. M. Hardening by Reheating and Quenching. Em: TOTTEN, G. E. Steel Heat Treatment - Metallurgy and Technologies. 2 ed. Taylor \& Francis Group. U.S, 2007, p. 248 - 295.

NATIONAL INSTRUMENTS. Disponível em: http://www.ni.com/labview. Acesso em: 20 Jun. 2011

NORTHOVER, S.; WILSON, M. SWT: The Standard Widget Toolkit. AddisonWesley Professional, v. 1, 2004.

OLIVEIRA, W.P.; SAVI, M.A.; PACHECO, P.M.C.; SOUZA, L.F. G. Thermomechanical analysis of steel cylinders quenching using a constitutive model with diffusional and non-diffusional phase transformations. Mechanics of Materials, v. 42,2010 , p. $31-43$.

PALANIRADJA, K.; ALAGMURTHI, N.; SOUNDARARAJAN, V. Modeling of Phase Transformation in Induction Hardening. Materials Science Journal, v. 4, 2010, p. $64-73$.

PAN, J.; GU, J. Mathematical Fundamentals of Thermal Process Modeling of Steels. Em: GÜR, C. H.; PAN, J. Handbook of Thermal Process Modeling of Steels. CRC Press, London, 2009, p. $1-62$.

PARRISH, G. Carburizing: Microstructures and Properties. ASM International. Materials Park, Ohio, 1999.247 p.

PASCON, F.; et al. Prediction of distortion during cooling of steel rolled rings using thermal-mechanical-metallurgical finite element model. Steel Grips Suppl. Metal Forming, v. 2, 2004.

PIETZSCH, R.; BRZOZA, M.; KAYMAK, Y.; SPECHT, E. Simulation of the Distortion of Long Steel Profiles during Cooling. Journal of Applied Mechanics. ASME, v. 74, 2007, p. $427-437$.

POIRIER, D.R.; GEIGER, G. H. Transport Phenomena in Materials Processing.TMS, Warrendale, Pennsylvania, USA, 1994.

PRABHU, N. K.; FERNANDES, P. Effect of Surface Roughness on Metal/ Quenchant Interfacial Transfer and Evolution of Microstructure. Materials and Design, v. 28, 2007, p. $544-550$.

PRABHU, N. K.; PRASAD, A. Metal/Quenchant Interfacial Heat Flux Transients During Quenching in Conventional Quench Media and Vegetable Oils. Journal of Materials Engineering and Performance, v. 12, 2003, p. 48 - 55. 
PREVÉY, P. S. X-ray Diffraction Residual Stress Techniques. ASM Metals Handbook, v. 10, 1986, p. $380-392$.

RIBEIRO, L. B. Introdução ao Método dos Elementos Finitos. Notas de Aula. COPPE - Universidade Federal de Rio de Janeiro. 2004.

RIGAKU. Residual stress data process program. Version $2.0 \mathrm{~d} /$ max-2000 instruction manual, Rigaku Corporation,10 ed. 2006.

RODRIGUES, G. M.; FERREIRA, S. S.; GONÇALVES, F. L. Modeling NonIsothermal austenite formation. Rev. Esc. Minas, 2010, p. 293 - 298.

ROHDE, J.; JEPPSSON, A. Literature review of heat treatment simulations with respect to phase transformation, residual stresses and distortion. Scandinavian Journal of Metallurgy, 2000, p. $47-62$.

ROTHERY, W. H. Estrutura das Ligas de Ferro - Introdução Elementar. Edgar Blücher Ltda, 1968.

SAUNDERS, N.; GUO, Z.; LI, X.; MIODOWNIK, A. P.; SCHILLE, J. P. The Calculation of TTT and CCT Diagrams for General Steels. Internal report, Surrey Technology Centre, 2004.

SCHEIL, E. Anlaufzeit der Austenitumwandlung. In: Archiv für das Eisenhüttenwess, v. 12, 1935, p. 565 - 567. Em: SIMSIR, C; GÜR, C. 3D FEM simulation of steel quenching and investigation of the effect of asymmetric geometry on residual stress distribution. Journal of Materials Processing Technology, v. 207, 2008, p. $211-221$.

SCHRÖDER, R. Influences on development of thermal and residual stresses in quenched steel cylinders of different dimensions. Materials Science and Technology, v. 1, 1985, p. $754-764$.

SCHULZE, V.; VÖHRINGER, O.; MACHERAUCH. E. Residual Stresses after Quenching. Em: LISCIC, B.; TENSI, H. M.; CANALE, L. C.; TOTTEN, G. E. Quenching Theory and Technology. 2. ed. Taylor \& Francis Group. 2010.

SEDIGHI, M.; McMAHON, C. A. The Influence of Quenchant Agitation on the Heat Transfer Coefficient and Residual Stress Development the Quenching of Steels. Proceedings of the Institution of Mechanical Engineers, v. 214 B, 2000. p. $555-567$.

SEDIGHI, M.; SALEK, M. Modeling and experimental study of quenching process for AISI 4340 aeronautical steel under different cooling conditions. Transactions the Canadian Society for Mechanical Engineering, v. 32, 2008.

SEGERBERG, S. Correlation Between Quenching Characteristics of Quenching Media and Hardness in Steel. Heat Treatment, London; 1984, p. 1-7. Em: SHUHUI MA. Characterization of the performance of mineral oil based quenchants using 
CHTE Quench Probe System. 2002. 134 p. Dissertação (Mestrado em Ciência e Engenharia de Materiais) - Worcester Polytechnic Institute, Massachussetts, USA.

SIMSIR, C.; GÜR, C.A review on Modeling and Simulation of Quenching. Em: Quenching and Cooling, Residual Stress and Distortion Control. ASTM International. 2010, p. 117 - 155.

SIMSIR, C. 3D Finite Element Simulation of Steel Quenching in Order to Determine the Microstructure and Residual Stress. 2008. $216 \mathrm{f}$. Tese de doutorado (Engenharia Metalúrgica e de Materiais), Middle East Technical University, 2008.

SJÔSTROM, S. Interactions and constitutive models for calculation quench stresses in steel. Materials Science and Technology, v. 1, n. 10, 1985, p. 823-829.

SJÖSTROM, S. Calculation of quench stresses in steel. 1982. Tese de Doutorado. University of Linköping. Sweden. Em: FLETCHER, A. J. Thermal stress and strain generation in heat treatment. London and New York: Elsevier Applied Science, 1989.

SOARES, J. P. Aços: Características e Tratamentos. 4 ed. Porto, Publindustria, 1987.

SOUZA, S. A. Aços de Baixa Liga. Em: Composição Química dos Aços. Ed. Edgard Blücher Ltda. São Paulo, 2001, p. 19-52.

SPRAUEL, J. M.; CASTEX L. X-Ray Stress Analysis. Materials Science Forum, v. 79-82, 1991, p. 143-152.

STULL, D. R.; PROPHET, H. JANAF Thermochemical Tables. National Standard Reference Data System, 2 ed. NSRDS-NBS 37. 1971. Em: OLIVEIRA, W.P.; SAVI, M.A.; PACHECO, P.M.C.; SOUZA, L.F. G. Thermomechanical analysis of steel cylinders quenching using a constitutive model with diffusional and non-diffusional phase transformations. Mechanics of Materials, v. 42, 2010, p. $31-43$.

SURAJ, S. S. Modeling of Industrial Heat Treatment Operations. Em: GÜR, C. H.; PAN, J. Handbook of Thermal Process Modeling of Steels. CRC Press, London, 2009 , p. $313-339$.

SVERDLIN, A. V.; NESS, A. R. Effect of Alloying Elements on the Heat Treatment of Steel. p. 166 -211.Em: TOTTEN, G. E. Steel Heat Treatment - Metallurgy and Technologies. 2. ed. Taylor \& Francis Group. U.S, 2007. 820 p.

TENSI, H. M. Quenching and quenching Technology. Em: Steel Heat Treatment Handbook. Marcel Dekker, Inc.,1997, p. 157 - 250.

THELNING, K. E. Steels and its Heat Treatment. Butterworths, London, 1975. 
TODINOV, M. T. Influence of some parameters on the residual stresses from quenching. Modelling Simul. Mater. Sci. Eng, v. 7, 1999, p. 25-41.

TOTTEN, G. E. Steel Heat Treatment - Metallurgy and Technologies. 2.ed. Taylor \& Francis Group. U.S, 2007. 820 p.

TOTTEN, G. E.; NAZARAKI, M.; BLACKWOOD, R.R., JARVIS, L.M. Failures Related to Heat Treating Operations. Em: Failure Analysis and Prevention. Becker, W. T.; Shipley, R.J. ASM Handbook, v. 11, 2002.

TROIANO, A. R.; GRENINGER, A. B. The Martensite Transformation. Metal Progress, v. 50, 1946, p. $303-307$.

WELLS, M. A; DAUN, K. J. Accurate Determination of Surface Heat Fluxes During Quenching Characterized by Boiling Water Heat Transfer. Journal of ASTM International, v. 6, 2009.

WOLDT, E. The Relationship between Isothermal and Non-Isothermal Description of Johnson-Mehl-Avrami-Kolmogorov Kinetics. Journal of Physics and Chemistry of Solids, v. 53, 1992, p. $521-527$.

WOODARD, P. R.; CHANDRASEKAR, S.; YANG, H. T. Y. Analysis of Temperature and Microstructure in the Quenching of Steel Cylinders. Metallurgical and Materials Trans. B-Process Metallurgy and Materials Processing Science, v.4, 1999, p. $815-822$.

XU, D.; ZHONGHUA, L.; JINGXIE, L. Expressions for predicting the residual stress in surface induction hardening of steel bars. Modelling and Simulation in Materials Science and Engineering, v. 4, 1996, p. 111- 122.

ZENER, C. Kinetics of the Decomposition Austenite. Metals Technology. AIME, v. 167,1946 , p. $550-595$.

ZIENKEWICZ, O. C. The Finite Element Method in Engineering Science. McGraw - Hill Publishing Co., 1971. 